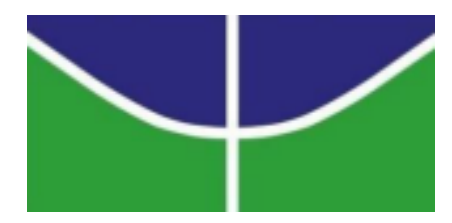

UNIVERSIDADE DE BRASÍLIA - UnB

INSTITUTO DE QUÍMICA - IQ

PROGRAMA DE PÓS-GRADUAÇÃO EM TECNOLOGIAS QUÍMICA E BIOLÓGICA - PPGTQB

\title{
OBTENÇÃO DE GASES COMBUSTÍVEIS VIA TRANSFORMAÇÃO TERMOQUÍMICA DE Eucalyptus grandis EM REATOR DE LEITO FLUIDIZADO
}

Albert Reis dos Anjos

Orientador: Prof. Fabricio Machado Silva, D.Sc.

Coorientador: Dr. Rossano Gambetta, D.Sc.

Brasília, fevereiro de 2017 


\title{
OBTENÇÃO DE GASES COMBUSTÍVEIS VIA TRANSFORMAÇÃO TERMOQUÍMICA DE Eucalyptus grandis EM REATOR DE LEITO FLUIDIZADO
}

\begin{abstract}
Dissertação apresentada ao Programa de PósGraduação em Tecnologias Química e Biológica da Universidade de Brasília como parte dos requisitos para a obtenção do título de Mestre em Tecnologia Química.
\end{abstract}

\section{ALBERT REIS DOS ANJOS}

Orientador: Prof. Fabricio Machado Silva, D.Sc.

Coorientador: Dr. Rossano Gambetta, D.Sc. 


\section{FOLHA DE APROVAÇÃO}

Comunicamos a aprovação da Defesa de Dissertação de Mestrado do (a) aluno (a) Albert Reis dos Anjos, matrícula no 16/0104335, intitulada "OBTENÇÃO DE GASES COMBUSTÍVEIS VIA TRANSFORMAÇÃO TERMOQUÍMICA DE Eucalyptus grandis EM REATOR DE LEITO FLUIDIZADO", apresentada no (a) Auditório Azul do Instituto de Química (IQ) da Universidade de Brasília (UnB) em 22 de fevereiro de 2017.

Prof. Dr. Fabricio Machado Silva

Presidente de Banca (IQ/UnB)

Prof.a Dra. Grace Ferreira Ghesti Membro Titular (IQ/UnB)

Dra. Anna Leticia Montenegro Turtelli Pighinelli Membro Titular (EMBRAPA Agroenergia)

Dr. Emerson Leo Schultz Membro Suplente (EMBRAPA Agroenergia)

Em 22 de fevereiro de 2017.

$\checkmark$ Cabxa Postal 4478 - CEP: 70904-970 - Brasilla - DF- BPASIL

D www.unb.briq/pg posglq@unb.br 


\section{AGRADECIMENTOS}

Aos meus orientadores Prof. Fabricio Machado e Rossano Gambetta por terem me dado todo o aporte necessário para a realização deste trabalho e disponibilizado de seu precioso tempo para me ajudar em tudo que fosse necessário. Pelo grande incentivo durante todos os momentos de dificuldades do projeto. Muito obrigado!

Aos meus pais, Maria e Vicente, e aos meus irmãos, Esio e Klênia, pelo apoio incondicional em todos os momentos da minha carreira acadêmica e da minha vida pessoal, pelo carinho e amor, sem vocês nada faria sentido.

Ao CNPq e à CAPES pelo aporte financeiro na realização deste trabalho.

Ao grupo de trabalho da Embrapa Agroenergia e UnB: Priscila, Emerson, José Dilcio, Alexandre Cardoso, Renan, Pedro e Rafael. Em especial agradeço de coração à Amanda, Anna, Diogo, Felipe e Juarez, sem a ajuda de vocês nada seria possível.

Aos meus amigos Gustavo, Emannuela, Shara, Paula, Helen, Diego, Fernanda, Amanda, Thiago.

À todos os funcionários e às instituições Universidade de Brasília, em especial ao Programa de Pós Graduação em Tecnologias Química e Biológica, e Embrapa Agroenergia.

À todos que direta ou indiretamente fizeram parte deste trabalho. 
"Penso noventa e nove vezes e nada descubro; deixo de pensar, mergulho em profundo silêncio - e eis que a verdade se me revela."

(Albert Einstein) 


\section{RESUMO}

A energia proveniente de combustíveis fósseis ainda é a responsável pela manutenção da grande maioria dos processos produtivos, porém, o aumento da demanda mundial por energia e a constante preocupação com o meio-ambiente têm trazido a tona uma discussão: como produzir energia de forma eficiente e sustentável? Dentre as diversas fontes de energias renováveis estudadas (solar, eólica, etc), a biomassa tem recebido bastante destaque pois, além de representar uma fonte para diversas cadeias produtivas, pode ter o seu uso aplicado também na geração de energia. Dentre as tecnologias capazes de transformar a biomassa em energia, a gaseificação surge como uma alternativa interessante pois é capaz de produzir uma mistura de gases combustíveis $\left(\mathrm{H}_{2}\right.$, $\mathrm{CO}, \mathrm{CH}_{4}$, etc) que pode ser utilizada na geração de energia elétrica de forma direta ou na produção de biocombustíveis. Desta forma, objetivo deste estudo foi avaliar a influência dos agentes de fluidização ar, vapor e nitrogênio na composição do gás combustível produzido através de processos de gaseificação e pirólise de Eucalyptus grandis em um sistema de reação em leito fluidizado. Inicialmente, caracterizou-se a biomassa por meio de análises imediata, elementar e poder calorífico, e determinou-se as vazões que promovem a fluidização do leito de quartzo ocre. Considerando os agentes: $i$ ) ar, o regime de fluidização foi alcançado a vazões entre 35 e $41 \mathrm{NL} / \mathrm{min}$ à temperatura ambiente e $6 \mathrm{NL} / \mathrm{min}$ à temperatura de gaseificação $\left(800^{\circ} \mathrm{C}\right)$; ii) nitrogênio, entre 49 e $52 \mathrm{NL} / \mathrm{min}$ à temperatura ambiente e $12 \mathrm{NL} / \mathrm{min}$ à temperatura de gaseificação, e para iii) vapor d'água, $12 \mathrm{~mL} / \mathrm{min}$ é suficiente para fluidizar o leito à temperatura de gaseificação. Os agentes de fluidização que apresentaram maior produção em massa de hidrogênio no gás produto foram vapor d'água (na condição experimental de razão vapor/biomassa igual a 2,81) e nitrogênio (na condição experimental de $16 \mathrm{NL} / \mathrm{min}$ ), ambos com produção média de 0,02 gramas de $\mathrm{H}_{2}$ por grama de biomassa. Com relação ao poder calorífico dos gases produzidos, a gaseificação com ar apresentou um poder calorífico inferior médio de 5,92 MJ/kg a 9,81 $\mathrm{MJ} / \mathrm{kg}$, para condições experimentais entre 0,23 e 0,40 de razão de equivalência (RE). O processo de pirólise com nitrogênio produziu gases com PCI entre 11,76 MJ/kg e 19,50 $\mathrm{MJ} / \mathrm{kg}$ para condições experimentais utilizando vazões de nitrogênio de $12 \mathrm{NL} / \mathrm{min}$ a 20 NL/min. Por fim, o vapor d'água apresentou os melhores resultados de PCI para os gases produzidos, sendo eles na faixa de $26,70 \mathrm{MJ} / \mathrm{kg}$ a $28,59 \mathrm{MJ} / \mathrm{kg}$, nas condições experimentais de razão vapor/biomassa (SBR) de 1,67 a 3,38. Tanto o processo de pirólise quanto o de gaseificação mostraram viabilidade técnica para produção de gás combustível, e o destaque se dá ao processo de gaseificação com vapor d'água que se apresentou viável do ponto de vista de produção de hidrogênio e de poder calorífico do gás gerado. 


\begin{abstract}
Energy from fossil fuels is still responsible for the maintenance of the vast majority of production processes, but increasing world demand for energy and constant concern for the environment have brought up a discussion: how to produce energy efficiently and in a sustaninable way? Among the various sources of renewable energy studied (solar, wind, etc.), biomass has received a lot of attention because, in addition to being a source for several production chains, it use can also be applied to energy generation. Among the technologies capable of transforming biomass into energy, gasification appears as an interesting alternative because it is capable of producing a mixture of combustible gases $\left(\mathrm{H}_{2}, \mathrm{CO}, \mathrm{CH}_{4}\right.$, etc.) that can be used in the generation of electric energy directly or in the production of biofuels. In this way, the objective of this study was to evaluate the influence of air, steam and nitrogen as fluidization agents on the composition of the fuel gas produced by gasification and pyrolysis processes of Eucalyptus grandis by using a fluidized bed reaction system. For this purpose, the biomass was characterized by means of proximate, elemental, and calorific analyses, and the gases flow rates were determined to promote the fluidization of the ocher quartz employed as bed material. Considering the gasification agents: $i$ ) air, the fluidization was achieved between 35 and $41 \mathrm{NL} / \mathrm{min}$ at room temperature and $6 \mathrm{NL} / \mathrm{min}$ at the gasification temperature $(600-$ $800{ }^{\circ} \mathrm{C}$ ); ii) for nitrogen between 49 and $52 \mathrm{NL} / \mathrm{min}$ at room temperture and $12 \mathrm{NL} / \mathrm{min}$ at the gasification temperature, and for $\mathrm{iii}$ ) steam, $12 \mathrm{~mL} / \mathrm{min}$ is enough to fluidize the bed at the gasification temperature. The fluidization agents those presented the highest hydrogen production in the product gas were steam (for steam to biomass ratio equals to 2,81 ) and nitrogen (by using $16 \mathrm{NL} / \mathrm{min}$ ) with an production of $0,02 \mathrm{~g} / \mathrm{min}$. Regarding the low heating value (LHV) of the gases formed the gasification with air presented an average heating value between $5,9227 \mathrm{MJ} / \mathrm{kg}$ and $9,8157 \mathrm{MJ} / \mathrm{kg}$ for equivalence ratio (ER) lying in the interval from 0,23 and 0,40. The pyrolysis process using nitrogen as fluidization agent produced a gas with heating value between 11,7627 $\mathrm{MJ} / \mathrm{kg}$ and $19,5029 \mathrm{MJ} / \mathrm{kg}$ for experimental conditions using nitrogen flows between $12 \mathrm{NL} / \mathrm{min}$ and $20 \mathrm{NL} / \mathrm{min}$. Finally, the steam presented the best LHV results for the gases produced, being in the range of $26,7044 \mathrm{MJ} / \mathrm{kg}$ to $28,586 \mathrm{MJ} / \mathrm{kg}$, at experimental conditions of SBR between 1,67 to 3,38. Both the pyrolysis process and the gasification process showed technical viability for the production of fuel gas, and it should be highlighted the the gasificatin process using steam as fluidization gas that was very feasible from the point of view of hydrogen production and the calorific value of the gas produced.
\end{abstract}




\section{Índice}

1. INTRODUÇÃ $O$................................................................................................................. 1

2. OBJETIVOS ............................................................................................................................. 3

2.1. OBJETIVO GERAL ………………………………………………….... 3

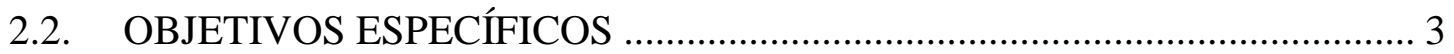

3. REVISÃO BIBLIOGRÁFICA............................................................................... 4

3.1. CONTEXTO ENERGÉTICO DO BRASIL ..................................................... 4

3.2. PROCESSOS TERMOQUÍMICOS DE CONVERSÃO DE BIOMASSA ...... 7

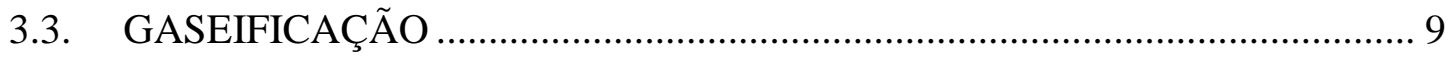

3.3.1. Tipos de gaseificadores.................................................................................. 10

3.3.2. Relação entre o agente de gaseificação e o combustível......................... 16

3.4. FLUIDIZAÇÃO.................................................................................... 19

3.4.1. Regimes de fluidização ................................................................................. 20

3.4.2. Classificação das partículas de Geldart.................................................... 22

3.5. ETAPAS DO PROCESSO DE GASEIFICAÇÃO........................................... 23

3.6. APLICAÇÃO DO GÁS PRODUTO E PLANTAS DE GASEIFICAÇÃO NO

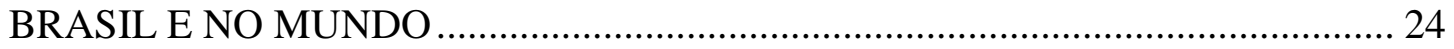

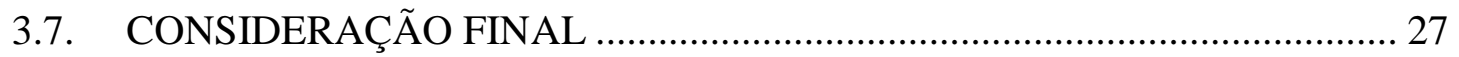

4. CARACTERIZAÇÃO DA BIOMASSA ......................................................... 28

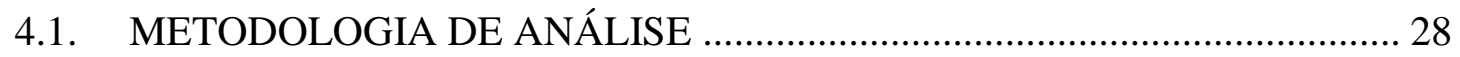

4.1.1. Poder calorífico.................................................................................................... 28

4.1.2. Análise elementar ............................................................................................. 29

4.1.3. Análise imediata.................................................................................................. 30

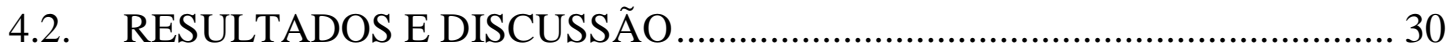

4.3. CONSIDERAÇÃO FINAL ………………………................................. 32

5. DESCRIÇÃO DA PLANTA PILOTO DE PIRÓLISE E GASEIFICAÇÃO.. 33

5.1. MÓDULO DE REAÇÃO 34 
5.1.1. Sistema de alimentação de sólidos...................................................... 35

5.1.2. Sistema de alimentação de gás.......................................................... 37

5.1.3. Sistema de alimentação de líquido ..................................................... 38

5.1.4. Sistema de reação em leito fluidizado ................................................ 38

5.1.1. Sistema de separação de sólidos ......................................................... 39

5.1.2. Sistema de remoção de alcatrão ................................................... 39

5.1.3. Sistema de remoção de particulado ................................................. 40

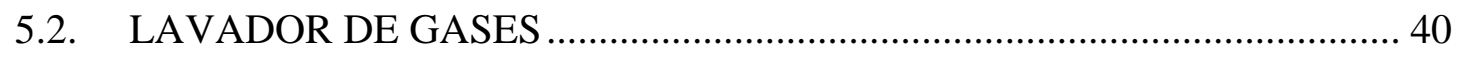

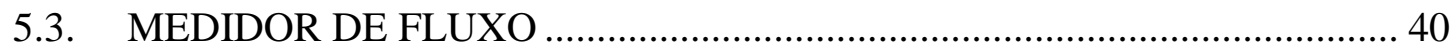

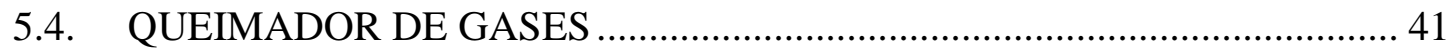

5.5. MÓDULO DE CONTROLE COMPUTACIONAL...................................... 41

5.6. EQUIPAMENTO DE ANÁLISE DE GASES ............................................. 41

6. CALIBRAÇÃO DO SISTEMA DE ALIMENTAÇÃO ....................................... 43

6.1. METODOLOGIA EXPERIMENTAL …................................................... 43

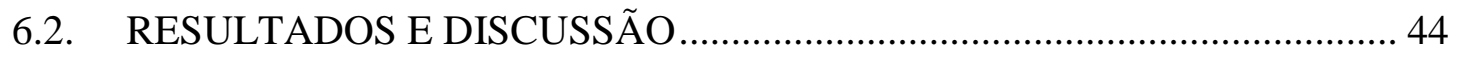

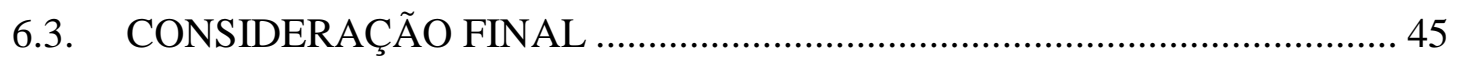

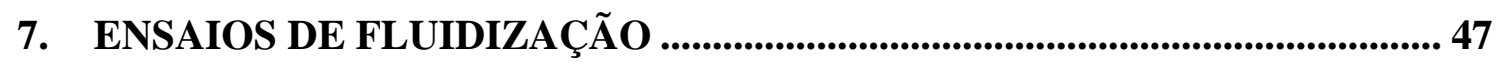

7.1. METODOLOGIA EXPERIMENTAL …................................................... 47

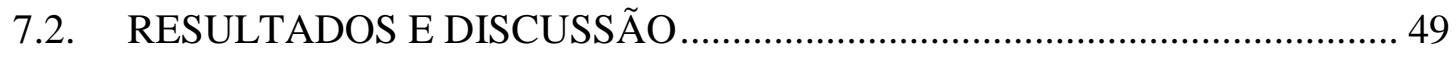

7.2.1. Teste de fluidização com ar comprimido............................................. 49

7.2.2. Teste de fluidização com vapor d'água ................................................... 49

7.2.3. Teste de fluidização com nitrogênio ......................................................... 51

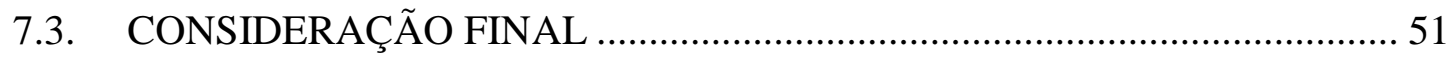

8. EXPERIMENTOS PARA PRODUÇÃO DE GÁS COMBUSTÍVEL .............. 52

8.1. METODOLOGIA EXPERIMENTAL …................................................. 52

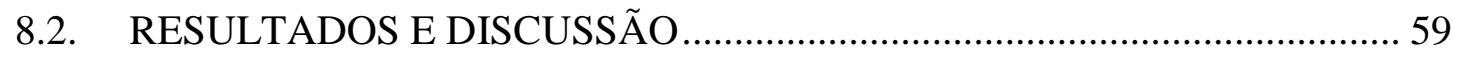


8.2.1. Avaliação de temperatura e pressão para os processos com ar, vapor e

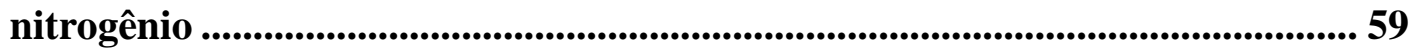

8.2.2. Gaseificação com ar comprimido ....................................................65

8.2.3. Gaseificação com vapor d'água................................................................. 71

8.2.4. Produção de gás combustível com nitrogênio ....................................... 80

8.2.5. Comparação entre os diferentes agentes de fluidização........................ 86

8.2.6. Poder calorífico do gás formado ........................................................90

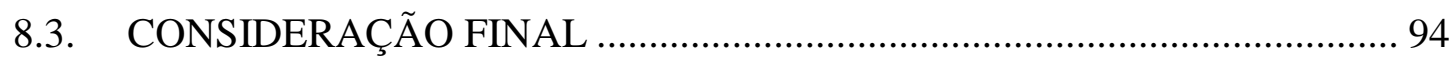

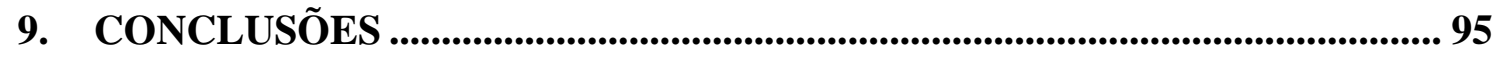

10. SUGESTÕES PARA TRABALHOS FUTUROS E MELHORIAS NO

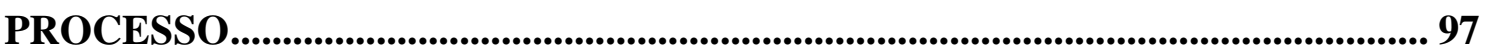

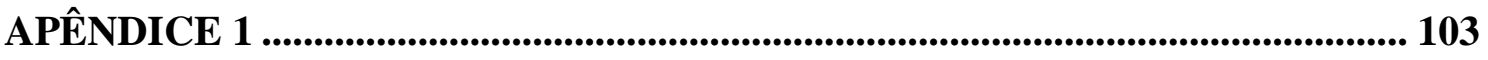

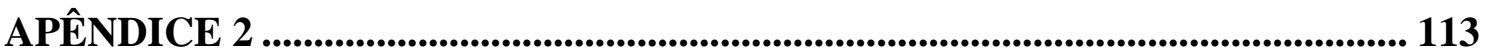

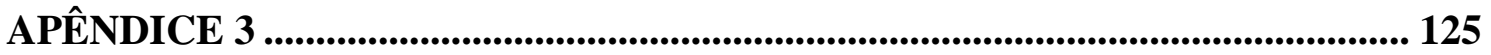

APÊNDICE 4 ..................................................................................................................... 134 


\section{LISTA DE FIGURAS}

Figura 3.1 - Oferta interna de energia no Brasil no ano de 2015. ${ }^{8}$................................. 4

Figura 3.2 - Oferta de energia elétrica no Brasil no ano de 2015. ${ }^{8}$............................... 5

Figura 3.3 - Distribuição da área de árvores plantadas por segmento no Brasil no ano de $2015 .^{3}$

Figura 3.4 - Processos de conversão de biomassa em energia. ${ }^{10}$ ….................................. 7

Figura 3.5 - Funcionamento básico de um sistema de pirólise de biomassa em leito fluidizado. Adaptado de $\mathrm{Basu}^{14}$............................................................................ 9

Figura 3.6 - Gaseificador de fluxo arrastado. Adaptado de Basu ${ }^{14}$............................... 13

Figura 3.7 - Gaseificador de Leito Fluidizado: (a) Borbulhante (b) Circulante. Adaptado de Gómez-Barea et $a l^{20}$ 16

Figura 3.8 - Regimes de fluidização em reatores de leito fluidizado caracterizados pela perda de pressão no leito em função da velocidade do agente de fluidização. ${ }^{31}$ 21 Figura 3.9 - (a) Representação das fases bolha e emulsão que constituem o leito fluidizado. ${ }^{33}$ (b) Representação das fases bolha, emulsão, nuvem e wake. ${ }^{34}$ 22 Figura 3.10 - Diagrama de classificação de partículas (pós) para fluidização com ar em condições ambiente. $^{35}$ 22 Figura 4.1 - Biomassa moída a) em moinho de martelo b) em moinho de facas willey.28 Figura 5.1 - Planta piloto de gaseificação e pirólise localizada na Área de Plantas Piloto da Embrapa Agroenergia. ${ }^{48}$ 33

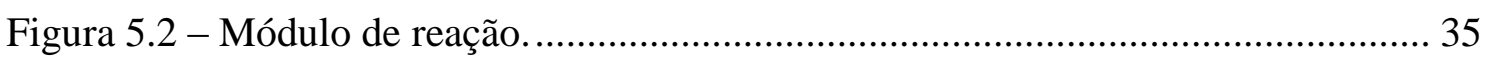

Figura 5.3 - Sistema de alimentação de combustível. ${ }^{48}$................................................. 36

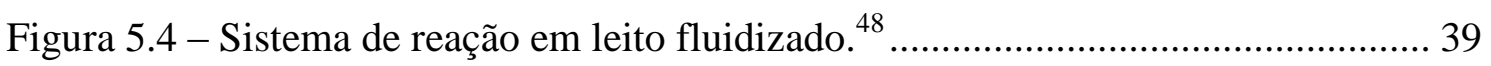

Figura 6.1 - Sistema de alimentação de biomassa da Planta Piloto de Pirólise e Gaseificação 43

Figura 6.2 - Aparato experimental utilizado na calibração do sistema de alimentação de sólidos

Figura 6.3 - Calibração de Eucalyptus grandis para os sistemas de alimentação 1 e 2.45 Figura 7.1 - Sistema de reação em leito fluidizado e transdutores de pressão PIA01, PDT03 e PI02. Adaptado de PID Eng \& Tech ${ }^{48}$ 48

Figura 7.2 - Perda de carga de leito de quartzo ocre mesh $30(1 \mathrm{~kg})$ em função da vazão de alimentação do agente de fluidização: a) ar à temperatura ambiente b) ar à 
temperatura de gaseificação c) vapor d'água à temperatura de gaseificação d) nitrogênio à temperatura ambiente e) nitrogênio à temperatura de gaseificação.

Figura 8.1 - Esquema de funcionamento da planta piloto de pirólise e gaseificação da Embrapa Agroenergia. Adaptado de PID Eng \& Tech $^{48}$ 58 Figura 8.2 - Perda de carga no reator (mbar) em função do tempo de processo estável de produção de gás com os agentes de fluidização: a) ar, b) vapor e c) nitrogênio. 62 Figura 8.3 - Temperatura de aquecimento em função do tempo de processo estável de produção de gás com os agentes de fluidização: a) ar, b) vapor e c) nitrogênio. 63 Figura 8.4 - Temperatura no reator em função do tempo de processo estável de produção de gás com os agentes de fluidização: a) ar, b) vapor e c) nitrogênio.

Figura 8.5 - Perfis de composição percentual dos de gases formados no processo de gaseificação de Eucalyptus grandis para (a) $\mathrm{RE}=0,23$ (b) $\mathrm{RE}=0,26$ (c) $\mathrm{RE}=0,28$ (d) $\mathrm{RE}=0,31$ (e) $\mathrm{RE}=0,37$ (f) $\mathrm{RE}=0,40$.

Figura 8.6 - Perfis de formação média (em percentagem) de gases no processo de gaseificação de Eucalyptus grandis utilizando ar como agente de gaseificação.

Figura 8.7 - Teste de Tukey realizado entre as razões de equivalência de 0,28 e 0,31 utilizadas no processo de gaseificação com ar para comparação entre as composições médias do gás.

Figura 8.8 - Perfis de composição percentual dos de gases formados no processo de gaseificação de Eucalyptus grandis para (a) $\mathrm{SBR}=1,69$ (b) $\mathrm{SBR}=1,97$ (c) $\mathrm{SBR}=2,25$ (d) $\mathrm{SBR}=2,53$ 73

Figura 8.9 - Perfis de composição percentual dos de gases formados no processo de gaseificação de Eucalyptus grandis para (a) $\mathrm{SBR}=2,81$ (b) $\mathrm{SBR}=3,10$ (c) $\mathrm{SBR}=3,38$.. 74 Figura 8.10 - Perfis de formação média (em percentagem) de gases no processo de gaseificação de Eucalyptus grandis utilizando vapor como agente de fluidização........ 76 Figura 8.11- Teste de Tukey realizado antre as razões vapor/biomassa utilizadas no processo de gaseificação com vapor: a) Comparação entre os percentuais do gás $\mathrm{CH}_{4}$ para as SBR's 1,69 e 2,25. b) Comparação entre os percentuais do gás $\mathrm{CH}_{4}$ para as SBR's 1,69 e 3,38. C) Comparação enre as vazões mássicas de $\mathrm{CH}_{4}$ para as SBR's 2,25 e 3,38. d) Comparação entre os percentuais de $\mathrm{H}_{2} \mathrm{~S}$ para as SBR's 1,69 e 2,25. e) Comparação entre os percentuais médios de CO para as SBR's 2,25 e 3,38. f) Comparação entre os percentuais de $\mathrm{CO}_{2}$ para as SBR's de 2,25 e 2,53. 78

Figura 8.12- Teste de Tukey realizado antre as razões vapor/biomassa utilizadas no processo de gaseificação com vapor: a) Comparação entre os percentuais de $\mathrm{H}_{2}$ para as 
SBR's 1,69 e 2,53. b) Comparação entre os percentuais de $\mathrm{H}_{2}$ para as SBR's 1,97 e 3,38. c) Comparação entre os percentuais de $\mathrm{H}_{2}$ para as SBR's 2,25 e 2,81

Figura 8.13 - Perfis de composição percentual dos de gases formados no processo de produção de gás combustível de Eucalyptus grandis com nitrogênio para (a) $12 \mathrm{NL} / \mathrm{min}$ (b) $14 \mathrm{NL} / \mathrm{min}$ (c) $16 \mathrm{NL} / \mathrm{min}$ (d) $18 \mathrm{NL} / \mathrm{min}$.

Figura 8.14 - Perfis de formação média (em percentagem) de gases no processo de gaseificação de Eucalyptus grandis utilizando ar como agente de fluidização. 86

Figura 8.15 - Produtividade dos gases $\mathrm{H}_{2}, \mathrm{CO}, \mathrm{CO}_{2}, \mathrm{CH}_{4}$ e $\mathrm{H}_{2} \mathrm{~S}$ em função das condições experimentais analisadas para produção de gás combustível com (a) ar (b) vapor e (c) nitrogênio.

Figura 8.16 - Poder calorífico inferior $\left(\mathrm{MJ} / \mathrm{Nm}^{3}\right)$ em função de: a) $\mathrm{RE}$ b) SBR c) vazão de nitrogênio (NL/min).

Figura 8.17 - Poder calorífico inferior (MJ/kg) em função de: a) RE b) SBR c) vazão de nitrogênio (NL/min). 93

Figura 11.1 - Perfis dos gases $\mathrm{H}_{2}, \mathrm{CO}, \mathrm{CH}_{4}$ e $\mathrm{H}_{2} \mathrm{~S}$, em porcentagem, formados de gaseificação utilizando ar como agente de fluidização para $\mathrm{RE}=0,23$. 104 Figura 11.2 - Perfil do gás $\mathrm{CO}_{2}$ em porcentagem, fluxo total volumétrico de gás formado (NL/min), e vazão mássica de $\mathrm{N}_{2}$ e $\mathrm{CO}_{2}$ em função do tempo em gaseificação utilizando ar como agente de fluidização para $\mathrm{RE}=0,23$. 104

Figura 11.3 - Perfis de vazão $(\mathrm{g} / \mathrm{min})$ dos gases $\mathrm{H}_{2}, \mathrm{CO}, \mathrm{CH}_{4}$ e $\mathrm{H}_{2} \mathrm{~S}$, em função do tempo, formados em gaseificação utilizando ar como agente de fluidização para RE = 0,23 . 105

Figura 11.4 - Perfis dos gases $\mathrm{H}_{2}, \mathrm{CO}, \mathrm{CH}_{4}$ e $\mathrm{H}_{2} \mathrm{~S}$, em porcentagem, formados de gaseificação utilizando ar como agente de fluidização para $\mathrm{RE}=0,26$. 105 Figura 11.5 - Perfil do gás $\mathrm{CO}_{2}$ em porcentagem, fluxo total volumétrico de gás formado (NL/min), e vazão mássica de $\mathrm{N}_{2}$ e $\mathrm{CO}_{2}$ em função do tempo emgaseificação utilizando ar como agente de fluidização para $\mathrm{RE}=0,26$. 106 Figura 11.6 - Perfis de vazão (g/min) dos gases $\mathrm{H}_{2}, \mathrm{CO}, \mathrm{CH}_{4}$ e $\mathrm{H}_{2} \mathrm{~S}$, em função do tempo, formados em gaseificação utilizando ar como agente de fluidização para RE = 0,26 . 106 Figura 11.7 - Perfis dos gases $\mathrm{H}_{2}, \mathrm{CO}, \mathrm{CH}_{4}$ e $\mathrm{H}_{2} \mathrm{~S}$, em porcentagem, formados de gaseificação utilizando ar como agente de fluidização para $\mathrm{RE}=0,28$. 107 
Figura 11.8 - Perfil do gás $\mathrm{CO}_{2}$ em porcentagem, fluxo total volumétrico de gás formado ( $\mathrm{NL} / \mathrm{min}$ ), e vazão mássica de $\mathrm{N}_{2}$ e $\mathrm{CO}_{2}$ em função do tempo em gaseificação utilizando ar como agente de fluidização para $\mathrm{RE}=0,28$.

Figura 11.9 - Perfis de vazão $(\mathrm{g} / \mathrm{min})$ dos gases $\mathrm{H}_{2}, \mathrm{CO}, \mathrm{CH}_{4}$ e $\mathrm{H}_{2} \mathrm{~S}$, em função do tempo, formados em gaseificação utilizando ar como agente de fluidização 108

Figura 11.10 - Perfis dos gases $\mathrm{H}_{2}, \mathrm{CO}, \mathrm{CH}_{4}$ e $\mathrm{H}_{2} \mathrm{~S}$, em porcentagem, formados de gaseificação utilizando ar como agente de fluidização para $\mathrm{RE}=0,31$. 108 Figura 11.11 - Perfil do gás $\mathrm{CO}_{2}$ em porcentagem, fluxo total volumétrico de gás formado (NL/min), e vazão mássica de $\mathrm{N}_{2}$ e $\mathrm{CO}_{2}$ em função do tempo em gaseificação utilizando ar como agente de fluidização para $\mathrm{RE}=0,31$

Figura 11.12 - Perfis de vazão (g/min) dos gases $\mathrm{H}_{2}, \mathrm{CO}, \mathrm{CH}_{4}$ e $\mathrm{H}_{2} \mathrm{~S}$, em função do tempo, formados em gaseificação utilizando ar como agente de fluidização para RE = 0,31 .

Figura 11.13 - Perfis dos gases $\mathrm{H}_{2}, \mathrm{CO}, \mathrm{CH}_{4}$ e $\mathrm{H}_{2} \mathrm{~S}$, em porcentagem, formados de gaseificação utilizando ar como agente de fluidização para $\mathrm{RE}=0,37$. 110 Figura 11.14 - Perfil do gás $\mathrm{CO}_{2}$ em porcentagem, fluxo total volumétrico de gás formado (NL/min), e vazão mássica de $\mathrm{N}_{2}$ e $\mathrm{CO}_{2}$ em função do tempo em gaseificação utilizando ar como agente de fluidização para $\mathrm{RE}=0,37$.

Figura 11.15 - Perfis de vazão (g/min) dos gases $\mathrm{H}_{2}, \mathrm{CO}, \mathrm{CH}_{4}$ e $\mathrm{H}_{2} \mathrm{~S}$, em função do tempo, formados em gaseificação utilizando ar como agente de fluidização para RE = 0,37 .

Figura 11.16 - Perfis dos gases $\mathrm{H}_{2}, \mathrm{CO}, \mathrm{CH}_{4}$ e $\mathrm{H}_{2} \mathrm{~S}$, em porcentagem, formados de gaseificação utilizando ar como agente de fluidização para $\mathrm{RE}=0,40$.

Figura 11.17 - Perfil do gás $\mathrm{CO}_{2}$ em porcentagem, fluxo total volumétrico de gás formado (NL/min), e vazão mássica de $\mathrm{N}_{2}$ e $\mathrm{CO}_{2}$ em função dotempo em gaseificação utilizando ar como agente de fluidização para $\mathrm{RE}=0,40$.

Figura 11.18 - Perfis de vazão $(\mathrm{g} / \mathrm{min})$ dos gases $\mathrm{H}_{2}, \mathrm{CO}, \mathrm{CH}_{4}$ e $\mathrm{H}_{2} \mathrm{~S}$, em função do tempo, formados em gaseificação utilizando ar como agente de fluidização para RE = 0,40 . 112

Figura 12.1 - Perfis dos gases $\mathrm{H}_{2}, \mathrm{CO}, \mathrm{CH}_{4}$ e $\mathrm{H}_{2} \mathrm{~S}$, em porcentagem, formados de gaseificação utilizando vapor como agente de fluidização para $\mathrm{SBR}=1,69$.

Figura 12.2 - Perfis do gás $\mathrm{CO}_{2}$ em porcentagem e vazão mássica (g/min), fluxo total volumétrico de gás formado (NL/min), e composição do gás formado determinado no 
analisador de gases considerando a injeção de $\mathrm{N}_{2}(\%)$, em função do tempo, em gaseificação utilizando vapor como agente de fluidização para $\mathrm{SBR}=1,69$. 114 Figura 12.3 - Perfis de vazão $(\mathrm{g} / \mathrm{min})$ dos gases $\mathrm{H}_{2}, \mathrm{CO}, \mathrm{CH}_{4}$ e $\mathrm{H}_{2} \mathrm{~S}$, em função do tempo, formados em gaseificação utilizando vapor como agente de fluidização para $\mathrm{SBR}=1,69$. 115

Figura 12.4 - Perfis dos gases $\mathrm{H}_{2}, \mathrm{CO}, \mathrm{CH}_{4}$ e $\mathrm{H}_{2} \mathrm{~S}$, em porcentagem, formados de gaseificação utilizando vapor como agente de fluidização para $\mathrm{SBR}=1,97$. 115 Figura 12.5 - Perfis do gás $\mathrm{CO}_{2}$ em porcentagem e vazão mássica (g/min), fluxo total volumétrico de gás formado (NL/min), e composição do gás formado determinado no analisador de gases considerando a injeção de $\mathrm{N}_{2}$ (\%), em função do tempo, em gaseificação utilizando vapor como agente de fluidização para $\mathrm{SBR}=1,97$. 116 Figura 12.6 - Perfis de vazão (g/min) dos gases $\mathrm{H}_{2}, \mathrm{CO}, \mathrm{CH}_{4}$ e $\mathrm{H}_{2} \mathrm{~S}$, em função do tempo, formados em gaseificação utilizando vapor como agente de fluidização para $\mathrm{SBR}=1,97$ 116 Figura 12.7 - Perfis dos gases $\mathrm{H}_{2}, \mathrm{CO}, \mathrm{CH}_{4}$ e $\mathrm{H}_{2} \mathrm{~S}$, em porcentagem, formados de gaseificação utilizando vapor como agente de fluidização para $\mathrm{SBR}=2,25$.

Figura 12.8 - Perfis do gás $\mathrm{CO}_{2}$ em porcentagem e vazão mássica (g/min), fluxo total volumétrico de gás formado (NL/min), e composição do gás formado determinado no analisador de gases considerando a injeção de $\mathrm{N}_{2}(\%)$, em função do tempo, em gaseificação utilizando vapor como agente de fluidização para $\mathrm{SBR}=2,25$.

Figura 12.9 - Perfis de vazão (g/min) dos gases $\mathrm{H}_{2}, \mathrm{CO}, \mathrm{CH}_{4}$ e $\mathrm{H}_{2} \mathrm{~S}$, em função do tempo, formados em gaseificação utilizando vapor como agente de fluidização para $\mathrm{SBR}=2,25$. 118

Figura 12.10 - Perfis dos gases $\mathrm{H}_{2}, \mathrm{CO}, \mathrm{CH}_{4}$ e $\mathrm{H}_{2} \mathrm{~S}$, em porcentagem, formados de gaseificação utilizando vapor como agente de fluidização para $\mathrm{SBR}=2,53$. 118 Figura 12.11 - Perfis do gás $\mathrm{CO}_{2}$ em porcentagem e vazão mássica (g/min), fluxo total volumétrico de gás formado (NL/min), e composição do gás formado determinado no analisador de gases considerando a injeção de $\mathrm{N}_{2}(\%)$, em função do tempo, em gaseificação utilizando vapor como agente de fluidização para $\mathrm{SBR}=2,53$.

Figura 12.12 - Perfis de vazão (g/min) dos gases $\mathrm{H}_{2}, \mathrm{CO}, \mathrm{CH}_{4}$ e $\mathrm{H}_{2} \mathrm{~S}$, em função do tempo, formados em gaseificação utilizando vapor como agente de fluidização para $\mathrm{SBR}=2,53$.

Figura 12.13 - Perfis dos gases $\mathrm{H}_{2}, \mathrm{CO}, \mathrm{CH}_{4}$ e $\mathrm{H}_{2} \mathrm{~S}$, em porcentagem, formados de gaseificação utilizando vapor como agente de fluidização para $\mathrm{SBR}=2,81$. 120 
Figura 12.14 - Perfis do gás $\mathrm{CO}_{2}$ em porcentagem e vazão mássica (g/min), fluxo total volumétrico de gás formado (NL/min), e composição do gás formado determinado no analisador de gases considerando a injeção de $\mathrm{N}_{2}(\%)$, em função do tempo, em gaseificação utilizando vapor como agente de fluidização para $\mathrm{SBR}=2,81$ 120 Figura 12.15 - Perfis de vazão (g/min) dos gases $\mathrm{H}_{2}, \mathrm{CO}, \mathrm{CH}_{4}$ e $\mathrm{H}_{2} \mathrm{~S}$, em função do tempo, formados em gaseificação utilizando vapor como agente de fluidização para $\mathrm{SBR}=2,81$.

Figura 12.16 - Perfis dos gases $\mathrm{H}_{2}, \mathrm{CO}, \mathrm{CH}_{4}$ e $\mathrm{H}_{2} \mathrm{~S}$, em porcentagem, formados de gaseificação utilizando vapor como agente de fluidização para $\mathrm{SBR}=3,10$.

Figura 12.17 - Perfis do gás $\mathrm{CO}_{2}$ em porcentagem e vazão mássica (g/min), fluxo total volumétrico de gás formado (NL/min), e composição do gás formado determinado no analisador de gases considerando a injeção de $\mathrm{N}_{2}(\%)$, em função do tempo, em gaseificação utilizando vapor como agente de fluidização para $\mathrm{SBR}=3,10$. 122 Figura 12.18 - Perfis de vazão (g/min) dos gases $\mathrm{H}_{2}, \mathrm{CO}, \mathrm{CH}_{4}$ e $\mathrm{H}_{2} \mathrm{~S}$, em função do tempo, formados em gaseificação utilizando vapor como agente de fluidização para $\mathrm{SBR}=3,10$.

Figura 12.19 - Perfis dos gases $\mathrm{H}_{2}, \mathrm{CO}, \mathrm{CH}_{4}$ e $\mathrm{H}_{2} \mathrm{~S}$, em porcentagem, formados de gaseificação utilizando vapor como agente de fluidização para $\mathrm{SBR}=3,38$.

Figura 12.20 - Perfis do gás $\mathrm{CO}_{2}$ em porcentagem e vazão mássica (g/min), fluxo total volumétrico de gás formado (NL/min), e composição do gás formado determinado no analisador de gases considerando a injeção de $\mathrm{N}_{2}(\%)$, em função do tempo, em gaseificação utilizando vapor como agente de fluidização para $\mathrm{SBR}=3,38$.

Figura 12.21 - Perfis de vazão (g/min) dos gases $\mathrm{H}_{2}, \mathrm{CO}, \mathrm{CH}_{4}$ e $\mathrm{H}_{2} \mathrm{~S}$, em função do tempo, formados em gaseificação utilizando vapor como agente de fluidização para $\mathrm{SBR}=3,38$.

Figura 13.1 - Perfis dos gases $\mathrm{H}_{2}, \mathrm{CO}, \mathrm{CH}_{4}$ e $\mathrm{H}_{2} \mathrm{~S}$, em porcentagem, formados de pirólise utilizando $12 \mathrm{NL} / \mathrm{min}$ de nitrogênio como agente de fluidização. 126 Figura 13.2 - Perfis do gás $\mathrm{CO}_{2}$ em porcentagem e vazão mássica (g/min), fluxo total volumétrico de gás formado (NL/min), e vazão volumétrica de nitrogênio de entrada (NL/min), em pirólise utilizando $12 \mathrm{NL} / \mathrm{min}$ de nitrogênio como agente de fluidização.

Figura 13.3 - Perfis de vazão $(\mathrm{g} / \mathrm{min})$ dos gases $\mathrm{H}_{2}, \mathrm{CO}, \mathrm{CH}_{4}$ e $\mathrm{H}_{2} \mathrm{~S}$, em função do tempo, formados em pirólise utilizando $12 \mathrm{NL} / \mathrm{min}$ de nitrogênio como agente de fluidização. 
Figura 13.4 - Perfis dos gases $\mathrm{H}_{2}, \mathrm{CO}, \mathrm{CH}_{4}$ e $\mathrm{H}_{2} \mathrm{~S}$, em porcentagem, formados de pirólise utilizando $14 \mathrm{NL} / \mathrm{min}$ de nitrogênio como agente de fluidização.

Figura 13.5 - Perfis do gás $\mathrm{CO}_{2}$ em porcentagem e vazão mássica (g/min), fluxo total volumétrico de gás formado (NL/min), e vazão volumétrica de nitrogênio de entrada (NL/min), em pirólise utilizando $14 \mathrm{NL} / \mathrm{min}$ de nitrogênio como agente de fluidização.

Figura 13.6 - Perfis de vazão $(\mathrm{g} / \mathrm{min})$ dos gases $\mathrm{H}_{2}, \mathrm{CO}, \mathrm{CH}_{4}$ e $\mathrm{H}_{2} \mathrm{~S}$, em função do tempo, formados em pirólise utilizando $14 \mathrm{NL} / \mathrm{min}$ de nitrogênio. 128 Figura 13.7 - Perfis dos gases $\mathrm{H}_{2}, \mathrm{CO}, \mathrm{CH}_{4}$ e $\mathrm{H}_{2} \mathrm{~S}$, em porcentagem, formados de pirólise utilizando $16 \mathrm{NL} / \mathrm{min}$ de nitrogênio como agente de fluidização.

Figura 13.8 - Perfis do gás $\mathrm{CO}_{2}$ em porcentagem e vazão mássica (g/min), fluxo total volumétrico de gás formado (NL/min), e vazão volumétrica de nitrogênio de entrada (NL/min), em pirólise utilizando 16 NL/min de nitrogênio como agente de fluidização.

Figura 13.9 - Perfis de vazão $(\mathrm{g} / \mathrm{min})$ dos gases $\mathrm{H}_{2}, \mathrm{CO}, \mathrm{CH}_{4}$ e $\mathrm{H}_{2} \mathrm{~S}$, em função do tempo, formados em pirólise utilizando $16 \mathrm{NL} / \mathrm{min}$ de nitrogênio como agente de fluidização.

Figura 13.10 - Perfis dos gases $\mathrm{H}_{2}, \mathrm{CO}, \mathrm{CH}_{4}$ e $\mathrm{H}_{2} \mathrm{~S}$, em porcentagem, formados de pirólise utilizando $18 \mathrm{NL} / \mathrm{min}$ nitrogênio como agente de fluidização. 130

Figura 13.11 - Perfis do gás $\mathrm{CO}_{2}$ em porcentagem e vazão mássica (g/min), fluxo total volumétrico de gás formado (NL/min), e vazão volumétrica de nitrogênio de entrada (NL/min), em pirólise utilizando 18 NL/min de nitrogênio como agente de fluidização.

Figura 13.12 - Perfis de vazão (g/min) dos gases $\mathrm{H}_{2}, \mathrm{CO}, \mathrm{CH}_{4}$ e $\mathrm{H}_{2} \mathrm{~S}$, em função do tempo, formados em gaseificação utilizando $18 \mathrm{NL} / \mathrm{min}$ de nitrogênio como agente de fluidização. 131

Figura 13.13 - Perfis dos gases $\mathrm{H}_{2}, \mathrm{CO}, \mathrm{CH}_{4}$ e $\mathrm{H}_{2} \mathrm{~S}$, em porcentagem, formados de pirólise utilizando $20 \mathrm{NL} / \mathrm{min}$ de nitrogênio como agente de fluidização.

Figura 13.14 - Perfis do gás $\mathrm{CO}_{2}$ em porcentagem e vazão mássica (g/min), fluxo total volumétrico de gás formado (NL/min), e vazão volumétrica de nitrogênio de entrada (NL/min), em pirólise utilizando $20 \mathrm{NL} / \mathrm{min}$ de nitrogênio como agente de fluidização. 
Figura 13.15 - Perfis de vazão (g/min) dos gases $\mathrm{H}_{2}, \mathrm{CO}, \mathrm{CH}_{4}$ e $\mathrm{H}_{2} \mathrm{~S}$, em função do tempo, formados em pirólise utilizando $20 \mathrm{NL} / \mathrm{min}$ de nitrogênio como agente de fluidização. 133

Figura 14.1 - Balanço de vazão volumétrica de entrada e saída de $\mathrm{N}_{2}$ analisando pela medição no medidor de fluxo total e suposição pelo resultado obtido do analisador de gases. 


\section{LISTA DE TABELAS}

Tabela 3.1 - Principais reações no processo de gaseificação de biomassa. ${ }^{36,37}$ 24

Tabela 4.1 - Valores médios para as análises elementar e imediata, poder calorífico e razões $\mathrm{H} / \mathrm{C}$ e $\mathrm{O} / \mathrm{C}$ de Eucalyptus grandis.

Tabela 5.1 - Pressões de entrada e saída e vazões máximas dos agentes de gaseificação. $^{48}$

Tabela 5.2 - Descrição dos módulos e faixas de medição dos gases medidos no equipamento de análise de gases.

Tabela 6.1 - Vazões mássicas médias de Eucalyptus grandis (g/min) em função da rotação dos motores alimentadores (SIC02B) dos sistemas de alimentação 1 e 2 ......... 45

Tabela 7.1 - Faixa de vazão para os ensaios de fluidização. 48

Tabela 7.2 - Agentes de fluidização e suas respectivas vazões com o leito de quartzo em estado de fluidização à temperatura ambiente e de gaseificação.

Tabela 8.1 - Vazões de ar e biomassa (média) e razões de equivalência utilizados no processo de gaseificação de Eucalyptus grandis utilizando ar como agente de fluidização.

Tabela 8.2 - Vazões de vapor e biomassa (média) e razões vapor/biomassa utilizados no processo de gaseificação de Eucalyptus grandis utilizando vapor como agente de fluidização.

Tabela 8.3 - Vazões de nitrogênio e biomassa (média) no processo de conversão termoquímica de Eucalyptus grandis utilizando nitrogênio como agente de fluidização.

Tabela 8.4 - Sistemas e equipamentos presentes na planta piloto de pirólise e gaseificação.

Tabela 8.5 - Temperatura setada para os termopares (TIC) apesentados na Figura 8.1 durante processo de produção de gás.

Tabela 8.6 - Composição média (\%) de $\mathrm{H}_{2}, \mathrm{CO}, \mathrm{CH}_{4}, \mathrm{CO}_{2}$ e $\mathrm{H}_{2} \mathrm{~S}$ no gás formado de processo de gaseificação de Eucalyptus grandis em função de RE.

Tabela 8.7 - Composição média de $\mathrm{H}_{2}, \mathrm{CO}, \mathrm{CH}_{4}, \mathrm{CO}_{2}$ e $\mathrm{H}_{2} \mathrm{~S}$ no gás formado de processo de gaseificação de Eucalyptus grandis em função de SBR. 76

Tabela 8.8 - Razões vapor/biomassa que apresentaram equivalência em teste Tukey de comparação de médias para as composições médias (\%). 77 
Tabela 8.9 - Solubilidade dos gases produzidos em água (ppm), quantidade máxima de cada gás que pode ficar retida em 200 L de água (g) e tempo médio de saturação da água utilizada para lavagem dos gases produzidos em função da vazão mássica média de cada gás.

Tabela 8.10 - Composição média de $\mathrm{H}_{2}, \mathrm{CO}, \mathrm{CH}_{4}, \mathrm{CO}_{2}$ e $\mathrm{H}_{2} \mathrm{~S}$ no gás formado de processo de pirólise de Eucalyptus grandis em função da vazão do agente de fluidização nitrogênio. 85

Tabela 8.11 - Melhor condição de produção média de cada gás (\%) no produto final para os diferentes agentes de fluidização. 86

Tabela 8.12 - Produtividade de cada gás medido no gás total formado de processo de gaseificação de Eucalyptus grandis utilizando ar como agente de fluidização.

Tabela 8.13 - Produtividade de cada gás medido no gás total formado de processo de gaseificação de Eucalyptus grandis utilizando vapor como agente de fluidização........ 88 Tabela 8.14 - Produtividade de cada gás medido no gás total formado de processo de produção de gás combustível a partir de Eucalyptus grandis utilizando nitrogênio como agente de fluidização. 88

Tabela 8.15 - Poder calorífico inferior (PCI) médio em $\mathrm{MJ} / \mathrm{m}^{3}$ em função da composição média do gás formado utilizando os agentes de fluidiação ar, vapor e nitrogênio. 90

Tabela 8.16 - Densidade dos gases $\mathrm{H}_{2}, \mathrm{CO}, \mathrm{CH}_{4}$ e $\mathrm{H}_{2} \mathrm{~S} 0{ }^{\circ} \mathrm{C}$ e 1 atm (CNTP). ${ }^{58}$.......... 91 Tabela 8.17 - Poder calorífico inferior do gás formado de processos termoquímicos de Eucalyptus grandis utilizando ar, vapor e nitrogênio como agentes de fluidização. ..... 91 


\section{LISTA DE ABREVIATURAS E SIGLAS}

ANOVA - análise de variância

ASTM - American Society for Testing and Material

BEN - Balanço Energético Nacional

C - carbono

${ }^{\circ} \mathrm{C}$ - graus Celsius

$\mathrm{C}_{2} \mathrm{H}_{2}$ - acetileno

$\mathrm{C}_{2} \mathrm{H}_{4}$ - etileno

$\mathrm{C}_{2} \mathrm{H}_{6}$ - etano

$\mathrm{C}_{6} \mathrm{H}_{6}$ - benzeno

CO - monóxido de carbono

$\mathrm{CO}_{2}$ - gás carbônico

$C_{\mathrm{pH}_{2} \mathrm{O}^{-}}$calor específico da água

$\mathrm{CH}_{4}-$ metano

cm - centímetros

E.: Eucalyptus

g - gramas

$H_{\%}$ - porcentagem mássica do gás hidrogênio

$\mathrm{H}_{2}$ - hidrogênio

$h_{g}$ - calor latente de vaporização

IR - infravermelho

kcal - quilocaloria

$\mathrm{kg}$ - quilograma

$\mathrm{kW}$ - quilowatt

LR - líquido de resfriamento

$\dot{m}_{g}$ - vazão mássica do gás

$\min -$ minuto

$\mathrm{mL}$ - mililitro

mbar - milibar 
$m_{\text {biomassa }}$ - massa de biomassa

MDR - methane dry reforming

MFC - controladores de fluxo mássico

$m_{\mathrm{H}_{2} \mathrm{O}}$ - massa de água

MJ - megajoule

mm - milimetro

MWh - Megawatt-hora

Mtep - Milhões de toneladas de petróleo

$\mathrm{N}_{2}$ - nitrogênio

NDIR - tecnologia de infravermelho não dispersivo

NL - normal litro

$\mathrm{Nm}^{3}$ - normal metro cúbico

$\mathrm{O}_{2}$ - oxigênio

$P_{\text {entrada }}$ - pressão de entrada

$P_{\text {saída }}$ - pressão de saída

PCI - poder calorífico inferior

PCS - poder calorífico superior

PDT - transdutor diferencial de pressão

Percentual $_{g}$ - percentual de cada gás gerado no processo

PI - transdutor de pressão

PIA - transdutor de pressão

PIB - Produto Interno Bruto

ppm - partes por milhão

$Q$ - quantidade de calor absorvida

$\left(R_{A / C}\right)_{\text {estequiométrica }}$ - razão ar/combustível estequiométrica

$\left(R_{A / C}\right)_{\text {real }}$ - razão ar/combustível real

$\mathrm{RE}$ - razão de equivalência

S - enxofre

SBR - razão vapor/biomassa 
SIC02A - motor dosador de biomassa

SIC02B - motor alimentador de biomassa

TCD - deterctor de condutividade térmica

Teste $\mathrm{t}$ - teste Tukey

TIC - controlador de temperatura

$T_{i}$ - temperatura inicial

$T_{f}$ - temperatura final

$u$ - velocidade superficial do leito

$u_{m f}$ - velocidade mínima de fluidização

UV - ultra-violeta

$\dot{V}_{T}$ - volume total de gás gerado no processo

$\mathrm{v} / \mathrm{v}$ - volume/volume

$x_{i}$ - fração volumétrica do gás i $\left(\mathrm{H}_{2}, \mathrm{CO}, \mathrm{CH}_{4}\right.$ e $\left.\mathrm{H}_{2} \mathrm{~S}\right)$

W - watt

WGS - water gas shift ou reação de deslocamento água-gás

$u_{t}$ - velocidade terminal dos sólidos

$\Delta P_{1}$ - perda de carga entre a região do leito e o topo do reator

$\Delta P_{2}$ - perda de carga entre a entrada do distribuidor de agente de fluidização e a região do leito

$\Delta P_{D}$ - perda de carga conferida ao gás de fluidização apenas pelo distribuidor

$\Delta P_{L}$ - perda de carga conferida ao gás de fluidização apenas pelo leito

$\Delta P_{T}$ - perda de carga total conferida ao gás de fluidização somando as perdas de cargas conferidas pelo leito e pelo distribuidor

$\rho_{p}$ - densidade da partícula

$\rho_{g}$ - densidade do gás

$\omega$ - porcentagem mássica de umidade da biomassa 


\section{INTRODUÇÃO}

A energia tem ganhado cada vez mais importância nos dias atuais, seja como um elemento essencial da economia, seja como um elemento relacionado a sustentabilidade. A dependência da tecnologia, o aumento da qualidade de vida principalmente nos países desenvolvidos e o aumento contínuo da população nos países em desenvolvimento certamente são fatores que corroboram com o aumento na demanda energética. Além disso, cerca de dois bilhões de pessoas em todo o mundo carecem de eletricidade. Assim, a fim de satisfazer essa demanda, o consumo de combustíveis fósseis vem aumentando, resultando em uma maior emissão de poluentes, mudanças climáticas e riscos ao meio-ambiente e à saúde humana. ${ }^{1}$

As fontes de energia podem ser dividas em três categorias principais: combustíveis fósseis, recursos nucleares e recursos renováveis. As fontes renováveis, que atualmente fornecem $23,7 \%$ da demanda mundial de energia, têm um importante papel para desempenhar no futuro do mundo, pois podem fornecer energia reduzindo a emissão de poluentes que agridem o meio-ambiente. Com isso, tem-se cada vez mais investido em pesquisas relacionadas a fontes alternativas de energia, destacando-se as energias solar, geotérmica, eólica, de biomassa, marinha, biocombustíveis, entre outras. ${ }^{1}$

A biomassa é uma das fontes que recebe enorme atenção no cenário nacional, pois possui um grande potencial para geração de energia proveniente de fontes renováveis. ${ }^{2}$ Dentre as fontes de biomassa, as florestas plantadas têm ganhado um importante destaque, pois, do ponto de vista ambiental influem na qualidade do ar, na integridade do solo e nos cursos d'água, e do ponto de vista socioeconômico representam uma grande matéria-prima para cadeias produtivas e produção energética. $\mathrm{O}$ incentivo ao consumo de produtos florestais tem cada vez mais se destacado, desde o papel e a madeira até combustíveis mais limpos como a própria biomassa, além de produtos químicos e farmacêuticos. Em 2015, a indústria de árvores plantadas, que empregou diretamente 540 mil pessoas, gerou $67 \%$ da energia consumida pelo próprio setor, e os subprodutos de seus processos produtivos são a principal matéria-prima para geração de energia térmica e elétrica. $\mathrm{O}$ licor negro, oriundo da produção de celulose, e a biomassa florestal representaram $62,5 \%$ e $17,3 \%$ da energia produzida no setor, respectivamente. ${ }^{3}$ 
O eucalipto é a principal fonte de biomassa florestal plantada no país, e tem seu uso aplicado em diversas áreas, desde produtos como roupas, medicamentos, alimentos, até as indústrias de papel e celulose, siderurgia e na produção de energia. Dentre as cerca de 700 espécies do gênero Eucalyptus, as espécies Eucalyptus grandis, Eucalyptus urophylla, Eucalyptus viminalis e híbridos de E. grandis x E. urophylla são as mais plantadas. Algumas vantagens do uso do eucalipto como fonte de madeira são: diversidade de espécies, que possibilita a adaptação da cultura às diversas condições de clima e solo, e vasto conhecimento acerca da silvicultura, do manejo e do melhoramento genético desse gênero. ${ }^{4}$

A principal forma de conversão de eucalipto em energia no Brasil é através da combustão, que ainda é um processo que não se apresenta eficiente. Uma das tecnologias alternativas capazes de gerar energia por meio da biomassa florestal, aumentando seu valor agregado, é a gaseificação que produz, dentre outros produtos gasosos, uma mistura gasosa constituída de monóxido de carbono e hidrogênio, geralmente denominada de gás de síntese, que pode ser aplicada na queima direta para geração de energia elétrica, e como matéria-prima para indústria química visando produção de amônia, hidrogênio e combustíveis líquidos. 5, 6

Dentre os principais tipos de sistemas utilizados na gaseificação, o processo em leito fluidizado se mostra muito atraente pois trabalha em regimes de fluidização, o que tornam os fenômenos de transferência de calor e massa mais eficientes que o processo em leito fixo, por exemplo. Além disso, em relação à capacidade de produção de gás, os reatores em leito fixo estão em torno de $2 \mathrm{Nm}^{3} / \mathrm{kg}$ de biomassa, e podem ser utilizados principalmente na produção de eletricidade em pequena escala (propriedades rurais, por exemplo) e os de leito fluidizado em uma faixa de 1,8 a $2,5 \mathrm{Nm}^{3} / \mathrm{kg}$ de biomassa, tendo seu uso mais aplicado em grande escala (áreas industriais). ${ }^{7}$

Diante deste contexto nacional de demanda energética e sustentabilidade, da importância da descentralização da matriz energética, da crescente disponibilidade da biomassa florestal no Brasil, de tornar processos industriais como os de papel e celulose cada vez mais autossustentáveis do ponto de vista energético e da existência de tecnologias capazes de converter a biomassa em energia, o presente trabalho tem como foco analisar o potencial da biomassa florestal (Eucalyptus grandis) na geração de energia via processo de gaseificação em leito fluidizado. 


\section{OBJETIVOS}

\subsection{OBJETIVO GERAL}

O objetivo geral do presente trabalho é a produção de gás combustível a partir da conversão termoquímica de Eucalyptus grandis visando a produção de energia em um reator de leito fluidizado.

\subsection{OBJETIVOS ESPECÍFICOS}

- Caracterização da biomassa de Eucalyptus grandis quanto às composições elementar e imediata e poder calorífico;

- Operacionalização da planta piloto de pirólise e gaseificação da Embrapa Agroenergia;

- Caracterização dos regimes de fluidização para os agentes de fluidização ar, vapor e nitrogênio;

- Produção de gás combustível e determinação das melhores condições experimentais utilizando ar, vapor e nitrogênio como agentes de fluidização;

- Determinação do poder calorífico dos gases produzidos no processo de conversão termoquímica de Eucalyptus grandis para os três agentes de fluidização estudados. 


\section{REVISÃO BIBLIOGRÁFICA}

\subsection{CONTEXTO ENERGÉTICO DO BRASIL}

Segundo dados do Balanço Energético Nacional - BEN de 2016, relativo ao ano de 2015, a oferta interna de energia total disponibilizada no Brasil (apresentada na Figura 3.1) registrou uma redução de 2,1\% em relação ao ano de 2014, totalizando 299,2 Mtep. Um dos fatores responsáveis por esta redução foi a diminuição da oferta de energia proveniente de petróleo e derivados, de 7,2\% no período, em consequência do superavit nos fluxos de exportação e importação de tais fontes energéticas. Outro fator que influenciou na redução de oferta energética foi o enfraquecimento da atividade econômica em 2015, onde o PIB teve uma redução de 3,8\%. O consumo de energia no país reduziu 1,9\% (260,7 Mtep de energia consumida no total) no mesmo período, queda principalmente nos setores industrial, $3,1 \%$, e de transporte, $2,6 \% .^{8}$

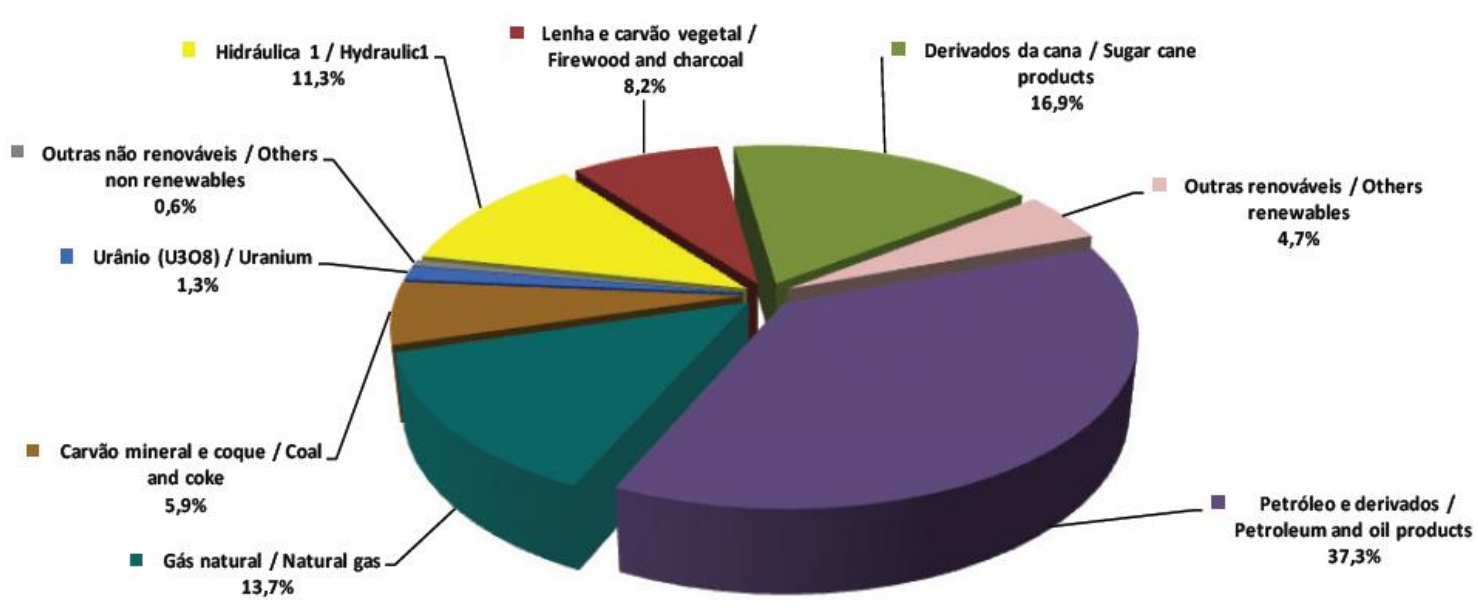

Figura 3.1 - Oferta interna de energia no Brasil no ano de $2015 .^{8}$

Já com relação à oferta de energia elétrica em 2015, houve redução de 1,3\% em comparação ao ano de 2014, com os recursos hídricos apresentando redução no fornecimento de 3,2\% (condições hidrológicas desfavoráveis). Apesar da queda de oferta de energia hídrica, houve aumento na utilização de energia proveniente de fontes renováveis na matriz elétrica brasileira, sendo 75,5\% da oferta de eletricidade no Brasil proveniente de fonte renovável, devido à redução da geração térmica a base de derivados de petróleo e do aumento da geração a base de biomassa, 8,0 \% (aumento de 0,8\% em relação a 2014), e eólica, 3,5\% (crescimento de $77,1 \%$ em relação a 2014). O consumo de energia elétrica reduziu $1,8 \%$, sendo maior a redução no setor industrial, cerca de 5\%. É interessante também destacar que o setor elétrico 
brasileiro emitiu em média $139,9 \mathrm{~kg}$ de $\mathrm{CO}_{2}$ para produzir $1 \mathrm{MWh}$, um índice muito baixo levando-se em consideração os países da União Européia, EUA e China. ${ }^{8}$

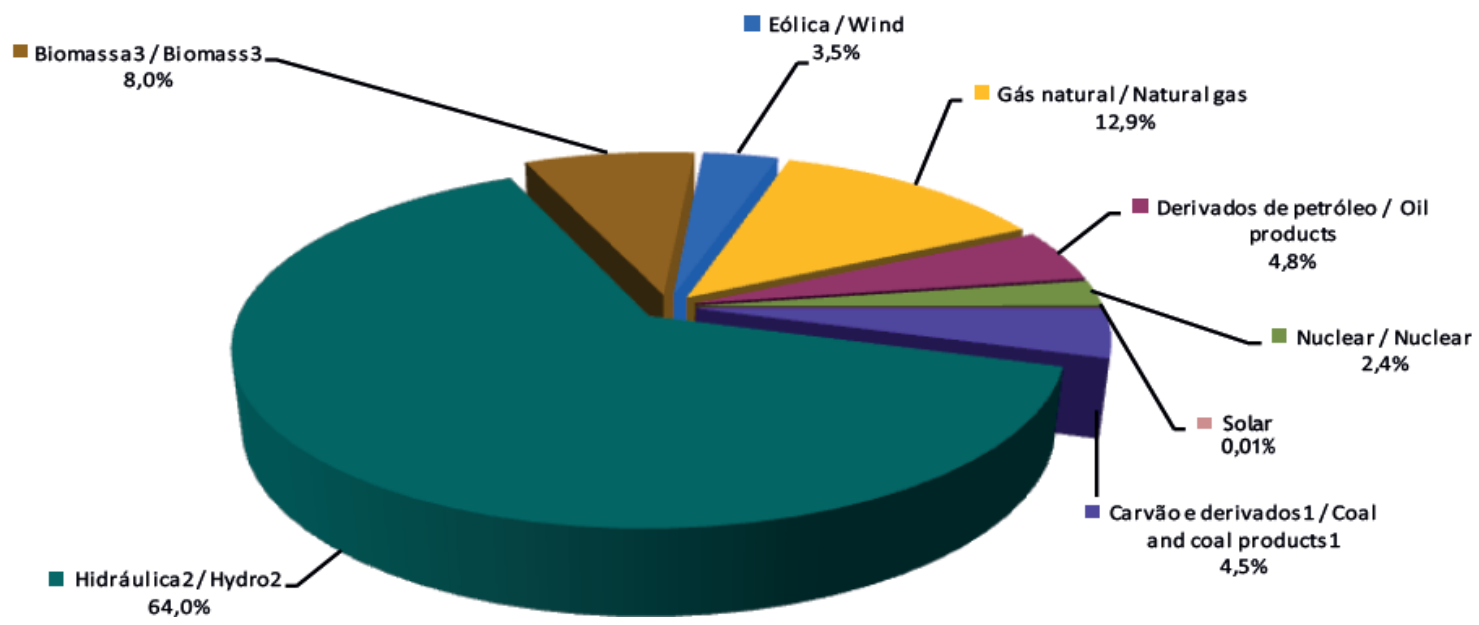

Figura 3.2 - Oferta de energia elétrica no Brasil no ano de $2015{ }^{8}$

A redução de reservas fósseis e o aumento da demanda por combutíveis para transporte, juntamente com as alterações climáticas provocadas pelas emissões de dióxido de carbono, também contribuem para o interesse no investimento em recursos energéticos novos e renováveis. A biomassa se mostra uma alternativa interessante em relação à matéria-prima fóssil, pois ela está disponível em grande escala e a sua utilização contribui para a redução de emissão de dióxido de carbono na atmosfera. ${ }^{9}$ O setor florestal brasileiro é destaque de produtividade no mundo, porém, alguns entraves dificultam a continuidade do crescimento dessa indústria, um deles é o custo de produção da madeira (que ficou mais caro em 2015), outro é a inflação do setor de árvores plantadas, que foi de 12,8\% em 2015, o que representou um crescimento de $2,1 \%$ a mais do que a média do aumento de custos e preços da economia brasileira, já que a inflação nacional foi de 10,7\%. Com o interesse na redução da dependência do consumo de derivados de petróleo, a inserção das florestas plantadas como fonte renovável e de biomassa florestal se torna cada vez mais interessante, e algumas tecnologias de aproveitamento energético dessa matéria-prima têm recebido bastante destaque em pesquisas, casos do etanol celulósico, da pirólise e da gaseificação, boas alternativas para a diversificação da matriz energética nacional. ${ }^{3}$

A área total de árvores plantadas no Brasil em 2015 foi de 7,8 milhões de hectares, o que representou um crescimento de $0,8 \%$ em comparação com o ano de 2014. Destaca-se que 5,6 milhões de hectares plantados são de eucalipto e estão localizados principalmente nos estados de Minas Gerais (24\%), São Paulo (17\%) e Mato Grosso do Sul (15\%). A Figura 3.3 
apresenta a composição da área de árvores plantadas por segmento no Brasil no ano de 2015, onde $34 \%$ são de posse de empresas do segmento de papel e celulose (Brasil é o quarto maior produtor mundial), $29 \%$ são de pequenos e médios produtores, que comercializam a madeira in natura, e 14\% são da indústria siderúrgica a carvão vegetal (do total de carvão consumido em $2015,82 \%$ foram produzidos a partir de madeira proveniente de floresta plantada). ${ }^{3}$

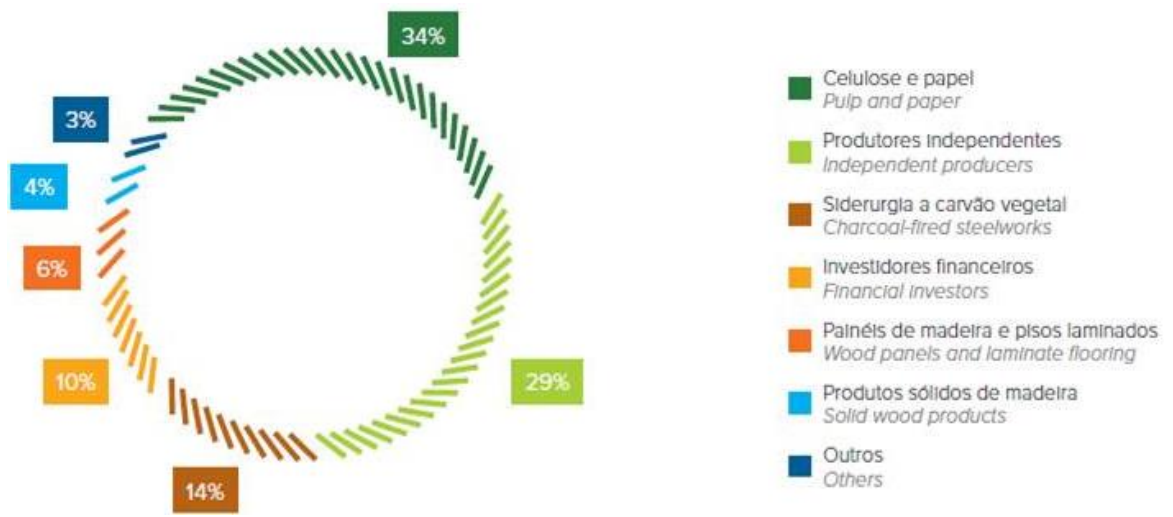

Figura 3.3 - Distribuição da área de árvores plantadas por segmento no Brasil no ano de $2015 .^{3}$

Em 2015, o setor de florestas plantadas gerou 46,8 milhões de toneladas de resíduos sólidos, sendo 70,5\% proveniente de atividades florestais e $29,5 \%$ de atividades industriais. Com relação à atividade florestal, 99,7\% dos resíduos sólidos, principalmente cascas, galhos e folhas, são mantidos no campo para proteção e fertilização do solo. Os demais, $0,3 \%$, entre óleos, graxas e embalagens de agroquímicos, são encaminhados de forma a atender aos critérios legais até a sua destinação. ${ }^{3}$

Já com relação à indústria, 65,9\% dos resíduos são destinados à geração de energia por meio da queima em caldeiras, que geram vapor e, eventualmente, energia elétrica para o processo produtivo. $24,6 \%$ dos resíduos, que são provenientes principalmente da produção de serrados (cavacos e serragem) e aparas de papel, são reutilizados como matéria-prima por outras empresas do setor. Resíduos como a lama de cal e a cinza das caldeiras representam $5,8 \%$ e são reutilizados, por exemplo, para produção de cimento e óleo combustível reciclado. Os demais resíduos representam $3,6 \%$ e são encaminhados para aterros industriais. ${ }^{3}$

A geração de energia elétrica a partir da queima da biomassa em fornos e caldeiras é um processo industrial ainda com baixa eficiência. Assim, com o objetivo de aumentar a eficiência de processo e reduzir impactos socioambientais tem-se cada vez mais o interesse em otimizar tecnologias de conversão de biomassa em energia. ${ }^{10}$ Resíduos de eucalipto e 
bagaço de cana são duas das principais matérias-primas que podem ser utilizadas para produção de energia no país. ${ }^{11}$ Dentro desse contexto, para que se tenha continuidade no investimento em florestas plantadas, principalmente de eucalipto, estudos de viabilidade de produção de energia utilizando outras tecnologias se tornam importantes para agregar valor a essa matéria-prima e também tornar processos industriais, como de papel e celulose por exemplo, cada vez mais autosuficientes do ponto de vista energético.

\subsection{PROCESSOS TERMOQUÍMICOS DE CONVERSÃO DE BIOMASSA}

Uma variedade de processos pode ser utilizada na conversão de biomassa em energia, onde o tipo e disponibilidade da biomassa, o valor agregado que pode ser dado a ela (produção de energia elétrica, biocombustível ou célula de hidrogênio, por exemplo), aliado a aspectos econômicos, técnicos e ambientais são fatores importates a serem analisados na escolha do melhor processo de conversão. Os principais são: os processos termoquímicos de combustão, gaseificação, pirólise e liquefação; e os processos biológicos de digestão anaeróbia e fermentação. ${ }^{6} \mathrm{O}$ foco do presente trabalho é nos processos termoquímicos, principalmente no processo de gaseificação de Eucalyptus grandis, portanto será dada ênfase a este processo ao decorrer desta seção.

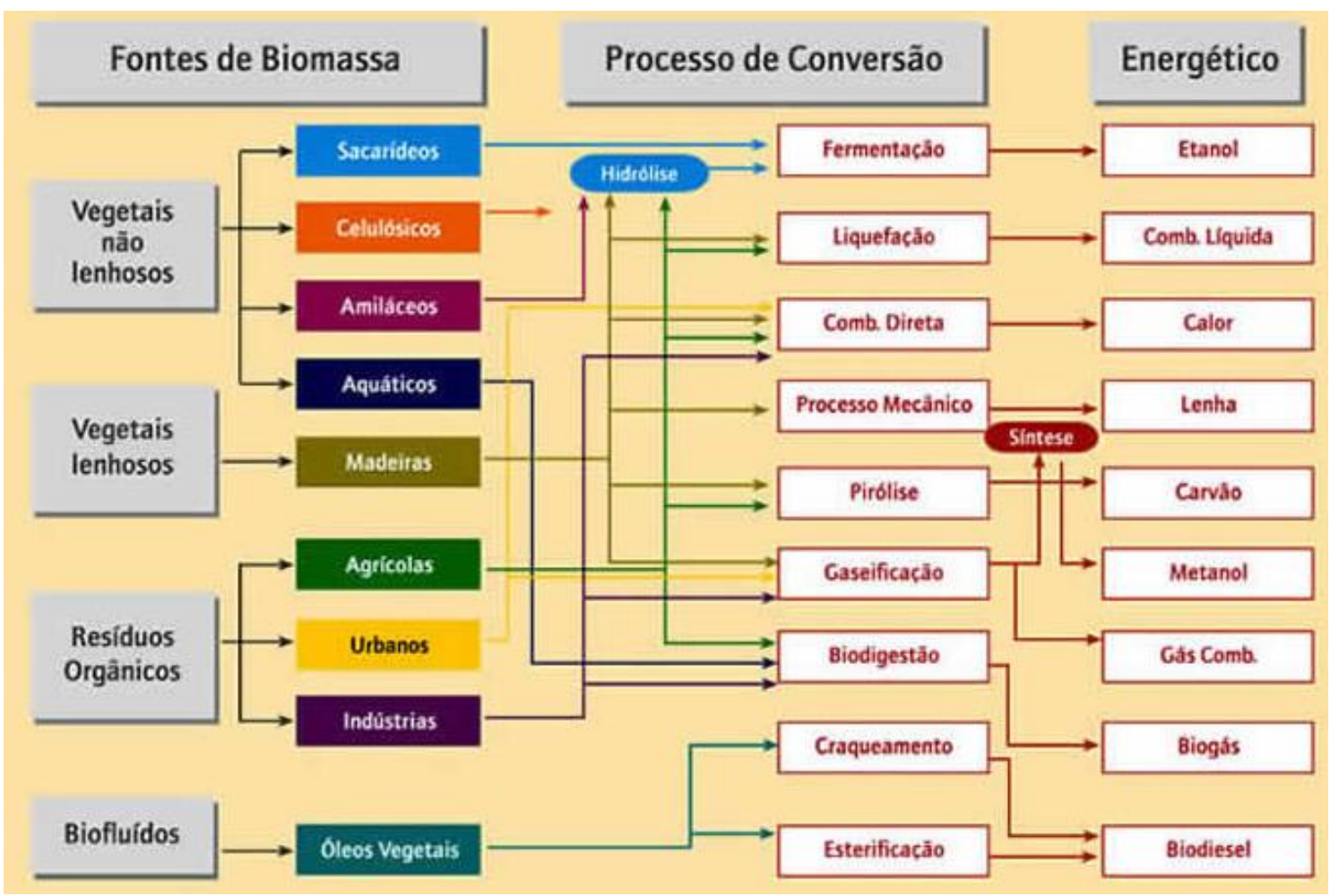

Figura 3.4 - Processos de conversão de biomassa em energia. ${ }^{10}$ 
A combustão é um processo de transformação de energia química dos combustíveis em calor por meio das reações dos elementos constituintes com o oxigênio fornecido. Os fornos e caldeiras são as principais aplicações desse tipo de processo. Com relação à utilização de biomassa na combustão, é importante destacar a ineficiência do processo, principalmente devido a alta umidade desta matéria-prima e também da baixa densidade energética da mesma. ${ }^{10}$

A pirólise é um processo de decomposição térmica que ocorre na ausência de oxigênio, onde a biomassa, ou outro combustível, sofre aquecimento em uma taxa específica até uma temperatura máxima, chamada de temperatura de pirólise. Os produtos obtidos dependem de vários fatores, incluindo a temperatura de pirólise e a taxa de aquecimento, sendo eles: uma fração sólida composta por carvão, denominada biochar, que pode ser utilizado como combustível e para produção de carvão ativado por meio de ativação com $\mathrm{CO}_{2}$ e/ou vapor d'água; uma fração líquida, chamada de bio-óleo, composta por alcatrão, hidrocarbonetos pesados e água; e uma fração gasosa, composta pelos gases não condesáveis $\mathrm{CO}_{2}, \mathrm{H}_{2}, \mathrm{CO}, \mathrm{C}_{2} \mathrm{H}_{2}, \mathrm{C}_{2} \mathrm{H}_{4}, \mathrm{C}_{2} \mathrm{H}_{6}, \mathrm{C}_{6} \mathrm{H}_{6}$, etc. ${ }^{11-13}$

Basu $^{14}$ ilustra, por meio da Figura 3.5, o processo de pirólise em um sistema de reação em leito fluidizado. Ao sistema de reação (pirolisador), contendo um leito de partículas sólidas inertes em estado de fluidização, é adicionada a biomassa. O leito de partículas sólidas aquece a biomassa até a temperatura de pirólise, na qual se inicia a decomposição. Os vapores condensáveis e não-condensáveis liberados da biomassa deixam o pirolisador, onde parte do carvão sólido produzido é carregado pelo gás e parte permanece no sistema de reação. O gás é separado do carvão em um ciclone, e posteriormente passa por um condensador de onde se obtém o bio-óleo ou óleo de pirólise. Após o condensador, os gases não condensáveis deixam o sistema como gás produto ou podem também ser recirculados e queimados para fornecer calor ao sistema de reação. Como a corrente de gás produto é livre de oxigênio, parte dela também pode ser recirculada para o pirolisador adicionalmente como uma agente de transporte de calor ou um agente de fluidização. De forma similar, o carvão sólido pode ser coletado como um produto comercial ou queimado em um reator para produzir o calor necessário para a pirólise. Uma outra alternativa para o aquecimento do sistema de reação é a utilização de resistência elétrica. 


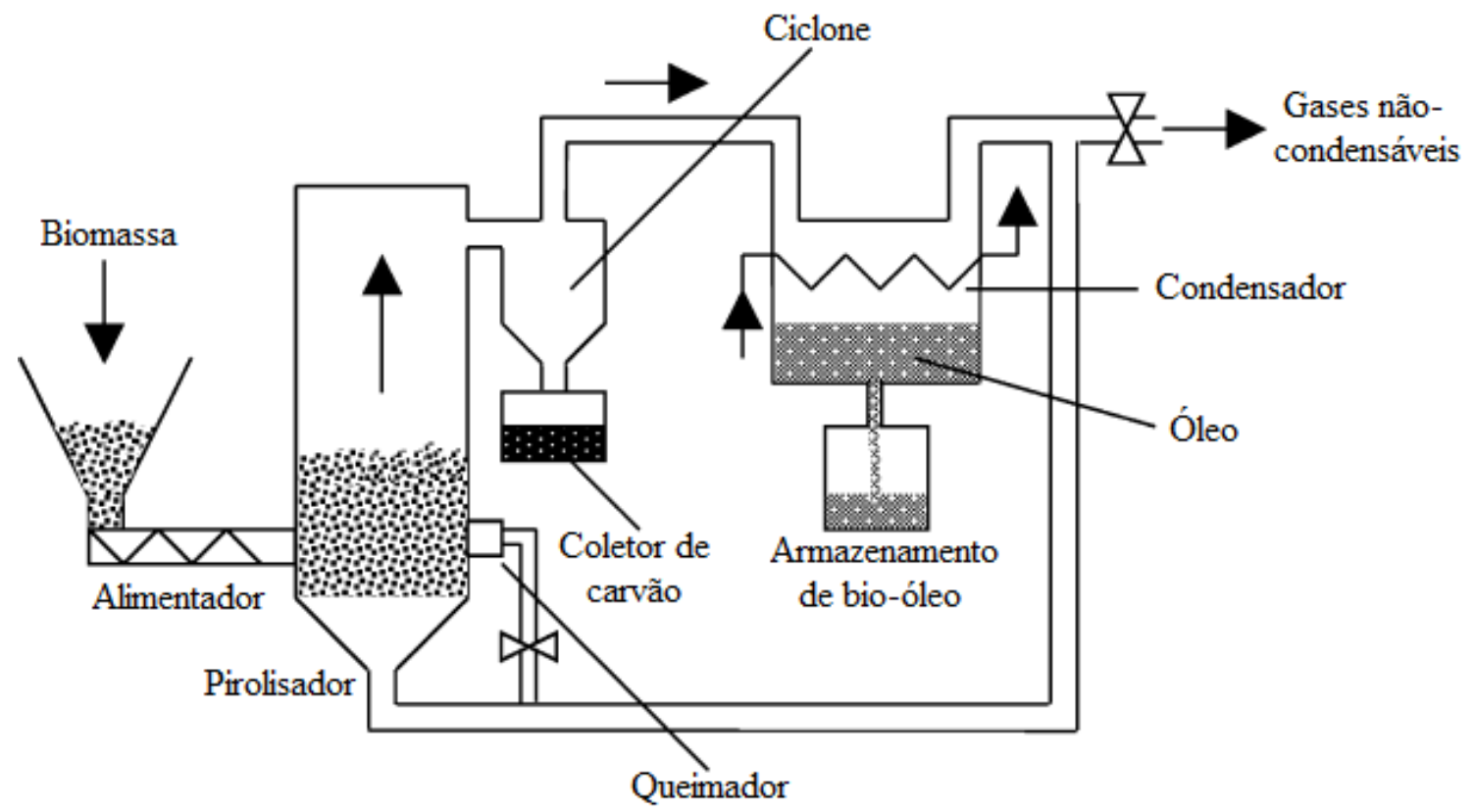

Figura 3.5 - Funcionamento básico de um sistema de pirólise de biomassa em leito fluidizado. Adaptado de Basu ${ }^{14}$.

A principal classificação para os tipos de pirólise está relacionada à taxa de aquecimento. A pirólise é lenta quando o tempo de aquecimento (tempo necessário para que o combustível alcance a temperatura de pirólise) é muito maior que o tempo de reação característico. Se o tempo de aquecimento é muito menor que o tempo de reação, tem-se uma pirólise rápida. $^{14}$

Já a gaseificação pode ser definida como um processo termoquímico localizado em uma região paramétrica entre a combustão e a pirólise, já que, além de gerar produtos de combustão, como $\mathrm{CO}_{2}, \mathrm{H}_{2} \mathrm{O}, \mathrm{O}_{2}$ (pequenas quantidades) e $\mathrm{N}_{2}$ (gaseificação com ar), por ter a fonte oxidante fornecida em condições subestequiométricas não permite oxidação completa do carbono e do hidrogênio presentes na biomassa, normalmente produz $\mathrm{H}_{2}, \mathrm{CO}$ e $\mathrm{CH}_{4}$, que são produtos gasosos também gerados no processo de pirólise. ${ }^{7}$

\subsection{GASEIFICAÇÃO}

A gaseificação é um processo de conversão termoquímica que por meio da oxidação parcial de um material (sólido ou líquido) contendo carbono em sua composição, que a temperaturas elevadas $\left(500\right.$ a $\left.1400{ }^{\circ} \mathrm{C}\right)$ e em pressões atmosféricas ou maiores, na presença de um agente de gaseificação (ar, vapor d'água, oxigênio, água supercrítica, dióxido de carbono, ou uma mistura destes) em quantidades inferiores à estequiométrica (mínimo teórico para a 
combustão), gera uma alta proporção de produtos gasosos de caráter combustível $\left(\mathrm{H}_{2}, \mathrm{CO}\right.$, $\mathrm{CH}_{4}, \mathrm{H}_{2} \mathrm{~S}, \mathrm{CO}_{2}, \mathrm{H}_{2} \mathrm{O}$, hidrocarbonetos), e também carvão e cinzas (produtos sólidos) e componentes condesáveis (alcatrão e óleos). ${ }^{15-17}$

De modo geral, os gaseificadores são classificados de acordo com o tipo de leito empregado, reatores de leito fixo e de leito fluidizado, podendo ainda ser subdivididos dependendo do funcionamento de cada um deles. ${ }^{18}$ Os gaseificadores em leito fluidizado são favorecidos com relação aos de leito fixo principalmente devido ao alto grau de mistura das fases e a consequente eficiência na transferência de calor, e são divididos em leito fluidizado borbulhante, que trabalha em regime de fluidização borbulhante, e leito fluidizado circulante que opera em transporte pneumático ${ }^{19}$ com recirculação das partículas sólidas do leito e do combustível. ${ }^{20}$ Um outro tipo de gaseificador interessante a ser citado é o de fluxo de arraste, que trabalha em regime de fluidização rápida.

\subsubsection{Tipos de Gaseificadores}

\subsubsection{Gaseificadores de Leito Fixo}

As principais soluções tecnológicas baseadas nos reatores de leito fixo são os reatores updraft e downdraft, e a diferença entre eles se dá pelo modo de contato entre o material combustível (biomassa, carvão) e o agente de gaseificação.

Nos reatores do tipo updraft a biomassa é alimentada no topo do reator, movendo-se em sentido descendente em relação ao agente de gaseificação, passando pelas zonas de secagem, pirólise, redução e oxidação, e o gás formado durante o processo desloca-se em sentido ascendente no reator, sendo por isto também chamado de contracorrente, conforme pode ser visto na Figura 3.1a. O gás gerado deixa o reator próximo à zona de pirólise, o que lhe confere um alto teor de componentes orgânicos (alcatrão). O carbono da biomassa é convertido em gás e alcatrão. ${ }^{20}$ Esse tipo de gaseificador é adequado para biomassas com altos conteúdos de cinzas (acima de $25 \%$ ) e umidade (acima de 60\%) e combustíveis com baixo teor de voláteis (como carvão). A produção de alcatrão é muito alta $\left(30-150 \mathrm{~g} / \mathrm{Nm}^{3}\right)$ o que o faz não recomendável para combustíveis com altos teores de voláteis. Além disso, este tipo de gaseificador tem boa efetividade na utilização do calor de combustão e alcança alta eficiência a frio do gás. Porém, é mais adequado para queima direta, onde o gás produzido é queimado em um forno ou caldeira sem limpeza ou resfriamento do gás. ${ }^{14}$ 
Molino et al. ${ }^{21}$ citam como principais vantagens na utilização do gaseificador do tipo updraft: alta eficiência térmica, bom contato entre o agente de gaseificação e a biomassa, o fato de poder trabalhar com materiais de diferentes granulometrias e alto teor de umidade, simples construção. Como desvantagens, os mesmos autores citam: alto teor de alcatrão no gás de síntese, baixa produção de $\mathrm{CO}$ e $\mathrm{H}_{2}$ necessitando de um tratamento subsequente de craqueamento do alcatrão, flexibilidade limitada para carga e processo (o material tratado deve ter propriedades homogêneas), dificuldade do controle de temperatura, necessidade de utilização de placas distribuidoras móveis para evitar a formação de caminhos preferenciais no leito fixo.

Já nos reatores do tipo downdraft, tanto o material combustível quanto o gás formado se movem em sentido descendente, sendo esse gaseificador também chamado de co-corrente (Figura 3.1b). ${ }^{21}$ Podem ser utilizados para combustíveis com maior teor de umidade, e o fluxo de combustível e de agente de gaseificação na mesma direção juntamente com o fato do gás deixar o reator próximo à zona mais quente faz com que a concentração de alcatrão seja muito menor que nos gaseificadores do tipo updraft, ${ }^{20}$ já que estas condições são favoráveis para o craqueamento do alcatrão. ${ }^{14} \mathrm{O}$ agente de gaseificação (ar), introduzido na zona de oxidação do gaseificador, flui de forma descendente e encontra com as partículas de char pirolisadas, desenvolvendo uma zona de combustão de aproximadamente 1200 a $1400{ }^{\circ} \mathrm{C}$. O gás passa através do leito de partículas de char aquecidas ocorrendo a gaseificação das mesmas. $\mathrm{O}$ conteúdo de alcatrão produzido é baixo $\left(0.015-3 \mathrm{~g} / \mathrm{Nm}^{3}\right)$, o que favorece a utilização desse tipo de gaseificador em conjunto com motores de combustão interna. ${ }^{14}$

Molino et al. ${ }^{21}$ citam como principais vantagens a utilização de gaseificadores do tipo downdraft: alta conversão de carbono, baixa produção de alcatrão, arrasto limitado de cinzas e particulados, alto tempo de residência dos sólidos, simples construção. E citam como principais desvantagens: capacidade limitada, baixa tolerância a variação na granulometria da matéria-prima (menores que $10 \mathrm{~cm}$ ), necessidade de alimentar matéria-prima com baixo teor de umidade, e baixo coeficiente de transferência de calor. 

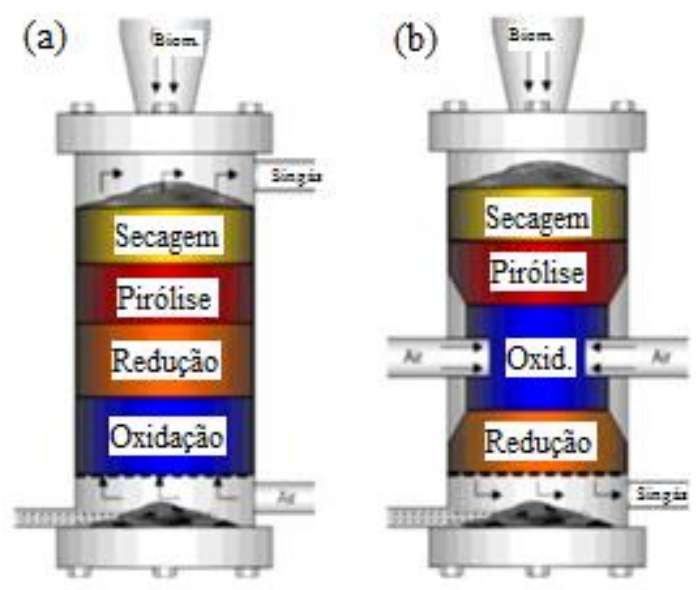

Figura 3.1 - Reatores de leito fixo: a) Updraft (fluxo contracorrente) b) Downdraft (fluxo cocorrente). Adaptado de Molino et al. ${ }^{21}$.

\subsubsection{Gaseificadores de fluxo arrastado}

No gaseificador de fluxo arrastado ou de arraste, a alimentação das partículas de combustível (granulometria entre 0,1 e $1 \mathrm{~mm}$ ) e do agente de gaseificação é feita de forma cocorrente, onde o sólido particulado alimentado é arrastado ao longo do reator pelo agente de gaseificação. O gaseificador opera a pressões entre 25 e 30 bar e a altas temperaturas, entre 1300 e $1500{ }^{\circ} \mathrm{C},{ }^{21}$ o que permite a produção de um gás quase livre de alcatrão com conversão quase completa de carbono, que são as duas principais desvantagens dos sistemas de leito fluidizado (será apresentado posteriormente). ${ }^{20}$ Além disso, a operação desse tipo de reator a temperaturas acima do ponto de fusão das cinzas faz com que estas saiam do reator como um resíduo fluido. Em caso de utilização de biomassa como matéria-prima, um pré-tratamento baseado em torrefação é indicado para reduzir a densidade aparente e o teor de umidade. ${ }^{21}$

As principais vantagens dos gaseificadores de fluxo arrastado são: flexibilidade do combustível, temperatura uniforme, alta conversão de carbono, boa capacidade para controlar os parâmetros do processo, curto tempo de residência, baixa concentração de alcatrão. E as principais desvantagens são: requer grande quantidade de agente oxidante, alto custo para construção da planta e de manutenção, baixa eficiência a frio do gás. ${ }^{21}$ 


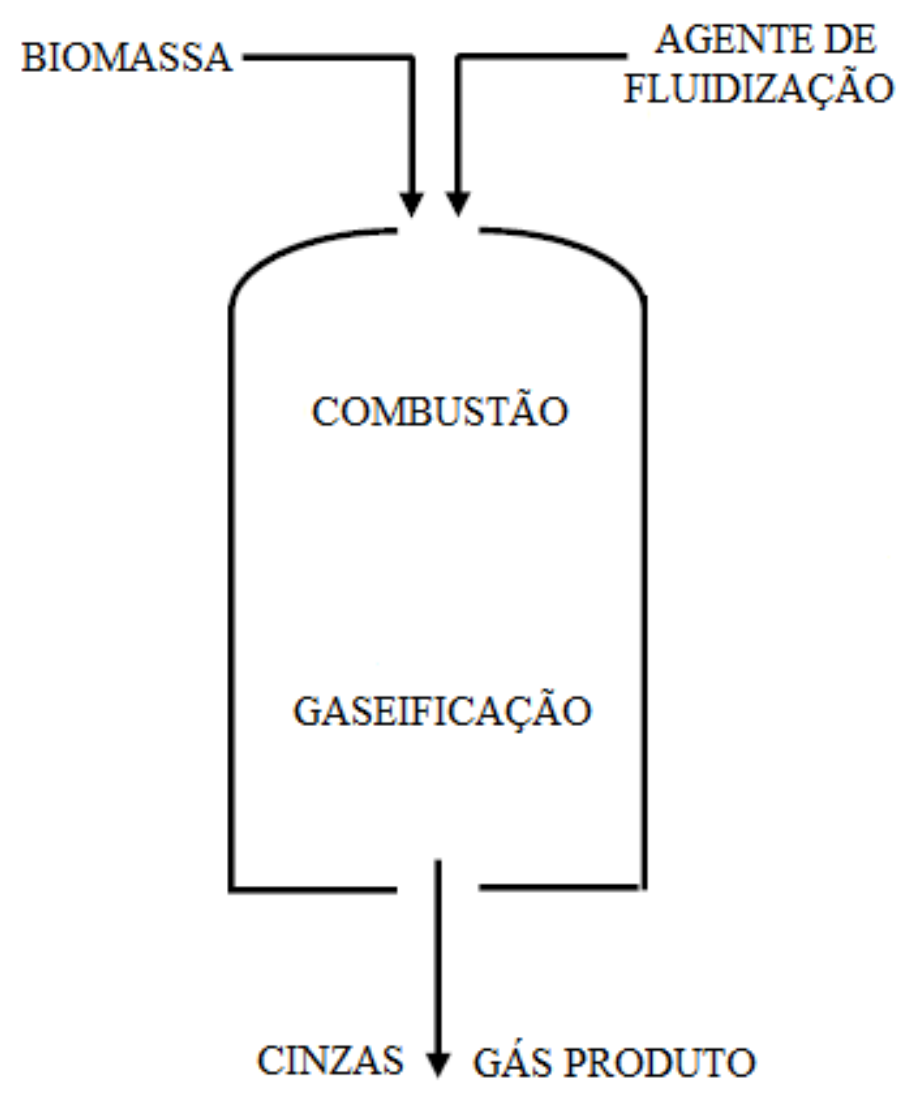

Figura 3.6 - Gaseificador de fluxo arrastado. Adaptado de Basu ${ }^{14}$

\subsubsection{3. $\quad$ Gaseificadores de leito fluidizado}

Os gaseificadores de leito fluidizado têm sido utilizados extensivamente para gaseificação de carvão há muitos anos, exibindo vantagem quando comparado aos gaseificadores de leito fixo, tal como a distribuição uniforme de temperatura na zona de gaseificação, que é alcançada por meio da utilização de um leito (areia, quartzo, catalisadores) no qual é introduzido um agente de gaseificação, ou fluidização, com velocidades apropriadas, podendo este ser ar, vapor, água supercrítica, oxigênio, nitrogênio ou uma mistura destes, que mantém o material do leito em uma condição de semi-suspensão (estado de fluidização) garantindo ótima mistura do material do leito aquecido, do gás de combustão e da biomassa alimentada. ${ }^{14,22} \mathrm{O}$ reator de leito fluidizado pode trabalhar sob alguns regimes de escoamento do agente de fluidização, dentre eles, o pneumático (comum em gaseificadores de leito fluidizado circulante) e o borbulhante (foco desse trabalho, utilizado em gaseificadores de leito fluidizado borbulhante). Esses regimes de fluidização são discutidos na próxima seção. 
Ao contrário dos gaseificadores de leito fixo, devido à intensa mistura gás-sólido, as zonas de secagem, pirólise, oxidação e redução não podem ser distinguidas. A excelente mistura gás-sólido e a grande inércia térmica do leito conferem temperatura e concentração gás-sólido uniformes no leito, assim, a conversão de biomassa nos gaseificadores de leito fluidizado é próxima de $100 \%$ e a produtividade, considerando a vazão de biomassa pela área de reator instalada, chega ser cerca de duas a dez vezes maior em relação aos reatores de leito fixo. Pelas mesmas razões, diferentemente dos gaseificadores de leito fixo, que necessitam de uma matéria-prima bem específica, os gaseificadores de leito fluidizado são em geral mais tolerantes e adequados para grandes instalações. ${ }^{23}$ Os dois principais tipos de gaseificadores de leito fluidizado são o borbulhante e o circulante.

O gaseificador de leito fluidizado circulante tem uma vantagem especial na utilização de biomassa como matéria-prima devido ao longo tempo de residência do gás no reator. Ele é adequado para combustíveis com alto teor de voláteis. Um gaseificador típico possui um reator, um ciclone, e um sistema de reciclo dos sólidos. Nesse tipo de gaseificador, os sólidos são dispersos por toda a altura do reator, permitindo um maior tempo de residência tanto para o gás quanto para as finas partículas de sólido. A velocidade do gás de fluidização é muito maior do que nos gaseificadores de leito fluidizado borbulhante. Além disso, por trabalharem em um regime pneumático há arraste de sólidos para fora do reator, que são capturados no ciclone e continuamente retornam para a base do reator por meio do sistema de reciclo. A taxa de reciclo dos sólidos e a velocidade de fluidização são suficientemente altas para manter o gaseificador em uma condição hidrodinâmica especial, conhecida como leito fluidizado rápido, e dependendo da matéria-prima utilizada e da aplicação, o gaseificador opera a temperaturas entre 800 e $1000{ }^{\circ} \mathrm{C} .{ }^{14}$

As principais vantagens dos reatores de leito fluidizado circulante são: menor produção de alcatrão, alta conversão de carbono, flexibilidade de carga e facilidade de utilização em maior escala. As principais desvantanges da utilização desse tipo de gaseificador são: redução da granulometria da matéria-prima, contato gás-sólido restrito, tecnologia complexa e de difícil controle, problemas de segurança, alto custo. ${ }^{21}$

O gaseificador de leito fluidizado borbulhante, desenvolvido por Fritz Winkler em 1921, é possivelmente a aplicação comercial mais antiga de leitos fluidizados, e tem seu uso comercial voltado para gaseificação de carvão, sendo também uma das opções mais populares 
para gaseificação de biomassa. Por serem adequados para unidades médias de geração de energia (<25 MW), muitos gaseificadores de biomassa operam em regime de fluidização borbulhante. $^{14}$

O gaseificador de leito fluidizado borbulhante opera de maneira que as partículas de combustível (biomassa), adicionadas na zona do leito, são fluidizadas pela ação de um gás (agente de fluidização ou gaseificação), que é adicionado na parte inferior do reator por meio de uma placa distribuidora, promovendo um fluxo constante ao longo da seção do leito, propiciando homogeneidade na fluidização. As partículas de biomassa se mantêm suspensas em um leito de partículas (areia, dolomita, catalisador, etc.) fluidizadas pelo agente de fluidização (ar, vapor, oxigênio, nitrogênio ou uma mistura destes), ${ }^{24}$ o que facilita os processos de transferência de massa e energia, alcançando-se uma distribuição quase uniforme de temperatura ao longo do equipamento. Este tipo de reator possui um alto grau de mistura, que proporciona boa distribuição do material sólido ao longo do leito e simultaneidade na ocorrência das etapas de secagem, desvolatilização, combustão e gaseificação, sem formação de regiões definidas para condução de cada etapa. O reator geralmente é operado a temperaturas entre 700 e $900{ }^{\circ} \mathrm{C}$. O gás obtido do processo é recolhido na parte superior do reator, zona freeboard, e pode passar por etapas de separação/purificação (ciclone, condensador, lavador de gases). ${ }^{25}$

O leito de partículas inertes, inicialmente estagnadas (empacotadas), se comporta como um fluido (pela ação do agente de fluidização), e é continuamente agitado pela presença de bolhas gasosas cuja mobilidade garante condições uniformes de troca de massa e energia entre o sólido e o gás. ${ }^{21}$

As principais vantagens dos gaseificadores de leito fluidizado borbulhante são: alto grau de mistura e contato entre a mistura gasosa e o sólido, alta conversão de carbono, alta carga térmica, bom controle de temperatura e distribuição de temperatura ao longo do reator, pode trabalhar com materiais com diferentes características, boa flexibilidade de carga e processo, adequado para matérias-primas de alta reatividade tais como biomassa e resíduos municipais pré-tratados, baixo conteúdo de alcatrão na mistura gasosa produzida, possibilidade de uso de catalisadores em grande escala. E tem como principais desvantagens: perda de carbono nas cinzas, arraste de impurezas e cinzas, necessidade de pré-tratamento com materiais heterogêneos, necessidade de ter uma temperatura relativamente baixa para 
manter o fenômeno de fluidização do leito (temperatura menor que a temperatura de fusão dos resíduos sólidos), restrições com relação à granulometria da matéria-prima e das partículas do leito, alto investimento e alto custo de manutenção. ${ }^{21}$

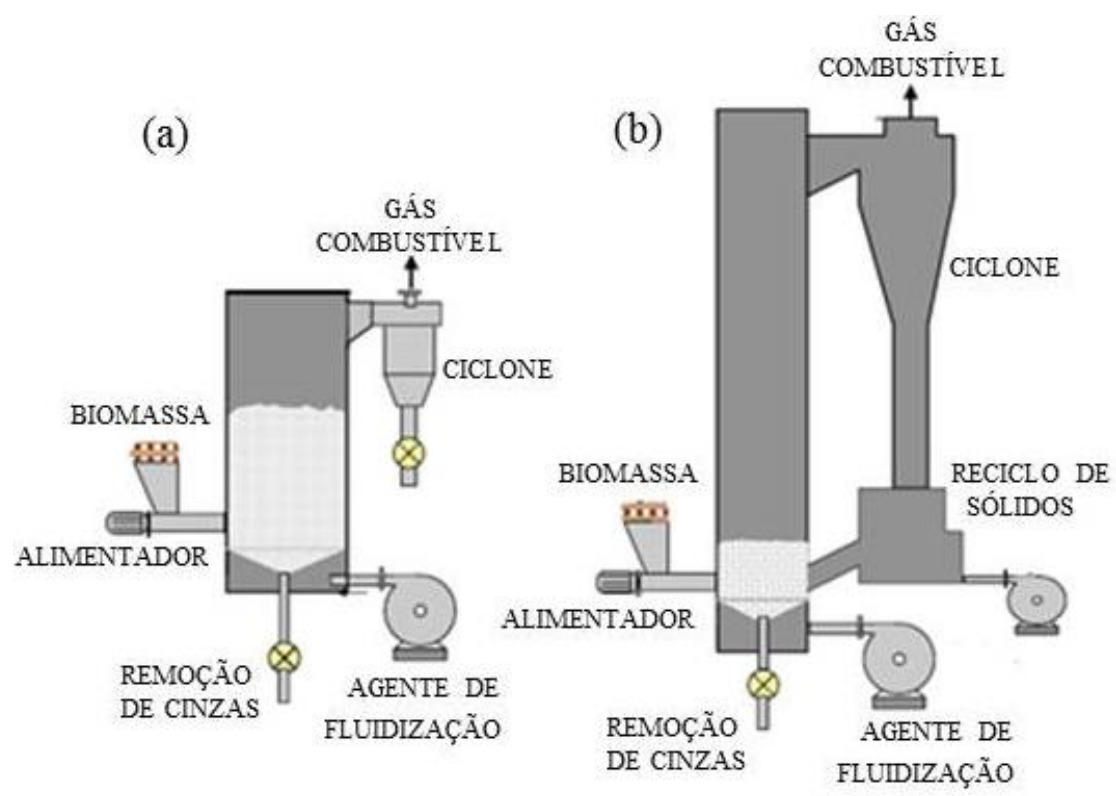

Figura 3.7 - Gaseificador de Leito Fluidizado: (a) Borbulhante (b) Circulante. Adaptado de Gómez-Barea et $a l^{20}$.

\subsubsection{Relação entre o agente de gaseificação e o combustível}

Segundo Basu ${ }^{14}$, o agente de fluidização pode ter diferentes efeitos na formação e conversão de alcatrão durante o processo de gaseificação de biomassa. De acordo com Gil et $a l^{26}$, o poder calorífico e o teor de $\mathrm{H}_{2}$ no gás produzido são mais altos quando a gaseificação utiliza como agente de fluidização o vapor em comparação com a gaseificação utilizando ar. Entretanto, há dúvidas sobre o efeito do agente de fluidização em outros resultados, como na fração de alcatrão no gás produzido, por exemplo.

A relação entre o agente de fluidização e o combustível é um parâmetro que tem importante influência no produto da gaseificação, e essa relação é expressa de forma diferente para os diferentes agentes. Para a gaseificação utilizando ar, tem-se o parâmetro chamado de razão de equivalência (RE); se o agente de gaseificação for vapor d'água, tem-se a razão vapor/biomassa, chamada de steam to biomass ratio (SBR); para a gaseificação utilizando a mistura vapor-oxigênio utiliza-se o termo razão de gaseificação (RG) ou gasifying ratio, em 
inglês ${ }^{14}$, e para a gaseificação utilizando dióxido de carbono como agente de gaseificação tem-se a razão $\mathrm{CO}_{2} / \mathrm{C}^{27}$

\subsubsection{Razão de equivalência}

A razão de equivalência (RE) corresponde ao valor da relação ar-combustível real utilizada durante o processo dividida pela relação ar-combustível estequiométrica necessária para que haja combustão. Este parâmetro define a proporção de combustível gaseificado (oxidação parcial e/ou redução) em relação à proporção de combustível queimado (combustão completa). Para uma razão de equivalência inferior a 0,2 tem-se processo de gaseificação incompleta, formação excessiva de carvão e um baixo poder calorífico do gás gerado. Já para valores superiores a 0,4 obtém-se um gás com grandes teores de produtos de combustão completa, como $\mathrm{CO}_{2}$ e $\mathrm{H}_{2} \mathrm{O}$, ao invés dos produtos desejados $\mathrm{H}_{2}$ e $\mathrm{CO}$, gerando um decréscimo no poder calorífico do gás produto. $\mathrm{O}$ valor mais usual para RE na gaseificação é entre 0,20 e $0,30 .{ }^{28}$ A razão de equivalência é dada pela Equação 3.1:

$$
R E=\frac{\left(R_{A / C}\right)_{\text {real }}}{\left(R_{A / C}\right)_{\text {estequiométrica }}}
$$

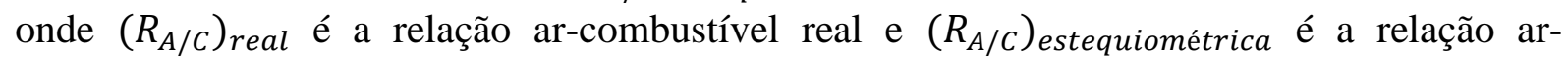
combustível estequiométrica.

\subsubsection{Razão Vapor/Biomassa}

Para a gaseificação com vapor d'água como agente de fluidização, o cálculo da razão vapor-biomassa (SBR) é geralmente dado pela relação entre a quantidade de vapor fornecido (fluxo mássico de vapor) e a quantidade de biomassa alimentada (fluxo mássico de biomassa), como pode ser viso na Equação 3.2:

$$
S B R=\frac{\text { Fluxo mássico de vapor }}{\text { Fluxo mássico de combustível }}
$$

Siedlecki ${ }^{29}$ cita que é interessante que o agente de fluidização consista de um gás que forneça oxigênio necessário para a oxidação parcial do combustível e ao mesmo tempo seja um meio útil para promover a fludização. O vapor, além de ser um agente de fluidização, é também um reagente em muitas reações de gaseificação, e sua presença e quantidade tem influência na composição do gás final. Em estudos de gaseificação realizados por Gil et al ${ }^{26}$ utilizando vapor como agente de fluidização, a concentração de $\mathrm{H}_{2}$ no gás produto foi máxima (cerca de 55\%) para valores de SBR entre 0,8 e 0,9. Vale ressaltar que para este intervalo de 
SBR, o conteúdo de vapor no gás produzido é de cerca de $50 \%$ em volume (base úmida), o que é um valor alto e pode significar um desperdício de energia, mas de certa forma, a adição de vapor dobra o teor de $\mathrm{H}_{2}$ em relação aos experimentos de pirólise realizados pelos autores. Dependendo da aplicação do gás produzido, faz-se necessária uma etapa secundária ou um tratamento a jusante do gaseificador para limpar o gás de processo usando dolomita ou reforma a vapor em catalisadores à base de níquel. Uma alta concentração de vapor na corrente gasosa favorece as reações de reforma a vapor de alcatrão e hidrocarbonetos leves neste estágio catalítico e evita a deposição de coque e a desativação do catalisador. Os autores então recomendam uma RE de 0,30 ótima na gaseificação com ar, e na gaseificação com vapor uma SBR entre 0,8 e 0,9. O teor de alcatrão no gás final é maior para a gaseificação com vapor, seguido da gaseificação mista vapor-oxigênio e menor na gaseificação com ar, porém, o rendimento de alcatrão no gás produzido não é suficiente para descrever completamente o problema do alcatrão, já que os alcatrões produzidos usando os três agentes de fluidização são bem diferentes do ponto de vista de composição. $\mathrm{O}$ alcatrão gerado na gaseificação com vapor é mais "fácil de destruir" em catalisadores à base de níquel ou dolomita do que o gerado na gaseificação com ar. Molino et al $^{16}$ apresentam de forma detalhada a formação do alcatrão no processo de gaseificação.

Gil et al. ${ }^{26}$ constataram que o teor de $\mathrm{H}_{2}$ e $\mathrm{CO}_{2}$ aumenta enquanto que o teor de $\mathrm{CO}$ diminue no gás de saída do gaseificador a medida que a SBR é aumentada, devido a reação de deslocamento gás-água (ou water-gas-shift), e que as quantidades de $\mathrm{H}_{2}$ e $\mathrm{CO}$ diminuem e a de $\mathrm{CO}_{2}$ aumenta com o aumento da RE. Além disso, o teor de metano e hidrocarbonetos $\mathrm{C}_{2}$ decresce com o aumento de RE e SBR, devido à oxidação parcial e as reações de reforma a vapor, e a adição (em devidas quantidades) de oxigênio no processo de gaseificação com vapor não reduz de forma tão significativa o poder calorífico e diminue o teor de alcatrão no gás produto.

\subsubsection{3. $\quad \mathrm{Raza \tilde {o } \mathrm { O }} \mathrm{CO}_{2} / \mathrm{C}$}

A razão $\mathrm{CO}_{2} / \mathrm{C}$ é a razão de massa de dióxido de carbono injetado através do agente de fluidização $\mathrm{CO}_{2}$ pela quantidade de carbono, em massa, entrando no reator relativa a alimentação de biomassa. $^{27}$

Sadhwani et $a l .{ }^{27}$ testaram quatro razões $\mathrm{CO}_{2} / \mathrm{C}$ diferentes, 0,6, 0,8, 1,04 e 1,52, para uma alimentação de biomassa de 300 gramas por hora. Seus resultados mostraram que o 
aumento mais significativo na composição de $\mathrm{H}_{2}$ e $\mathrm{CO}$ no gás final obtido do processo de gaseificação em leito fluidizado foi na mudança da razão $\mathrm{CO}_{2} / \mathrm{C}$ de 0,8 para 1,04 . Segundo os autores, não houve um aumento tão significativo da concentração destes gases com o aumento da razão de 1,04 para 1,52, e uma possibilidade para este fato é de que o tempo de residência da partícula de carvão na atmosfera de $\mathrm{CO}_{2}$, durante a etapa de gaseificação do carvão, é suficiente para que apenas uma quantidade ótima de $\mathrm{CO}_{2}$ reaja com o carvão, assim, a adição de $\mathrm{CO}_{2}$ acima desta quantidade não causa efeito positivo na etapa de gaseificação. Os mesmos autores também concluíram que com a elevação da temperatura de processso a gaseificação com $\mathrm{CO}_{2}$ produz um carvão altamente microporoso que favorece muito a difusão de $\mathrm{CO}_{2}$ durante a etapa de gaseificação levando a maior conversão em $\mathrm{H}_{2}$ e $\mathrm{CO}$, tendo como principais reações Boudouard, deslocamento gás-água e radicais livres que conduzem a formação de hidrogênio. Um fato interessante é de que há também o aumento da concentração de $\mathrm{CH}_{4}$ com aumento da temperatura, mas que este reage com $\mathrm{CO}_{2}$ através da reação de reforma a seco do metano (methane dry reforming - MDR), uma reação que é termodinamicamente possível somente acima de $640{ }^{\circ} \mathrm{C}$, aumentando a concentração de $\mathrm{H}_{2}$ e CO no gás produto.

\subsection{FLUIDIZAÇÃO}

A fluidização de partículas sólidas no leito consiste em adicionar um fluido em fluxo ascendente através do leito em quantidade suficiente para que a força de arrasto sobre as partículas seja equivalente ao peso das mesmas (entendido em termos de energia potencial). Isso confere ao leito propriedades de um fluido, como capacidade de escoar, se deformar, com movimentos aleatórios das partículas. ${ }^{30}$ As partículas sólidas em regime de fluidização passam a ter algumas características similares às de um fluido: a pressão estática em qualquer altura do reator é aproximadamente equivalente ao peso das partículas sólidas do leito por unidade de área transversal acima daquele nível; um objeto mais denso que a densidade aparente do leito "afundará", de modo que um menos denso "flutuará". Os sólidos do leito podem ser drenados como um líquido através de um orifício na parte lateral ou inferior do reator. Além disto, independente da inclinação do leito, a superfície do leito mantém um nível horizontal; há um alto grau de misturas das partículas e o leito mantém a temperatura muito próxima da uniformidade. ${ }^{28}$ 


\subsubsection{Regimes de Fluidização}

Um fluido pode assumir diversos regimes de escoamento dentro de um reator, e dois parâmetros básicos são utilizados para classificar tais tipos de escoamentos: a perda de pressão no leito $(\Delta \mathrm{P})$ e a velocidade superficial $(u)$ do agente de fluidização no reator. Considerando como estágio inicial o leito empacotado composto por um determinado sólido particulado, se o agente de fluidização é adicionado em baixas velocidades, a perda de pressão no leito aumenta de forma linear com o aumento da velocidade do gás, caracterizando um regime em leito fixo, onde o gás apenas percola o leito afastando levemente algumas partículas. $^{28,30}$

Aumentando-se a velocidade do agente de fluidização, o leito se expande e algumas partículas apresentam leve vibração. Quando atingida a velocidade mínima de fluidização $\left(u_{m f}\right)$, a perda de carga conferida pelas partículas ao leito é equivalente ao próprio peso das partículas, e as partículas presentes no leito são então suspensas e passam a se movimentar intensamente, caracterizando um regime de fluidização incipiente, onde a perda de pressão do leito tende a não variar com o aumento da velocidade $u .^{28}$

Com novos incrementos de velocidade do agente de fluidização, inicia-se o aparecimento de bolhas no leito provenientes do excesso de gás adicionado em relação à quantidade mínima de gás necessária para fluidizar as partículas, definindo um regime de fluidização borbulhante, onde é atingida a velocidade mínima de borbulhamento. Nesse regime, as bolhas são consideradas livres ou quase livres de partículas sólidas, se deslocando no leito em um movimento ascendente. Nesta etapa de fluidização não é observada variação na perda de carga no leito, e o tamanho das bolhas aumenta com o aumento da velocidade do gás, até atingir uma velocidade em que as bolhas ocupam toda a área transversal do leito, formadas pela coalescência de bolhas menores, determinando o regime de fluidização slug, onde são observadas grandes variações na pressão com o aumento da velocidade do gás de fluidização. $^{30,31}$

Novo acréscimo na velocidade $u$ do agente de fluidização faz com que as partículas sólidas atravessem a fronteira das bolhas, atingindo a fluidização turbulenta, onde as oscilações na queda de pressão do leito diminuem devido ao desaparecimento das grandes bolhas e espaços vazios. ${ }^{31}$ 
Quando é atingida a velocidade terminal dos sólidos $\left(u_{t}\right)$, ocorre o transporte pneumático das partículas, sendo esta a velocidade limite superior para fluidização das partículas, e que produz a sua elutriação do reator. ${ }^{32}$

Reatores de leito fluidizado borbulhante operam a uma faixa de velocidades que corresponde ao regime de fluidização borbulhante, e gaseificadores de leito fluidizado circulante operam a velocidades acima da velocidade terminal das partículas. A Figura 3.8 mostra os regimes de fluidização em reatores de leito fluidizado caracterizados pela perda de pressão no leito em função da velocidade do agente de fluidização.

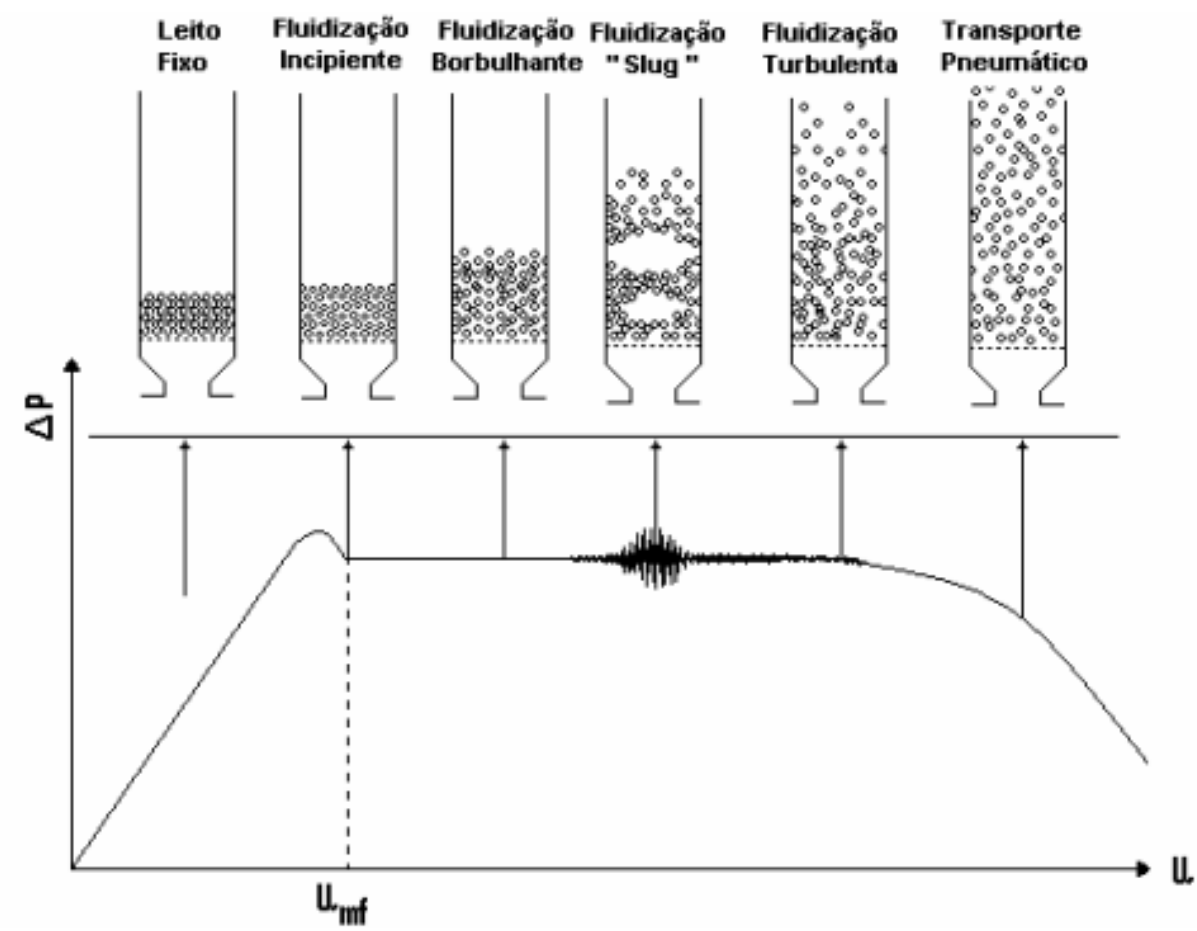

Figura 3.8 - Regimes de fluidização em reatores de leito fluidizado caracterizados pela perda de pressão no leito em função da velocidade do agente de fluidização. ${ }^{31}$

Um dos principais modelos utilizados para representar o fenômeno de fluidização na modelagem de reatores de leito fluidizado borbulhante é o modelo de Kunii-Levenspiel a duas fases. A Figura 3.9a traz uma representação simplificada de um leito fluidizado, de onde é possível observar a descrição das duas fases de acordo com Kunii et al. ${ }^{32}$ Segundo este modelo, a região do leito pode ser dividida em duas fases: fase bolha, considerada quase livre de partículas sólidas, e fase emulsão, constituída por gás e partículas sólidas. Segundo Kunii et $\mathrm{al}^{32}$, a fase bolha não interage diretamente com a fase emulsão, inicialmente há troca de calor e massa entre a fase bolha e as interfaces nuvem e wake, e estas interfaces trocam calor e massa com a fase emulsão (Figura 3.9b). 

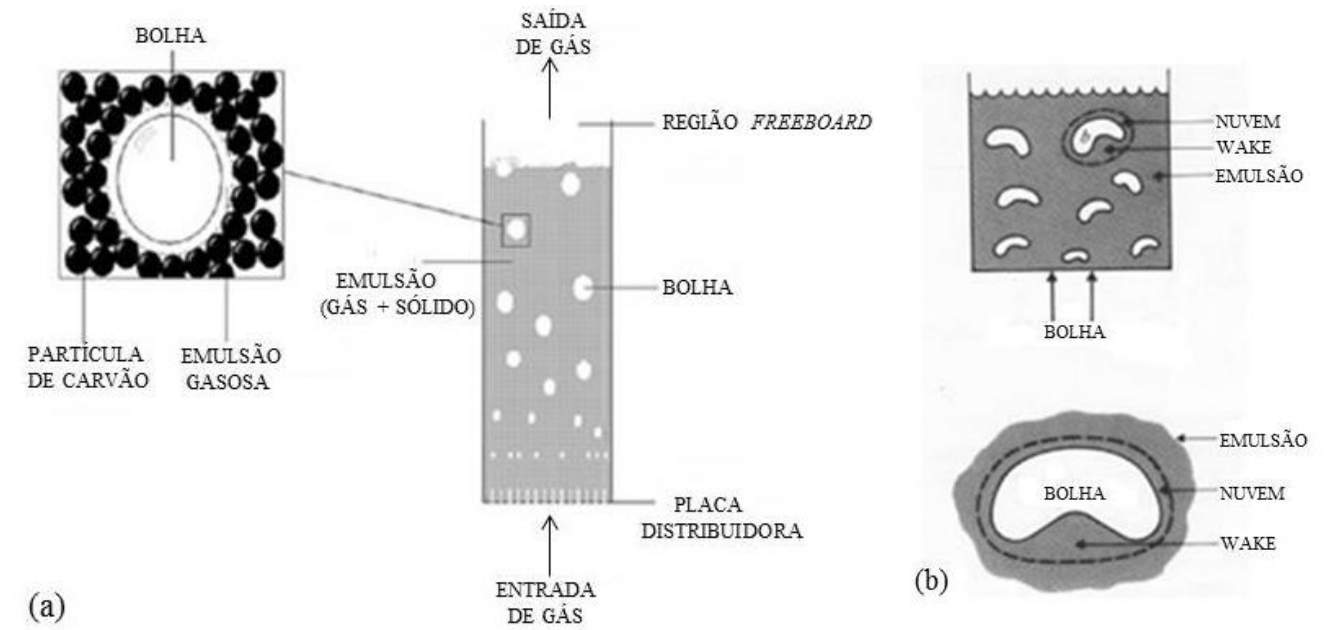

(b)

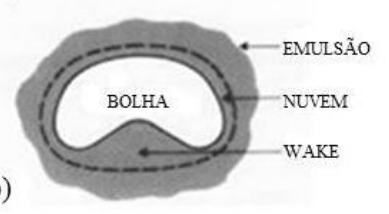

Figura 3.9 - (a) Representação das fases bolha e emulsão que constituem o leito fluidizado. ${ }^{33}$ (b) Representação das fases bolha, emulsão, nuvem e wake. ${ }^{34}$

\subsubsection{Classificação das Partículas de Geldart}

A classificação de partículas de Geldart é um sistema bastante utilizado no projeto de reatores de leito fluidizado, tendo em vista que diferentes partículas podem ter comportamentos diferentes na condição de fluidização. Segundo Geldart ${ }^{35}$, o comportamento de sólidos fluidizados por gases divide-se em quatro grupos, designados pelas letras A, B, C e $\mathrm{D}$, caracterizados pela diferença de densidade entre o sólido e o fluido $\left(\rho_{p}-\rho_{g}\right)$ e diâmetro de partícula $\left(d_{p}\right)$. Esta classificação é mostrada na Figura 3.10, e é válida para leitos fluidizados com ar (agente de fluidização) em condições ambiente.

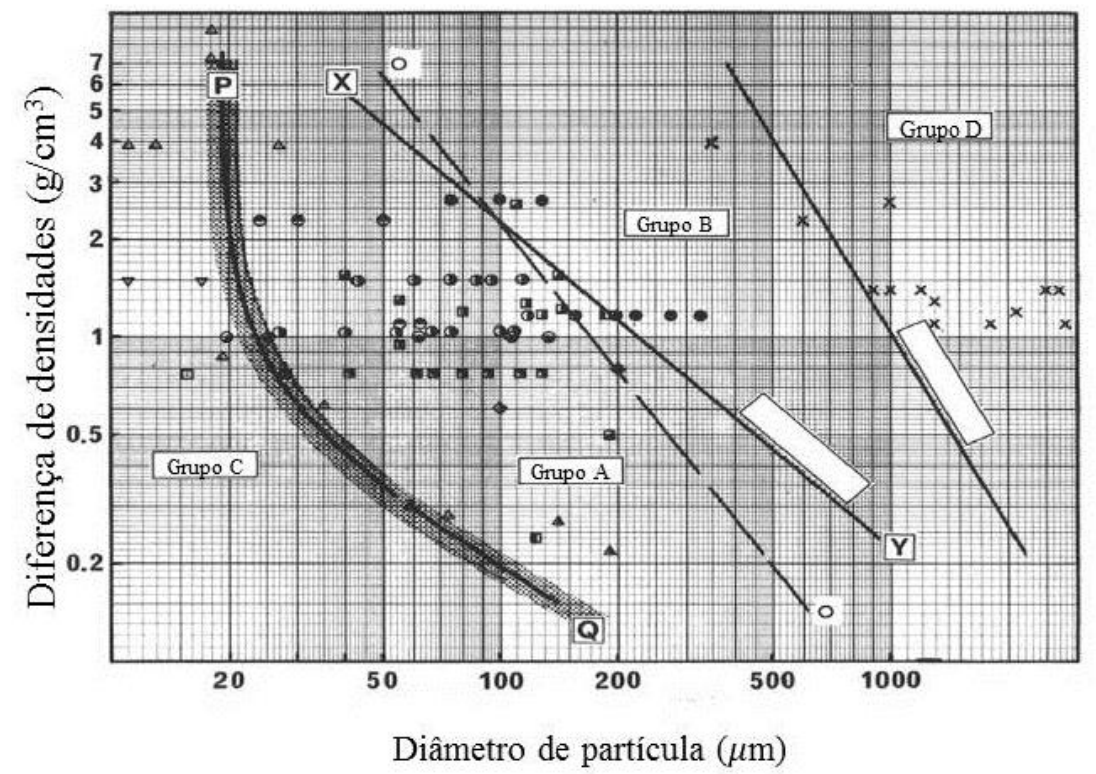

Figura 3.10 - Diagrama de classificação de partículas (pós) para fluidização com ar em condições ambiente. ${ }^{35}$ 


\subsection{ETAPAS DO PROCESSO DE GASEIFICAÇÃO}

As partículas de biomassa sofrem uma série de processos de conversão durante o processo de gaseificação em leito fluidizado. Inicialmente, ocorrem a secagem e a desvolatilização (ou pirólise), em seguida oxidação dos voláteis e do carvão formados, e por fim, gaseificação do carvão por $\mathrm{CO}_{2}$ e vapor d'água. As partículas de biomassa são inseridas ao reator na região do leito e sofrem encolhimento (shrinkage) e fragmentação primária (rompimento da partícula em partículas menores), ocorrendo imediatamente depois da injeção das partículas no leito devido a tensões e pressões internas causadas pela liberação dos voláteis. ${ }^{20}$ Basu $^{14}$ destaca que na secagem ocorre evaporação da água e extração de alguns ácidos orgânicos, na pirólise são produzidos vários produtos, dependendo das condições de processo, sendo temperatura, pressão e tempo de residência as principais, e que a extração de carbono e hidrogênio do combustível inicia em uma faixa de temperatura de 300 a $500{ }^{\circ} \mathrm{C}$ e 500 e $700^{\circ} \mathrm{C}$, respectivamente.

A Tabela 3.1 mostra as principais reações que podem ocorrer durante o processo de gaseificação de biomassa em um sistema de reação em leito fluidizado. Inicialmente a partícula de combustível sofre processos de secagem, que ocorre a temperaturas entre 100 e $200{ }^{\circ} \mathrm{C}$ reduzindo o teor de umidade da biomassa (o vapor liberado reagirá posteriormente), e devolatilização ou pirólise primária (R3.1) produzindo carvão e voláteis $\left(\mathrm{CO}_{2}, \mathrm{H}_{2}, \mathrm{CH}_{4}, \mathrm{CO}_{2}\right.$, gases condensáveis como o alcatrão, hidrocarbonetos leves como o eteno). Os compostos que se formam dependem exclusivamente da composição inicial da biomassa. Subsequentemente, o alcatrão (R3.2), o carvão (R3.3) e os voláteis (R3.4 a R3.7) formados podem ser oxidados, produzindo $\mathrm{H}_{2} \mathrm{O}, \mathrm{CO}_{2}$ e $\mathrm{CO}$. O metano, o alcatrão e o carvão formados podem ser gaseificados (reforma) por vapor d'água (R3.8, R3.9 e R3.10) obtendo-se CO, $\mathrm{H}_{2}$ e alcatrão2, que pode sofrer oxidação (R3.2). O carvão pode ser gaseificado por $\mathrm{CO}_{2}(\mathrm{R} 3.11)$, tendo como produtos $\mathrm{CO}$ e carvão (que pode sofrer oxidação R3.3). Outras reações importantes são a reforma e o craqueamento do alcatrão (R3.13 e R3.14), a hidrogenação do carvão (R.15) e a hidrogenação do alcatrão (R.16). ${ }^{36,37} \mathrm{O}$ sistema de reação pode ser aquecido de duas maneiras, por meio da combusão de parte do combustível ou por meio de uma fonte externa de energia, como resistência elétrica, por exemplo, como é o caso da planta piloto de gaseificação e pirólise da Embrapa Agroenergia. 
Tabela 3.1 - Principais reações no processo de gaseificação de biomassa. ${ }^{36,37}$

\begin{tabular}{|c|c|c|}
\hline Estequiometria & Nome & Reação \\
\hline $\begin{array}{l}\mathrm{C}_{\mathrm{x}} \mathrm{H}_{\mathrm{y}} \mathrm{O}_{\mathrm{z}} \rightarrow \text { alcatrão }+ \text { carvão }+\mathrm{H}_{2} \mathrm{O}+\mathrm{CO}+\mathrm{CO}_{2}+ \\
\mathrm{H}_{2}+\mathrm{CH}_{4}+\ldots\end{array}$ & Desvolatilização & $\mathrm{R} 3.1$ \\
\hline $\mathrm{C}_{\mathrm{n}} \mathrm{H}_{\mathrm{m}}+(\mathrm{n} / 2) \mathrm{O}_{2} \rightarrow \mathrm{nCO}+(\mathrm{m} / 2) \mathrm{H}_{2}$ & Oxidação do Alcatrão & $\mathrm{R} 3.2$ \\
\hline $\mathrm{C}+\mathrm{O}_{2} \rightarrow \mathrm{CO}_{2}$ & Oxidação do Carvão & $\mathrm{R} 3.3$ \\
\hline $\mathrm{H}_{2}+0,5 \mathrm{O}_{2} \rightarrow \mathrm{H}_{2} \mathrm{O}$ & Oxidação do Hidrogênio & $\mathrm{R} 3.4$ \\
\hline $\mathrm{CO}+0,5 \mathrm{O}_{2} \rightarrow \mathrm{CO}_{2}$ & $\begin{array}{l}\text { Oxidação do Monóxido de } \\
\text { Carbono }\end{array}$ & $\mathrm{R} 3.5$ \\
\hline $\mathrm{CH}_{4}+2 \mathrm{O}_{2} \rightarrow \mathrm{CO}_{2}+2 \mathrm{H}_{2} \mathrm{O}$ & Oxidação do Metano & $\mathrm{R} 3.6$ \\
\hline $\mathrm{C}_{2} \mathrm{H}_{4}+3 \mathrm{O}_{2} \rightarrow 2 \mathrm{CO}_{2}+2 \mathrm{H}_{2} \mathrm{O}$ & Oxidação do Eteno & R3.7 \\
\hline $\mathrm{CH}_{4}+\mathrm{H}_{2} \mathrm{O} \rightarrow \mathrm{CO}+3 \mathrm{H}_{2}$ & Reforma a Vapor do Metano & $\mathrm{R} 3.8$ \\
\hline $\mathrm{C}_{\mathrm{n}} \mathrm{H}_{\mathrm{m}}+\mathrm{H}_{2} \mathrm{O} \rightarrow(\mathrm{m} / 2+\mathrm{n}) \mathrm{H}_{2}+(\mathrm{n}) \mathrm{CO}_{2}$ & Reforma a Vapor do Alcatrão & R3.9 \\
\hline $\mathrm{C}+\mathrm{H}_{2} \mathrm{O} \rightarrow \mathrm{CO}+\mathrm{H}_{2}$ & Reforma a Vapor do Carvão & $\mathrm{R} 3.10$ \\
\hline $\mathrm{C}+\mathrm{CO}_{2} \rightarrow 2 \mathrm{CO}$ & Reação de Boudouard & $\mathrm{R} 3.11$ \\
\hline $\mathrm{CO}+\mathrm{H}_{2} \mathrm{O} \rightarrow \mathrm{CO}_{2}+\mathrm{H}_{2}$ & Deslocamento gás-água & $\mathrm{R} 3.12$ \\
\hline $\mathrm{C}_{\mathrm{n}} \mathrm{H}_{\mathrm{m}}+(\mathrm{n}) \mathrm{CO}_{2} \rightarrow(\mathrm{m} / 2) \mathrm{H}_{2}+(2 \mathrm{n}) \mathrm{CO}_{2}$ & Reforma a seco do alcatrão & $\mathrm{R} 3.13$ \\
\hline $\mathrm{C}_{\mathrm{n}} \mathrm{H}_{\mathrm{m}} \rightarrow(\mathrm{m} / 4) \mathrm{CH}_{4}+(\mathrm{n}-\mathrm{m} / 4) \mathrm{C}$ & Craqueamento do alcatrão & R3.14 \\
\hline $\mathrm{C}+2 \mathrm{H}_{2} \rightarrow \mathrm{CH}_{4}$ & Hidrogenação do carvão & $\mathrm{R} 3.15$ \\
\hline $\mathrm{C}_{\mathrm{n}} \mathrm{H}_{\mathrm{m}}+(2 \mathrm{n}-\mathrm{m} / 2) \mathrm{H}_{2} \rightarrow(\mathrm{n}) \mathrm{CH}_{4}$ & Hidrogenação & $\mathrm{R} 3.16$ \\
\hline
\end{tabular}

\subsection{APLICAÇÃO DO GÁS PRODUTO E PLANTAS DE GASEIFICAÇÃO NO} BRASIL E NO MUNDO

Como foi apresentado, o gás produzido da gaseificação de biomassa é composto por uma mistura gasosa com caráter combustível, destacando-se principalmente o gás de síntese $\left(\mathrm{CO}\right.$ e $\left.\mathrm{H}_{2}\right)$. Para a aplicação do gás de síntese, seja na queima direta em fornos ou caldeiras, turbinas a gás e motores de combustão interna, seja na produção de químicos, amônia, combustíveis líquidos (Fischer-Tropsch) e hidrogênio para célula a combustível, existem 
requerimentos de qualidade do gás no que diz respeito ao teor de impurezas presentes no mesmo (que depende do tipo de reator, parâmetros de processo, agente de fluidização) para proteção dos equipamentos que utilizam o gás como combustível.

As principais impurezas presentes no gás formado são descritas por Bridgwater: ${ }^{38}$ metais alcalinos, principalmente sódio e potássio (dependendo da composição da biomassa) que podem causar corrosão a altas temperaturas, sendo alguns métodos de remoção resfriamento, filtragem e adsorção; nitrogênio, que na forma de amônia e ácido cianídrico pode causar problemas durante a combustão formando $\mathrm{NO}_{\mathrm{x}}$, podendo ser removido do gás produto através de lavagem ou redução catalítica seletiva; enxofre e cloro, que na presença de $\mathrm{H}_{2} \mathrm{~S}$ e $\mathrm{HCl}$ pode causar emissão de poluentes, podendo ser removido do gás por meio de lavagem; alcatrão, que é definido como uma mistura de hidrocarbonetos complexos cuja a composição depende da composição da matéria-prima (biomassa) utilizada no processo (Molino et al $^{16}$ detalham com muito propriedade a composição do alcatrão), que pode causar obstrução de filtros, válvulas, tubulações, corrosão, podendo ser removido através de craqueamento (catalítico ou térmico) ou remoção mecânica (lavadores, filtros, separadores, ciclones); partículas sólidas como cinzas, carvão e material do leito que podem ser removidos por meio de filtragem e lavagem.

Uma aplicação bastante atrativa da gaseificação é o IGCC (Integrated Gasification combined cycle), que combinando gaseificação e combustão utiliza basicamente de um ciclo Rankine onde um gaseificador gera o gás combustível que após processo de limpeza é queimado numa turbina a gás (para produção de energia elétrica). Os gaseificadores de leito fluidizado são bastante utilizados neste tipo de sistema. Os motores de combustão interna (a diesel) têm também recebido bastante atenção na aplicação do gás de síntese. ${ }^{7}$

As células a combustível são tecnologias que possuem alta eficiência na conversão de combustível em energia elétrica, destaca-se o projeto BioCellus desenvolvido na Europa, onde são estudados ciclos combinados de sistemas de gaseificação acoplados a células a combustível. Uma outra grande aplicabilidade da gaseificação é a produção de combustíveis de segunda geração, seja ela pela síntese Fischer-Tropsch, onde através de uma reação catalítica $(\mathrm{Co}, \mathrm{Fe})$ a temperaturas entre $200{ }^{\circ} \mathrm{C}$ e $350{ }^{\circ} \mathrm{C}$ converte-se o gás de síntese em produtos como gasolina, diesel, nafta e querosene de aviação, seja na produção de metanol ou dimetil éter (DME), um combustível sintético semelhante ao GLP. Um parâmetro importante 
a ser analisado na aplicabilidade do gás produto de gaseificação é a relação $\mathrm{H}_{2} / \mathrm{CO}$, que para utilização em células a combustível e na síntese Fischer-Tropsch recomenda-se ser próxima de $2 .{ }^{39}$

Algumas plantas em operação no mundo que utilizam da gaseificação para geração de energia são: ${ }^{40}$

- Biomassekraftwerk Gussing: unidade em operação desde 2008 na Áustria, que produz gás natural sintético (SNG) a partir de gás de síntese produzido de gaseificação de madeira em leito fludizado (vapor como agente de fluidização).

- Chemrec AB: empresa sueca com mais de 15 anos de experiência na gaseificação do licor negro para produção de DME.

- ECN: produção de gás de síntese (gaseificador de leito fluidizado borbulhante modificado) e SNG (em pequena escala) em operação desde 2008 na Holanda. Utiliza madeira como matéria-prima.

- Hawaii biomasss gasifier project: projeto do Departamento de Energia dos Estados Unidos em sistemas de gaseificação para conversão de biomassas em eletricidade através de gaseificação.

- BioTfuel: projeto na França que visa a produção de biocombustíveis a partir de conversão de biomassa (produtos agrículos, florestais, culturas energéticas) em gás de síntese a partir de gaseificação;

- Enamora CHP plant: planta de gaseificação de biomassa em leito fluidizado, na Espanha, para produção de eletricidade.

Algumas empresas, associações, universidades e institutos de pesquisas destacadas por Ett et al. ${ }^{41}$ são:

- No mundo: AEW (Associated Engineering Works), Ankur Scientific Energy Technologies, Chiptec Wood Energy Systems, GE, GTC (Gasification Technologies Council), HTV Energy, Indian Institute of Science, Martezo Energia Renovável, National Renewable Energy Laboratory (NREL), Shell, Siemens, The Biomass Energy Foundation (BEF), VTT Gasification R\&D Center, Zaragoza University; 
- No Brasil: Embrapa Agroenergia, Instituto de Pesquisas Tecnológicas (IPT), Universidade de Campinas (UNICAMP), CENBIO, Carbogas, Delta $\mathrm{H}$ Desenvolvimentos Tecnológicos, Universidade Federal do Rio de Janeiro (UFRJ), Petrobras S.A.

O mapa online elaborado pelo programa Bioenergy $2020+{ }^{42}$ lista com detalhes as plantas em operação, construção e planejamento de biocombustíveis líquidos e gasosos produzidos a partir de biomassa.

\subsection{CONSIDERAÇÃO FINAL}

Neste capítulo foi apresentado o contexto da produção de energia no Brasil, que mostra boas perspectivas de crescimento da utilização de energia proveniente de fontes alternativas, sendo uma delas a biomassa. A gaseificação se apresenta como uma alternativa interessante para agregar valor a este tipo de matéria-prima tendo um papel importante na diversificação da matriz energética brasileira, já que a mistura gasosa produzida pode ser utilizada tanto para a geração de energia elétrica quanto para produção de químicos e combustíveis líquidos. Posto isto, apresentou-se os principais tipos de sistemas de gaseificação, dando ênfase ao sistema em leito fluidizado, tema do presente trabalho. Esse tipo de sistema é atrativo para ser aplicado à biomassa devido à distribuição uniforme de temperatura na região do leito, o que permite melhor eficiência dos fenômenos de transferência de calor e massa durante o processo, além de possuir um baixo conteúdo de alcatrão no gás produto. Dentre os agentes de fluidização ar, vapor e dióxido de carbono, o que tem apresentado o melhor rendimento na produção de gás com caráter combustível segundo a literatura é o vapor, que apresenta também um elevado teor de hidrogênio. 


\section{CARACTERIZAÇÃO DA BIOMASSA}

A biomassa florestal utilizada neste estudo foi a da espécie Eucalyptus grandis, e as seguintes análises foram realizadas para determinação da composição química e do potencial energético do material: poder calorífico, análise elementar e análise imediata. Para tais análises, a biomassa passou por processo de moagem em moinho de facas tipo willey utilizando peneira de $2 \mathrm{~mm}$. A Figura 4.1 mostra a biomassa em estágio inicial (moída em moinho de martelo) e após o processamento em moinho willey. Todas as análises foram realizadas em triplicata.
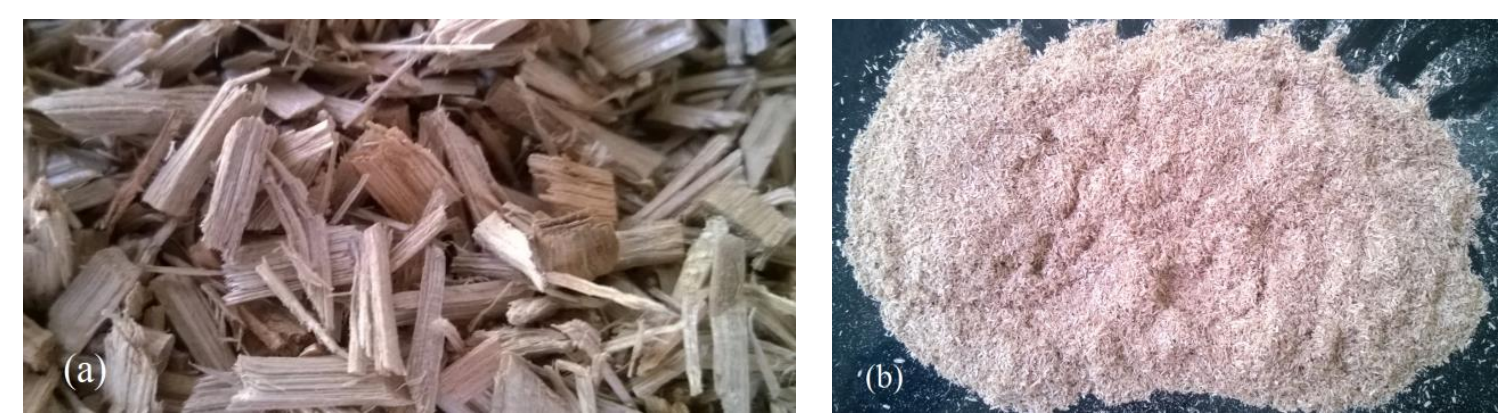

Figura 4.1 - Biomassa moída a) em moinho de martelo b) em moinho de facas willey.

\subsection{METODOLOGIA DE ANÁLISE}

\subsubsection{Poder calorífico}

O poder calorífico é a quantidade de calor (energia térmica) liberada através da combustão de uma unidade de massa ou volume de combustível $\left(\mathrm{kJ} / \mathrm{kg}\right.$ ou $\left.\mathrm{kJ} / \mathrm{m}^{3}\right)$, e é denominado inferior (PCI) quando não considera o calor latente de vaporização da água (durante a combustão) e superior (PCS) quando este valor é considerado, sendo este 10 a 20\% maior que o PCI.

A análise foi realizada no calorímetro IKA C-2000, seguindo o procedimento baseado na norma ASTM D-2015. ${ }^{43}$ Entre 0,2 e 0,3 g da amostra de Eucalyptus grandis foram pastilhadas, e deixadas em estufa a $105{ }^{\circ} \mathrm{C}$ overnight. A massa da amostra seca foi determinada em balança analítica e a análise seguiu as seguintes etapas:

- Selecionou-se o método Dynamic;

- A amostra é colocada em um cadinho em contato com um fio de algodão (pavio), e ambos são fechados em um vaso de pressão;

- A massa da amostra foi inserida no equipamento; 
- O vaso de pressão foi colocado no equipamento, que automaticamente pressuriza com 30 bar de oxigênio;

- A análise foi realizada.

O cálculo do poder calorífico é feito da seguinte forma: o vaso de pressão contendo a pastilha de biomassa seca é imerso em uma massa de água que possui temperatura monitorada. A quantidade de calor liberada pela reação de combustão é absorvida pela água elevando a sua temperatura. Quando a temperatura atinge a estabilidade, a quantidade de calor absorvida $(Q)$ é determinada através da Equação 4.1:

$$
Q=m_{\mathrm{H}_{2} \mathrm{O}} \cdot C_{p_{\mathrm{H}_{2} \mathrm{O}}} \cdot\left(T_{\text {final }}-T_{\text {inicial }}\right)
$$

Onde o $m_{\mathrm{H}_{2} \mathrm{O}}$ é a massa de água, $C_{p_{\mathrm{H}_{2} \mathrm{O}}}$ é o calor específico da água, e $T_{\text {final }}$ e $T_{\text {inicial }}$ são as temperaturas final e inicial da água. Considerando que o calor absorvido pela água é igual ao calor da reação de combustão e dividindo esse valor pela massa de biomassa $\left(m_{\text {biomassa }}\right)$ tem-se o poder calorífico superior do combustível

$$
P C S=\frac{Q}{m_{\text {biomassa }}}
$$

O cálculo do PCI a partir do PCS para a biomassa pode ser realizado de acordo com a Equação $4.3:^{14}$

$$
P C I=P C S-h_{g} \cdot\left(\frac{9 H}{100}+\frac{\omega}{100}\right)
$$

Onde $h_{g}, H$ e $\omega$ são calor latente de vaporização a $25^{\circ} \mathrm{C}$ e 1 atm, porcentagem mássica de hidrogênio e porcentagem mássica de umidade da biomassa, respectivamente.

\subsubsection{Análise elementar}

A análise elementar foi realizada no Analisador Elementar CHN/O 2400 da marca Perekin Elmer. A análise elementar permite determinar a composição química do material, no que diz respeito aos elementos carbono, hidrogênio, nitrogênio por meio da combustão da amostra em uma atmosfera de oxigênio puro, onde os gases resultantes dessa combustão $\left(\mathrm{CO}_{2}, \mathrm{H}_{2} \mathrm{O}, \mathrm{NO}_{\mathrm{x}}\right)$ são quantificados em um detector TCD (detector de condutividade térmica). As normas para realização da análise elementar são ASTM D3176, ${ }^{44}$ E777, ${ }^{45}$ e E778. ${ }^{46}$ 
Utilizando-se do espectrômetro de fluorescência de raio-X (FRX/EDX) da marca Shimadzu, modelo 720 , determinou-se os elementos que vão de sódio $\left({ }_{11} \mathrm{Na}\right)$ a urânio $\left({ }_{92} \mathrm{U}\right)$, com tubos de raios $\mathrm{X}$ com alvo de ródio $(\mathrm{Rh})$. Esta análise em conjunto com a os resultados da análise elementar de carbono, hidrogênio e nitrogênio permite a identificação da fórmula molecular do composto final. O percentual de oxigênio é determinado pela diferença.

\subsubsection{Análise imediata}

A análise imediata é uma técnica utilizada para determinação dos teores de umidade, voláteis, carbono fixo e cinzas da amostra, e essa análise foi realizada seguindo os seguintes passos:

- A determinação da umidade foi feita de acordo com a norma ASTM D3173, ${ }^{44}$ com aquecimento da amostra até $105^{\circ} \mathrm{C}$, em atmosfera inerte de $\mathrm{N}_{2}$, até estabilização do peso da amostra;

- Para o teor de voláteis, baseando-se na norma ASTM E872, ${ }^{46}$ mediu-se a fração de biomassa que volatiliza durante o aquecimento em atmosfera inerte até uma temperatura de $950{ }^{\circ} \mathrm{C}$, que é mantida por 7 minutos. $\mathrm{O}$ material resultante do processo é o carbono fixo e as cinzas;

- O teor de cinzas foi determinado de acordo com a norma ASTM D3174, ${ }^{44}$ com aquecimento até $750{ }^{\circ} \mathrm{C}$ da amostra sem umidade e voláteis, até peso constante, em atmosfera de oxigênio. No fim do processo restam apenas as cinzas;

- O carbono fixo foi determinado por diferença.

\subsection{RESULTADOS E DISCUSSÃO}

Os resultados das análises elementar (composição de C, H, N e O em porcentagem) e imediata (teor, em porcentagem, de umidade, voláteis, cinzas e carbono fixo), poder calorífico $(\mathrm{MJ} / \mathrm{kg})$ e das razões H/C e O/C para a biomassa de Eucalyptus grandis são mostrados na Tabela 4.1.

A análise elementar é um dos parâmetros importantes para quantificar a relação arcombustível necessária para o processo de gaseificação com ar. Como foi mencionado, a gaseificação é um processo de oxidação parcial do combustível (biomassa) e um dos parâmetros que definem o processo como gaseificação é a razão de equivalência (RE), que por recomendação deve estar na faixa de 0,2 a 0,4 . Outro fator interessante da importância da 
análise imediata para a produção de energia por meio dos processos termoquímicos é o conhecimento das razões de H/C (hidrogênio/carbono) e O/C (oxigênio/carbono).

Tabela 4.1 - Valores médios para as análises elementar e imediata, poder calorífico e razões $\mathrm{H} / \mathrm{C}$ e $\mathrm{O} / \mathrm{C}$ de Eucalyptus grandis.

\begin{tabular}{|c|c|}
\hline \multicolumn{2}{|c|}{ Composição Elementar (\%) } \\
\hline Carbono & 47,11 \\
\hline Hidrogênio & 6,29 \\
\hline Nitrogênio & 0,06 \\
\hline Oxigênio & 42,04 \\
\hline $\mathrm{Na}$ & 3,479 \\
\hline $\mathrm{K}$ & 0,428 \\
\hline $\mathrm{Ca}$ & 0,228 \\
\hline $\mathrm{Al}$ & 0,143 \\
\hline $\mathrm{Si}$ & 0,112 \\
\hline S & 0,048 \\
\hline $\mathrm{Fe}$ & 0,033 \\
\hline Mn & 0,031 \\
\hline \multicolumn{2}{|c|}{ Composição imediata (\%) } \\
\hline Umidade & 11,52 \\
\hline Voláteis & 72,02 \\
\hline Cinzas & 4,48 \\
\hline Carbono fixo & 11,98 \\
\hline \multicolumn{2}{|c|}{ Propriedade (MJ/kg) } \\
\hline Poder calorífico superior & 17,61 \\
\hline Poder calorífico inferior & 16,84 \\
\hline \multicolumn{2}{|c|}{ Razões molares } \\
\hline Razão H/C & 0,13 \\
\hline Razão O/C & 0,89 \\
\hline
\end{tabular}

Levando-se em consideração os parâmetros $\mathrm{H} / \mathrm{C}$ e O/C da biomassa em comparação com combustíveis fósseis, tem-se que a biomassa é caracterizada por possuir estes parâmetros mais altos em comparação com os combustíveis fósseis. Comparando a biomassa com o carvão por exemplo, tem-se que os maiores valores de $\mathrm{H} / \mathrm{C}$ e $\mathrm{O} / \mathrm{C}$ reduzem o poder calorífico devido a menor quantidade de energia contida nas ligações carbono-oxigênio e carbonohidrogênio em comparação com as ligações carbono-carbono. ${ }^{47}$

De acordo com Lora ${ }^{7}$, combustíveis com alto teor de carbono fixo e baixo teor de matéria volátil tendem a queimar de forma mais lenta, requerendo um tempo de residência maior no processo comparado a combustíveis com baixo teor de carbono fixo. O carbono fixo 
determinado na análise imediata difere do carbono determinado na análise elementar, pois o primeiro não leva em consideração o carbono presente na matéria volátil e está diretamente relacionado ao rendimento de carvão após a etapa de devolatilação da biomassa. ${ }^{14}$

Lora $^{7}$ destaca que umidade e granulometria têm efeitos importantes na gaseificação de biomassa. A primeira pode afetar consideravelmente a composição do gás produto devido a redução da temperatura no sistema de reação, pois quanto mais umidade o combustível tiver mais energia será requerida para vaporização da água presente no combustível. Teores inferiores a $20 \%$ de umidade podem ter influência positiva na gaseificação intensificando a reação de desclocamento gás-água. Já com relação à granulometria, partículas com diâmetro característico menor que $2 \mathrm{~mm}$ favorecem o predomínio da reação química (em detrimento das transferências de calor e massa) no processo de gaseificação. As partículas maiores apresentam menores taxas de volatilização e maior transferência de calor entre as mesmas partículas e partículas próximas, ao mesmo que favorecem a formação de espaços entre as partículas do leito assim como o desenvolvimento de canais preferenciais que dão origem a flutuações e heterogeneidade na temperatura do reator, o que aumenta o teor de alcatrão no gás produto.

\subsection{CONSIDERAÇÃO FINAL}

A análise elementar é um dos parâmetros importantes utilizados para quantificar a relação ar-combustível necessária para o processo de gaseificação com ar. Como foi mencionado, a gaseificação é um processo de oxidação parcial do combustível (biomassa) e um dos parâmetros que define o processo como gaseificação é que a razão de equivalência (RE) esteja na faixa de 0,2 a 0,4. Outro fator importante da caracterização do Eucalyptus grandis através de análise imediata para a produção de energia por meio dos processos termoquímicos é o conhecimento da razão H/C (hidrogênio/carbono), que está dentro do estabelecido pela literatura $^{14}$ (faixa de 0,13 a 0,14 para madeira). Altos valores de $\mathrm{H} / \mathrm{C}$ e $\mathrm{O} / \mathrm{C}$ representam um baixo poder calorífico do material, o que é característico de biomassa. Estes valores de razão $\mathrm{H} / \mathrm{C}$ e O/C decrescem com o aumento da idade geológica do combustível, podendo ser citado, por exemplo, o antracite que é um carvão mineral que possui alto poder calorífico. ${ }^{14}$ Com base nos resultados apresentados é possível afirmar que a biomassa de Eucalyptus grandis caracterizada apresenta potencial para produção de energia por meio de processos termoquímicos. 


\section{DESCRIÇÃO DA PLANTA PILOTO DE PIRÓliSE E GASEIFICAÇÃo}

O presente projeto trata da produção de gás combustível a partir de Eucalyptus grandis em uma planta piloto de gaseificação e pirólise localizada na Área de Plantas Piloto da Embrapa Agroenergia. A planta foi projetada e construída pela empresa PID Eng\&TECH para o desenvolvimento de pesquisas nas áreas de pirólise e gaseificação de sólidos (principalmente biomassa) em leito fluidizado utilizando como agentes de fluidização ar, nitrogênio, vapor d'água, dióxido de carbono, oxigênio ou uma mistura destes. A Figura 5.1 apresenta a planta piloto de gaseificação e pirólise, que é composta por:

1. Módulo de controle computacional;

2. Módulo de reação;

3. Lavador de gases;

4. Medidor de fluxo;

5. Queimador de gases.

Além dos cinco módulos, foi adicionado um sistema de análise de gases em tempo real, que será apresentado e discutido posteriormente ainda neste capítulo.

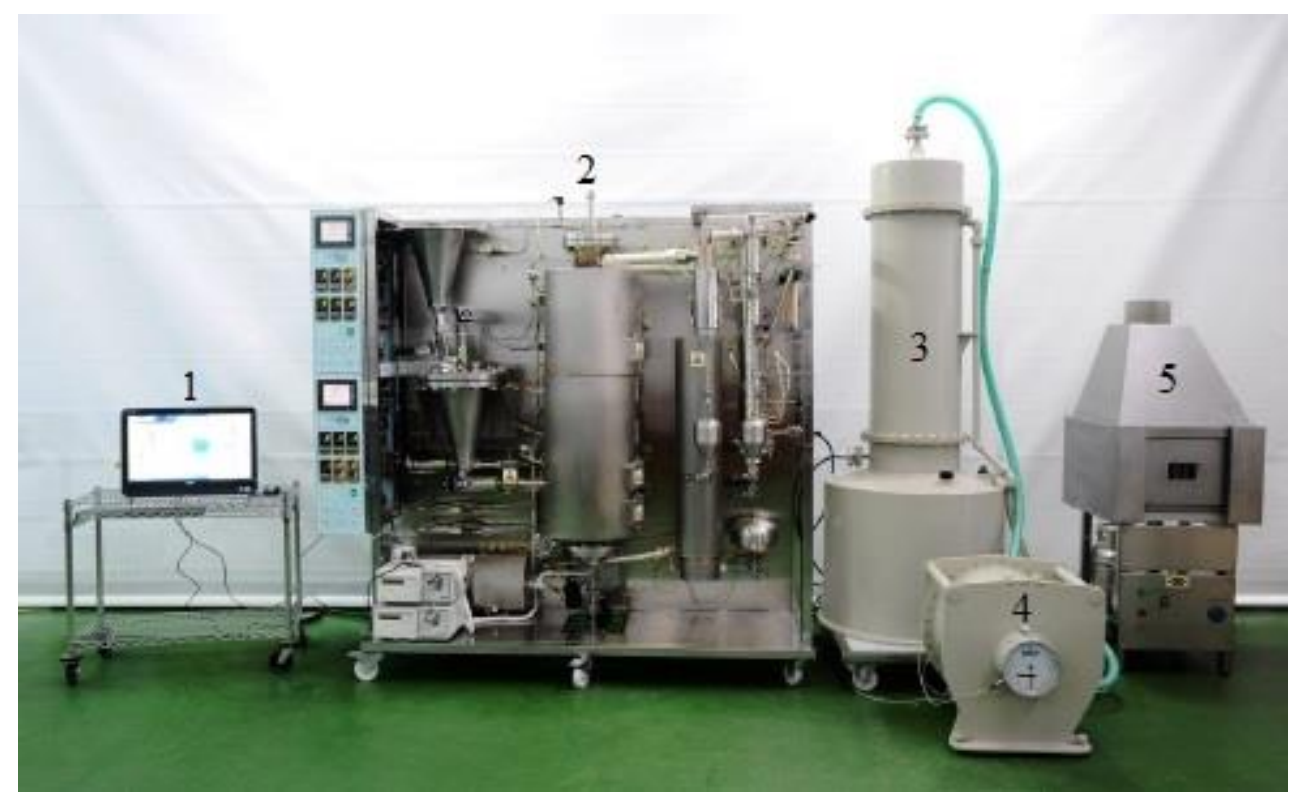

Figura 5.1 - Planta piloto de gaseificação e pirólise localizada na Área de Plantas Piloto da Embrapa Agroenergia. ${ }^{48}$ 


\subsection{MÓDULO DE REAÇÃO}

O módulo de reação da planta piloto de gaseificação e pirólise, apresentado na Figura 5.2, é composto pelos sistemas de:

1. Alimentação de sólidos (combustível);

2. Alimentação de gás: ar, nitrogênio, dióxido de carbono, oxigênio ou uma mistura destes;

3. Alimentação de líquido: vapor d'água, glicerina;

4. Reação em leito fluidizado com aquecimento por resistência elétrica: no interior do reator é adicionado o leito (areia), o agente de fluidização (que pode ser previamente aquecido por meio de resistência elétrica) e o combustível para que ocorram as reações;

5. Separação de sólidos (ciclones): responsáveis por separar o material sólido (cinzas, biomassa que não reagiu, areia do leito) que pode ser arrastado pela mistura gasosa gerada no processo de gaseificação da biomassa florestal;

6. Remoção de alcatrão (condensador): que possibilita condensar e obter o alcatrão contido no gás produzido no reator;

7. Remoção de particulado residual: filtros. 


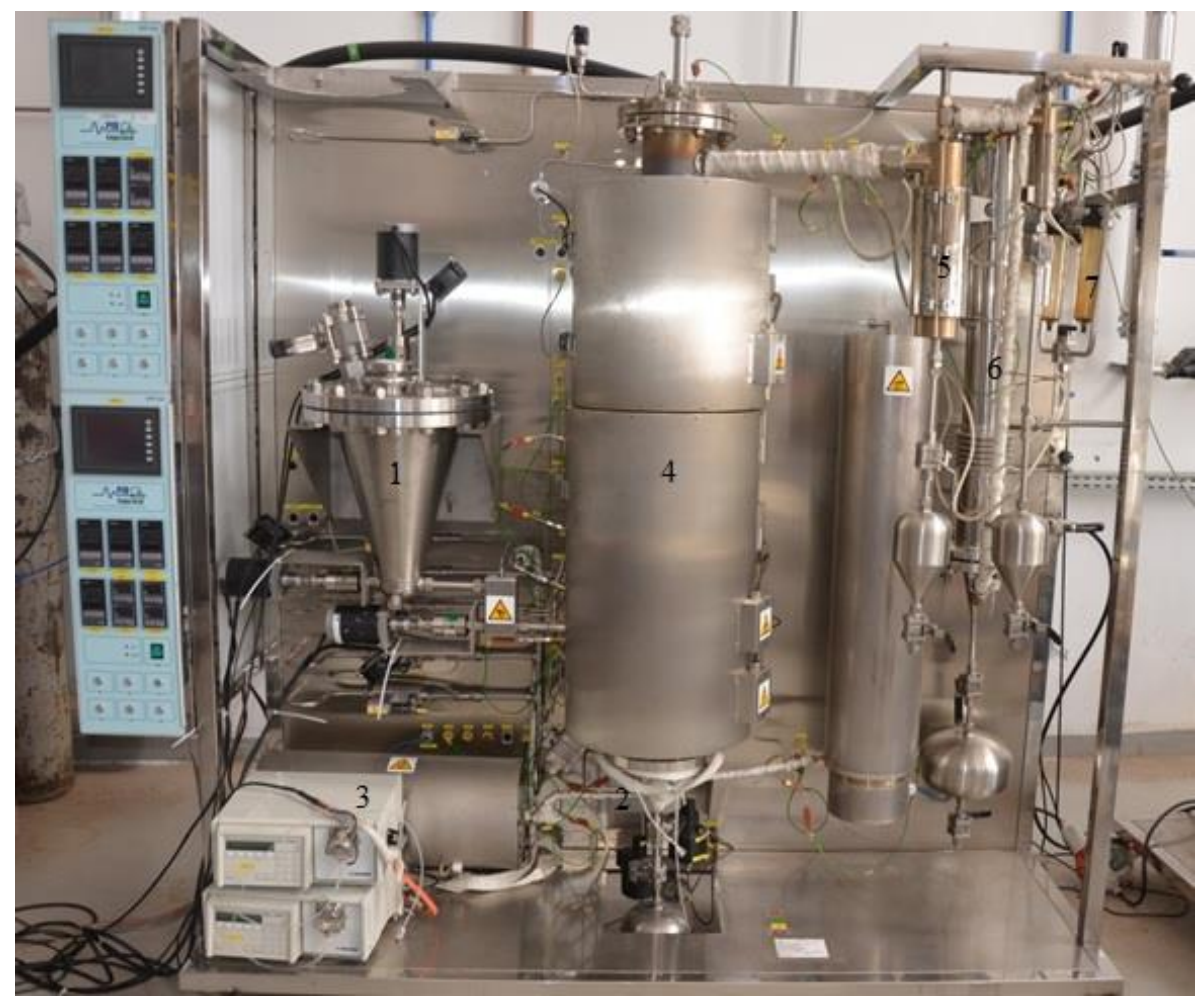

Figura 5.2 - Módulo de reação.

\subsubsection{Sistema de alimentação de sólidos}

O sistema de alimentação de sólidos é baseado em duas roscas sem fim alimentadoras que regulam e controlam a taxa de alimentação de sólidos na região do leito do reator, conforme pode ser visualizado na Figura 5.3, e é composto por:

1. Funil de armazenamento (capacidade de 10 litros, pressão de operação de até 0,5 barg);

2. Funil ou silo de alimentação (capacidade de 10 litros, pressão de operação de até 0,5 barg);

3. Agitador;

4. Rosca dosadora (rosca de $200 \mathrm{~mm}$ de comprimento e $16 \mathrm{~mm}$ de diâmetro);

5. Rosca alimentadora (rosca de $300 \mathrm{~mm}$ de comprimento e $16 \mathrm{~mm}$ de diâmetro);

6. Câmara de expansão com fluxo de nitrogênio para pressurizar o sistema de alimentação.

A Figura 5.3 mostra o sistema de alimentação de combustível da planta piloto de pirólise e gaseificação. O combustível sólido é adicionado ao funil de armazenamento (1), e por meio de uma válvula a biomassa é transferida ao funil de alimentação (2), que possui um 
sistema de agitação (3) utilizado para movimentar as partículas de combustível com o objetivo de melhorar a dosagem de sólidos. A biomassa é dosada, através da rosca dosadora (4), até uma câmara de expansão (6), e alimentada na região do leito do reator mediante uma rosca alimentadora (5). A câmara de expansão possui um fluxo de nitrogênio (fluxo máximo de $4 \mathrm{NL} / \mathrm{min}$ ) para pressurizar o sistema de alimentação e evitar que parte da atmosfera gasosa presente no interior do reator retorne para a rosca alimentadora.

A velocidade de rotação do motor da rosca alimentadora é 30\% maior que a da rosca dosadora, isso se dá para que todo o combustível dosado na câmara de expansão seja alimentado no reator com o mínimo de tempo possível evitando entupimento. O tubo que envolve a rosca de alimentação possui um sistema de resfriamento com água para mantê-la resfriada e evitar que haja alguma reação dentro do tubo.

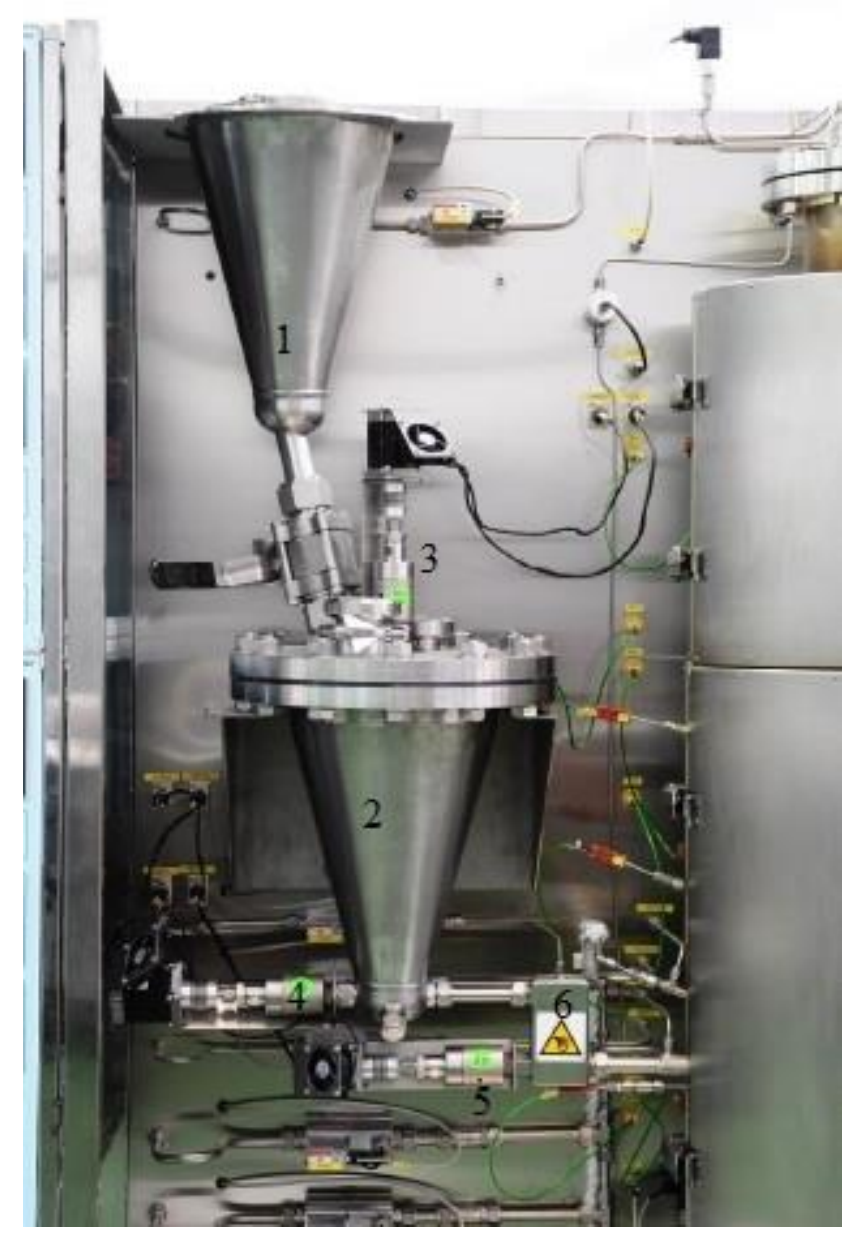

Figura 5.3 - Sistema de alimentação de combustível. ${ }^{48}$ 


\subsubsection{Sistema de alimentação de gás}

Os agentes de gaseificação são introduzidos na planta piloto por três pontos:

- Gás primário: é introduzido na parte inferior do reator $\left(\operatorname{ar}, \mathrm{CO}_{2}, \mathrm{~N}_{2}\right.$ e $\left.\mathrm{O}_{2}\right)$;

- Gás secundário (ar): É introduzido no topo da região do leito no reator, na parte inferior da região freeboard.

- Gás do sistema de alimentação de sólidos (nitrogênio): É introduzido na câmera de expansão do sistema de alimentação de sólidos.

Por meio de controladores de fluxo mássico - MFC's (marca Bronkhorst High-tech) é possível regular a vazão de alimentação dos agentes de fluidização ar, dióxido de carbono, oxigênio e nitrogênio no reator (gás primário). $\mathrm{O}$ nitrogênio também pode ser utilizado pelo sistema de segurança da planta em caso de alarme da mesma, e para resfriamento em atmosfera inerte evitando a queima de carvão produzido no processo. Os controladores MFC's têm pressão de entrada de 3 barg, e o fluxo mássico máximo de cada agente de fluidização, bem como as pressões de entrada $\left(\mathrm{P}_{\text {entrada }}\right)$ e saída $\left(\mathrm{P}_{\text {saída }}\right)$ dos gases primários (agentes de fluidização), gás secundário (ar introduzido na região do leito) e gás do sistema de alimentação (nitrogênio), são mostrados na Tabela 5.1:

Tabela 5.1 - Pressões de entrada e saída e vazões máximas dos agentes de gaseificação. ${ }^{48}$

\begin{tabular}{|l|c|c|c|}
\hline \multicolumn{1}{|c|}{ Gases } & $\mathrm{P}_{\text {entrada }}$ (barg) & $\mathrm{P}_{\text {saida }}$ (barg) & $\begin{array}{c}\text { Fluxo mássico } \\
\text { máximo do } \\
\text { controlador MFC } \\
\text { (NL/min) }\end{array}$ \\
\hline Ar & 3 & 1 & 200 \\
\hline Nitrogênio & 3 & 1 & 200 \\
\hline Oxigênio & 3 & 1 & 40 \\
\hline Dióxido de carbono & 3 & 1 & 40 \\
\hline Gás Secundário (ar) & 3 & 1 & 3 \\
\hline $\begin{array}{l}\text { Gás Alimentação } \\
\left(\mathrm{N}_{2}\right)\end{array}$ & 3 & 1 & 200 \\
\hline Alarme & 3 & 1 & 30 \\
\hline
\end{tabular}

O gás primário passa, antes de entrar no reator, por um pré-aquecedor (potência máxima de aquecimento de $4 \mathrm{~kW}$ ) que é formado por um tubo em espiral com um aquecedor interno em seu interior. Com o sistema, é possível aumentar a temperatura até $400^{\circ} \mathrm{C}$. 


\subsubsection{Sistema de alimentação de líquido}

Outro agente de fluidização que pode ser utilizado no processo de gaseificação é o vapor d'água. A água é bombeada utilizando-se de uma bomba de alta pressão GILSON 305 50SC e convertida em vapor através de aquecimento em um evaporador (4 kW de potência) com aquecimento máximo da água de $400{ }^{\circ} \mathrm{C}$.

\subsubsection{Sistema de reação em leito fluidizado}

O sistema de reação consiste de um reator e dois fornos que permitem alcançar a temperatura de processo.

O reator possui $1515 \mathrm{~mm}$ de altura, e é dividido em duas regiões: zona do leito (770 de comprimento e 82,8 de diâmetro interno), e zona freeboard (535 $\mathrm{mm}$ de altura e 134,5 $\mathrm{mm}$ de diâmetro interno). A alimentação de sólidos é realizada na região do leito, acima da placa distribuidora, responsável pela alimentação dos agentes de fluidização. Durante o processo, o gás produto deixa o reator pelo topo da região freeboard e segue para o sistema de separação de sólidos (ciclone). Os agentes de fluidização ar, nitrogênio e vapor são introduzidos ao gaseificador abaixo da placa distribuidora, e há também a possibilidade de injeção de ar secundário na região freeboard. A retirada do leito pode ser feita através de um tubo situado sobre a placa distribuidora (por uma válvula manual) ou abrindo-se a tampa superior do reator (acima da região freeboard).

A temperatura no sistema de reação é medida através de três termopares do tipo K ($200{ }^{\circ} \mathrm{C}$ a $1250{ }^{\circ} \mathrm{C}$ ) sendo eles TIC08, TIC10 e TIC13, que estão localizados na zona do leito. A pressão no reator é medida por dois transdutores de pressão (marca WIKA) que mede na faixa de 0 a 1,6 bar e estão localizados na saída da placa distribuidora (PI01), e no topo da região freeboard (PIA02). Há um diferencial de pressão (marca SENSORTECHNICS) que mede na faixa de 0 a 350 mbar (PDT03), que mede a perda de carga gerada pelo leito. $\mathrm{O}$ sistema de aquecimento do reator é realizado por resistências elétricas. Dois fornos para o sistema de reação, um na região do leito (potência total de $7 \mathrm{~kW}$ ) dividido em duas partes, onde cada parte tem duas fibras Kanthal, que suportam até $1150^{\circ} \mathrm{C}$, e outro que aquece a região freeboard (potência total de $6,2 \mathrm{~kW}$ ). 

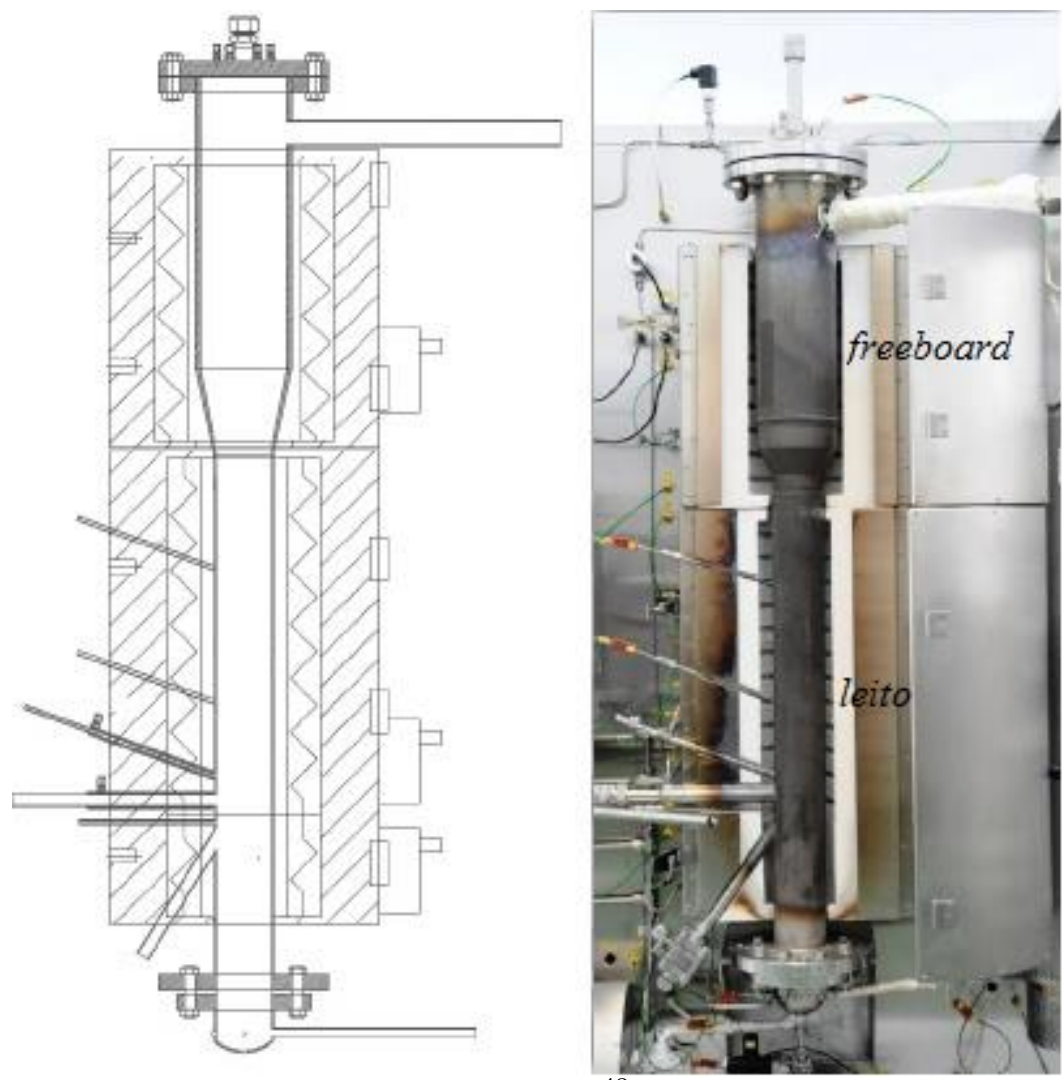

Figura 5.4 - Sistema de reação em leito fluidizado. ${ }^{48}$

\subsubsection{Sistema de separação de sólidos}

Após a saída do gás do sistema de reação, o mesmo pode conter partículas de carvão, cinzas e leito. Assim, para a remoção destes particulados do gás produzido utiliza-se dois ciclones, de diâmetro interno de 83 e $43 \mathrm{~mm}$ respectivamente, que separam as partículas sólidas do gás pela ação da força centrífuga exercida sobre as partículas. As partículas entram em contato com as paredes do ciclone e se direcionam para a base do mesmo, onde são coletadas por um funil. Os ciclones podem ser aquecidos até $400^{\circ} \mathrm{C}$ por meio de resistência elétrica, o primeiro ciclone com uma resistência de $3 \mathrm{~kW}$ de potência e o segundo com 800 W.

\subsubsection{Sistema de remoção de alcatrão}

A remoção de alcatrão e água do gás produto é feita mediante a utilização de um trocador de calor do tipo casco e tubo. Este tipo de sistema opera com um dos fluidos escoando pelo casco (fluido de resfriamento) e o outro através dos tubos (gás de processo), não havendo contato entre eles. O gás proveniente dos dois ciclones arranjados em série entra no condensador por baixo e sobe em direção ao topo do mesmo, assim, o alcatrão mais pesado 
condensa, sendo recuperado no recipiente de armazenamento. O fluido de resfriamento a ser utilizado pode ser água, etanol, etilenoglicol, acetona, etc, e circula pelo casco entrando na parte inferior e saindo na parte superior, e o resfriamento do fluido é feito por meio de um banho termostático.

É importante destacar que cada tubulação por onde o gás produto passa, desde a saída do sistema de reação até a entrada do sistema de condensação, possui sistema de aquecimento elétrico a $400{ }^{\circ} \mathrm{C}$ (potência de $0,7 \mathrm{~kW}$ ) para que não haja condensação de água e alcatrão e consequentemente entupimento das mesmas.

\subsubsection{Sistema de remoção de particulado}

Após a passagem pelo sistema de condensação, o gás de processo passa por um filtro para remoção de particulado. O filtro fornecido pela PID Eng\&Tech trabalha com pressões de até 10 bar e $150^{\circ} \mathrm{C}$ de temperatura, e o seu material é o poli(fluoreto de vinilideno) (PVDF).

\subsection{LAVADOR DE GASES}

Para a remoção de alguns compostos ácidos, como o $\mathrm{H}_{2} \mathrm{~S}$, e também o $\mathrm{CO}_{2}$, que são solúveis em água, utiliza-se um sistema lavagem com água (scrubber). O gás produto, após passar pelo sistema de remoção de particulados, entra no sistema de lavagem de gases e segue um fluxo ascendente, enquanto que um "spray" de água é lançado no sentindo contracorrente, e enquanto o líquido resultante da lavagem é recirculado para o lavador de gases por meio de uma bomba de vácuo (600 L/min de capacidade), o gás produzido, limpo, segue para a próxima etapa do processo. A capacidade do reservatório de água do scrubber é de 200 litros.

\subsection{MEDIDOR DE FLUXO}

A medição do fluxo de gás produzido durante a gaseificação ou pirólise da planta piloto em questão é realizada após a lavagem dos gases com água, utilizando um medidor de fluxo da (Ritter) do tipo tambor modelo TG25-6, que utiliza o princípio de deslocamento positivo, possuindo um mecanismo de medição rotativo (tambor de medição) submerso num líquido. O tambor mede o volume através de enchimentos e esvaziamentos das quatro câmaras rígidas e a maior vantagem desse tipo de medidor é a medição direta do volume, onde a composição do gás não influencia na precisão da medição. Não são necessários fatores 
de correção para tipo do gás, temperatura e umidade. ${ }^{49}$ A medição do fluxo volumétrico de gás, em L/min, é dada à temperatura de $0{ }^{\circ} \mathrm{C}$ e $1 \mathrm{~atm}$.

\subsection{QUEIMADOR DE GASES}

O gás produzido pode ser queimado em um queimador (marca Tellsa com potência de $10^{5} \mathrm{kcal}$ por hora). Ao queimador é ligado um sistema de alimentação de ar (2 bar) e um cilindro contendo GLP, que permite manter uma chama piloto iniciando então a combustão dos gases formados do processo de gaseificação.

\subsection{MÓDULO DE CONTROLE COMPUTACIONAL}

O software computacional Process@, também desenvolvido pela PID Eng\&Tech através da plataforma LabVIEW, permite aquisição de dados e controle de todos os parâmetros e sistemas apresentados nesta seção. O programa possui um projeto personalizado para a Embrapa Agroenergia que contém todos os dados de processo a serem controlados. $\mathrm{O}$ software possui as seguintes aplicações:

- Painel de controle, cuja função é controlar todos os parâmetros de processo;

- Tabela de seções que permite programar os experimentos a serem realizados com o controle de todos os parâmetros, inclusive controlando quanto tempo cada parâmetro irá ser utilizado. Esta função permite que o processo seja realizado de forma autônoma, uma vez ajustados os valores de cada variável e o tempo, todos os comandos são realizados de acordo com o que foi programado;

- Interface gráfica que mostra em tempo real os valores das variáveis medidas (vazões de gases, temperaturas, pressões) durante o processo. É possível analisar uma variável de cada vez ou plotar várias variáveis a título de comparação;

- Experiment viewer, uma plataforma que permite visualizar todos os dados experimentais adquiridos em cada processo, e plotar gráficos dos processos já realizados através desses dados. Por meio dessa plataforma pode-se extrair os dados experimentais em formato Excel (xls).

\subsection{EQUIPAMENTO DE ANÁLISE DE GASES}

A análise dos gases produzidos na planta piloto de pirólise e gaseificação pode ser realizada utilizando-se o analisador de gases da marca SICK modelo GMS800. Os gases a serem analisados pelo equipamento foram calibrados em fábrica, e durante a instalação e 
treinamento do mesmo foi realizada validação da calibração. A Tabela 5.2 apresenta os gases que podem ser analisados, seus respectivos módulos (e uma descrição do princípio de medição utilizado), a faixa de medição de cada gás e a incerteza de medição relativa a cada faixa de medição.

Tabela 5.2 - Descrição dos módulos e faixas de medição dos gases medidos no equipamento de análise de gases.

\begin{tabular}{|c|c|c|c|c|}
\hline Gás & Módulo & Descrição & $\begin{array}{l}\text { Faixa de } \\
\text { medição } \\
(\% \text { vol })\end{array}$ & $\begin{array}{c}\text { Incerteza } \\
\text { em relação } \\
\text { à faixa de } \\
\text { medição } \\
(\%)\end{array}$ \\
\hline $\mathrm{H}_{2} \mathrm{~S}$ & DEFOR & $\begin{array}{l}\text { Analisador de gás UV que pode ser utilizado } \\
\text { para medição de até } 3 \text { componentes de gás }\end{array}$ & $0-10$ & $<1 \%$ \\
\hline $\mathrm{CH}_{4}$ & \multirow{3}{*}{ MULTOR } & \multirow{3}{*}{$\begin{array}{l}\text { Analisador NDIR de múltiplos componentes } \\
\text { para medição de até } 3 \text { gases absorventes de } \\
\text { IR e } \mathrm{H}_{2} 0 \text { para a correção interna da } \\
\text { sensibilidade cruzada }\end{array}$} & $0-25$ & \multirow{3}{*}{$<1 \%$} \\
\hline $\mathrm{CO}$ & & & $0-50$ & \\
\hline $\mathrm{CO}_{2}$ & & & $0-27,5$ & \\
\hline $\mathrm{O}_{2}$ & OXOR-P & \begin{tabular}{|lllll}
$\begin{array}{l}\text { Analisador } \\
\text { segundo oxigênio } \\
\text { paramagnético }\end{array}$ & $\begin{array}{l}\text { oxine } \\
\text { princípio }\end{array}$ & $\begin{array}{l}\text { funciona } \\
\text { medição }\end{array}$ \\
\end{tabular} & $0-25$ & $<1 \%$ \\
\hline $\mathrm{H}_{2}$ & THERMOR & $\begin{array}{l}\text { Analisador de condutibilidade térmica para } \\
\text { determinação de concentrações em misturas } \\
\text { de gases binárias ou quase binárias }\end{array}$ & $0-25$ & $<1 \%$ \\
\hline
\end{tabular}




\section{CALIBRAÇÃO DO SISTEMA DE ALIMENTAÇÃO}

\subsection{METODOLOGIA EXPERIMENTAL}

A calibração do sistema de alimentação foi realizada com o objetivo de determinar a taxa de alimentação de Eucalyptus grandis em função da rotação dos motores dosador e alimentador. Segundo dado fornecido pelo fabricante, o motor alimentador (SIC02B) trabalha a uma rotação $30 \%$ maior que o motor dosador (SIC02A). Em testes preliminares de gaseificação de Eucalyptus grandis os motores apresentaram travamento, assim, novos motores com potências maiores mas com vazões de alimentação menores foram adquiridos junto ao fabricante. A calibração de ambos os sistemas de alimentação (Figura 6.1), motor 1 (antigo) e motor 2 (novo), utilizando biomassa de Eucalyptus grandis com granulometria inferior a $2 \mathrm{~mm}$, foi realizada conforme segue (metodologia experimental idealizada pelo fabricante):

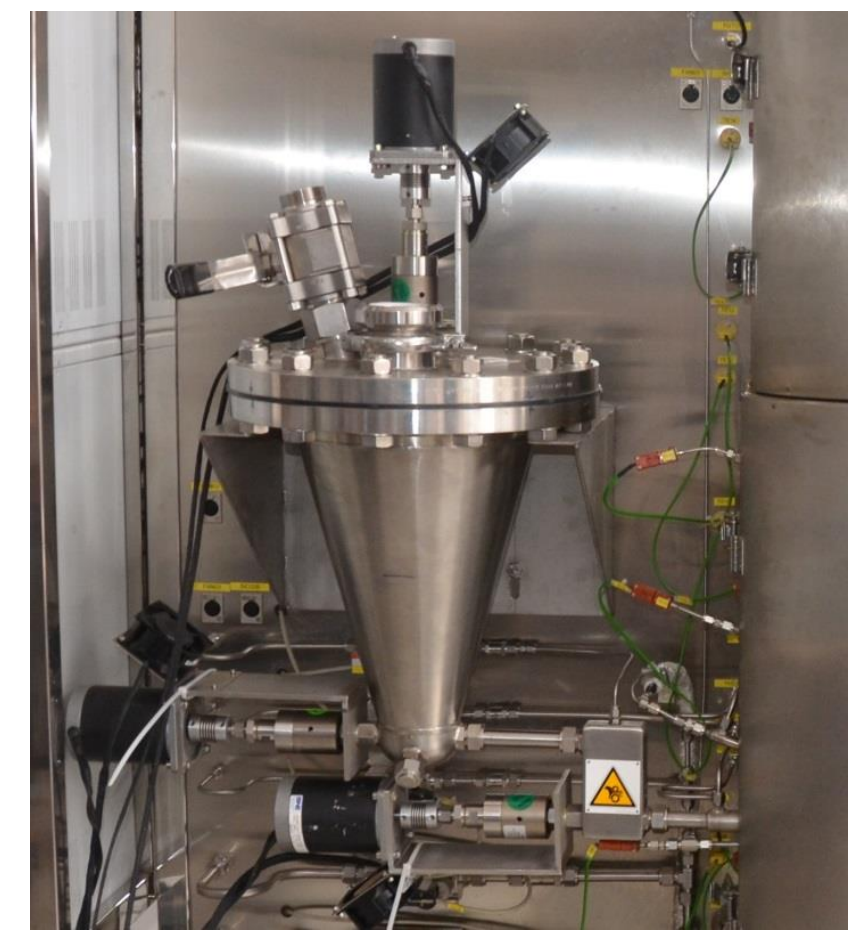

Figura 6.1 - Sistema de alimentação de biomassa da Planta Piloto de Pirólise e Gaseificação.

- Desconectou-se a câmara de expansão do tubo que a conecta ao reator;

- Conectou-se um tubo à câmara de expansão, conforme mostrado na Figura 6.2; 


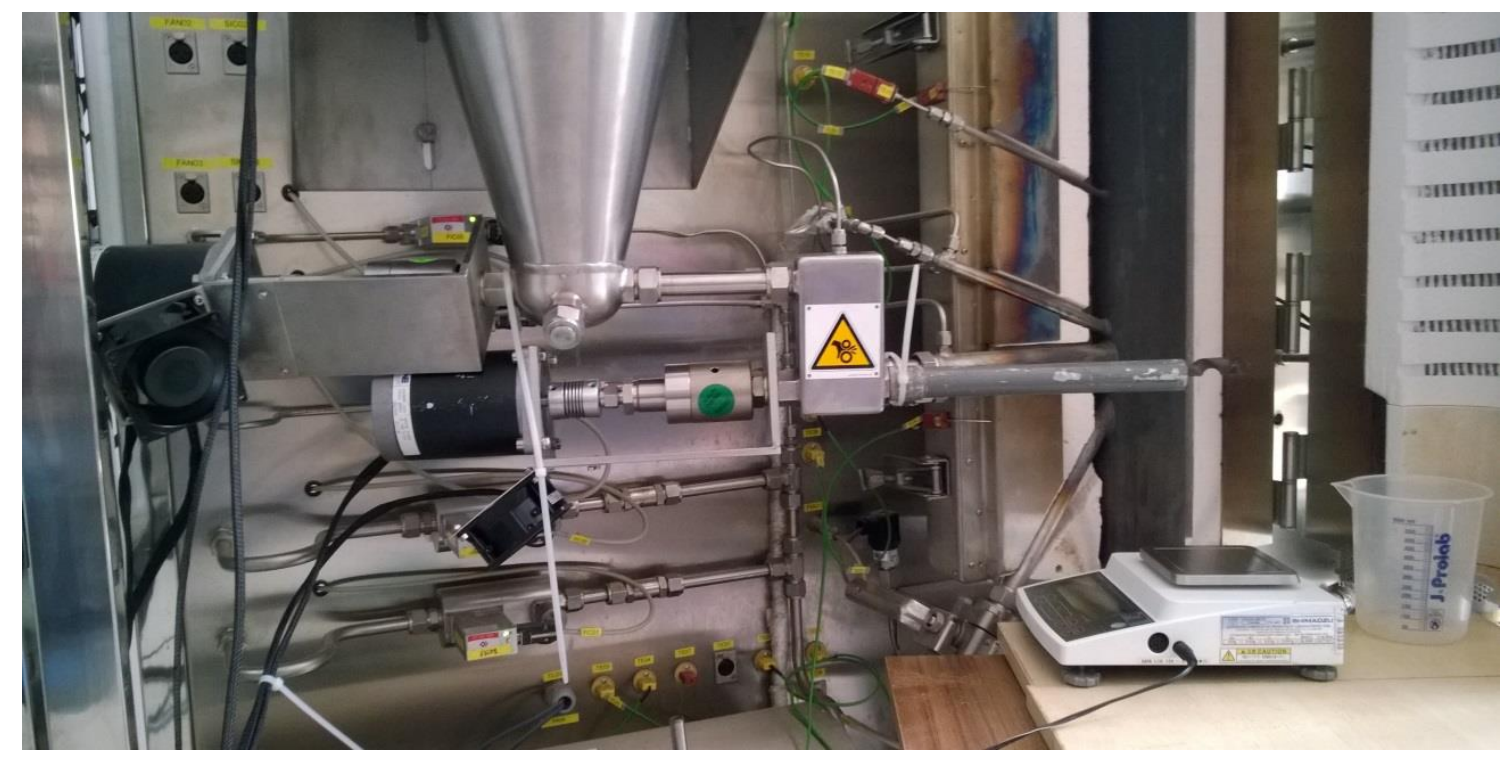

Figura 6.2 - Aparato experimental utilizado na calibração do sistema de alimentação de sólidos.

- Ligou-se o sistema de alimentação à rotação de $20 \%$ dos motores de dosagem e alimentação e mediu-se a vazão de biomassa, obtida da rosca alimentadora (SIC02B), por minuto por meio de uma balança analítica e um cronômetro. Obteve-se essa medição durante 5 minutos e calculou-se a média de biomassa alimentada por minuto;

- O mesmo procedimento foi realizado para as rotações de 40, 60, 80 e $100 \%$ dos motores dosador e alimentador.

\subsection{RESULTADOS E DISCUSSÃO}

O comportamento da vazão mássica de biomassa $(\mathrm{g} / \mathrm{min})$ em função da rotação do motor (\%) da rosca alimentadora (SIC02B) é apresentado na Tabela 6.1 e na Figura 6.3 para os motores 1 e 2 . Para uma rotação máxima (100\%), obteve-se vazão de 17,9 g/min para o motor 1 e 7,42 g/min para o motor 2. Assim, a substituição dos motores do sistema de alimentação da planta resolveu, em partes (isso será detalhado posteriormente nos experimentos de gaseificação), o problema de travamento durante a alimentação de biomassa, mas em contrapartida reduziu para cerca de $41,5 \%$ da alimentação inical (motor 1). 
Tabela 6.1 - Vazões mássicas médias de Eucalyptus grandis $(\mathrm{g} / \mathrm{min})$ em função da rotação dos motores alimentadores (SIC02B) dos sistemas de alimentação 1 e 2.

$\begin{array}{ccc}\begin{array}{c}\text { Rotação } \\ (\%)\end{array} & \begin{array}{c}\text { Motor 1 } \\ \text { Vazão Média } \\ (\mathrm{g} / \mathrm{min})\end{array} & \begin{array}{c}\text { Motor 2 } \\ \text { Vazão média } \\ (\mathrm{g} / \mathrm{min})\end{array} \\ 20 & 3,1 & 1,93 \\ 40 & 6,6 & 4,19 \\ 60 & 10,7 & 5,16 \\ 80 & 14,1 & 6,7 \\ 100 & 17,9 & 7,42\end{array}$

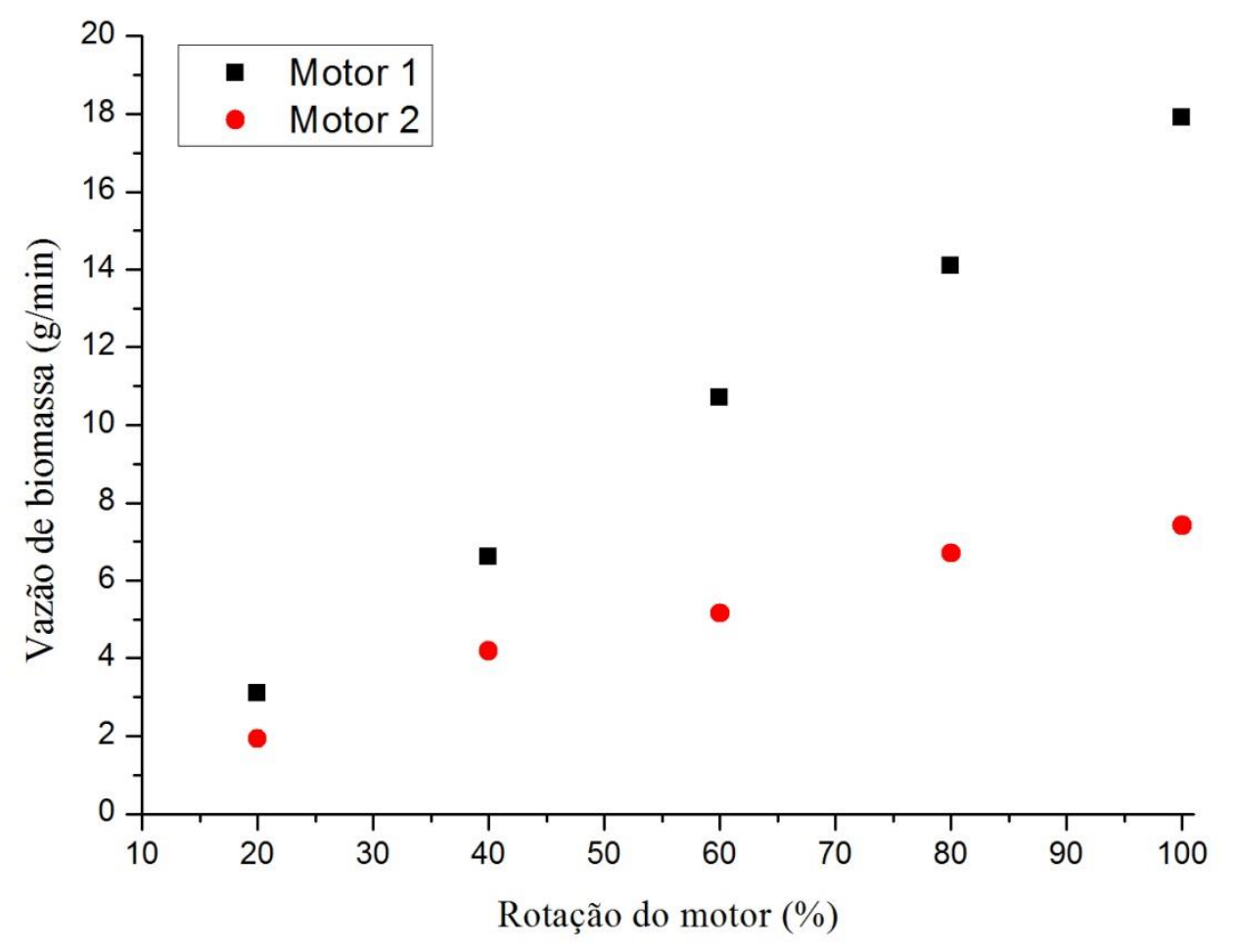

Figura 6.3 - Calibração de Eucalyptus grandis para os sistemas de alimentação 1 e 2.

\subsection{CONSIDERAÇÃO FINAL}

Por meio dos testes de calibração observou-se que a vazão de alimentação de biomassa (g/min) tem um comportamento linear em função da rotação dos motores do sistema de alimentação. O motor 2 possui uma alimentação reduzida para 41,5\% da máxima que foi projetada pela empresa construtora do equipamento. É importante destacar que a razão de equivalência é um parâmetro que depende da vazão de alimentação de biomassa e do agente de fluidização. Este, por sua vez, principalmente levando-se em conta a gaseificação 
utilizando ar como agente fluidizante, tem uma relação muito forte com a fluidização do leito de partículas sólidas. Posto isso, uma alimentação reduzida faz com que os parâmetros utilizados para o leito de partículas sólidas e a vazão de alimentação do gás de fluidização tenham que ser adequados à baixa alimentação de biomassa, o que de certa forma reduz a aplicabilidade da planta piloto de gaseificação e pirólise, implicando negativamente na variação de parâmetros de processos. 


\section{ENSAIOS DE FLUIDIZAÇÃO}

O ensaio consiste em determinar a perda de carga no leito de partículas sólidas em função da vazão do agente de fluidização, sendo fundamental para caracterizar os regimes de fluidização e determinar a faixa de operação de vazão do gás utilizado para fluidizar as partículas do leito. O objetivo do teste foi avaliar o comportamento da fluidização às temperaturas ambiente e de gaseificação $\left(800^{\circ} \mathrm{C}\right)$ para ar, nitrogênio e vapor. Como material do leito foi utilizado $1 \mathrm{~kg}$ quartzo ocre mesh 30 (diâmetro característico de aproximadamento $0,6 \mathrm{~mm})$.

\subsection{METODOLOGIA EXPERIMENTAL}

O reator possui três transdutores de pressão, PIA01, PI02 e PDT03, como mostrado na Figura 7.1. O transdutor PDT03 mede o diferencial de pressão entre a região do leito, saída da placa distribuidora (responsável pela injeção do agente fluidizante no reator), e o topo do reator $\left(\Delta P_{1}\right)$, região ideal para caracterização dos regimes de fluidização. Mas o fato de o transdutor estar localizado na região do leito faz com que componentes sólidos (material do leito, biomassa) e gasosos causem entupimento do mesmo, o que acarreta em incerteza na medição do diferencial de pressão inviabilizando a sua utilização. O transdutor PIA01 mede a pressão na entrada do distribuidor, e o transdutor PI02 mede a pressão no topo da região freeboard. Assim, é possível obter a perda de carga conferida ao gás de fluidização da entrada do distribuidor em relação ao topo da região freeboard $\left(\Delta P_{1}+\Delta P_{2}\right)$.

Para determinar a perda de carga que o leito de partículas sólidas confere ao gás de fluidização $\left(\Delta P_{L}\right)$, são necessários dois ensaios experimentais para cada agente de fluidização. O primeiro ensaio é com o reator vazio (sem leito), determinando-se a perda de carga da entrada do distribuidor até o topo do reator $\left(\Delta P_{1}+\Delta P_{2}\right)$, onde tem-se assim a perda de carga conferida ao gás pelo distribuidor $\left(\Delta P_{D}\right)$. O segundo ensaio é com o leito de partículas sólidas, ou seja, determinando-se a perda de carga total $\left(\Delta P_{T}\right)$ da entrada do distribuidor ao topo da região freeboard $\left(\Delta P_{1}+\Delta P_{2}\right)$. Neste segundo caso, está também embutida a perda de carga relativa ao distribuidor, assim, faz-se necessário subtrair da perda de carga total $\left(\Delta P_{T}\right.$ do segundo ensaio) a perda de carga relativa ao distribuidor $\left(\Delta P_{D}\right.$ do primeiro ensaio) para obterse a perda de carga relativa apenas ao leito. 

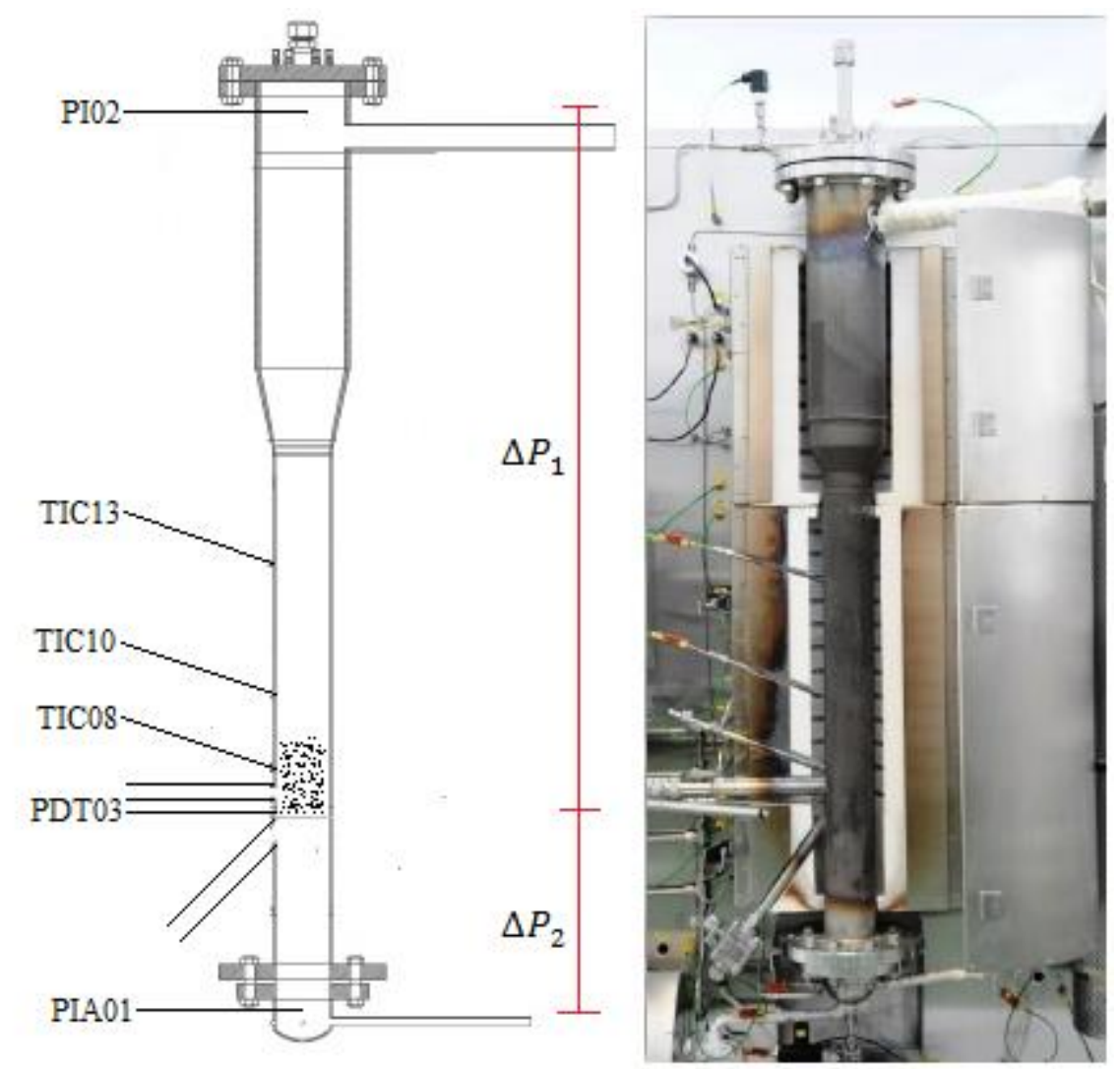

Figura 7.1 - Sistema de reação em leito fluidizado e transdutores de pressão PIA01, PDT03 e PI02. Adaptado de PID Eng \& Tech $^{48}$

Os ensaios de fluidização para os agentes de gaseificação ar, nitrogênio e vapor foram conduzidos seguindo os seguintes passos, em ambos os casos com leito e sem leito de partículas sólidas:

- Variou-se a vazão do agente de fluidização dentro do range estabelecido na Tabela 7.1, de 3 em $3 \mathrm{~L} / \mathrm{min}$ ( $3 \mathrm{~mL} / \mathrm{min}$ no caso do vapor), mantendo cada vazão por 3 minutos para estabilização do controlador de fluxo mássico e garantia de fluxo em estado estacionário. A análise foi realizada aumentando-se (ida) e diminuindo-se (volta) a vazão;

Tabela 7.1 - Faixa de vazão para os ensaios de fluidização.

\begin{tabular}{|c|c|c|c|} 
& $\operatorname{Ar}(\mathrm{L} / \mathrm{min})$ & Nitrogênio (L/min) & Vapor (mL/min) \\
\hline $\mathrm{T}$ (amb) & $0-99$ & $0-99$ & ------ \\
\hline $\mathrm{T}$ (gaseif.) & $0-36$ & $0-39$ & $0-48$ \\
\hline
\end{tabular}

- Os dados foram adquiridos em intervalos de 12 segundos; 
- Análise gráfica: determinou-se a perda de carga média no intervalo de 3 minutos avaliado.

\subsection{RESULTADOS E DISCUSSÃO}

\subsubsection{Teste de fluidização com ar comprimido}

A Figura 7.2a apresenta o comportamento da perda de carga no leito em função da vazão de ar com o reator em condição de temperatura ambiente, aumentando-se (incremento positivo) e reduzindo-se (incremento negativo) a vazão de ar, respectivamente. Observa-se que à temperatura ambiente o comportamento da perda de carga no leito é similar ao descrito na literatura, onde em baixas vazões (entre 0 e $30 \mathrm{~L} / \mathrm{min}$ ) a perda de carga aumenta de forma linear (diretamente proporcional a velocidade do gás), caracterizando um regime de leito fixo onde o gás apenas percola o leito afastando algumas partículas. Quando a condição de mínima fluidização é atingida, entre as vazões de 35 e $41 \mathrm{~L} / \mathrm{min}$, a perda de carga no leito não varia com o aumento da vazão de ar. Novos incrementos de velocidade do gás representam outros regimes de fluidização, como slug, turbulento por exemplo, porém esses regimes não foram caracterizados, pois o objetivo do teste foi obter a vazão mínima de fluidização do leito.

À temperatura de gaseificação (entre 700 e $800{ }^{\circ} \mathrm{C}$ na região do leito), Figura $7.2 \mathrm{~b}$ (incremento positivo e negativo respectivamente), tem-se que a região de fluidização ocorre em vazões menores do agente de gaseificação em comparação à temperatura ambiente. Este fato ocorre devido a expansão do gás de fluidização com o aumento da temperatura do mesmo. Devido à instabilidade do controlador de vazões, não é possível caracterizar a região entre 0 e $6 \mathrm{~L} / \mathrm{min}$ (o controlador não consegue estabilizar nessas vazões), mas nota-se que a partir da vazão de $6 \mathrm{~L} / \mathrm{min}$ a perda de carga se mantém constante com o aumento da vazão de ar, apresentando comportamento de fluidização típico de processo em leito fluidizado. Assim, pode-se considerar que a partir desta vazão o leito de quartzo se comporta como um leito fluidizado clássico.

\subsubsection{Teste de fluidização com vapor d'água}

A Figura 7.2c apresenta o perfil da perda de carga no leito em função da vazão de vapor d'água com o reator em condição de temperatura de gaseificação (entre 700 e $800{ }^{\circ} \mathrm{C}$ ), inicialmente aumentando a vazão de vapor (incremente posivito), e posteriormente diminuindo a vazão de vapor (incremento negativo). Observa-se que em baixas vazões (entre 0 e $6 \mathrm{~mL} / \mathrm{min}$ ) a perda de carga possui um certo comportamento linear, o que caracteriza um 
regime de leito fixo. A partir de uma vazão de $12 \mathrm{~mL} / \mathrm{min}$ o aumento da vazão de vapor não provoca grandes aumentos na perda de carga relativa ao leito, assim, considera-se que a condição de fluidização é atingida.
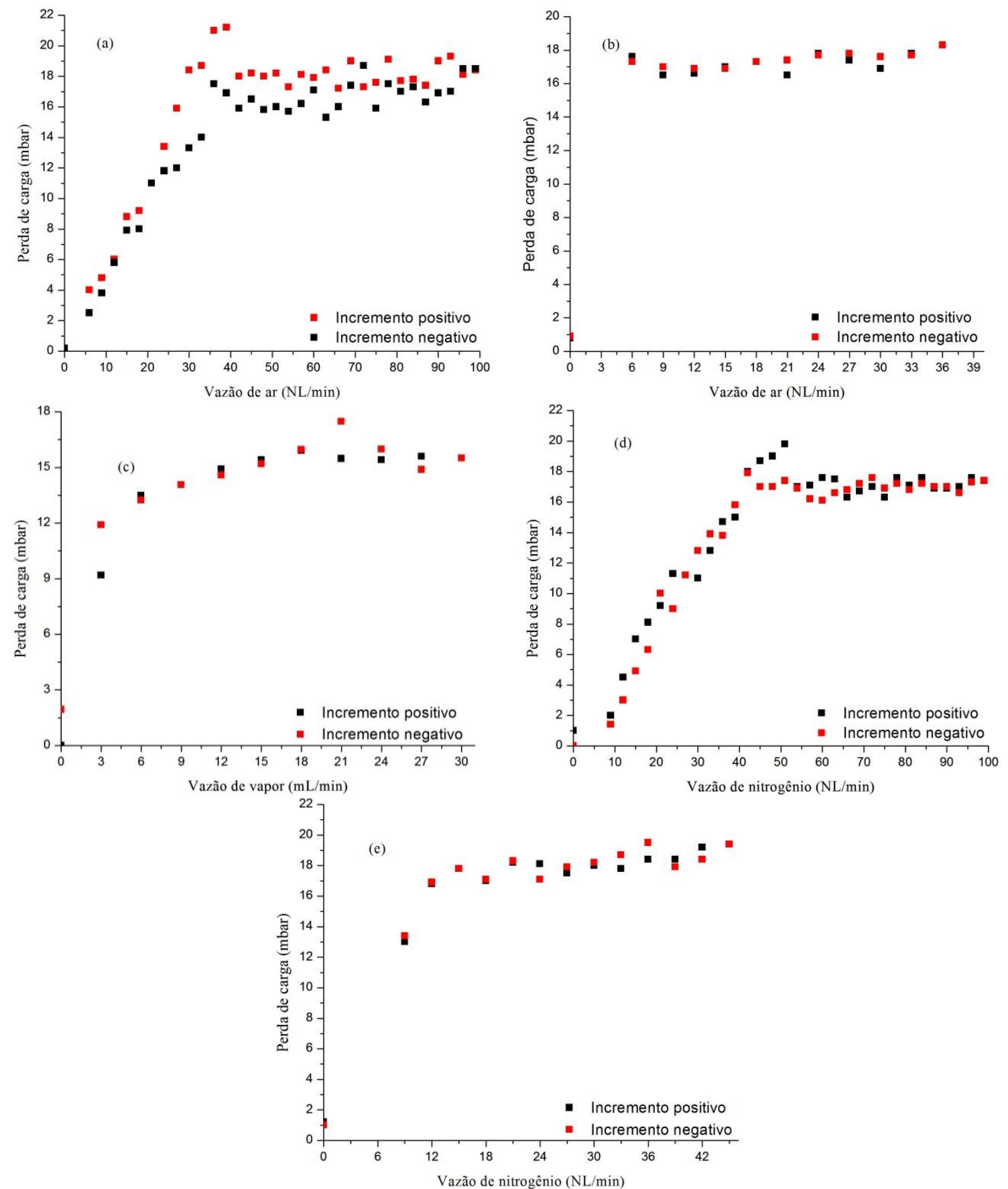

Figura 7.2 - Perda de carga de leito de quartzo ocre mesh $30(1 \mathrm{~kg})$ em função da vazão de alimentação do agente de fluidização: a) ar à temperatura ambiente b) ar à temperatura de gaseificação c) vapor d'água à temperatura de gaseificação d) nitrogênio à temperatura ambiente e) nitrogênio à temperatura de gaseificação. 


\subsubsection{Teste de fluidização com nitrogênio}

A Figura 7.2d mostra o comportamento da perda de carga no leito em relação à vazão superficial de nitrogênio com o reator em condição de temperatura ambiente, inicialmente aumentando a vazão de nitrogênio (incremento positivo), e posteriormente diminuindo a vazão de nitrogênio (incremento negativo). Observa-se que a partir de vazões entre 49 e 52 NL/min a perda de carga se mantém constante com o aumento da vazão de ar, apresentando comportamento de fluidização típico de processo em leito fluidizado.

A Figura 7.2e mostra o comportamento da perda de carga no leito em relação à vazão superficial de nitrogênio com o reator em condição de temperatura de gaseificação (entre 700 e $800{ }^{\circ} \mathrm{C}$ ). Devido à instabilidade do controlador de vazões, não é possível caracterizar a região entre 0 e $9 \mathrm{NL} / \mathrm{min}$ (o controlador não consegue estabilizar nessas vazões), mas nota-se que a partir da vazão de $12 \mathrm{NL} / \mathrm{min}$ a perda de carga se mantém constante com o aumento da vazão de ar, apresentando comportamento de fluidização típico de processo em leito fluidizado.

\subsection{CONSIDERAÇÃO FINAL}

A determinação da região de fluidização é um parâmetro básico fundamental para que se tenha um planejamento experimental visando determinar a melhor condição de produção de gás, pois garante que o leito trabalha em regime de fluidização. A Tabela 7.2 mostra as vazões de ar, vapor e nitrogênio em que o leito de quartzo está em condição de fluidização. Verificou-se que a condição de fluidização com ar é menor do que com nitrogênio, tanto à temperatura ambiente quanto à temperatura de gaseificação, o que torna o ar bem atrativo avaliando apenas a fluidização, já que o nitrogênio tem um custo elevado. Com relação ao vapor, $12 \mathrm{~mL} / \mathrm{min}$ é suficiente para fluidizar o leito.

Tabela 7.2 - Agentes de fluidização e suas respectivas vazões com o leito de quartzo em estado de fluidização à temperatura ambiente e de gaseificação.

$\begin{array}{lll}\begin{array}{l}\text { Agente de } \\ \text { fluidização }\end{array} & \text { Temperatura }\left({ }^{\circ} \mathrm{C}\right) & \begin{array}{l}\text { Vazão em condição de fluidização } \\ (\mathrm{NL} / \mathrm{min})\end{array} \\ \mathrm{Ar} & \text { ambiente } & 35-41 \\ \text { Vapor } & \text { gaseificação } & 6 \\ \text { Nitrogênio } & \text { gaseificação } & 12(\mathrm{~mL} / \mathrm{min}) \\ & \text { ambiente } & 49-52 \\ & \text { gaseificação } & 12\end{array}$




\section{EXPERIMENTOS PARA PRODUÇÃO DE GÁS COMBUSTÍVEL}

Nesta seção serão apresentados e discutidos a metodologia e os resultados experimentais dos processos de produção de gás combustível obtido a partir da conversão termoquímica de Eucalyptus grandis para os agentes de fluidização ar e vapor e nitrogênio. Para cada agente de fluidização foram realizados experimentos com diferentes vazões do agente nas mesmas condições de temperatura do reator, objetivando assim determinar a melhor condição experiemental em cada agente de fluidização e posteriormente o melhor agente de fluidização a ser utilizado na produção de gás combustível.

O objetivo inicial do trabalho era avaliar o potencial de produção de gás combustível a partir de processo de conversão termoquímica de Eucalyptus grandis utilizando vários agentes de fluidização. Devido a problemas operacionais da planta piloto de gaseificação e pirólise, não foi possível realizar experimentos de gaseificação com dióxido de carbono e misturas ar-vapor e nitrogênio-vapor. Assim, a título de comparação com os resultados experimentais obtidos da gaseificação com ar e vapor d'água, optou-se por realizar um processo de produção de gás utilizando nitrogênio nas mesmas condições operacionais dos agentes ar e vapor.

Segundo bibliografia pesquisada, o processo de gaseificação às temperaturas mais elevadas $\left(1000-1100{ }^{\circ} \mathrm{C}\right)$ possibilita a obtenção de um gás produto com menor teor de alcatrão e maior concentração de gases com caráter combustível. A planta piloto da Embrapa Agroenergia possui aquecimento por resistência elétrica e foi projetada para trabalhar à temperaturas próximas de $800{ }^{\circ} \mathrm{C}$ no sistema de reação. $\mathrm{O}$ sistema de alarme da planta é acionado quando a temperatura no sistema de reação alcança 1000 ${ }^{\circ} \mathrm{C}$, o que impossibilita que experimentos com temperaturas mais elevadas sejam realizados. Sendo assim, optou-se por realizar os experimentos a temperatura de $800{ }^{\circ} \mathrm{C}$.

\subsection{METODOLOGIA EXPERIMENTAL}

Os experimentos de produção de gás combustível a partir de biomassa florestal foram realizados com os agentes de fluidização ar, vapor d'água e nitrogênio em um sistema de reação em leito fluidizado, e como material do leito foi utilizado quartzo ocre mesh 30. 
Nos processos de gaseificação com ar foram realizados experimentos de produção de gás combustível com seis condições de razão de equivalência (RE), afim de obter o valor de RE que apresenta a melhor condição de produção de gás combustível. A vazão mínima de fluidização do leito utilizando-se ar foi determinada experimentalmente (ensaios de fluidização) como sendo de $6 \mathrm{NL} / \mathrm{min}$ na temperatura de gaseificação $\left(800^{\circ} \mathrm{C}\right)$. Para que RE esteja na faixa entre 0,2 e 0,4 , garantindo assim que o processo de fato seja gaseificação, a vazão de ar deverá estar na faixa de 7 a 13 $\mathrm{NL} / \mathrm{min}$ (esta faixa garante que o leito está em condição de fluidização e que o regime pneumático não foi atingido). Assim, realizou-se os experimentos para esta faixa de vazão, e a partir da vazão de alimentação média de biomassa na gaseificação, calculouse os respectivos valores de RE. A Tabela 8.1 apresenta os valores de RE utilizados nos experimentos de gaseificação com ar. Cada condição experimental de RE foi mantida durante 50 minutos.

Tabela 8.1 - Vazões de ar e biomassa (média) e razões de equivalência utilizados no processo de gaseificação de Eucalyptus grandis utilizando ar como agente de fluidização.

\begin{tabular}{ccc|} 
Vazão de ar (L/min) & $\begin{array}{c}\text { Vazão média de } \\
\text { biomassa (g/min) }\end{array}$ & $\mathrm{RE}$ \\
\hline 7 & 5,69 & 0,23 \\
8 & 5,95 & 0,26 \\
9 & 5,95 & 0,28 \\
10 & 5,95 & 0,31 \\
12 & 5,95 & 0,37 \\
13 & 5,95 & 0,40 \\
\hline
\end{tabular}

Para os processos de gaseificação utilizando vapor d'água como agente de fluidização, observou-se por meio de ensaio de fluidização que em uma vazão de 12 $\mathrm{mL} / \mathrm{min}$ tem-se condição de fluidização para $1 \mathrm{~kg}$ de leito de quartzo ocre mesh 30 . Assim, definiu-se como faixa de vazões de vapor a serem utilizadas as vazões apresentadas na Tabela 8.2 (partindo-se da vazão mínima de fluidização até valores superiores garantindo que o leito não estava em regime pneumático), e após o processo, obtendo-se a média de biomassa alimentada, foi possível determinar a razão vapor/biomassa (SBR) real do processo. Tais valores são apresentados na Tabela 8.2, onde cada condição experimental de SBR foi mantida durante 50 minutos. 
Tabela 8.2 - Vazões de vapor e biomassa (média) e razões vapor/biomassa utilizados no processo de gaseificação de Eucalyptus grandis utilizando vapor como agente de fluidização.

\begin{tabular}{ccc} 
Vazão de vapor (mL/min) & $\begin{array}{c}\text { Vazão média de } \\
\text { biomassa (g/min) }\end{array}$ & SBR \\
\hline 12 & 6,81 & 1,69 \\
14 & 6,81 & 1,97 \\
16 & 6,81 & 2,25 \\
18 & 6,81 & 2,53 \\
20 & 6,81 & 2,81 \\
22 & 6,81 & 3,10 \\
24 & 6,81 & 3,38
\end{tabular}

Nos testes utilizando nitrogênio como agente de fluidização, considerou-se que o leito de quartzo está em condição de fluidização a partir de uma vazão de $12 \mathrm{NL} / \mathrm{min}$. Assim, foram realizados experimentos com as vazões de nitrogênio mostradas na Tabela 8.3 .

Tabela 8.3 - Vazões de nitrogênio e biomassa (média) no processo de conversão termoquímica de Eucalyptus grandis utilizando nitrogênio como agente de fluidização.

\begin{tabular}{cc|}
$\begin{array}{c}\text { Vazão de nitrogênio } \\
\text { (NL/min) }\end{array}$ & $\begin{array}{c}\text { Vazão média de biomassa } \\
(\mathrm{g} / \mathrm{min})\end{array}$ \\
12 & 8,94 \\
14 & 8,94 \\
16 & 8,94 \\
18 & 8,94 \\
20 & 8,94 \\
\hline
\end{tabular}

A Figura 8.1 apresenta o esquema de funcionamento da planta piloto de pirólise e gaseificação. A planta foi dividida em 14 pontos principais para facilitar a compreensão (Tabela 8.4), e os números correspondem aos sistemas apresentados na Figura 8.1. As tubulações de passagem do gás possuem resistência elétrica para aquecimento e cada tubulação tem o seu respectivo termopar (TIC - sensor de temperatura) responsável pela medição de temperatura na determinada região. 
Tabela 8.4 - Sistemas e equipamentos presentes na planta piloto de pirólise e gaseificação.

$\begin{array}{ll}\text { Número } & \text { Sistema correspondente na planta piloto } \\ 1 & \text { Alimentação de gás } \\ 2 & \text { Alimentação de líquido } \\ 3 & \text { Alimentação de biomassa } \\ 4 & \text { Reação em leito fluidizado } \\ 5 & \text { Separação de sólidos (ciclone 1) } \\ 6 & \text { Separação de sólidso (ciclone 2) } \\ 7 & \text { Amostragem de gás produto } \\ 8 & \text { Condensação } \\ 9 & \text { Banho termostático } \\ 10 & \text { Filtragem } \\ 11 & \text { Amostragem (analisador de gases) } \\ 12 & \text { Lavagem de gases } \\ 13 & \text { Medição de fluxo gasoso } \\ 14 & \text { Queima }\end{array}$

Os experimentos de gaseificação foram realizados em quatro dias. No primeiro dia, o experimento realizado com ar consistiu em avaliar as razões de equivalência 0,23 (7 NL/min) e 0,34 (11 NL/min), mas apenas os resultados para $\mathrm{RE}=0,23$ foram satisfatórios. No segundo dia de experimentos, realizou-se gaseificação com ar avaliando as $\mathrm{RE}$ de $0,26,0,28,0,31,0,37$ e 0,40 . No terceiro dia, os experimentos foram realizados para todas as condições de vapor $(1,69,1,97,2,25,2,53,2,81,3,10$ e 3,38). E no último dia realizou-se todos os procedimentos experimentais com nitrogênio. Os experimentos eram iniciados na menor vazão do agente de fluidização, e após a estabilização da composição de gás (50 a 60 minutos), a vazão era aumentada. Em resumo, os experimentos de gaseificação foram realizados da seguinte forma:

- Adição de leito de quartzo ocre mesh 30 ao sistema de reação;

- Pressurização do sistema de alimentação de biomassa, por meio da adição de 3 NL/min de nitrogênio na câmara de expansão (item 6 na Figura 5.3);

- Aquecimento do sistema de alimentação de gás (TIC01) e da linha de adição de gás (TIC05) até temperatura de $400{ }^{\circ} \mathrm{C}$ para o processo com ar e nitrogênio, e aquecimento do sistema de alimentação de vapor (TIC03) e da linha de adição de vapor (TIC06) até temperatura de $200{ }^{\circ} \mathrm{C}$ para a gaseificação com vapor.

- Adição de $35 \mathrm{NL} / \mathrm{min}$ de ar para fluidização das partículas do leito em temperatura ambiente. Ao longo do aquecimento do sistema de reação e do 
sistema de alimentação de gás, a vazão de ar para fluidização do leito era reduzida, conforme apresentado nos ensaios de fluidização. A fluidização do leito para os processos com vapor e nitrogênio foi realizada inicialmente com ar, e após o aquecimento a mudança de agente era realizada;

- Aquecimento do sistema de reação durante 2 horas até a temperatura de $800{ }^{\circ} \mathrm{C}$. Os termopares TIC 08, 10 e 13 medem a temperatura na região do leito;

- Aquecimento das linhas e tubulações pelo qual o gás irá passar durante todo o processo, conforme listados na Tabela 8.5:

Tabela 8.5 - Temperatura setada para os termopares (TIC) apesentados na Figura 8.1 durante processo de produção de gás.

$\begin{array}{lcc}\text { Termopar (TIC) } & \begin{array}{c}\text { Temperatura de set point na } \\ \text { resistência de aquecimento } \\ \left({ }^{\circ} \mathrm{C}\right)\end{array} \\ \text { Ar e nitrogênio } & 01 \text { e } 05 & 400 \\ \text { Vapor d'água } & 03 \text { e } 06 & 200 \\ \text { Reator } & 08,10 \text { e } 13 & 800 \\ \text { Tubulação } & 15 \text { a } 19 & 200 \\ \text { Condensador } & 20 & 30 \\ \text { Tubulação } & 21 & 200\end{array}$

- Adição de $350 \mathrm{~g}$ de biomassa ao sistema de alimentação. O resfriamento do sistema de alimentação foi realizado com água à temperatura ambiente;

- Após duas horas de aquecimento do sistema e do agente de fluidização, dava-se início ao processo de gaseificação.

- A alimentação de biomassa (previamente seca a $105^{\circ} \mathrm{C}$ ) foi feita com o sistema de alimentação funcionando a $100 \%$ de rotação dos motores de agitação, dosagem e alimentação. A cada 40 ou 50 minutos de experimento era realizada nova alimentação de 250 a 300 g de biomassa;

- Variou-se os agentes de fluidização ar, vapor d'água e nitrogênio segundo as Tabelas 8.1, 8.2 e 8.3, respectivamente. Cada condição de vazão de cada agente era mantida na faixa de 50 a 60 minutos para estabilização da condição e análise dos resultados experimentais de cada condição estabilizada;

- Após iniciada a gaseificação, o fluxo de gás produzido passa pelas seguintes etapas:

- Separação de sólidos (carvão, partículas do leito e cinzas) nos ciclones 1 e 2. Os sólidos são recolhidos em um recipente logo abaixo dos ciclones; 
- Condensação de água e alcatrão no condensador. Os gases condesáveis passam por um sistema de condensação, que tem etanol como líquido de resfriamento (LR), e são recolhidos em um recipiente abaixo do sistema de condensação.

- Separação de particulado em filtro de papel.

- Lavagem com água para retirada principalmente de alcatrão, particulado e $\mathrm{H}_{2} \mathrm{~S}$;

- Análise do gás pelo sistema de análise de gases;

○ Medição do fluxo de gás;

○ Liberação do gás área externa;

- A aquisição de dados do gaseificador (software Process@) e do analisador de gases (software SOPAS) foi realizada por meio de medições a cada 5 segundos. 


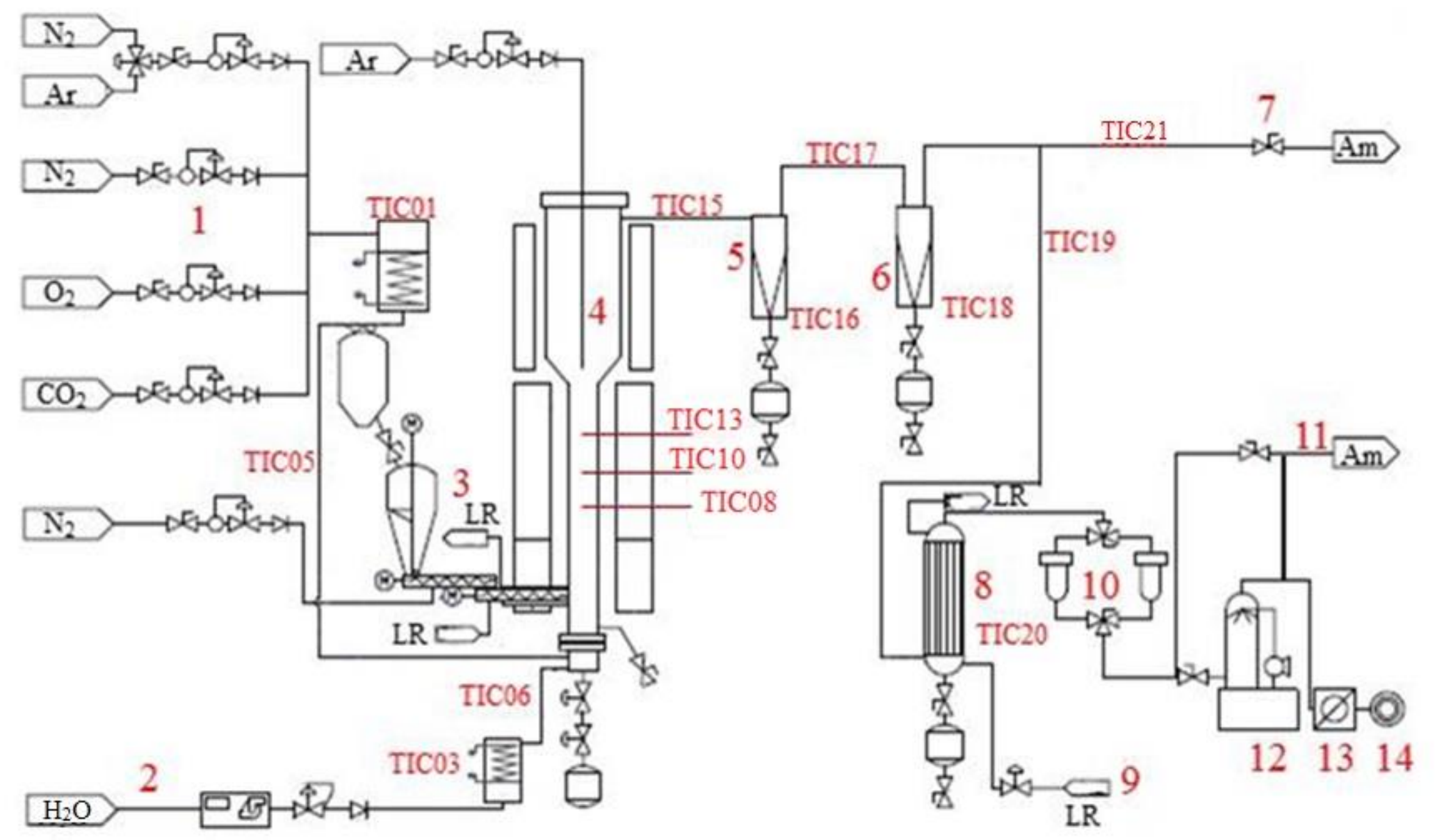

Figura 8.1 - Esquema de funcionamento da planta piloto de pirólise e gaseificação da Embrapa Agroenergia. Adaptado de PID Eng \& Tech $^{48}$. 


\subsection{RESULTADOS E DISCUSSÃO}

Nas próximas seções serão apresentados e discutidos os resultados experimentais para os processos de produção de gás combustível a partir de conversão termoquímica de Eucalyptus grandis utilizando os agentes de fluidização ar, vapor d'água e nitrogênio. Serão apresentados os perfis de temperatura do agente de fluidização durante os experimentos, ou seja, os TIC01 e TIC05 para o ar e o nitrogênio e os TIC03 e TIC06 para o vapor d'água, a perda de carga sofrida pelo leito durante cada processo, e as temperaturas do reator (TIC08, TIC10 e TIC13).

Serão apresentados também os perfis percentuais dos gases produzidos $\left(\mathrm{H}_{2}, \mathrm{CO}\right.$, $\mathrm{CH}_{4}, \mathrm{CO}_{2}, \mathrm{H}_{2} \mathrm{~S}$ ) nos experimentos realizados com os três agentes de fluidização (ar, vapor e nitrogênio) em função do tempo de processo para cada condição experimental apresentada nas Tabelas 8.1, 8,2 e 8.3. Um comporativo entre as médias percentuais dos mesmos componentes gasosos para determinação da melhor condição experimental de cada agente de fluidização e o poder calorífico inferior médio (em $\mathrm{MJ} / \mathrm{kg}$ e $\mathrm{MJ} / \mathrm{m}^{3}$ ) para cada condição experimental de cada agente de fluidização será realizado.

Os gráficos contendo as composições em percentagem e vazão mássica em função do tempo de cada gás formado bem como o fluxo total de gás formado (NL/min) são mostrados nos Apêndices 1 (ar), 2 (vapor) e 3 (nitrogênio).

\subsubsection{Avaliação de temperatura e pressão para os processos com ar, vapor e nitrogênio}

Como o gás produzido passa pela torre de lavagem de gases com água, tem-se que esperar um tempo de resposta para a leitura do gás no sistema de análise de gases. Esse tempo de resposta depende da vazão de gás produto, quanto maior a vazão menor o tempo de resposta no analisador de gases. Assim, para cada condição experimental mostrada neste capítulo, os perfis apresentados consideram apenas a produção de gás estabilizada, ou seja, esperou-se o tempo de resposta do analisador e plotou-se os perfis de temperatura, pressão e composição do gás (seção seguinte) já em condição de estabilização.

A Figura 8.2 apresenta a perda de carga no leito em função do tempo de processo estável para cada condição do agente de fluidização. Como foi mencionado, cada condição experimental analisada de cada agente de fluidização foi mantida durante 50 minutos, neste tempo, algumas condições se estabilizaram mais rapidamente e outras 
têm um tempo de estabilização maior. Tomando como exemplo a Figura 8.2a, tem-se a perda de carga no leito em função das razões de equivalência analisadas na gaseificação com ar, no experimento com RE igual a 0,23 tem-se que dos 50 minutos de processo cerca de 10 minutos apresentaram condição estável de produção de gás (o processo demorou cerca de 40 minutos para estabilizar), já para RE igual a 0,28 cerca de 26 minutos, dos 50 minutos de experimento, apresentaram condição estável. Desta forma, optou-se por analisar cada condição experimental, para os três agentes de fluidização, em condição estável. Todos os gráficos apresentados daqui para frente irão considerar esta condição estável. Nota-se oscilação muito grande no processo utilizando o vapor d'água como agente de fluidização (Figura 8.2b) e um processo com perda de carga mais estável com o nitrogênio (Figura 8.2c).

A Figura 8.3 apresenta a temperatura de aquecimento do gás de fluidização em função do tempo de processo para cada condição experimental para os diferentes agentes de fluidização. Como foi apresentado nesta seção, os termopares TIC01 (termopar que mede a temperatura do agente de fluidização no aquecedor) e TIC05 (termopar que mede a temperatura do agente de fluidização na tubulação entre o aquecedor e o reator) são responsáveis pela medição da temperatura de adição dos agentes de fluidização ar e nitrogênio ao reator, e os valores de setpoint da temperatura de aquecimento desses gases foi de $400{ }^{\circ} \mathrm{C}$, porém, apenas a resistência do TIC05 trabalhou na temperatura determinada. A seção monitorada pelo TIC01 (indicador de temperatura do aquecedor dos agentes ar e nitrogênio) trabalhou à temperatura em torno de $275{ }^{\circ} \mathrm{C}$ para o processo com ar e em torno de $270{ }^{\circ} \mathrm{C}$ para o processo com nitrogênio. Já com relação à temperatura de adição do vapor d'água ao sistema de reação, apresentada na Figura 8.3b, as resistências da caldeira (TIC03) e da tubulação que leva o vapor da caldeira até o sistema de reação (TIC06) apresentaram oscilação no processo de aquecimento, trabalhando em temperaturas em torno de $150{ }^{\circ} \mathrm{C}$ e $250{ }^{\circ} \mathrm{C}$.

A Figura 8.4 apresenta os perfis de temperatura medidos pelos termopares TIC08, TIC10 e TIC13, localizados na região do leito do sistema de reação, em função do tempo de processo estável de produção de gás para os agentes de fluidização ar (8.4a), vapor (8.4b) e nitrogênio (8.5b). Na gaseificação com ar, observa-se que o termopar TIC08 apresentou medição de temperatura inferior (entre $720{ }^{\circ} \mathrm{C} \mathrm{e} 780{ }^{\circ} \mathrm{C}$ ) às temperaturas medidas nos termopares TIC10 e TIC13, que se mantiveram estáveis na temperatura de $800^{\circ} \mathrm{C}$. O TIC08 está localizado em uma região mais próxima da adição 
do agente de fluidização, logo, como o agente é adicionado a uma temperatura inferior à $800{ }^{\circ} \mathrm{C}$, este fato pode ter contribuído para que a temperatura nesta região tenha sido mais baixa. Na gaseificação com vapor, nota-se que a temperatura no TIC08 se manteve em torno de $700^{\circ} \mathrm{C}$ para os SBR de 2,25 até 3,38, mas apresentou temperatura menor (entre $700{ }^{\circ} \mathrm{C}$ e $600{ }^{\circ} \mathrm{C}$ ) para os dois primeiros SBR analisados. O TIC10 apresentou tendência de redução de temperatura com o aumento de SBR e o TIC13 se manteve estável à $800{ }^{\circ} \mathrm{C}$. Por fim, no processo de produção de gás com nitrogênio, o TIC13 apresentou redução de temperatura considerável em comparação com os outros processos, se manteve estável em $500{ }^{\circ} \mathrm{C}$, isto pode ter ocorrido devido ao fato de não haver agente oxidante no gás de fluidização. 

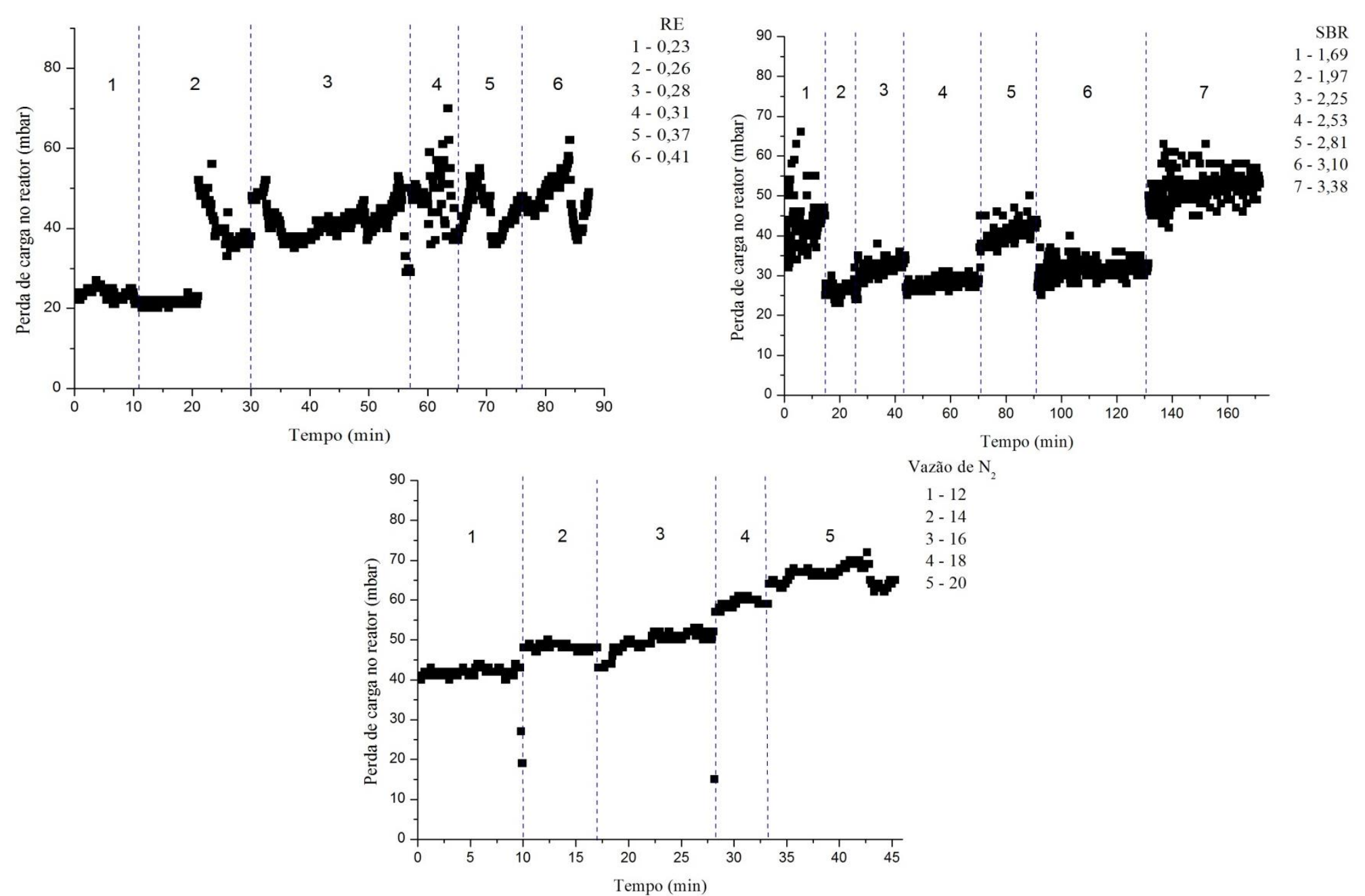

Figura 8.2 - Perda de carga no reator (mbar) em função do tempo de processo estável de produção de gás com os agentes de fluidização: a) ar, b) vapor e c) nitrogênio. 

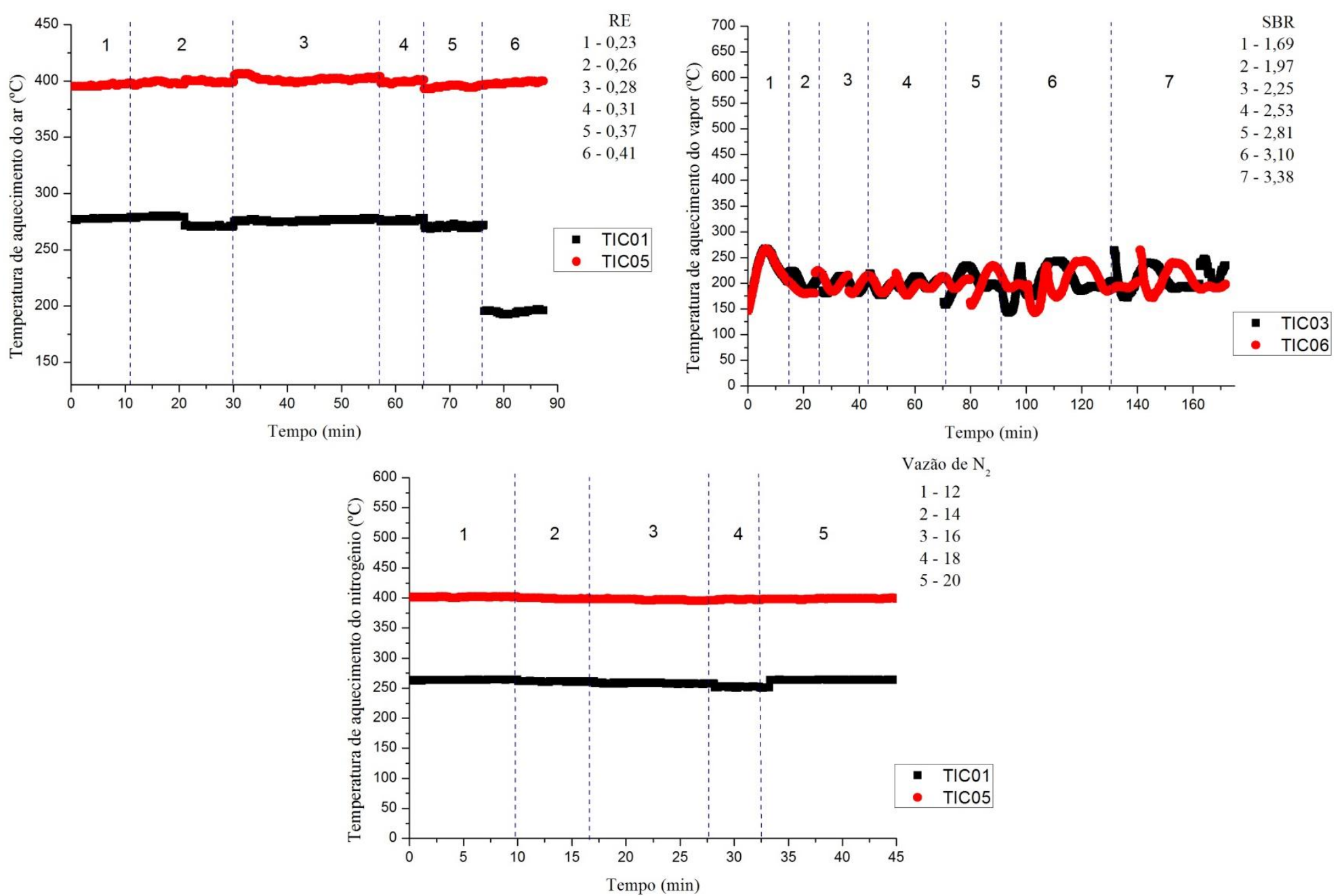

Figura 8.3 - Temperatura de aquecimento em função do tempo de processo estável de produção de gás com os agentes de fluidização: a) ar, b) vapor e c) nitrogênio. 

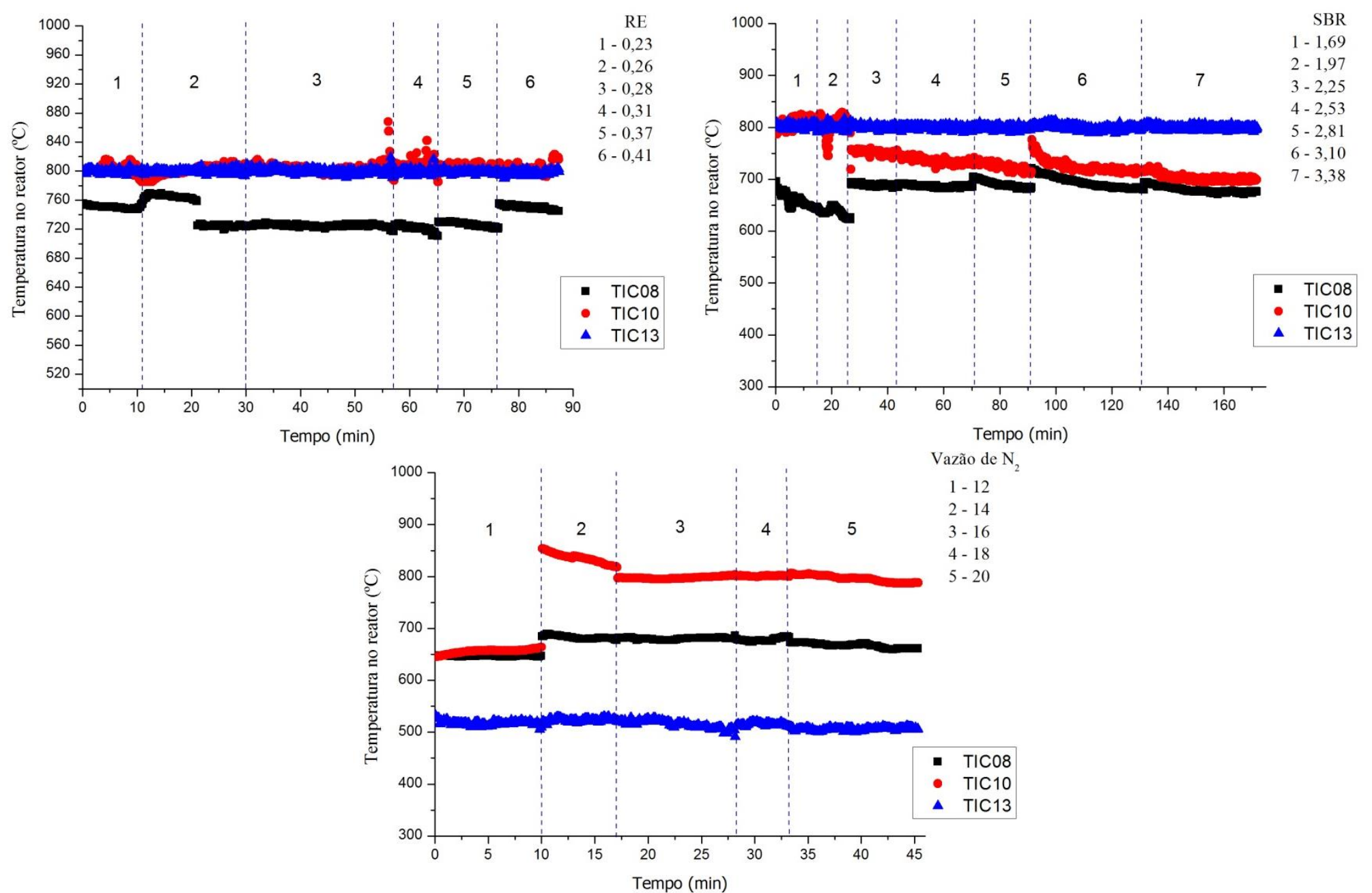

Figura 8.4 - Temperatura no reator em função do tempo de processo estável de produção de gás com os agentes de fluidização: a) ar, b) vapor e c) nitrogênio. 


\subsubsection{Gaseificação com ar comprimido}

\subsubsection{Apresentação dos resultados para cada razão de equivalência analisada}

A presente seção apresenta os resultados obtidos da gaseificação de Eucalyptus grandis para as razões de equivalência avaliadas (Tabela 8.1). Serão apresentados perfis de composição dos gases $\mathrm{H}_{2}, \mathrm{CO}, \mathrm{CH}_{4}, \mathrm{CO}_{2}$ e $\mathrm{H}_{2} \mathrm{~S}$, em percentagem (v/v), no gás produzido, em função do tempo estável de processo (min) para cada valor de $\operatorname{RE}(0,23$, 0,26, 0,28, 0,31, 0,37 e 0,40). Em cada perfil de composição de gás será apresentado valor médio de cada gás produzido.

A Figura 8.5a apresenta os resultados experimentais de composição do gás produto para RE igual a 0,23 . Nota-se que o $\mathrm{H}_{2} \mathrm{~S}$ apresentou comportamento estável, já os gases $\mathrm{CH}_{4}, \mathrm{H}_{2}$ e $\mathrm{CO}$ apresentaram uma ligeira queda e o $\mathrm{CO}_{2}$ um aumento gradativo com o tempo. O gás que apresentou maior concentração média em percentagem no gás formado foi o $\mathrm{CO}$, com $15,21 \%$, e os gases $\mathrm{CH}_{4}$ e $\mathrm{H}_{2}$ apresentaram composição média de $4,69 \%$ e $3,92 \%$, respectivamente.

Da Figura 8.5b observa-se comportamento estável dos gases $\mathrm{H}_{2} \mathrm{~S}, \mathrm{CH}_{4}, \mathrm{H}_{2}$ e $\mathrm{CO}_{2}$, e uma ligeira queda no $\mathrm{CO}$ para um RE de 0,26 . Os principais gases de interesse do ponto de vista de geração de energia, $\mathrm{H}_{2}, \mathrm{CO}$ e $\mathrm{CH}_{4}$, apresentaram composição média no gás formado de 4,52\%, 17,02\% e 5,05\%, respectivamente.

Para RE igual a 0,28 (Figura 8.5c) os gases $\mathrm{CO}_{2}$ e $\mathrm{H}_{2} \mathrm{~S}$ apresentaram comportamento estável, com a composição não variando com o tempo. Os gases $\mathrm{CH}_{4} \mathrm{e}$ $\mathrm{H}_{2}$ apresentaram perfis bem similares com uma tendência de queda na composição, e uma composição média de 4,10\% e 3,44\% respectivamente. Já o CO apresentou queda acentuada ao longo do processo, com produção média de $14,80 \%$.

O gás obtido do processo utilizando um valor de RE igual a 0,31 apresentou composição percentual estável dos gases $\mathrm{H}_{2} \mathrm{~S}, \mathrm{CH}_{4}, \mathrm{H}_{2}, \mathrm{CO}$ e $\mathrm{CO}_{2}$, com destaque para produção de $\mathrm{CO}\left(14,80 \%\right.$ em média). Os gases $\mathrm{H}_{2}$ e $\mathrm{CH}_{4}$ apresentaram produção média de $3,36 \%$ e $4,05 \%$.

Para o processo de gaseificação de Eucalyptus grandis utilizando RE igual a 0,37 (Figura 8.5e), o gás obtido apresentou composição percentual estável dos gases $\mathrm{H}_{2} \mathrm{~S}, \mathrm{CH}_{4}, \mathrm{H}_{2}, \mathrm{CO}$ e $\mathrm{CO}_{2}$, com o $\mathrm{CO}_{2}$ apresentando maior produção média em 
porcentagem $(12,79 \%)$. Para os gases $\mathrm{CO}, \mathrm{H}_{2}$ e $\mathrm{CH}_{4}$ obteve-se composição média de $13,13 \%, 2,57 \%$ e $3,37 \%$, respectivamente.

Por fim, o gás obtido do processo utilizando um valor de RE igual a 0,40 (Figura 8.5f) apresentou composição percentual estável dos gases $\mathrm{H}_{2} \mathrm{~S}, \mathrm{CH}_{4}, \mathrm{H}_{2}$ e $\mathrm{CO}_{2}$, com o $\mathrm{CO}$ apresentando redução a partir de 7 minutos de processo. Os gases $\mathrm{CO}$ e $\mathrm{CO}_{2}$ apresentaram percentual médio muito próximo, $12,70 \%$ e $13,05 \%$, respectivamente, e os gases $\mathrm{H}_{2}$ e $\mathrm{CH}_{4}$ apesentaram composição média de $2,38 \%$ e 3,15\%, respectivamente. 

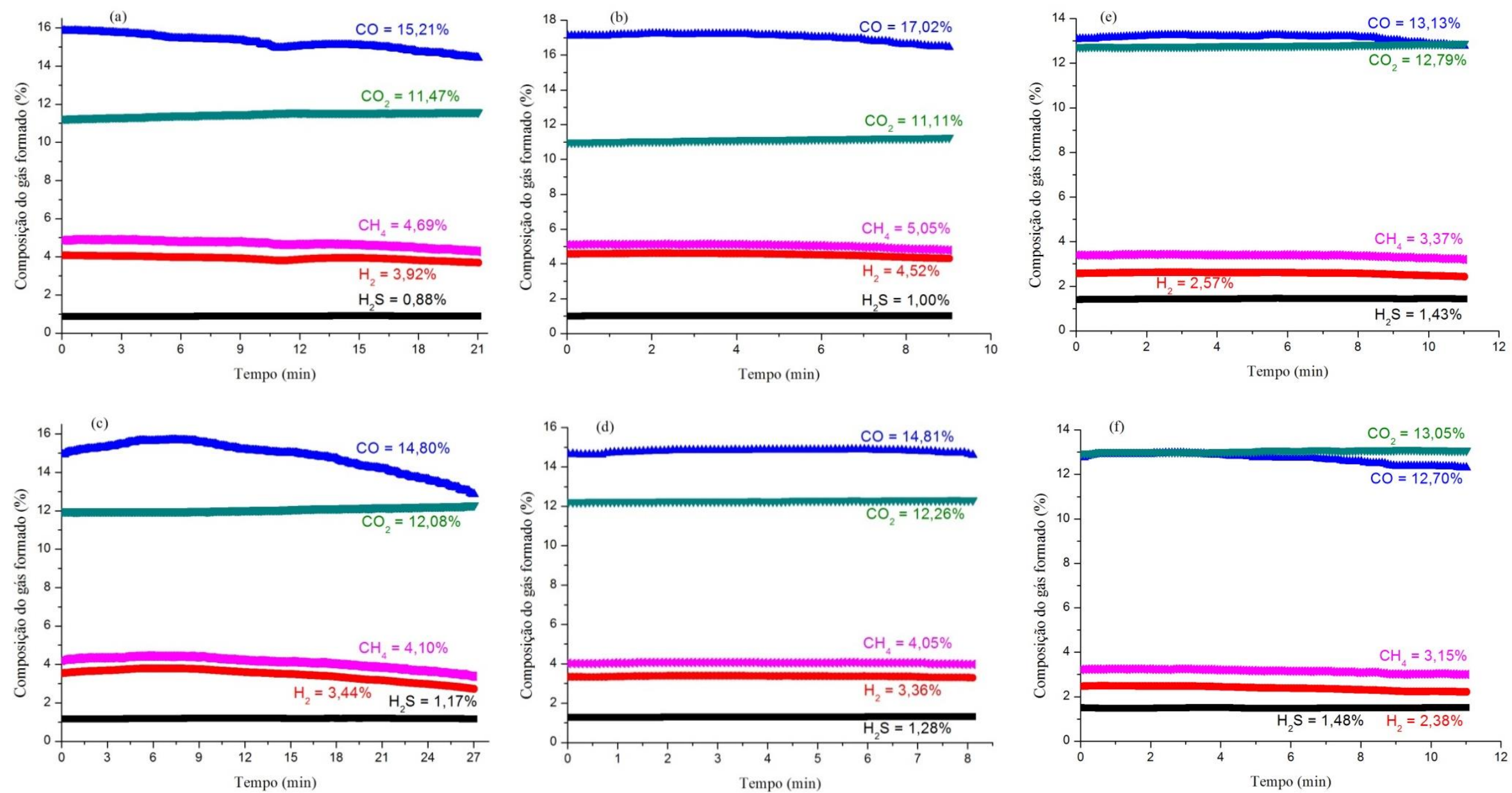

Figura 8.5 - Perfis de composição percentual dos de gases formados no processo de gaseificação de Eucalyptus grandis para (a) RE=0,23 (b) $\mathrm{RE}=0,26$ (c) $\mathrm{RE}=0,28$ (d) $\mathrm{RE}=0,31$ (e) $\mathrm{RE}=0,37$ (f) $\mathrm{RE}=0,40$ 


\subsubsection{Comparação entre as razões de equivalência}

A Figura 8.6 mostra uma comparação entre as composições médias, em percentagem, dos principais componentes gasosos formados no processo de gaseificação utilizando ar como agente de fluidização em função da razão de equivalência.

A razão de equivalência de 0,26 apresentou os maiores valores em percentagem para os principais gases de interesse levando-se em conta a aplicação do gás na geração de energia, produzindo em média 4,52\%, 17,02\% e 5,05\% de $\mathrm{H}_{2}, \mathrm{CO}$ e $\mathrm{CH}_{4}$, respectivamente. É interessante destacar que este mesmo valor de RE apresentou a menor produção de $\mathrm{CO}_{2}(11,11 \%)$ e a segunda menor produção de $\mathrm{H}_{2} \mathrm{~S}(1,00 \%)$, o que torna esta a melhor condição experimental para a gaseificação com ar.

Observa-se da Figura 8.6 que os gases $\mathrm{CO}, \mathrm{H}_{2}$ e $\mathrm{CH}_{4}$ apresentaram comportamento similar de produção média em função de RE, apresentando aumento na produção com o aumento de RE de 0,23 para 0,26 , e redução na produção com aumento de $\mathrm{RE}$ de 0,26 para 0,40. Como os experimentos foram realizados considerando-se a condição de mínima fluidização do leito ( $\mathrm{RE}=0,23$ e vazão de ar=7NL/min) até valores superiores ( $\mathrm{RE}=0,40$ e vazão de $\operatorname{ar}=13 \mathrm{NL} / \mathrm{min}$ ), os resultados mostram que o excesso de ar adicionado acima da quantidade mínima de fluidização do leito favorece o aumento na geração destes três gases de interesse até um valor ótimo de RE, 0,26, valores acima deste representam uma redução na geração dos gases.

Narváez et al $^{50}$ analisaram a influência de RE na gaseificação de madeira (com leito de sílica) e obtiveram as maiores concentrações dos gases $\mathrm{H}_{2}, \mathrm{CO}$ e $\mathrm{CH}_{4}$ também para RE igual a 0,26, com a concentração destes gases diminuindo com o aumento de RE, conforme foi observado no presente trabalho.

Já o gás $\mathrm{CO}_{2}$ apresentou comportamento exatamente contrário aos gases citados anteriormente, redução de RE igual a 0,23 para 0,26 e aumento de RE igual a 0,26 para 0,40, o que mostra que quanto mais próximo do limite de combustão (RE igual a 0,40 ) maior o teor de $\mathrm{CO}_{2}$. Já o $\mathrm{H}_{2} \mathrm{~S}$ apresentou aumento com aumento de RE.

A Tabela 8.6 mostra os intervalos de confiança considerando a análise de variância (ANOVA) com 95\% de significância para os gases $\mathrm{H}_{2}, \mathrm{CO}, \mathrm{CH}_{4}, \mathrm{CO}_{2}$ e $\mathrm{H}_{2} \mathrm{~S}$ em percentagem em função da razão de equivalência para o processo de gaseificação 
com ar. Realizou-se também o teste de Tukey (essencialmente um teste t) com nível de significância de $95 \%$ entre todas as razões de equivalência, para todos os gases medidos, utilizadas nos experimentos de gaseificação com o objetivo de determinar se houve alguma equivalência entre as médias das condições experimentais de RE analisadas. Ao todo foram realizados 90 testes t e as únicas condições experimentais que apresentaram equivalência foram os valores de RE de 0,28 e 0,31 para o gás CO, apresentados na Figura 8.7 (como o número de testes realizado foi muito grande optouse por apresentar apenas o teste que mostrou significância). Como a melhor condição experimental obtida foi com RE igual a 0,26, conclui-se baseando-se nas análises estatísticas, que esta de fato foi a melhor condição experimental.

Tabela 8.6 - Composição média $(\%)$ de $\mathrm{H}_{2}, \mathrm{CO}, \mathrm{CH}_{4}, \mathrm{CO}_{2}$ e $\mathrm{H}_{2} \mathrm{~S}$ no gás formado de processo de gaseificação de Eucalyptus grandis em função de RE.

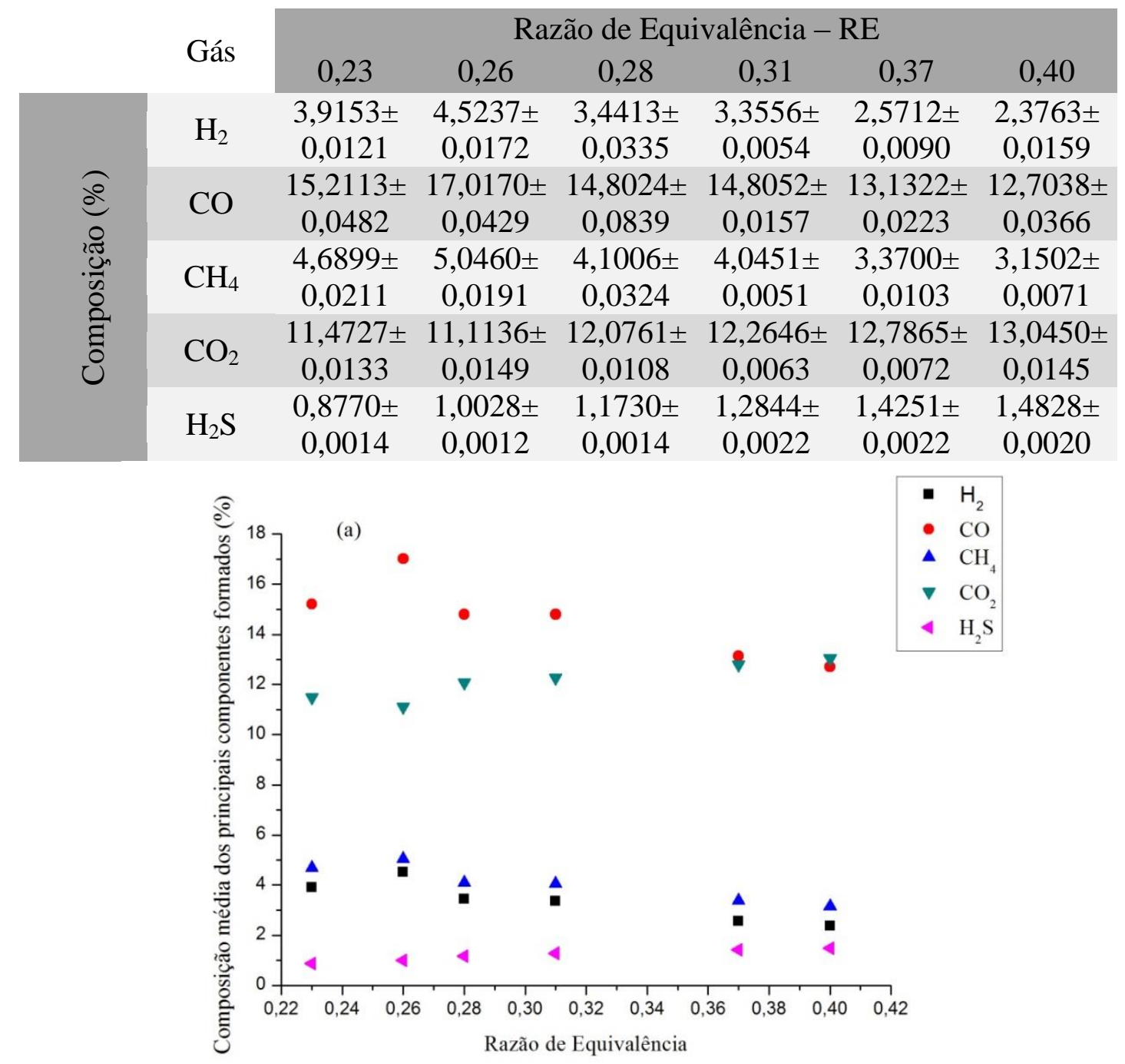

Figura 8.6 - Perfis de formação média (em percentagem) de gases no processo de gaseificação de Eucalyptus grandis utilizando ar como agente de gaseificação. 


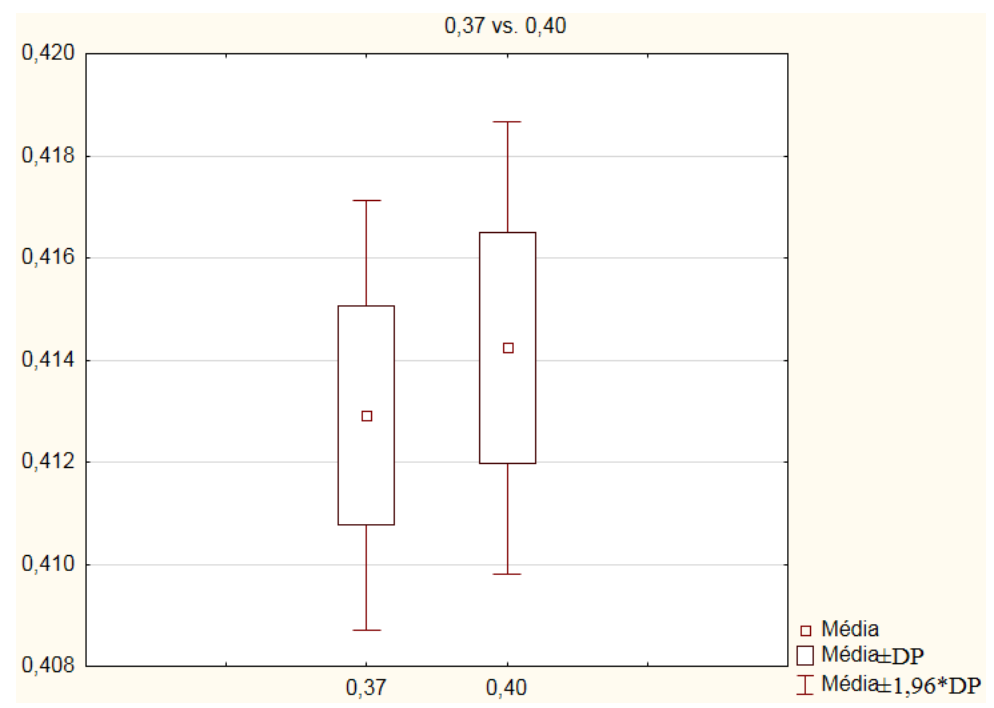

Figura 8.7 - Teste de Tukey realizado entre as razões de equivalência de 0,28 e 0,31 utilizadas no processo de gaseificação com ar para comparação entre as composições médias do gás. 


\subsubsection{Gaseificação com vapor d'água}

Em teste preliminar de gaseificação de Eucalyptus grandis utilizando vapor d'água como agente de fluidização, observou-se que para algumas vazões de vapor o percentual de $\mathrm{H}_{2}$ gerado poderia estar próximo ou até mesmo ultrapassar o range de medição deste gás no equipamento de análise de gases, o que prejudicaria a precisão de medição deste gás. Desta forma, optou-se por adicionar $12 \mathrm{NL} / \mathrm{min}$ de nitrogênio na injeção de ar secundário do reator (topo do reator), assim, o gás formado do processo foi diluído e a medição do gás $\mathrm{H}_{2}$ pôde ser realizada de forma correta. Logo, foi necessário recalcular a percentagem de todos os gases medidos pelo analisador de gases desconsiderando o valor de $12 \mathrm{NL} / \mathrm{min}$ de nitrogênio.

Serão apresentados nessa seção perfis comparativos de composição do gás medido no analisador, em percentagem (volume/volume), contendo a composição real dos gases $\mathrm{H}_{2}, \mathrm{CO}, \mathrm{CO}_{2}, \mathrm{CH}_{4}$ e $\mathrm{H}_{2} \mathrm{~S}$ no gás formado durante os experimentos, já desconsiderando o nitrogênio adicionado no topo do reator, em função do tempo de processo para as razões vapor/biomassa analisadas. No Apêndice 2 serão apresentados os gráficos individuais de cada gás contendo a vazão mássica em função do tempo, e um comparativo em percentagem da medição realizada pelo analisador de gases, ou seja, considerando a injeção de $\mathrm{N}_{2}$, que será chamado de composição do gás formado considerando injeção de $\mathrm{N}_{2}$, em função do tempo.

\subsubsection{Apresentação dos resultados para cada valor de razão vapor/biomassa analisada}

As Figuras 8.8 e 8.9 apresentam a composição do gás, formado de processo de gaseificação de Eucalyptus grandis, em percentagem (v/v) em função do tempo (min), para os valores de 1,69, 1,97, 2,25, 2,53, 2,81, 3,10 e 3,38 de SBR.

Para a razão vapor/biomassa de 1,69, em termos percentuais, os principais gases

de interesse, $\mathrm{H}_{2}, \mathrm{CO}$ e $\mathrm{CH}_{4}$ apresentaram composição média de 18,40\%, 20,39\% e $7,18 \%$, respectivamente.

No SBR de 1,97 (vazão de vapor de $14 \mathrm{~mL} / \mathrm{min}$ ), os gases $\mathrm{H}_{2}, \mathrm{CO}$ e $\mathrm{CH}_{4}$ apresentaram composição média no gás formado de 16,38\%, 24,57\% e 8,92\%, respectivamente. 
Os principais gases de interesse, $\mathrm{H}_{2}, \mathrm{CO}$ e $\mathrm{CH}_{4}$, foram obtidos em média de $17,28 \%, 22,30 \%$ e $7,16 \%$ para SBR igual a 2,25 .

Para a razão de SBR de 2,53, em relação à composição percentual média obtevese os gases $\mathrm{H}_{2}, \mathrm{CO}$ e $\mathrm{CH}_{4}$ nos teores de $18,37 \%, 23,07 \%$ e $7,59 \%$.

Analisando o gráfico para a razão vapor/biomassa de 2,81, os principais gases de interesse, $\mathrm{H}_{2}, \mathrm{CO}$ e $\mathrm{CH}_{4}$, foram obtidos em média de 17,22\%, 21,03\% e 6,68\%.

O teor obtido de $\mathrm{H}_{2}$, $\mathrm{CO}$ e $\mathrm{CH}_{4}$ no gás final foi em média de 17,69\%, 21,66\% e $6,84 \%$, respectivamente, para um SBR igual a 3,10.

Por fim, para SBR igual a 3,38, os principais gases de interesse, $\mathrm{H}_{2}, \mathrm{CO}$ e $\mathrm{CH}_{4}$, foram obtidos em média de $16,87 \%, 22,27 \%$ e $7,08 \%$, respectivamente.

O processo de gaseificação com vapor d'água apresentou dispersão no perfil de composição percentual ao longo do tempo principalmente nos gases que apresentaram maior teor no gás formado $\left(\mathrm{H}_{2}, \mathrm{CO}\right.$ e $\left.\mathrm{CH}_{4}\right)$. $\mathrm{O}$ cálculo do percentual real produzido desconsiderando o nitrogênio utilizado para diluir o gás foi feito com base na vazão volumétrica de gás total formado no processo, assim, como a vazão total de gás formado apresentou dispersão, o percentual real e a vazão mássica também apresentaram tal comportamento. Uma possibilidade para que esta variação de gás formado ocorra é uma possível instabilidade na alimentação de biomassa. As Figuras $12.2,12.5,12.8,12.11,12.14,12.17$ e 12.20 no Apêndice 2 apresentam a variação de fluxo total formado na gaseificação com vapor ao longo do tempo de processo e observa-se tal dispersão. As mesmas figuras apresentam também o perfil porcentual medido no sistema de análise de gases quando foi utilizada a diluição do gás com $\mathrm{N}_{2}$, e nota-se que o comportamento é estável, reforçando assim que as dispersões nas vazões mássicas e nos percentuais recalculados são de fato oriundas das dispersões apresentadas no fluxo total de gás formado. 

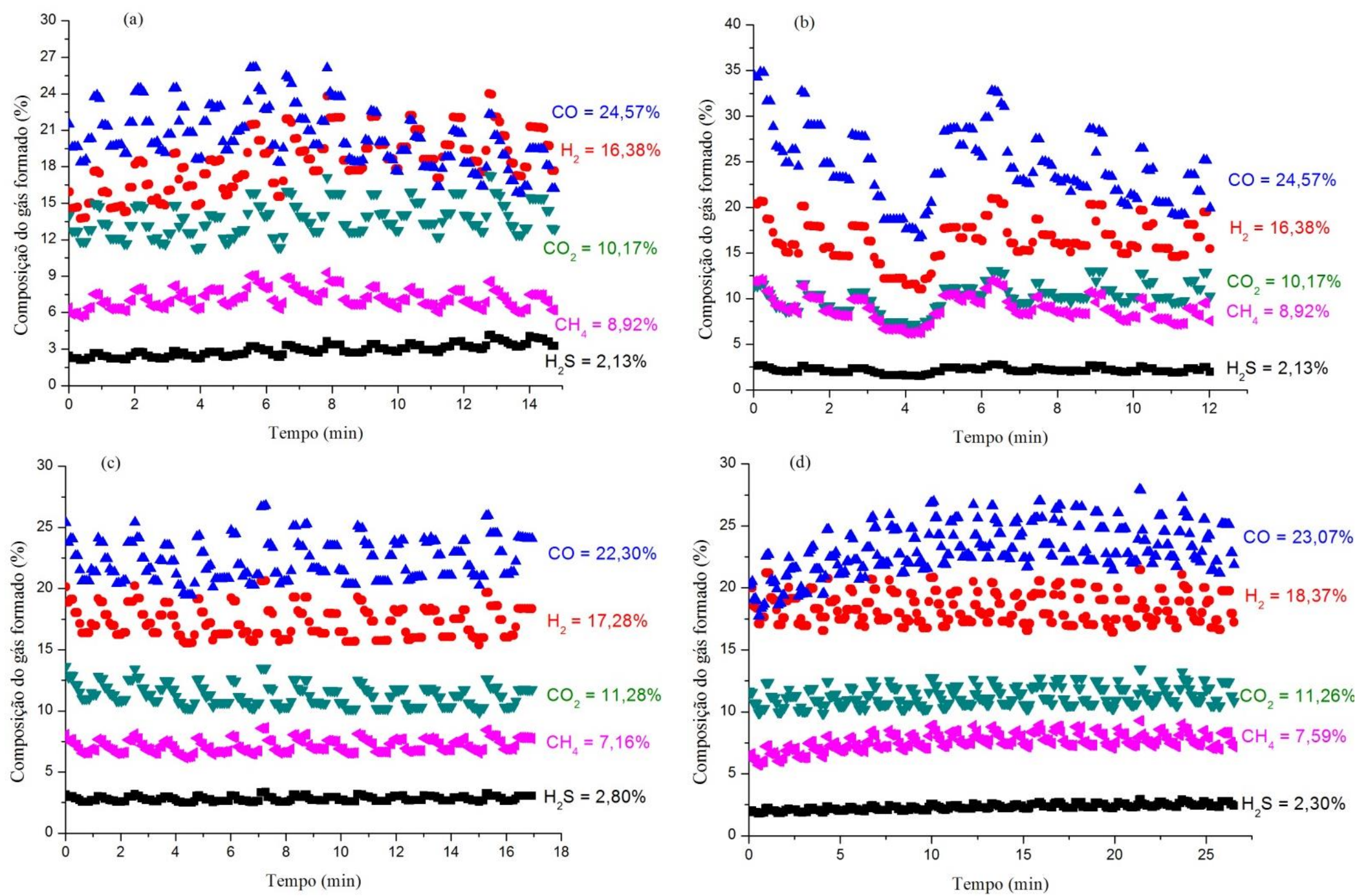

Figura 8.8 - Perfis de composição percentual dos de gases formados no processo de gaseificação de Eucalyptus grandis para (a) SBR=1,69 (b) $\mathrm{SBR}=1,97$ (c) $\mathrm{SBR}=2,25$ (d) $\mathrm{SBR}=2,53$. 

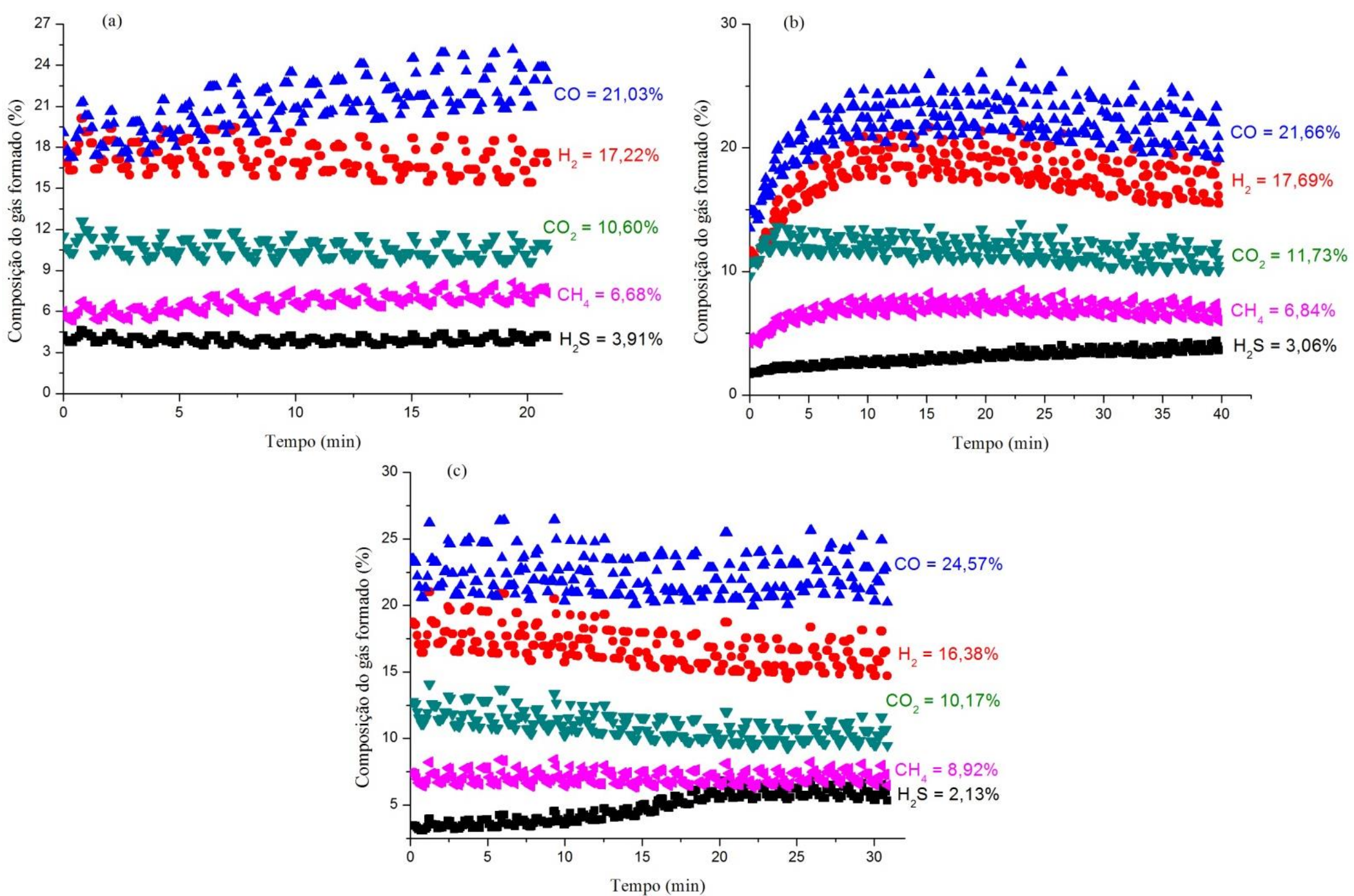

Figura 8.9 - Perfis de composição percentual dos de gases formados no processo de gaseificação de Eucalyptus grandis para (a) SBR=2,81 (b) $\mathrm{SBR}=3,10$ (c) $\mathrm{SBR}=3,38$. 


\subsubsection{Comparação entre as razões vapor/biomassa (SBR)}

A Figura 8.10 mostra uma comparação entre as composições médias, em percentagem, dos principais componentes gasosos formados no processo de gaseificação utilizando vapor como agente de fluidização em função da razão vapor/biomassa (SBR).

A razão vapor/biomassa de 1,69 apresentou o maior valor em percentagem para o gás $\mathrm{H}_{2}$, produzindo em média $18,75 \%$ em relação ao gás total (v/v). A razão de 1,97 produziu $24,57 \%$ e $8,92 \%$ de $\mathrm{CO}$ e $\mathrm{CH}_{4}$ respectivamente, maiores valores médios para estes gases. É importante destacar que a SBR de 1,97 também produziu os menores percentuais médios dos gases $\mathrm{CO}_{2}(10,17 \%)$ e $\mathrm{H}_{2} \mathrm{~S}(2,13 \%)$, que são gases que não são interessantes do ponto de vista de produção de energia limpa.

Alguns trabalhos da literatura que obtiveram valores que concordam com os valores obtidos no presente trabalho para os gases $\mathrm{H}_{2}$ e $\mathrm{CO}$ na gaseificação em leito fluidizado com vapor. São eles: Campoy et al, ${ }^{51}$ que obtiveram teores de $\mathrm{H}_{2}$ na faixa de $8,7 \%$ e $16,2 \%$ e $\mathrm{CO}$ na faixa de $11,9 \%$ e $15,9 \%$ para uma faixa de SBR de 0,22 a 0,60 ; Detournay et al ${ }^{52}$ gaseificaram serragem e obtiveram os gases $\mathrm{H}_{2}$ e $\mathrm{CO}$ nas faixas de 18,7-21,6\% e 53,2-55,3\%, respectivamente, para uma faixa de $\mathrm{SBR}$ de 0,4 a 1,0 . Sreejith ${ }^{53}$ obtiveram para o $\mathrm{H}_{2}$ uma concentração entre $10,5 \%$ e $28,3 \%$, e para o CO $18,8 \%$ e $26,2 \%$, para SBR na faixa de 0 a 2,5 na gaseificação de serragem.

A Tabela 8.7 mostra os intervalos de confiança considerando a análise de variância (ANOVA) com 95\% de significância para os gases $\mathrm{H}_{2}, \mathrm{CO}, \mathrm{CH}_{4}, \mathrm{CO}_{2}$ e $\mathrm{H}_{2} \mathrm{~S}$ em percentagem em função da razão vapor/biomassa para o processo de gaseificação com ar. Realizou-se também o teste de Tukey com nível de significância de 95\% entre todas as razões SBR, para todos os gases medidos, utilizadas nos experimentos de gaseificação com o objetivo de determinar se houve alguma equivalência entre as médias das condições experimentais de SBR analisadas. Ao todo foram realizados 126 testes t e as únicas condições experimentais que apresentaram equivalência foram os valores de SBR apresentados na Tabela 8.8 (as Figuras 8.11 e 8.12 mostram os testes que apresentaram significância).

Segundo teste $t$, destaca-se que as condições experimentais de SBR iguais a 1,69 e 2,53 são equivalentes em relação à composição percentual de $\mathrm{H}_{2}$, ou seja, tem-se que ambos são melhores condições de produção de $\mathrm{H}_{2}$. Os gases $\mathrm{CO}$ e $\mathrm{CH}_{4}$ não apresentaram 
significância nos testes realizados, portanto, o SBR de 1,97 é a melhor condição experimental de produção destes gases (analisando em termos percentuais).

Tabela 8.7 - Composição média de $\mathrm{H}_{2}, \mathrm{CO}, \mathrm{CH}_{4}, \mathrm{CO}_{2}$ e $\mathrm{H}_{2} \mathrm{~S}$ no gás formado de processo de gaseificação de Eucalyptus grandis em função de SBR.

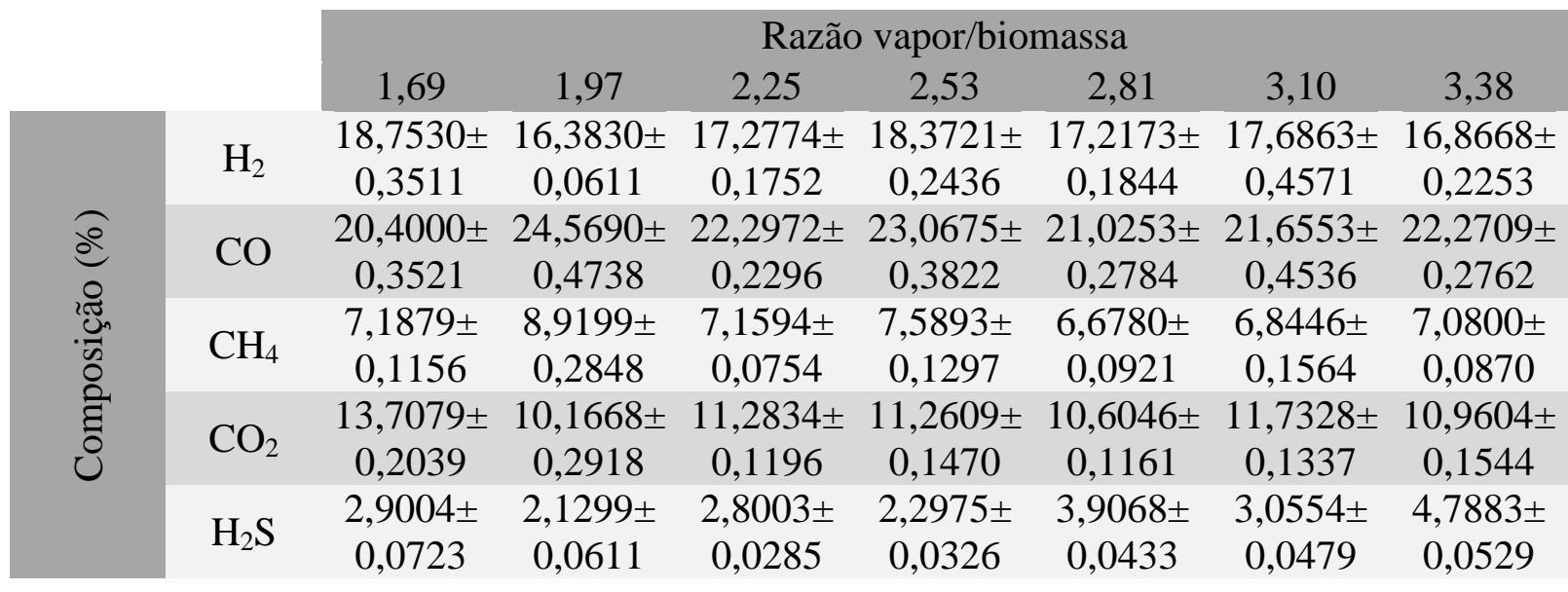

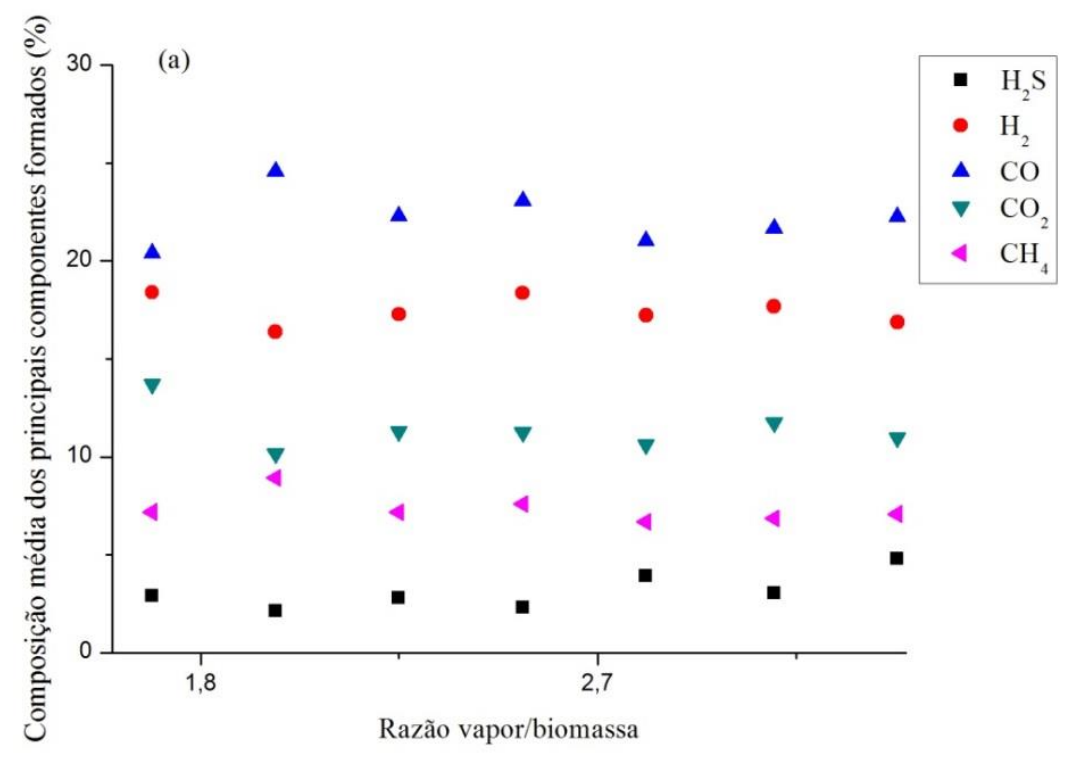

Figura 8.10 - Perfis de formação média (em percentagem) de gases no processo de gaseificação de Eucalyptus grandis utilizando vapor como agente de fluidização. 
Tabela 8.8 - Razões vapor/biomassa que apresentaram equivalência em teste Tukey de comparação de médias para as composições médias (\%).

$\begin{array}{lc}\text { Gás } & \begin{array}{c}\text { SBR's equivalentes } \\ \text { Composição média }(\%)\end{array} \\ \mathrm{CO}_{2} & 2,25 \times 2,53 \\ \mathrm{H}_{2} \mathrm{~S} & 1,69 \times 2,25 \\ \mathrm{CH}_{4} & 1,69 \times 2,25,1,69 \times 3,38,2,25 \times 338 \\ \mathrm{CO} & 2,25 \times 3,38 \\ \mathrm{H}_{2} & 1,69 \times 2,53,1,97 \times 3,38,2,25 \times 2,81\end{array}$



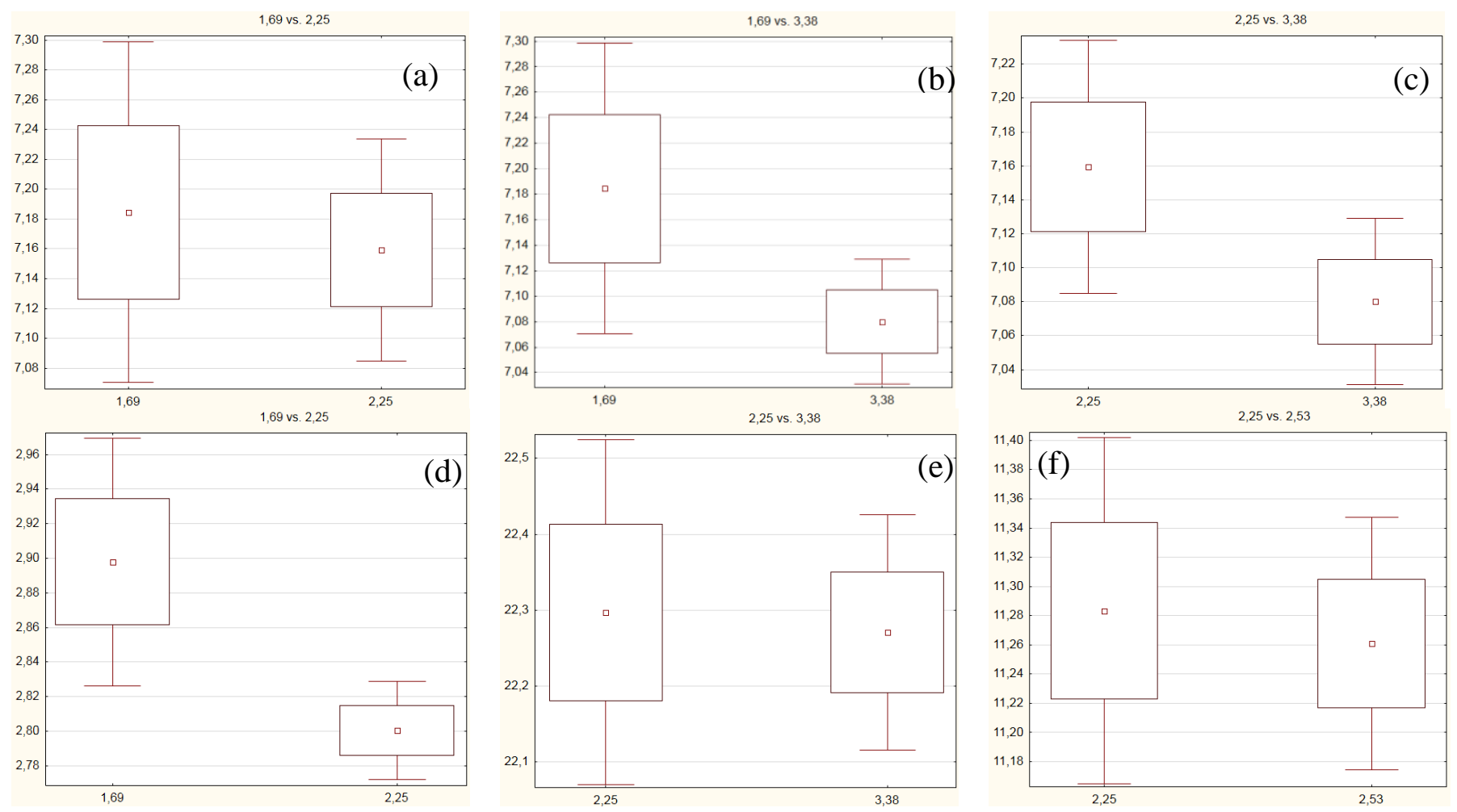

Figura 8.11- Teste de Tukey realizado antre as razões vapor/biomassa utilizadas no processo de gaseificação com vapor: a) Comparação entre os percentuais do gás $\mathrm{CH}_{4}$ para as SBR's 1,69 e 2,25. b) Comparação entre os percentuais do gás $\mathrm{CH}_{4}$ para as SBR's 1,69 e 3,38. C) Comparação enre as vazões mássicas de $\mathrm{CH}_{4}$ para as SBR's 2,25 e 3,38. d) Comparação entre os percentuais de $\mathrm{H}_{2} \mathrm{~S}$ para as SBR's 1,69 e 2,25. e) Comparação entre os percentuais médios de CO para as SBR's 2,25 e 3,38. f) Comparação entre os percentuais de $\mathrm{CO}_{2}$ para as SBR's de 2,25 e 2,53 . 
1,69 vs 2.53

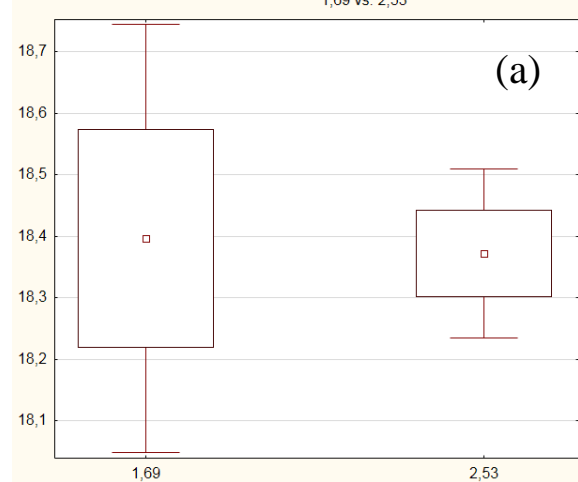

(a)

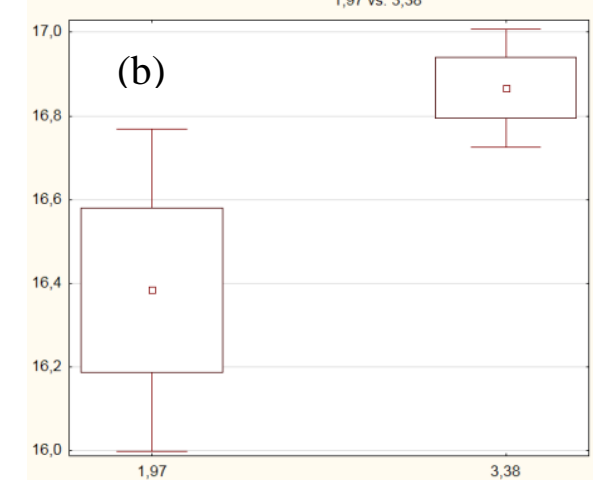

2,25 vs. 2,81

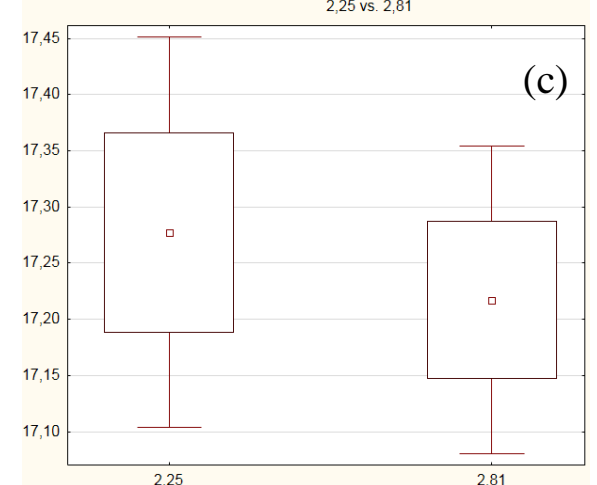

Figura 8.12- Teste de Tukey realizado antre as razões vapor/biomassa utilizadas no processo de gaseificação com vapor: a) Comparação entre os percentuais de $\mathrm{H}_{2}$ para as SBR's 1,69 e 2,53. b) Comparação entre os percentuais de $\mathrm{H}_{2}$ para as SBR's 1,97 e 3,38. c) Comparação entre os percentuais de $\mathrm{H}_{2}$ para as SBR's 2,25 e 2,81 . 


\subsubsection{Produção de gás combustível com nitrogênio}

Nesta seção serão apresentados os resultados obtidos dos ensaios de produção de gás combustível a partir de Eucalyptus grandis para os valores de vazão de nitrogênio apresentados na Tabela 8.3. Serão apresentados perfis de composição dos gases $\mathrm{H}_{2}, \mathrm{CO}$, $\mathrm{CH}_{4}, \mathrm{CO}_{2}$ e $\mathrm{H}_{2} \mathrm{~S}$, em percentagem (v/v), em função do tempo estável de processo (min) para cada valor de vazão de nitrogênio (12, 14, 16, 18 e $20 \mathrm{NL} / \mathrm{min})$. Em cada perfil de composição de gás será apresentado valor médio de cada gás produzido.

\subsubsection{Apresentação dos resultados para cada valor de vazão de nitrogênio}

Os gráficos da Figura 8.13 apresenta a composição do gás formado de processo de produção de gás combustível a partir de processo termoquímico de Eucalyptus grandis, em percentagem (v/v) em função do tempo (min), para os valores de 12, 14, 16,18 e $20 \mathrm{NL} / \mathrm{min}$ de vazão de nitrogênio.

Para a vazão de $12 \mathrm{NL} / \mathrm{min}$ de nitrogênio, os gases $\mathrm{H}_{2} \mathrm{~S}, \mathrm{H}_{2}, \mathrm{CO}, \mathrm{CO}_{2}$ e $\mathrm{CH}_{4}$ apresentaram comportamento estável ao longo do tempo, para valores medidos no analisador de gases (em porcentagem), como mostra a Figura 8.15a. O gás que apresentou maior concentração média em porcentagem no gás formado foi o $\mathrm{CO}$, com $14,95 \%$, e os gases $\mathrm{H}_{2}$ e $\mathrm{CH}_{4}$ apresentaram composição média de 12,70\% e 5,37\%, respectivamente.

Da Figura 8.13b observa-se comportamento estável dos gases para a vazão de 14 NL/min de nitrogênio, com destaque para a produção máxima média do gás $\mathrm{CO}$ de $13,76 \%$, e também para o gás $\mathrm{H}_{2}$ de $12,24 \%$. A produção média de $\mathrm{CH}_{4}$ foi de 3,98\%.

Para a vazão de $16 \mathrm{NL} / \mathrm{min}$, além do comportamento estável dos gases produzidos, os gases $\mathrm{CO}$ e $\mathrm{H}_{2}$ apresentaram perfis muito similares, com produção média de $11,55 \%$ e $11,56 \%$, respectivamente. Esta condição de processo foi a única que apresentou o $\mathrm{H}_{2}$ com maior produção média. Com relação ao $\mathrm{CH}_{4}$, obteve-se 3,83\%.

O gás obtido do processo utilizando $18 \mathrm{NL} / \mathrm{min}$ de nitrogênio como agente de fluidização apresentou composição percentual estável dos gases $\mathrm{H}_{2} \mathrm{~S}, \mathrm{CH}_{4}, \mathrm{H}_{2}, \mathrm{CO}$ e $\mathrm{CO}_{2}$, com destaque para produção média de $\mathrm{CO}, \mathrm{H}_{2}$ e $\mathrm{CH}_{4}$ de 10,46\%, 9,99\% e 2,99\%, respectivamente.

Por fim, o gás obtido do processo utilizando $20 \mathrm{NL} / \mathrm{min}$ de nitrogênio apresentou comportamento estável do gás $\mathrm{H}_{2} \mathrm{~S}$, mas um crescimento linear dos gases $\mathrm{CO}, \mathrm{H}_{2}, \mathrm{CH}_{4} \mathrm{e}$ 
$\mathrm{CO}_{2}$. Considerando a produção média ao longo dos 12 minutos de processo, o $\mathrm{CO}$ apresentou produção média de $10,72 \%$, e os gases $\mathrm{H}_{2}$ e $\mathrm{CH}_{4}$ apresentaram produção média de $6,99 \%$ e $4,49 \%$, respectivamente.

Os processos de produção de gás a partir da biomassa florestal utilizando ar e vapor'água são classificados como gaseificação, já o processo com nitrogênio, nas dadas condições pode ser classificado como pirólise. A pirólise é um processo termoquímico, sem a presença de oxigênio, que produz biochar e bio-óleo como produtos sólido e líquido, respectivamente, e como produtos gasosos $\mathrm{CO}_{2}, \mathrm{H}_{2}, \mathrm{CO}$ e alguns hidrocarbonetos. Levando-se em consideração apenas os produtos gasosos (não foram analisados os produtos sólido e líquido) e o fato do processo ter sido conduzido à temperatura do leito em torno de $500{ }^{\circ} \mathrm{C}$ a $800{ }^{\circ} \mathrm{C}$, o processo realizado com nitrogênio se encaixa na definição de pirólise em leito fluidizado. Mas é importante destacar que o foco do trabalho foi a produção de gás combustível através de processos termoquímicos, independente de delimitações de pirólise ou gaseificação o que importa é a obtenção de um gás de qualidade, seja esta relativa ao poder calorífico ou à quantidade de hidrogênio e monóxido de carbono no gás final, já que esta mistura pode ser utilizada para a produção de químicos ou biocombustíveis.

É fundamental destacar que durante os processos de produção de gases, o gás produzido passa pelo sistema de lavagem com água (scrubber) antes da leitura no sistema de análise de gases. Sabe-se que os gases $\mathrm{H}_{2}, \mathrm{CO}, \mathrm{CO}_{2}, \mathrm{CH}_{4}, \mathrm{H}_{2} \mathrm{~S}$ e $\mathrm{N}_{2}$ são solúveis em água, logo, durante o processo de lavagem do gás para retirada principalmente de alcatrão, particulado e $\mathrm{H}_{2} \mathrm{~S}$, parte dos outros gases pode também ficar retida na água. $\mathrm{Na}$ produção de gás utilizando vapor d'água e ar como agentes de fluidização, a água presente no sistema de lavagem havia passado por inúmeros testes de gaseificação (cerca de 40 horas de processo), assim, é seguro assumir que a mesma estava saturada e iria interferir minimamente na medição de gases no analisador. Já no processo de produção de gás utilizando nitrogênio, a água presente na torre de lavagem foi trocada, com isso, parte dos gases produzidos durante os experimentos certamente ficou retida na água.

A Tabela 8.9 apresenta os coeficientes de solubilidade em água (ppm) dos gases $\mathrm{H}_{2}, \mathrm{CO}, \mathrm{CO}_{2}, \mathrm{CH}_{4}, \mathrm{H}_{2} \mathrm{~S}$ e $\mathrm{N}_{2}$ calculados segundo o software SolGas (cálculo da solubilidade de gases na água), ${ }^{54}$ a quantidade total máxima de cada gás, em gramas, 
que pode ficar retida na lavadora (considerando eficência máxima de retenção na água para cada gás e uma quantidade de 200 L de água na lavadora), a vazão mássica média (g/min) de cada gás produzido obtida em cada condição experimental e o tempo médio de processo (min) para que haja saturação da água para a sua respectiva vazão média (g/min) de processo.

Uma inconsistência que foi encontrada nos processos de produção de gás com nitrogênio, e que não foi encontrada nos processos com ar e vapor d'água, é de que o fluxo de saída de gás medido no medidor de gás de fluxo total, após a lavadora de gases, foi muito baixo, sendo inferior a soma dos gases de entrada no processo. Este fato é relatado detalhadamente no Apêndice 4. 

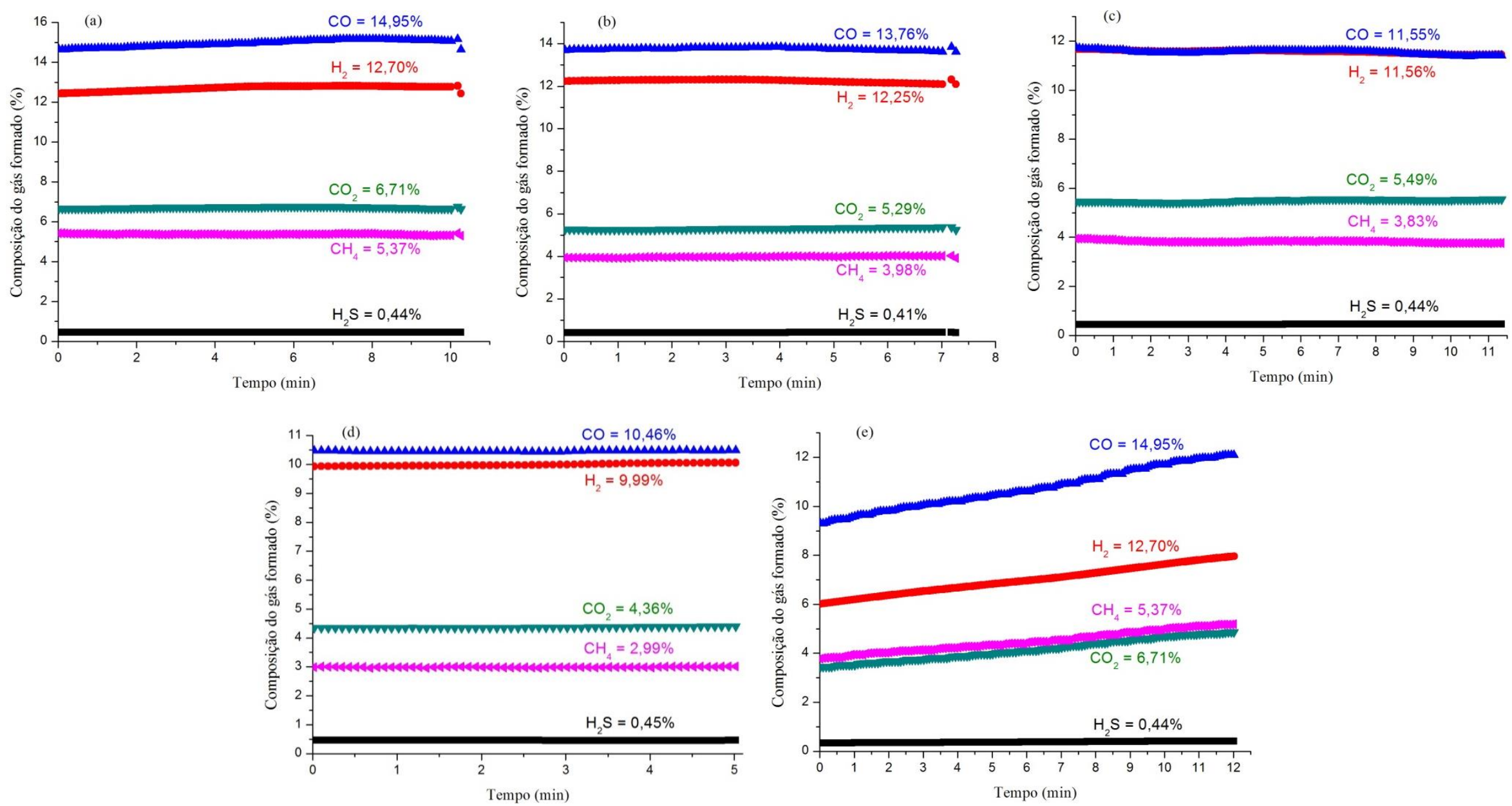

Figura 8.13 - Perfis de composição percentual dos de gases formados no processo de produção de gás combustível de Eucalyptus grandis com nitrogênio para (a) $12 \mathrm{NL} / \mathrm{min}$ (b) $14 \mathrm{NL} / \min$ (c) $16 \mathrm{NL} / \min$ (d) $18 \mathrm{NL} / \mathrm{min}$. 
Tabela 8.9 - Solubilidade dos gases produzidos em água (ppm), quantidade máxima de cada gás que pode ficar retida em 200 L de água (g) e tempo médio de saturação da água utilizada para lavagem dos gases produzidos em função da vazão mássica média de cada gás.

\begin{tabular}{ccccccccccccccc} 
& & \multicolumn{4}{c}{ Vazão mássica média de cada gás no processo (g/min) } & \multicolumn{5}{c}{ Tempo médio de saturação (min) } \\
Gás & $\begin{array}{c}\text { Solubilidade } \\
\text { em }\end{array}$ & $\begin{array}{c}\text { Quant. } \\
\text { máx. }\end{array}$ & 12 & 14 & 16 & 18 & 20 & 12 & 14 & 16 & 18 & 20 \\
& água (ppm) & retida (g) & NL/min & NL/min & NL/min & NL/min & NL/min & NL/min & NL/min & NL/min & NL/min & NL/min \\
$\mathrm{H}_{2} \mathrm{~S}$ & $3.785,416$ & 757,083 & 0,0085 & 0,0083 & 0,0131 & 0,0147 & 0,0070 & 89068,61 & 91214,84 & 57792,61 & 51502,26 & 108154,74 \\
$\mathrm{H}_{2}$ & 1,584 & 0,317 & 0,0141 & 0,0144 & 0,0199 & 0,0186 & 0,0076 & 22,46 & 21,99 & 15,91 & 17,03 & 41,67 \\
$\mathrm{CO}$ & 28,224 & 5,645 & 0,2380 & 0,2324 & 0,2852 & 0,2801 & 0,1672 & 23,72 & 24,29 & 19,79 & 20,15 & 33,76 \\
$\mathrm{CO}_{2}$ & $1.663,198$ & 332,640 & 0,1690 & 0,1412 & 0,2145 & 0,1847 & 0,1026 & 1968,28 & 2355,80 & 1550,77 & 1800,97 & 3242,10 \\
$\mathrm{CH}_{4}$ & 24,226 & 4,845 & 0,0491 & 0,0385 & 0,0542 & 0,0460 & 0,0402 & 98,68 & 125,85 & 89,40 & 105,33 & 120,53 \\
$\mathrm{~N}_{2}$ & 18,712 & 3,742 & 16,6179 & 18,9192 & 21,1437 & 23,5136 & 25,8058 & 0,23 & 0,20 & 0,18 & 0,16 & 0,15
\end{tabular}




\subsubsection{Comparação entre as vazões de nitrogênio}

A Figura 8.14 mostra uma comparação entre as composições médias, em percentagem, dos principais componentes gasosos formados no processo de produção de gás utilizando nitrogênio como agente de fluidização em função da vazão de nitrogênio. Destaca-se a condição de processo de $12 \mathrm{NL} / \mathrm{min}$, onde se obteve as maiores produções médias dos gases $\mathrm{H}_{2}, \mathrm{CO}$ e $\mathrm{CH}_{4}$, sendo elas de 12,70\%, 14,95\% e 5,37\%, respectivamente, o que torna esta a melhor condição experimental em termos de composição percentual dos gases de interesse.

A Tabela 8.10 apresenta os valores dos intervalos de confiança segundo a ANOVA (com 95\% de confiança) para os gases $\mathrm{H}_{2}, \mathrm{CO}, \mathrm{CH}_{4}, \mathrm{CO}_{2}$ e $\mathrm{H}_{2} \mathrm{~S}$ em percentagem em função da vazão de nitrogênio. Realizou-se também o teste de Tukey (teste t) com nível de significância de $95 \%$ entre todas as condições experimentais utilizadas, para todos os gases, com o objetivo de comparar as médias através deste método. Ao todo foram realizadas 50 comparações e em nenhuma houve significância.

Tabela 8.10 - Composição média de $\mathrm{H}_{2}, \mathrm{CO}, \mathrm{CH}_{4}, \mathrm{CO}_{2}$ e $\mathrm{H}_{2} \mathrm{~S}$ no gás formado de processo de pirólise de Eucalyptus grandis em função da vazão do agente de fluidização nitrogênio.

\begin{tabular}{|c|c|c|c|c|c|c|}
\hline & \multirow{2}{*}{ Gás } & \multicolumn{5}{|c|}{ Vazão de nitrogênio (NL/min) } \\
\hline & & 12 & 14 & 16 & 18 & 20 \\
\hline \multirow{5}{*}{ 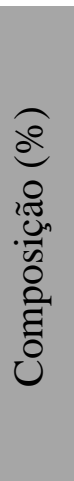 } & $\mathrm{H}_{2}$ & $\begin{array}{c}12,7040 \pm \\
0,217\end{array}$ & $\begin{array}{c}12,2475 \pm \\
0,0139\end{array}$ & $\begin{array}{c}11,5614 \pm \\
0,0117\end{array}$ & $\begin{array}{c}9,9915 \pm \\
0,0107\end{array}$ & $\begin{array}{c}6,9882 \pm \\
0,0979\end{array}$ \\
\hline & $\mathrm{CO}$ & $\begin{array}{c}14,9531 \pm \\
0,0303\end{array}$ & $\begin{array}{c}13,7564 \pm \\
0,0117\end{array}$ & $\begin{array}{c}11,5526 \pm \\
0,0143\end{array}$ & $\begin{array}{c}10,4621 \pm \\
0,0037\end{array}$ & $\begin{array}{c}10,7171 \pm \\
0,1347\end{array}$ \\
\hline & $\mathrm{CH}_{4}$ & $\begin{array}{c}5,3742 \pm \\
0,0043\end{array}$ & $\begin{array}{c}3,9781 \pm \\
0,0063\end{array}$ & $\begin{array}{c}3,8271 \pm \\
0,0075\end{array}$ & $\begin{array}{c}2,9940 \pm \\
0,0028\end{array}$ & $\begin{array}{c}4,4873 \pm \\
0,0676\end{array}$ \\
\hline & $\mathrm{CO}_{2}$ & $\begin{array}{c}6,7058 \pm \\
0,0055\end{array}$ & $\begin{array}{c}5,2896 \pm \\
0,0080\end{array}$ & $\begin{array}{c}5,4908 \pm \\
0,0081\end{array}$ & $\begin{array}{c}4,3586 \pm \\
0,0043\end{array}$ & $\begin{array}{c}4,1465 \pm \\
0,0713\end{array}$ \\
\hline & $\mathrm{H}_{2} \mathrm{~S}$ & $\begin{array}{c}0,4434 \pm \\
0,0007\end{array}$ & $\begin{array}{c}0,4057 \pm \\
0,0006\end{array}$ & $\begin{array}{c}0,4402 \pm \\
0,0009\end{array}$ & $\begin{array}{c}0,4528 \pm \\
0,0004\end{array}$ & $\begin{array}{c}0,3706 \pm \\
0,0041\end{array}$ \\
\hline
\end{tabular}




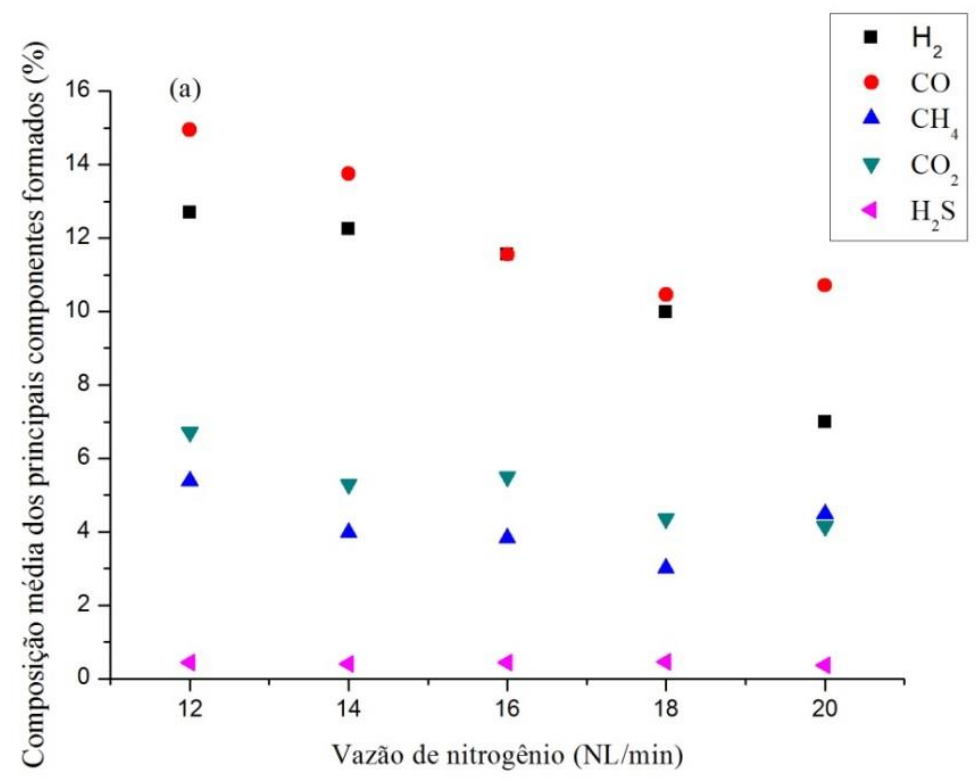

Figura 8.14 - Perfis de formação média (em percentagem) de gases no processo de gaseificação de Eucalyptus grandis utilizando ar como agente de fluidização.

\subsubsection{Comparação entre os diferentes agentes de fluidização}

\subsubsection{Comparação em termos de produção percentual dos gases}

A Tabela 8.11 apresenta os melhores resultados de produção média percentual dos gases $\mathrm{H}_{2}, \mathrm{CO}, \mathrm{CH}_{4}, \mathrm{H}_{2} \mathrm{~S}$ e $\mathrm{CO}_{2}$ para cada agente de fluidização. Destaca-se que a produção máxima percentual de $\mathrm{H}_{2}, \mathrm{CO}$ e $\mathrm{CH}_{4}$ foi de $18,75 \%, 24,57 \%$ e $8,92 \%$ utilizando o vapor d'água como agente de fluidização. Assim, considerando estes três gases de interesse, em termos percentuais, a utilização do vapor d'água como agente de fluidização se torna a mais atrativa.

Tabela 8.11 - Melhor condição de produção média de cada gás (\%) no produto final para os diferentes agentes de fluidização.

\begin{tabular}{c|ccc} 
Gás (\%) & \multicolumn{3}{|c}{ Agente de Fluidização } \\
& Ar & Vapor & Nitrogênio \\
$\mathrm{CO}$ & 17,0170 & 24,5690 & 14,9531 \\
$\mathrm{H}_{2}$ & 4,5237 & 18,7530 & 12,7040 \\
$\mathrm{CH}_{4}$ & 5,0460 & 8,9199 & 5,3742 \\
$\mathrm{CO}_{2}$ & 13,0405 & 13,7079 & 6,7058 \\
$\mathrm{H}_{2} \mathrm{~S}$ & 1,4828 & 4,7883 & 0,4528
\end{tabular}




\subsubsection{Comparação em termos de produtividade dos gases (grama de gás/grama de biomassa)}

Com o objetivo de determinar a maior produção em massa dos gases produzidos, determinou-se a produtividade dos gases $\mathrm{H}_{2}, \mathrm{CO}, \mathrm{CO}_{2}, \mathrm{CH}_{4}$ e $\mathrm{H}_{2} \mathrm{~S}$ em grama de cada gás por grama de biomassa alimentada no reator.

A Tabela 8.12 e a Figura 8.15a apresentam a produtividade em função da razão de equivalência na gaseificação com ar. Para RE igual a 0,26 obteve-se as produtividades médias máximas de 0,01 grama de $\mathrm{H}_{2}$ por grama de biomassa e 0,08 gramas de $\mathrm{CH}_{4}$ por grama de biomassa. Já para o $\mathrm{CO}$, tem-se que a produtividade média máxima foi para a RE de 0,40 , valor de 0,51 .

Tabela 8.12 - Produtividade de cada gás medido no gás total formado de processo de gaseificação de Eucalyptus grandis utilizando ar como agente de fluidização.

\begin{tabular}{ccccccc} 
& \multicolumn{5}{c}{ Produtividade (g de gás/g de biomassa) } \\
& $\mathrm{H}_{2}$ & $\mathrm{CO}$ & $\mathrm{CH}_{4}$ & $\mathrm{CO}_{2}$ & $\mathrm{H}_{2} \mathrm{~S}$ \\
\hline 0,23 & 0,0064 & 0,3562 & 0,0630 & 0,4249 & 0,0248 \\
0,26 & 0,0091 & 0,4924 & 0,0838 & 0,5086 & 0,0351 \\
$\underline{\underline{1}}$ & 0,28 & 0,0071 & 0,4373 & 0,0696 & 0,5622 & 0,0417 \\
0,31 & 0,0076 & 0,4817 & 0,0756 & 0,6314 & 0,0505 \\
0,37 & 0,0067 & 0,4927 & 0,0726 & 0,7590 & 0,0646 \\
0,40 & 0,0067 & 0,5115 & 0,0728 & 0,8310 & 0,0721
\end{tabular}

A Tabela 8.13 e a Figura 8.15 b mostram a produtividade em função da razão vapor/biomassa na gaseificação com vapor. Os valores máximos médios obtidos foram de 0,07 e 0, 39 para os gases $\mathrm{CH}_{4}$ e CO, respectivamente, para um SBR de 2,53. Já para o $\mathrm{H}_{2}$, a melhor condição de produtividade foi de 0,02 (SBR de 2,81). Porém, é importante destacar que para o SBR de 2,53 obteve-se valor muito próximo da produtividade média máxima para $\mathrm{H}_{2}$, o que torna esse valor de SBR muito interessante em termos de produção mássica dos três gases de interesse. 
Tabela 8.13 - Produtividade de cada gás medido no gás total formado de processo de gaseificação de Eucalyptus grandis utilizando vapor como agente de fluidização.

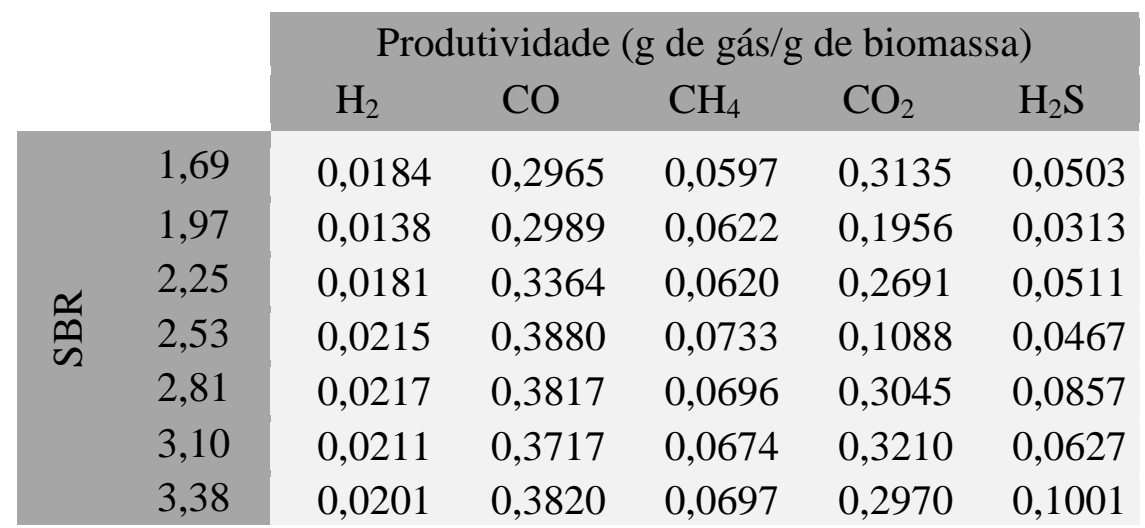

Para a produção de gás com nitrogênio, tem-se da Tabela 8.14 e da Figura 8.15c que a maior produtividade do gás $\mathrm{H}_{2}$ foi de $0,02(16 \mathrm{NL} / \mathrm{min})$, do $\mathrm{CO}$ foi de 0,32 (20 $\mathrm{NL} / \mathrm{min}$ ) e do $\mathrm{CH}_{4}$ foi de 0,08 (20 NL/min).

Tabela 8.14 - Produtividade de cada gás medido no gás total formado de processo de produção de gás combustível a partir de Eucalyptus grandis utilizando nitrogênio como agente de fluidização.

\begin{tabular}{|c|c|c|c|c|c|c|}
\hline & \multicolumn{5}{|c|}{ Produtividade (g de gás/g de biomassa) } \\
\hline & & $\mathrm{H}_{2}$ & $\mathrm{CO}$ & $\mathrm{CH}_{4}$ & $\mathrm{CO}_{2}$ & $\mathrm{H}_{2} \mathrm{~S}$ \\
\hline \multirow{5}{*}{ 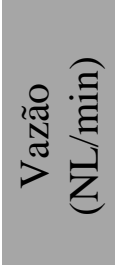 } & 12 & 0,0178 & 0,3015 & 0,0622 & 0,2140 & 0,0108 \\
\hline & 14 & 0,0196 & 0,3162 & 0,0525 & 0,1924 & 0,0113 \\
\hline & 16 & 0,0212 & 0,3049 & 0,0580 & 0,2293 & 0,0140 \\
\hline & 18 & 0,0204 & 0,3065 & 0,0503 & 0,2021 & 0,0160 \\
\hline & 20 & 0,0148 & 0,3270 & 0,0786 & 0,2003 & 0,0137 \\
\hline
\end{tabular}

Comparando-se então os três processos de produção de gás em termos de produtividade, tem-se que para o gás $\mathrm{H}_{2}$, o maior valor de produtividade foi obtido na gaseificação com vapor e na pirólise com nitrogênio, 0,02 gramas de $\mathrm{H}_{2}$ por grama de biomassa alimentada. Na gaseificação com ar, obteve-se a maior produtividade média do gás $\mathrm{CO}$, que foi de 0,51 . 


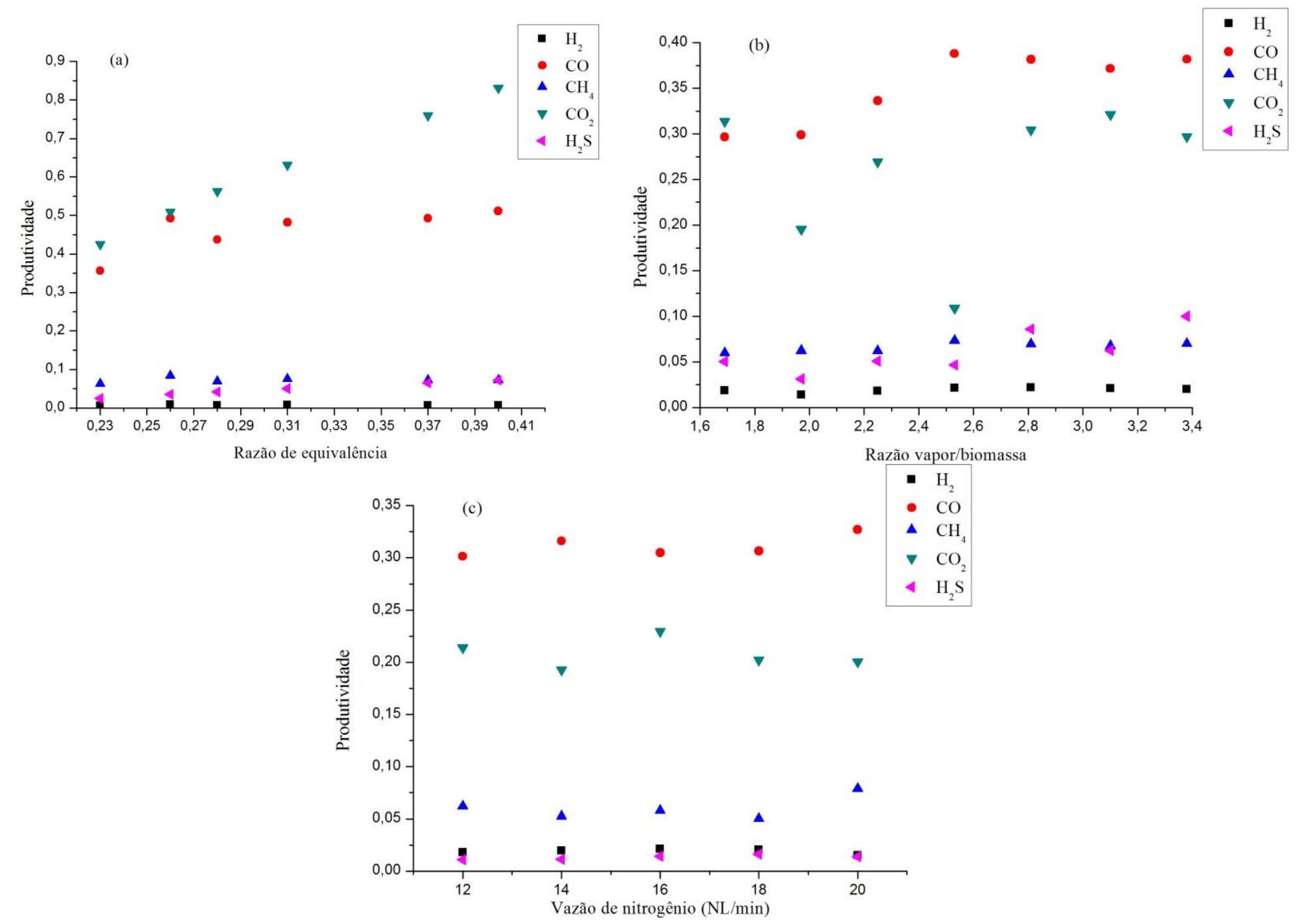

Figura 8.15 - Produtividade dos gases $\mathrm{H}_{2}, \mathrm{CO}, \mathrm{CO}_{2}, \mathrm{CH}_{4}$ e $\mathrm{H}_{2} \mathrm{~S}$ em função das condições experimentais analisadas para produção de gás combustível com (a) ar (b) vapor e (c) nitrogênio. 


\subsubsection{Poder calorífico do gás formado}

Para o cálculo do poder calorífico inferior (PCI) do gás produzido, utiliza-se da fração volumétrica (\%) dos componentes $\mathrm{H}_{2}, \mathrm{CO}, \mathrm{CH}_{4}$ e $\mathrm{H}_{2} \mathrm{~S}$, que têm poder calorífico de $10,789 \mathrm{MJ} / \mathrm{Nm}^{3}, \quad 12,626 \mathrm{MJ} / \mathrm{Nm}^{3}, 35,796 \mathrm{MJ} / \mathrm{Nm}^{3}$ e $23,142 \mathrm{MJ} / \mathrm{Nm}^{3}$, respectivamente ${ }^{55}$. A equação 8.2 apresenta o cálculo do PCI $\left(\mathrm{em} \mathrm{MJ} / \mathrm{m}^{3}\right.$ ) para o gás produto:

$$
P C I_{\text {gás produto }}=10,789 \cdot x_{H_{2}}+12,626 \cdot x_{C O}+35,796 \cdot x_{C H_{4}}+23,142 \cdot x_{H_{2} S}
$$

onde, $\boldsymbol{x}_{\boldsymbol{H}_{2}}, \boldsymbol{x}_{\boldsymbol{C} \boldsymbol{o}}, \boldsymbol{x}_{\boldsymbol{C H}_{\mathbf{4}}}$ e $\boldsymbol{x}_{\boldsymbol{H}_{2} \boldsymbol{S}}$ são as frações volumétricas, em percentagem, de $\mathrm{H}_{2}, \mathrm{CO}$, $\mathrm{CH}_{4}$ e $\mathrm{H}_{2} \mathrm{~S}$ no gás formado.

A Tabela 8.15 e as Figuras 8.16a até 8.16c apresentam o poder calorífico inferior (PCI) médio, em $\mathrm{MJ} / \mathrm{Nm}^{3}$, obtido dos processos de produção de gás utilizando ar, vapor e nitrogênio como agente de fluidização a partir de biomassa florestal (Eucalyptus grandis). O poder calorífico inferior de um gás produzido de gaseificação utilizando ar como agente de fluidização está na faixa de 3 a $6 \mathrm{MJ} / \mathrm{Nm}^{3},{ }^{7,28,56}$ na pirólise com nitrogênio na faixa de 3,5 a $9 \mathrm{MJ} / \mathrm{Nm}^{3},{ }^{14}$ e na gaseificação com vapor d'água na faixa de 5 a $13 \mathrm{MJ} / \mathrm{Nm}^{3} .{ }^{57} \mathrm{O}$ maior valor médio encontrado de poder calorífico para o ar foi de $4,68 \mathrm{MJ} / \mathrm{m}^{3}$, para um RE de 0,26. Para o vapor d'água, o maior valor encontrado foi de $8,56 \mathrm{MJ} / \mathrm{m}^{3}$ com SBR de 1,97. E para o nitrogênio, com $12 \mathrm{NL} / \mathrm{min}$, obteve-se um gás com PCI de 5,29 MJ $/ \mathrm{m}^{3}$. É interessante destacar que o menor poder calorífico obtido com vapor d'água, $7,81 \mathrm{MJ} / \mathrm{m}^{3}$ (SBR igual 2,81), foi maior do que os maiores valores para ar e nitrogênio, mostrando a viabilidade técnica do processo de produção de gás combustível através de gaseificação utilizando vapor como agente de fluidização levando-se em consideração o poder calorífico do gás.

Tabela 8.15 - Poder calorífico inferior (PCI) médio em $\mathrm{MJ} / \mathrm{m}^{3}$ em função da composição média do gás formado utilizando os agentes de fluidiação ar, vapor e nitrogênio.

$\begin{array}{lccccccc}\operatorname{Ar}(\mathrm{RE}) & 0,23 & 0,26 & 0,28 & 0,34 & 0,37 & 0,40 & \\ \mathrm{PCI}\left(\mathrm{MJ} / \mathrm{m}^{3}\right) & 4,2248 & 4,6750 & 3,9795 & 3,9766 & 3,4716 & 3,3312 & \\ \text { Vapor }(\mathrm{SBR}) & 1,69 & 1,97 & 2,25 & 2,53 & 2,81 & 3,10 & 3,38 \\ \mathrm{PCI}\left(\mathrm{MJ} / \mathrm{m}^{3}\right) & 7,8432 & 8,5555 & 7,8901 & 8,1430 & 7,8068 & 7,7995 & 8,2741 \\ \begin{array}{l}\text { Nitrogênio } \\ (\mathrm{NL} / \mathrm{min})\end{array} & 12 & 14 & 16 & 18 & 20 & & \\ \mathrm{PCI}\left(\mathrm{MJ} / \mathrm{m}^{3}\right) & 5,2850 & 4,5762 & 4,1778 & 3,5754 & 3,7991 & & \end{array}$


Considerando a densidade dos gases $\mathrm{H}_{2}, \mathrm{CO}, \mathrm{CH}_{4}$ e $\mathrm{H}_{2} \mathrm{~S}$ apresentada na Tabela 8.16, dada em gramas por litro com base na CNTP $\left(0{ }^{\circ} \mathrm{C}\right.$ e 1 atm $)$, obtém-se o valor do poder calorífico do gás gerado em MJ/kg (apresentado na Tabela 8.17 e nas Figuras $8.17 \mathrm{a}$ até $8.17 \mathrm{c})$.

Tabela 8.16 - Densidade dos gases $\mathrm{H}_{2}, \mathrm{CO}, \mathrm{CH}_{4}$ e $\mathrm{H}_{2} \mathrm{~S} 0{ }^{\circ} \mathrm{C}$ e 1 atm $(\mathrm{CNTP}) .{ }^{58}$

\begin{tabular}{lc}
\multicolumn{1}{c}{ Gases } & Densidade $(\mathrm{g} / \mathrm{L})$ \\
\hline $\mathrm{H}_{2}$ & 0,090 \\
$\mathrm{CO}$ & 1,250 \\
$\mathrm{CH}_{4}$ & 0,718 \\
$\mathrm{H}_{2} \mathrm{~S}$ & 1,536 \\
\hline
\end{tabular}

Tabela 8.17 - Poder calorífico inferior do gás formado de processos termoquímicos de Eucalyptus grandis utilizando ar, vapor e nitrogênio como agentes de fluidização.

\begin{tabular}{lccccccc} 
& \multicolumn{7}{c}{ Poder Calorífico inferior (MJ/kg) } \\
Ar & 0,23 & 0,26 & 0,28 & 0,34 & 0,37 & 0,40 & \\
$\begin{array}{l}\text { PCI } \\
\text { (MJ/kg) }\end{array}$ & 8,7067 & 9,8157 & 7,8472 & 7,7337 & 6,3078 & 5,9297 & \\
Vapor & 1,69 & 1,97 & 2,25 & 2,53 & 2,81 & 3,10 & 3,38 \\
$\begin{array}{l}\text { PCI } \\
\text { (MJ/kg) }\end{array}$ & 28,5868 & 26,9119 & 26,9784 & 28,5086 & 26,7044 & 27,2856 & 26,7430 \\
$\begin{array}{l}\text { Nitrogênio } \\
\text { (NL/min) }\end{array}$ & 12 & 14 & 16 & 18 & 20 & & \\
$\begin{array}{l}\text { PCI } \\
\text { (MJ/kg) }\end{array}$ & 19,5029 & 18,1320 & 17,0160 & 14,6083 & 11,7627 & & \\
\hline
\end{tabular}

No Capítulo 4 determinou-se que o poder calorífico inferior da biomassa de Eucalyptus grandis é de 16,84 MJ/kg. Comparando a energia liberada pela queima do combustível com o potencial energético do gás produzido do mesmo material, nota-se um aumento interessante. As condições experimentais de 12, 14 e $16 \mathrm{NL} / \mathrm{min}$ utilizando nitrogênio como agente de fluidização apresentaram poder calorífico de 19,50 MJ/kg, $18,13 \mathrm{MJ} / \mathrm{kg}$ e $17,02 \mathrm{MJ} / \mathrm{kg}$, respectivamente, maiores que o poder calorífico da biomassa in natura. Na gaseificação com ar, o poder calorífico do gás obtido foi menor que o da biomassa in natura em todos os casos, mas é importante destacar que não foram analisados os co-produtos, alcatrão e carvão. E com relação ao vapor, o pior caso de poder calorífico, 26,70 MJ/kg (SBR de 2,81), ainda assim possui maior valor que o poder calorífico da biomassa in natura. A melhor condição de poder calorífico obtido considerando todos os agentes de fluidização foi de $28,59 \mathrm{MJ} / \mathrm{kg}$, na condição experimental de SBR igual a 1,69 (gaseificação com vapor). 

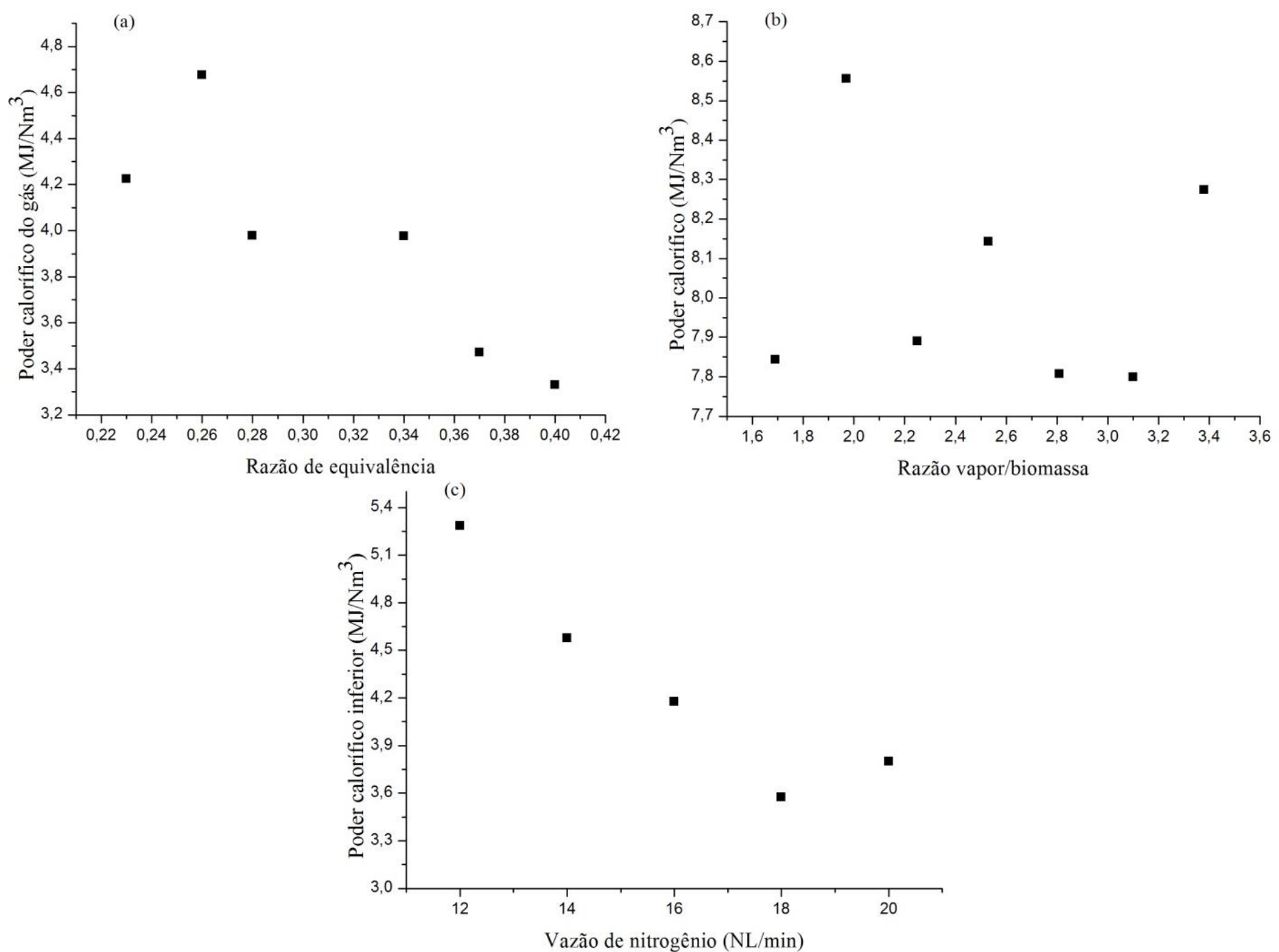

Figura 8.16 - Poder calorífico inferior $\left(\mathrm{MJ} / \mathrm{Nm}^{3}\right)$ em função de: a) RE b) SBR c) vazão de nitrogênio (NL/min). 

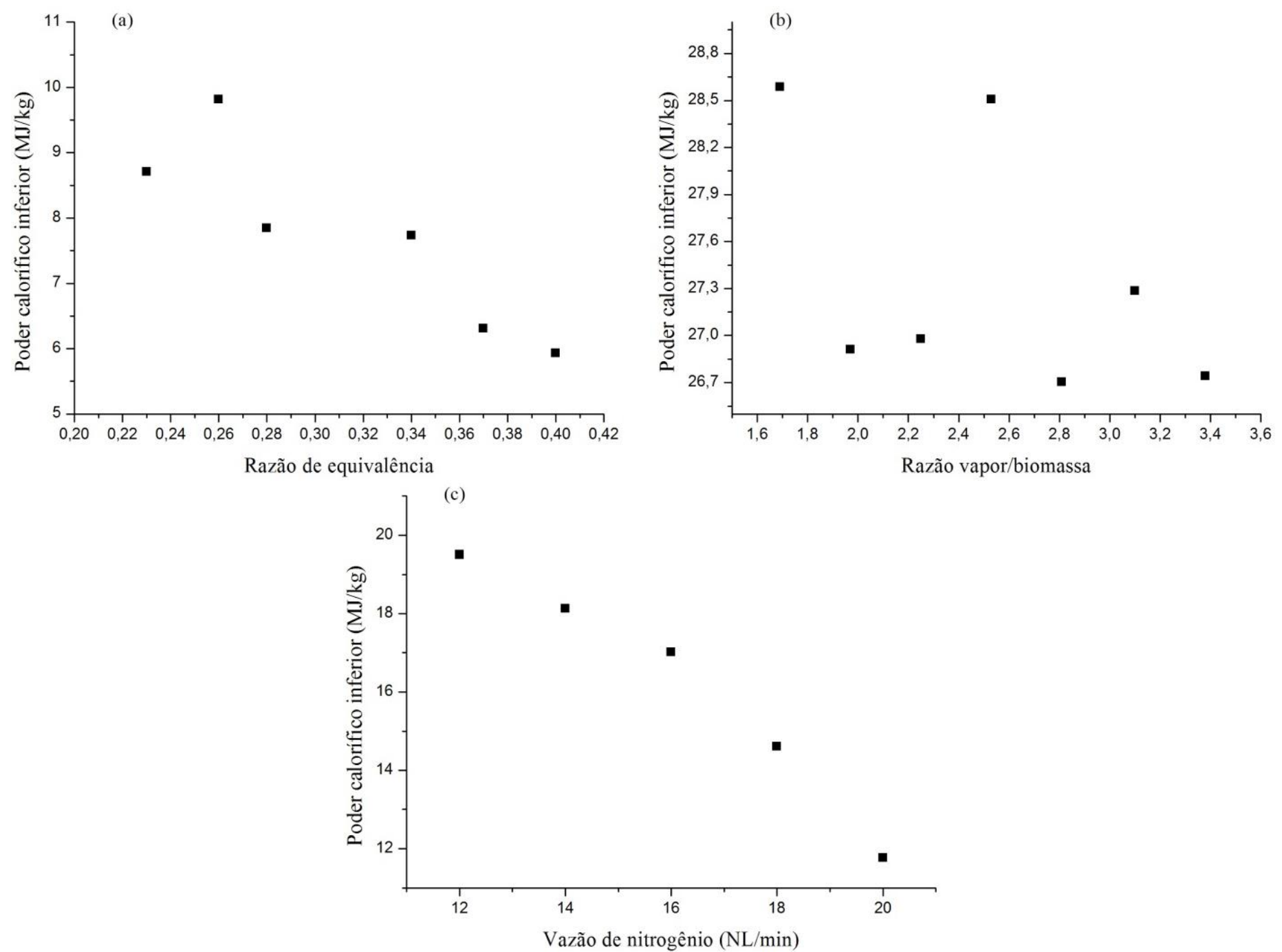

Figura 8.17 - Poder calorífico inferior (MJ/kg) em função de: a) RE b) SBR c) vazão de nitrogênio (NL/min). 


\subsection{CONSIDERAÇÃO FINAL}

Os processsos de produção de gás combustível através de gaseificação com ar e vapor d'água e pirólise com nitrogênio produziram gases com interessante poder calorífico, principalmente o processo com vapor, de onde obteve-se um gás com poder calorífico mínimo de $7,80 \mathrm{MJ} / \mathrm{m}^{3}$ (SBR iguala 3,10) e máximo de $8,56 \mathrm{MJ} / \mathrm{m}^{3}$ (SBR igual a 1,97). O valor mínimo de poder calorífico produzido com vapor foi maior que o valor máximo de poder calorífico produzido com nitrogênio, 5,29 MJ/m³ (vazão de 12 $\mathrm{NL} / \mathrm{min}$ ), e com ar, 4,68 MJ/m³ (RE igual a 0,26). Além disso, como foi discutido, para os valores de vazão de nitrogênio de 12, 16 e $18 \mathrm{NL} / \mathrm{min}$ e para todas as condições experimentais utilizando vapor como agente de fluidização, o poder calorífico do gás, em $\mathrm{MJ} / \mathrm{kg}$, é maior que o poder calorífico da biomassa in natura, o que reforça a viabilidade técnica da utilização do vapor d'água como agente de fluidização no processo de gaseificação de biomassa. 


\section{CONCLUSÕES}

Por meio dos ensaios de fluidização determinou-se a vazão mínima de fluidização do leito de quartzo ocre para os agentes de fluidização ar, vapor e nitrogênio à temperatura ambiente e de gaseificação. Os valores obtidos foram de $6 \mathrm{NL} / \mathrm{min}, 12$ $\mathrm{mL} / \mathrm{min}$ e $12 \mathrm{NL} / \mathrm{min}$ para ar, vapor e nitrogênio, respectivamente, à temperatura de gaseificação.

A melhor condição experimental dos processos de produção de gás combustível está intimamente ligada à aplicação deste gás. Se o objetivo do processo for a utilização do gás para geração de energia elétrica, deve-se levar em consideração a condição experimental com maior poder calorífico do gás formado. A melhor condição experimental para a gaseificação com ar foi utilizando a razão de equivalência igual a 0,26, onde obteve-se um gás com poder calorífico inferior de 9,82 MJ/kg (4,68 $\left.\mathrm{MJ} / \mathrm{Nm}^{3}\right)$. Na pirólise com nitrogênio, foi obtido um PCI máximo de 19,50 MJ/kg (5,29 $\mathrm{MJ} / \mathrm{Nm}^{3}$ ) na condição experimental de $12 \mathrm{NL} / \mathrm{min}$ (condição mínima de fluidização). O maior PCI médio obtido dentre todos os processos de produção de gás combustível foi de 28,59 MJ/kg $\left(8,56 \mathrm{MJ} / \mathrm{Nm}^{3}\right)$ para a gaseificação com vapor d'água, na condição de mínima fluidização do leito, com um SBR de 1,69. Todas as condições experimentais de SBR apresentaram poder calorífico superior às condições experimentais utilizando nitrogênio e ar, o que confirma que o vapor d'água apresenta um grande potencial de geração de energia a partir da gaseificação.

Se o objetivo do processo de produção de gás é obter a maior quantidade em massa de $\mathrm{H}_{2}$ para a produção de químicos, combustíveis e hidrogênio, por exemplo, a partir do gás de síntese $\left(\mathrm{H}_{2}\right.$ e $\left.\mathrm{CO}\right)$ deve-se analisar os resultados experimentais levandose em consideração a produtividade destes gases. A melhor condição experimental de produtividade para o gás $\mathrm{H}_{2}$ na gaseificação com ar foi 0,01 grama de $\mathrm{H}_{2}$ por grama de biomassa, para RE igual a 0,26. Na gaseificação com vapor, obteve-se 0,02 gramas de $\mathrm{H}_{2}$ por grama de biomassa para SBR igual a 2,81. E na pirólise, a condição experimental de $16 \mathrm{NL} /$ min produziu 0,02 gramas de $\mathrm{H}_{2}$ por grama de biomassa.

Nos processos de gaseificação e pirólise em leito fluidizado em escala piloto apresentados neste trabalho foram obtidos bons resultados de produção de gás combustível, principalmente na gaseificação com vapor d'água. Destaca-se que as florestas plantadas têm ganhando cada vez mais destaque no cenário nacional como 
fonte de diversas cadeias produtivas. Alguns dos processos produtivos que utilizam as florestas plantadas têm utilizado o licor negro e resíduos sólidos como fonte de energia através da queima. A gaseificação aplicada a estas matérias-primas pode representar uma boa alternativa de aumentar o valor agregado destes processos produtivos na produção de químicos, biocombustíveis (síntese Fischer-Tropsch, metanol) e energia elétrica a partir de células a combustível ou IGCC (Integrated Gasification combined cycle).

A utilização de plantas de gaseificação em comunidades rurais com difícil acesso à energia elétrica também representa uma alternativa interessante para a geração de energia para estas comunidades e se apresentam como soluções tecnológicas interessantes para a descentralização da matriz energética nacional. 


\section{SUGESTÕES PARA TRABALHOS FUTUROS E MELHORIAS NO PROCESSO}

O objetivo inicial do presente projeto era avaliar várias condições de processo para os agentes de gaseificação ar, vapor e uma mistura destes, bem como comparar com o processo nas mesmas condições experimentais utilizando nitrogênio como agente de fluidização. Infelizmente, problemas operacionais no sistema de reação (danos no sistema de distribuição de ar, mais precisamente na placa distribuidora) impossibilitaram a realização de todos os experimentos. O planejamento inicial foi realizar uma batelada de experimentos utilizando ar, vapor, nitrogênio e uma mistura destes, e após análise dos resultados, repetir a condição experimental ótima de cada agente de fluidização analisando o balanço de massa (gás, alcatrão e água e produtos sólidos) de cada uma delas. Com a inviabialidade de repetição da condição ótima de cada agente de fluidização (danos da placa distribuidora do agente de fluidização), não foram quantificados os co-produtos carvão e condensado (alcatrão, água, óleos).

Outro fator que dificulta a quantificação do carvão e cinzas gerados é que os ciclones não foram projetados para trabalhar com a granulometria dos sólidos gerados no processo, e a maior parte dos sólidos acumula nas tubulações da planta tanto anterior ao ciclone quanto posterior ao mesmo (algumas vezes causando entupimento). A quantificação de alcatrão sofre do mesmo problema, já que a fração mais pesada do alcatrão fica acumulada nas paredes do condensador e nas tubulações posteriores ao mesmo, e o alcatrão mais leve e mais "limpo" (quase livre de particulado) é obtido no recipiente que fica abaixo do condensador. Desta forma, optou-se por apenas focar o projeto na determinação das condições ótimas de produção de gás combustível, sem se importar com os co-produtos gerados.

Uma sugestão para melhorar o processo de produção de gás combustível na planta piloto de pirólise e gaseificação é a substituição principalmente das tubulações anteriores aos ciclones e posteriores ao condensador por tubulações de diâmetro maior, evitando ou diminuindo o risco de entupimento. Outra sugestão, com relação à limpeza do gás, é o projeto de ciclones que sejam capazes de realizá-la de maneira mais eficiente, já que para a biomassa utilizada neste trabalho os ciclones não se comportaram de forma satisfatória. 
Um outro gargalo do processo é a alimentação de sólidos. O sistema de alimentação não se apresenta viável. A planta foi projetada para trabalhar com uma alimentação de $1,2 \mathrm{~kg}$ de biomassa por hora, e o que se obteve em média para os processos de gaseificação de ar, vapor e nitrogênio foi de 357 g/hora, 408,6 g/hora e 536 g/hora, respectivamente, o que está bem longe da alimentação de projeto. Uma outra questão relativa à alimentação de biomassa é o vazamento de gás no momento de realimentação de combustível, o que de certa forma compromete a segurança de utilização da planta. A realimentação de Eucalyptus grandis era realizada a uma faixa de 40 a 50 minutos durante o processo, e neste momento, o nitrogênio alimentado na câmara de expansão não consegue evitar um fluxo contrário (sentido do reator para o sistema de alimentação) de gás produto e leito de quartzo, o que acarreta em travamento do motor durante a realimentação. Nesse caso, uma solução bem sucedida foi reduzir a rotação dos motores de alimentação para uma velocidade menor $(60,40 \%)$, durante alguns poucos minutos (2,3 minutos), e aumentar gradativamente essa rotação até $100 \%$ novamente. Nota-se, pelo "barulho" que o sistema de alimentação faz que há de fato um fluxo de leito de quartzo para o tubo de alimentação da rosca alimentadora (tubo que liga a câmara de expansão ao reator), mas em poucos minutos o sistema de alimentação consegue "devolver" o quartzo ao sistema de reação, e o "barulho" de quartzo na alimentação cessa.

Com relação à sugestão para trabalhos futuros na planta:

- Projeto do sistema de distribuição de agente de fluidização;

- Projeto de um sistema de ciclones que seja capaz de trabalhar com granulometrias próximas das obtidas no processo de gaseificação deste trabalho;

- Projeto de melhoria no sistema de alimentação de biomassa;

- Testes de gaseificação com oxigênio, dióxido de carbono;

- Balanço de massa, considerando as frações sólida e líquida, das melhores condições experimentais obtidas no presente trabalho;

- Estudos de recuperação da água utilizada no processo de gaseificação com vapor d'água e da água de lavagem de gás;

- Estudos de viabilidade econômica e energética;

- Ensaios de gaseificação com outros tipos de biomassa. 


\section{REFERÊNCIAS BIBLIOGRÁFICAS}

[1] HUSSAIN, A., ARIF, S. M. \& ASLAM, M. Emerging Renewable and Sustainable Energy Technologies: State of the Art. Renewable and Sustainable Energy Reviews, v. 71, p. 12-28, 2017.

[2] PANOS, E., DENSING, M. \& VOLKART, K. Access to Electricity in the World Energy Council's Global Energy Scenarios: An Outlook for Developing Regions until 2030. Energy Strategy Reviews, v. 9, p. 28-49, 2016.

[3] IBÁ, I. B. D. Á. Relatório Ibá 2016. 2015.

[4] SANTAROSA, E., PENTEAdO JÚNIOR, J. F. \& GOULART, I. C. G. D. R. Transferência De Tecnologia Florestal: Cultivo De Eucalipto Em Propriedades Rurais: Diversificação Da Produção E Renda. p. 138 p., 2014.

[5] BALAT, H. \& KıRTAY, E. Hydrogen from Biomass - Present Scenario and Future Prospects. International Journal of Hydrogen Energy, v. 35, n. 14, p. 7416-7426, 2010.

[6] GOYAL, H. B., SEAL, D. \& SAXENA, R. C. Bio-Fuels from Thermochemical Conversion of Renewable Resources: A Review. Renewable and Sustainable Energy Reviews, v. 12, n. 2, p. 504-517, 2008.

[7] LORA, E. E. S. \& VENTURINI, O. J. Gaseificação E Pirólise Para a Conversão Da Biomassa Em Eletricidade E Biocombustíveis. In: (Ed.). Biocombustíveis: Interciência v.1, 2012. cap. 6, p.1200.

[8] ENERGIA, M. D. M. E. Balanço Energético Nacional 2016: Ano Base 2015. p. 292, Rio de Janeiro, 2016.

[9] ZHENG, J.-L., ZHU, M.-Q., WEN, J.-L. \& SUN, R.-C. Gasification of Bio-Oil: Effects of Equivalence Ratio and Gasifying Agents on Product Distribution and Gasification Efficiency. Bioresource Technology, v. 211, p. 164-172, 2016.

[10] ANEEL. Atlas De Energia Do Brasil. Brasília, 2005.

[11] PIGHinelli, A. L. M. T., BOATENG, A. A., MULLEN, C. A. \& ELKASABI, Y. Evaluation of Brazilian Biomasses as Feedstocks for Fuel Production Via Fast Pyrolysis. Energy for Sustainable Development, v. 21, p. 42-50, 2014.

[12] BRIDGWATER, A. V. Renewable Fuels and Chemicals by Thermal Processing of Biomass. Chemical Engineering Journal, v. 91, n. 2-3, p. 87-102, 2003.

[13] MEIER, D., VAN DE BELD, B., BRIDGWATER, A. V., ELLIOTT, D. C., OASMAA, A. \& PRETO, F. State-of-the-Art of Fast Pyrolysis in Iea Bioenergy Member Countries. Renewable and Sustainable Energy Reviews, v. 20, p. 619641, 2013.

[14] BASU, P. Chapter 5 - Gasification Theory and Modeling of Gasifiers. In: (Ed.). Biomass Gasification and Pyrolysis. Boston: Academic Press, 2010.

[15] RUIZ, J. A., JUÁREZ, M. C., MORALES, M. P., MUÑOZ, P. \& MENDÍVIL, M. A. Biomass Gasification for Electricity Generation: Review of Current Technology Barriers. Renewable and Sustainable Energy Reviews, v. 18, p. 174-183, 2013.

[16] MOLINO, A., CHIANESE, S. \& MUSMARRA, D. Biomass Gasification Technology: The State of the Art Overview. Journal of Energy Chemistry, v. 25, n. 1, p. 10-25, 2016.

[17] MORRIN, S., LETTIERI, P., CHAPMAN, C. \& MAZZEI, L. Two Stage Fluid Bed-Plasma Gasification Process for Solid Waste Valorisation: Technical Review and Preliminary Thermodynamic Modelling of Sulphur Emissions. Waste Management, v. 32, n. 4, p. 676-684, 2012.

[18] SARKER, S., BIMBELA, F., SÁNCHEZ, J. L. \& NIELSEN, H. K. Characterization and Pilot Scale Fluidized Bed Gasification of Herbaceous Biomass: 
A Case Study on Alfalfa Pellets. Energy Conversion and Management, v. 91, p. 451-458, 2015.

[19] GRÄBNER, M., OGRISECK, S. \& MEYER, B. Numerical Simulation of Coal Gasification at Circulating Fluidised Bed Conditions. Fuel Processing Technology, v. 88, n. 10, p. 948-958, 2007.

[20] GÓMEZ-BAREA, A. \& LECKNER, B. Modeling of Biomass Gasification in Fluidized Bed. Progress in Energy and Combustion Science, v. 36, n. 4, p. 444$509,2010$.

[21] MOLINO, A., CHIANESE, S. \& MUSMARRA, D. Biomass Gasification Technology: The State of the Art Overview. Journal of Energy Chemistry,

[22] MCKENDRY, P. Energy Production from Biomass (Part 3): Gasification Technologies. Bioresource Technology, v. 83, n. 1, p. 55-63, 2002.

[23] BOCCI, E., SISINNI, M., MONETI, M., VECCHIONE, L., DI CARLO, A. \& VILLARINI, M. State of Art of Small Scale Biomass Gasification Power Systems: A Review of the Different Typologies. Energy Procedia, v. 45, p. 247-256, 2014.

[24] IM-ORB, K., SIMASATITKUL, L. \& ARPORNWICHANOP, A. Analysis of Synthesis Gas Production with a Flexible H2/Co Ratio from Rice Straw Gasification. Fuel, v. 164, p. 361-373, 2016.

[25] KHALIL, R., VARHEGYI, G., JASCHKE, S., GRONLI, M. G. \& HUSTAD, J. Co2 Gasification of Biomass Chars: A Kinetic Study. Energy \& Fuels, v. 23, n. 1, p. 94-100, 2009.

[26] GIL, J., CORElla, J., AZNAR, M. A. P. \& CABAllerO, M. A. Biomass Gasification in Atmospheric and Bubbling Fluidized Bed: Effect of the Type of Gasifying Agent on the Product Distribution. Biomass and Bioenergy, v. 17, n. 5, p. 389-403, 1999.

[27] SADHWANI, N., ADHIKARI, S. \& EDEN, M. R. Biomass Gasification Using Carbon Dioxide: Effect of Temperature, Co2/C Ratio, and the Study of Reactions Influencing the Process. Industrial \& Engineering Chemistry Research, v. 55, n. 10, p. 2883-2891, 2016.

[28] BASU, P. Combustion and Gasification in Fluidized Beds. Florida, USA: CRC Press in Taylor \& Francis Group, 2006.

[29] SIEDLECKI, M. On the Gasification of Biomass in a Steam-Oxygen Blown Cfb Gasifier with the Focus on Gas Quality Upgrading: Technology Background, Experiments and Mathematical Modeling. Doctoral Thesis. p. 255, 2011.

[30] KUNII, D. In: (Ed.). Fluidization Engineering (Second Edition). Boston: Butterworth-Heinemann, 1991. p.xvii-xviii.

[31] NITZ, M. \& GUARDANI, R., 'Fluidização Gás-Sólido: Fundamentos E Avanços', Revista Brasileira de Engenharia Química 2008.

[32] KUNII, D. \& LEVENSPIEL, O. Phase Interchange Coefficients in Bubbling Fluidized-Beds. Journal of Chemical Engineering of Japan, v. 24, n. 1, p. 138141, 1991.

[33] SADAKA, S. S., GHALY, A. E. \& SABBAH, M. A. Two Phase Biomass AirSteam Gasification Model for Fluidized Bed Reactors: Part I-Model Development. Biomass and Bioenergy, v. 22, n. 6, p. 439-462, 2002.

[34] GORDILLO, E. D. \& BELGHIT, A. A Two Phase Model of High Temperature Steam-Only Gasification of Biomass Char in Bubbling Fluidized Bed Reactors Using Nuclear Heat. International Journal of Hydrogen Energy, v. 36, n. 1, p. 374-381, 2011.

[35] GELDART, D. Types of Gas Fluidization. Powder Technology, v. 7, n. 5, p. 285292, 1973. 
[36] MIRANDA, G. P. Modelagem E Simulação De Reatores De Leito Fluidizado Para a Gaseificação Da Biomassa. Dissertação de Mestrado em Engenharia Química. Universidade Federal do Rio de Janeiro, p. 110, 2014.

[37] CORELLA, J. \& SANZ, A. Modeling Circulating Fluidized Bed Biomass Gasifiers. A Pseudo-Rigorous Model for Stationary State. Fuel Processing Technology, v. 86, n. 9, p. 1021-1053, 2005.

[38] BRIDGWATER, A. V. The Technical and Economic Feasibility of Biomass Gasification for Power Generation. Fuel, v. 74, n. 5, p. 631-653, 1995.

[39] SATTAR, A., LEEKE, G. A., HORNUNG, A. \& WOOD, J. Steam Gasification of Rapeseed, Wood, Sewage Sludge and Miscanthus Biochars for the Production of a Hydrogen-Rich Syngas. Biomass and Bioenergy, v. 69, p. 276-286, 2014.

[40] BACOVSKY, D., LUDWICZEK, N., OGNISSANTO, M. \& WÖRGETTER, M. Status of Advanced Biofuels Demonstration Facilities in 2012: A report to IEA bioenergy task 392013.

[41] ETT, G. \& LANDGRAF, F. Gaseificação De Biomassa - Projeto Biosyngas. In: (Ed.). Anais Do Simpósio Nacional De Biocombustíveis De Aviação: Estado Da Arte, Desafios Atuais E Visão Do Futuro. Brasília, DF: Embrapa, 2013.

[42] 2020, B. Commercializing Liquid Biofuels from Biomass. Disponível em: < http://demoplants.bioenergy2020.eu/ >. Acesso em: 17 de março de 2017.

[43] AMERICAN SOCIETY FOR TESTING MATERIALS, A. D.-., STANDARD TESTE FOR GROSS CALORIFIC VALUE OF COAL AND COKE BY THE ADIABATIC BOMB CALORIMETER, 1996, 9P. .

[44] AMERICAN SOCIETY FOR TESTING MATERIALS, A. D., STANDARD TESTE METHOD FOR ULTIMATE ANALYSIS OF COAL AND COKE, 1989, 3P. .

[45] AMERICAN SOCIETY FOR TESTING MATERIALS, A. E.-., STANDARD TESTE METHOD FOR CARBON AND HYDROGEN IN THE ANALYSIS SAMPLE OF REFUSE-DERIVED FUEL, 2008, 5P. .

[46] AMERICAN SOCIETY FOR TESTING MATERIALS, A. E., STANDARD TESTE METHOD FOR NITROGEN IN THE ANALYSIS SAMPLE OF REFUSED-DERIVED FUEL, 2008, 5P.,

[47] ROCHA, E. P. A., GOMES, F. J. B., SERMYAGINA, E., CARDOSO, M. \& COLODETTE, J. L. Analysis of Brazilian Biomass Focusing on Thermochemical Conversion for Energy Production. Energy \& Fuels, v. 29, n. 12, p. 7975-7984, 2015.

[48] TECH, P. E. User Manual - Gasification Pilot Plant.

[49] RITTER. Gas Meters. KG, R. A. G. C. Germany 2007.

[50] NARVÁEZ, I., ORIO, A., CORELLA, J. \& AZNAR, M. P. Biomass Gasification with Air in a Bubbling Fluidized Bed. Industrial \& Engineering Chemistry Research, v. 35, p. 2110-2120, 1996.

[51] CAMPOY, M., GÓMEZ-BAREA, A., VIDAL, F. B. \& OLLERO, P. Air-Steam Gasification of Biomass in a Fluidised Bed: Process Optimisation by Enriched Air. Fuel Processing Technology, v. 90, n. 5, p. 677-685, 2009.

[52] DETOURNAY, M., HEMATI, M. \& ANDREUX, R. Biomass Steam Gasification in Fluidized Bed of Inert or Catalytic Particles: Comparison between Experimental Results and Thermodynamic Equilibrium Predictions. Powder Technology, v. 208, n. 2, p. 558-567, 2011.

[53] SREEJITH, C., MURALEEDHARAN, C. \& ARUN, P. Performance Prediction of Fluidised Bed Gasification of Biomass Using Experimental Data-Based Simulation Models. In: (Ed.). Biomass Conversion and Biorefinery, v.3, 2013. p.283-304. 
[54] SILVA, F. M. Solgas - Cálculo Da Solubilidade De Gás Na Água 1988.

[55] WALDHEIM, L. \& NILSSON, T. Heating Value of Gases from Biomass Gasification IEA Bioenergy Agreement, Task 20 - Thermal Gasification of Biomass p. 60, 2001.

[56] HEIDENREICH, S. \& FOSCOLO, P. U. New Concepts in Biomass Gasification. Progress in Energy and Combustion Science, v. 46, p. 72-95, 2015.

[57] OLOFSSON, I., NORDIN, A. \& SÖDERLIND, U. Initial Review and Evaluation of Process Technologies and Systems Suitable for Cost-Efficient Medium-Scale Gasification for Biomass to Liquid Fuels., ETPC Report, University Umea and Mid Swedish University, Sweden (2005).

[58] HIGH-TECH, B. General Instructions Digital Mas Flow/Pressure Instruments Laboratory Style/in-Flow. 2010. 


\section{APÊEDICE 1}

São apresentados os perfis dos gases $\mathrm{H}_{2}, \mathrm{CO}, \mathrm{CH}_{4}, \mathrm{H}_{2} \mathrm{~S}$ e $\mathrm{N}_{2}$ formados de gaseificação utilizando ar como agente de fluidização em porcentagem e vazão mássica em função do tempo, bem como a vazão volumétrica total de gás formado durante o processo para as razões de equivalência $0,23,0,26,0,28,0,31,0,37$ e 0,40. 

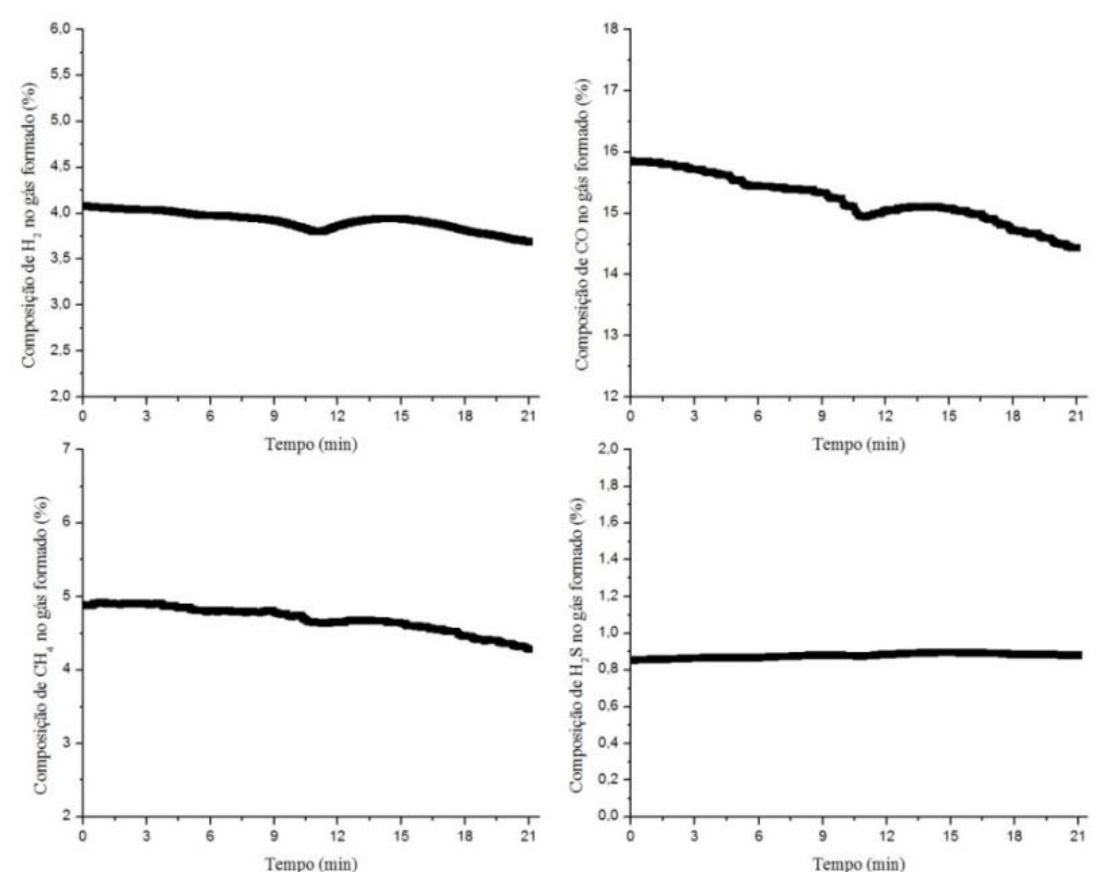

Figura 11.1 - Perfis dos gases $\mathrm{H}_{2}, \mathrm{CO}, \mathrm{CH}_{4}$ e $\mathrm{H}_{2} \mathrm{~S}$, em porcentagem, formados de gaseificação utilizando ar como agente de fluidização para $\mathrm{RE}=0,23$.
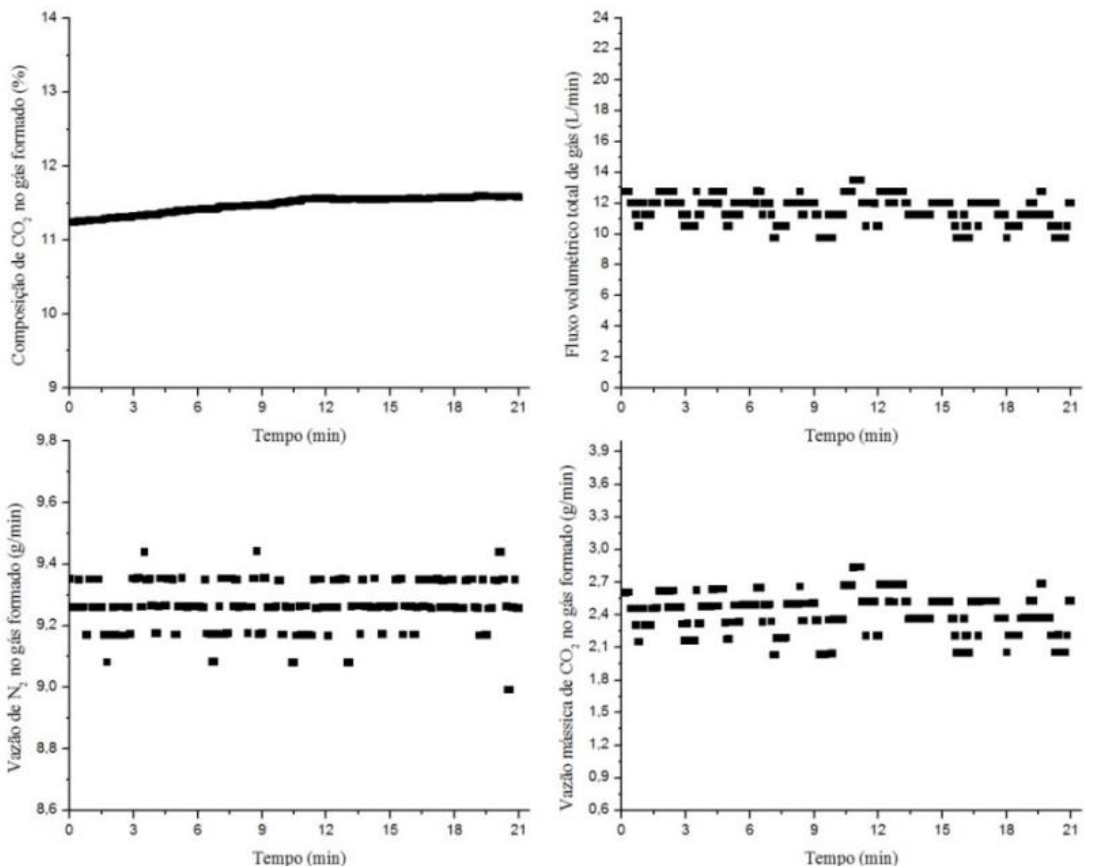

Figura 11.2 - Perfil do gás $\mathrm{CO}_{2}$ em porcentagem, fluxo total volumétrico de gás formado (NL/min), e vazão mássica de $\mathrm{N}_{2}$ e $\mathrm{CO}_{2}$ em função do tempo em gaseificação utilizando ar como agente de fluidização para $\mathrm{RE}=0,23$. 

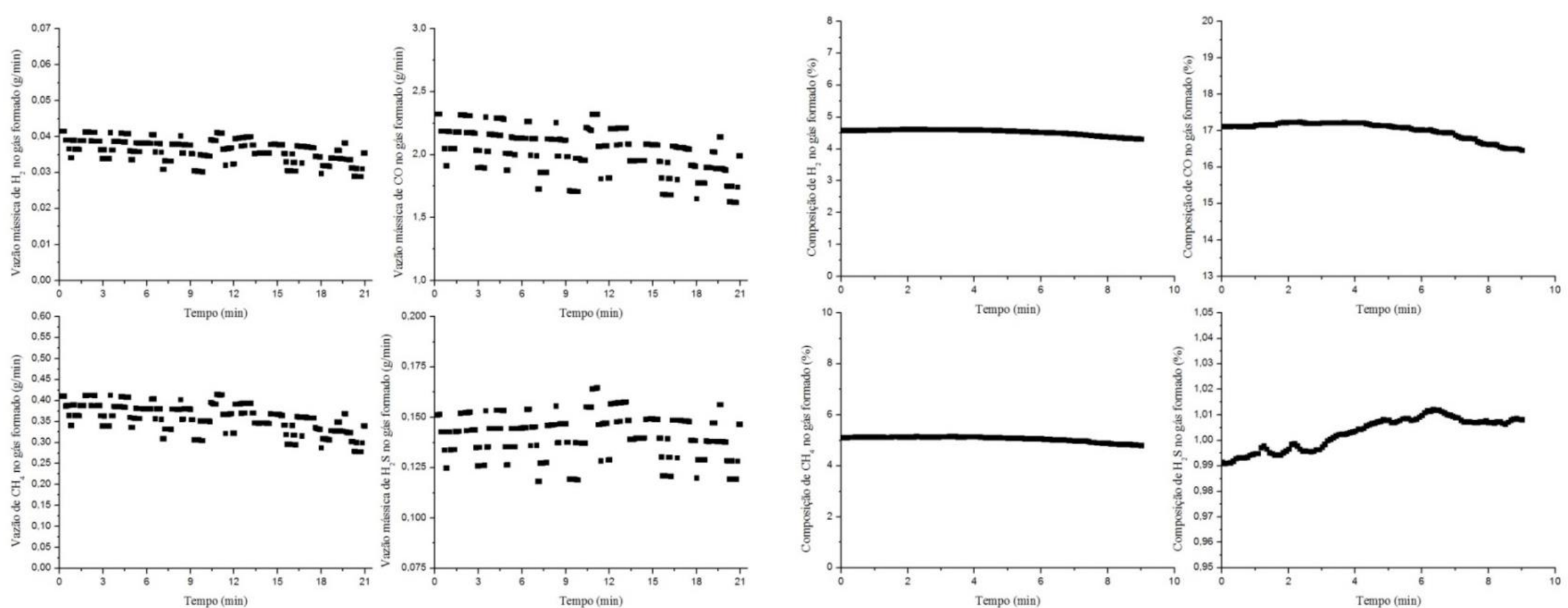

Figura 11.3 - Perfis de vazão (g/min) dos gases $\mathrm{H}_{2}, \mathrm{CO}, \mathrm{CH}_{4}$ e $\mathrm{H}_{2} \mathrm{~S}$, em função do tempo, formados em gaseificação utilizando ar como agente de fluidização para $\mathrm{RE}=0,23$.

11.4 - Perfis dos gases $\mathrm{H}_{2}, \mathrm{CO}, \mathrm{CH}_{4}$ e $\mathrm{H}_{2} \mathrm{~S}$, em porcentagem, formados de gaseificação utilizando ar como agente de fluidização para $\mathrm{RE}=0,26$. 

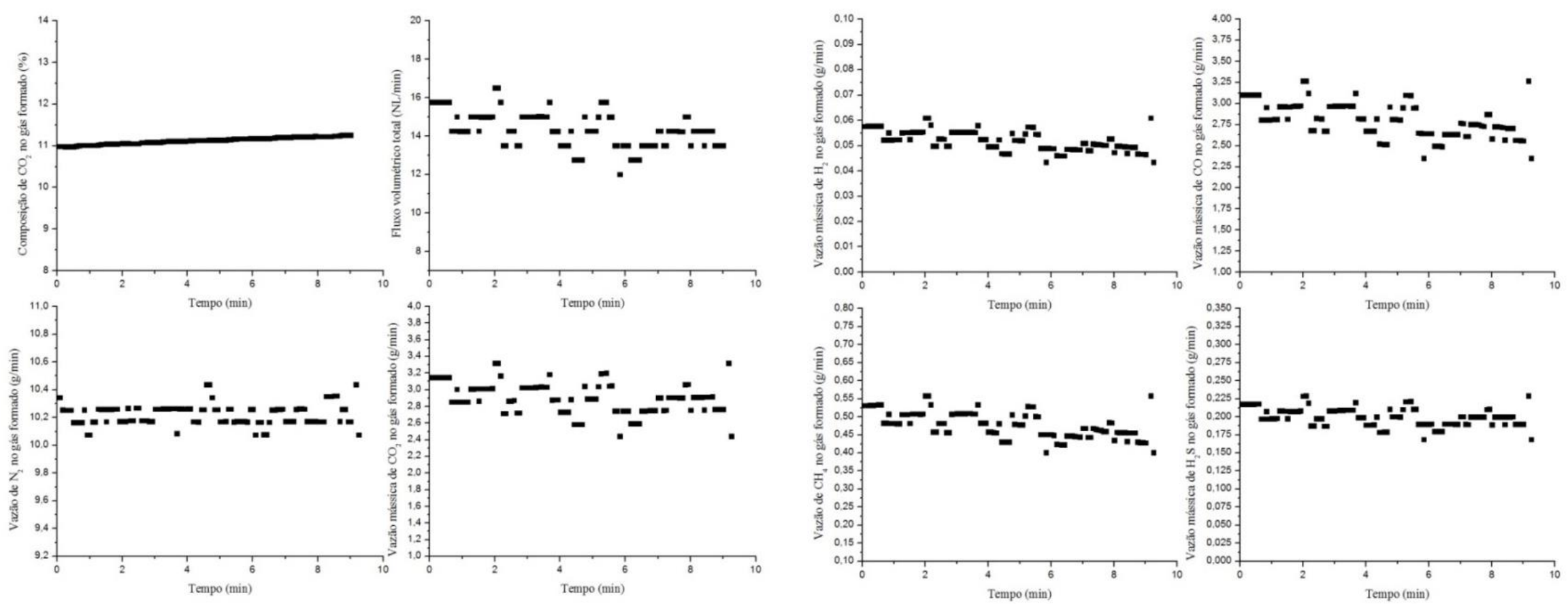

Figura 11.5 - Perfil do gás $\mathrm{CO}_{2}$ em porcentagem, fluxo total Figura 11.6 - Perfis de vazão $(\mathrm{g} / \mathrm{min})$ dos gases $\mathrm{H}_{2}, \mathrm{CO}, \mathrm{CH}_{4}$ e $\mathrm{H}_{2} \mathrm{~S}$, volumétrico de gás formado (NL/min), e vazão mássica de $\mathrm{N}_{2} \mathrm{C}_{2}$ em função do tempo, formados em gaseificação utilizando ar como em função do tempo emgaseificação utilizando ar como agente de agente de fluidização para RE = 0,26.

fluidização para $\mathrm{RE}=0,26$. 

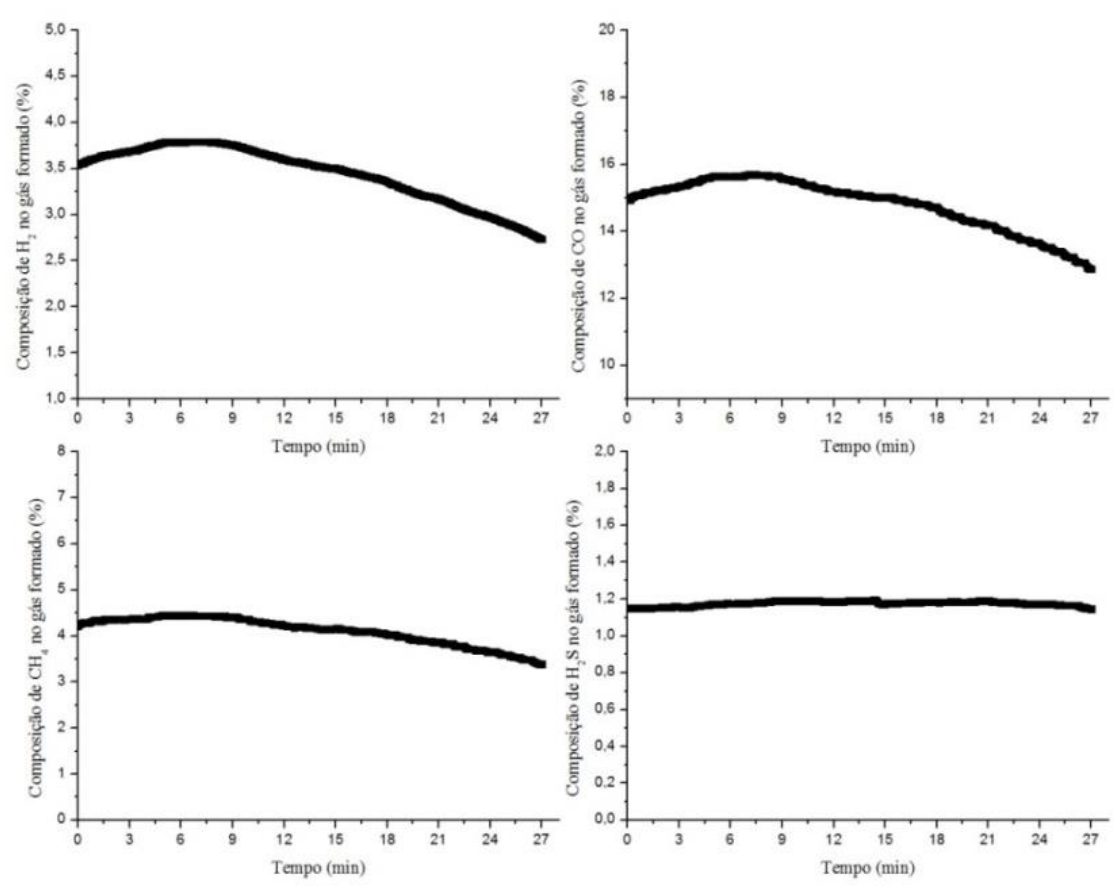

Figura 11.7 - Perfis dos gases $\mathrm{H}_{2}, \mathrm{CO}, \mathrm{CH}_{4}$ e $\mathrm{H}_{2} \mathrm{~S}$, em porcentagem, formados de gaseificação utilizando ar como agente de fluidização para $\mathrm{RE}=0,28$.

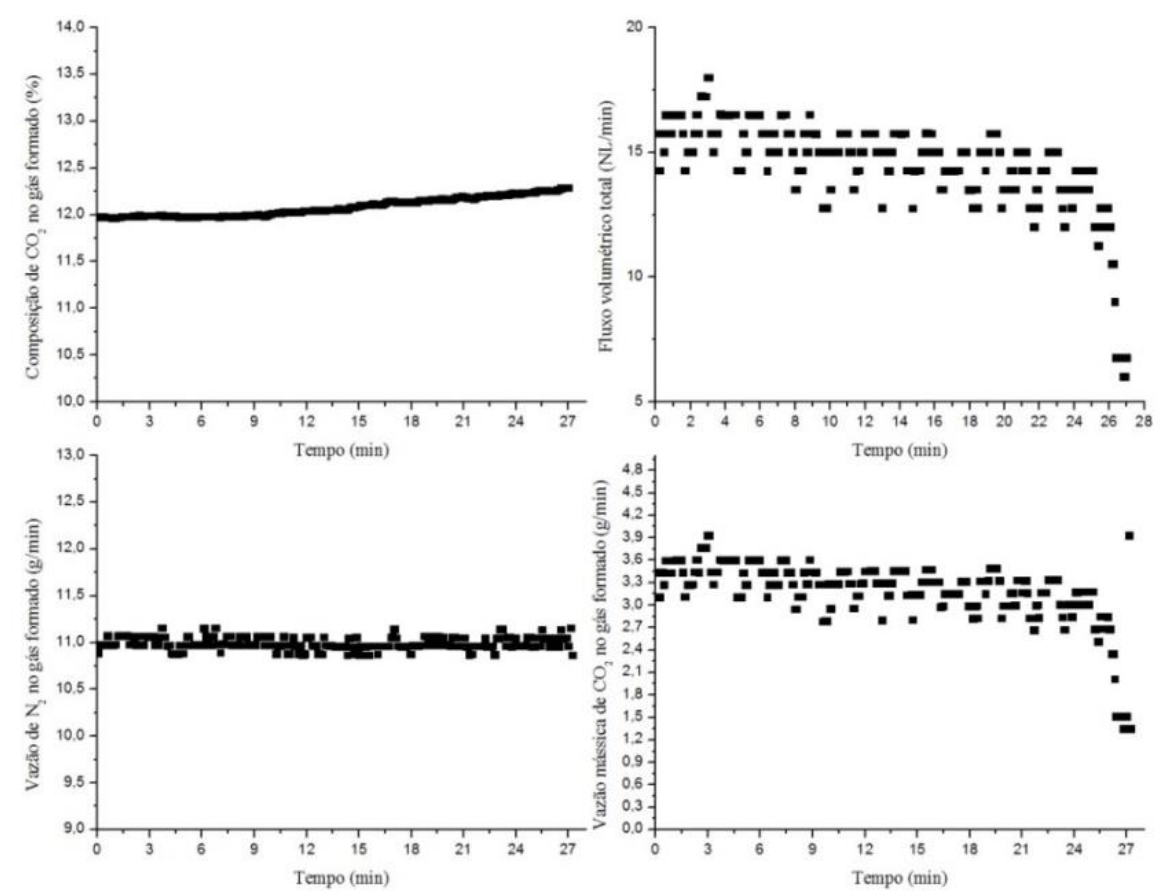

Figura 11.8 - Perfil do gás $\mathrm{CO}_{2}$ em porcentagem, fluxo total volumétrico de gás formado (NL/min), e vazão mássica de $\mathrm{N}_{2}$ e $\mathrm{CO}_{2}$ em função do tempo em gaseificação utilizando ar como agente de fluidização para $\mathrm{RE}=0,28$. 

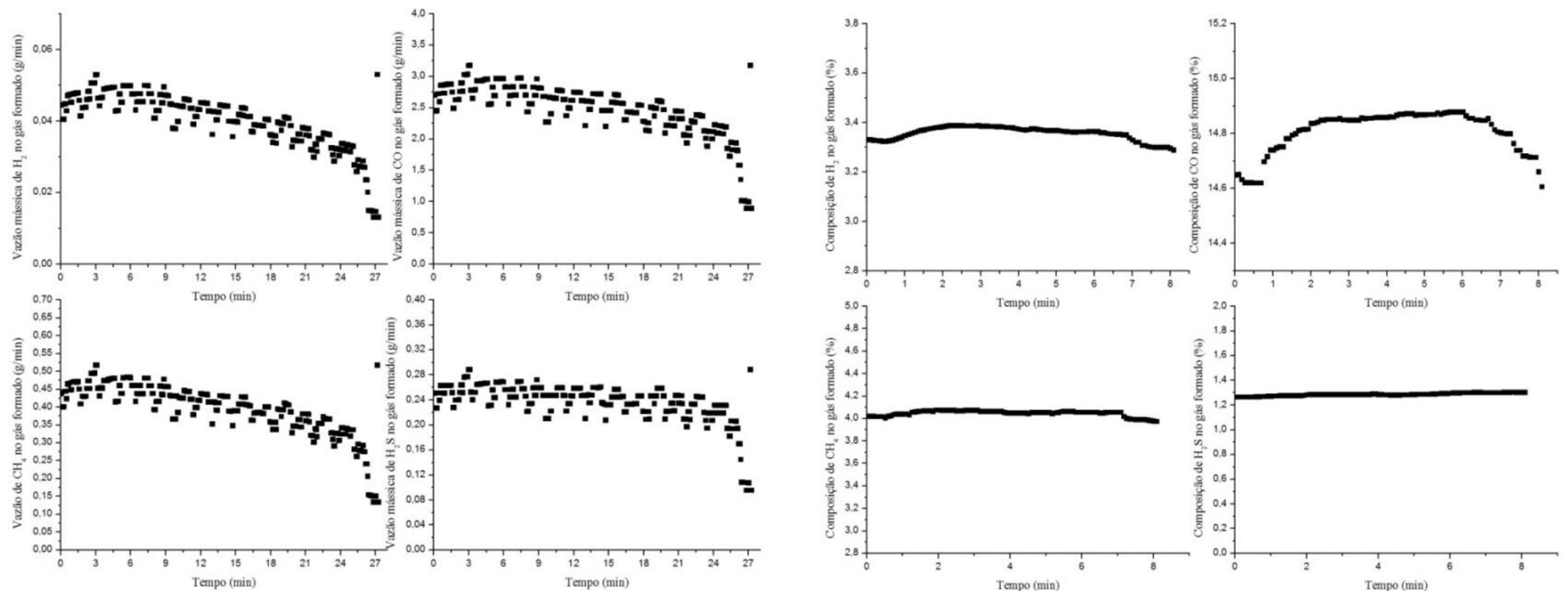

Figura 11.9 - Perfis de vazão $(\mathrm{g} / \mathrm{min})$ dos gases $\mathrm{H}_{2}, \mathrm{CO}, \mathrm{CH}_{4}$ e $\mathrm{H}_{2} \mathrm{~S}$, Figura 11.10 - Perfis dos gases $\mathrm{H}_{2}, \mathrm{CO}, \mathrm{CH}_{4}$ e $\mathrm{H}_{2} \mathrm{~S}$, em em função do tempo, formados em gaseificação utilizando ar como porcentagem, formados de gaseificação utilizando ar como agente agente de fluidização para $\mathrm{RE}=0,28$.

de fluidização para $\mathrm{RE}=0,31$ 

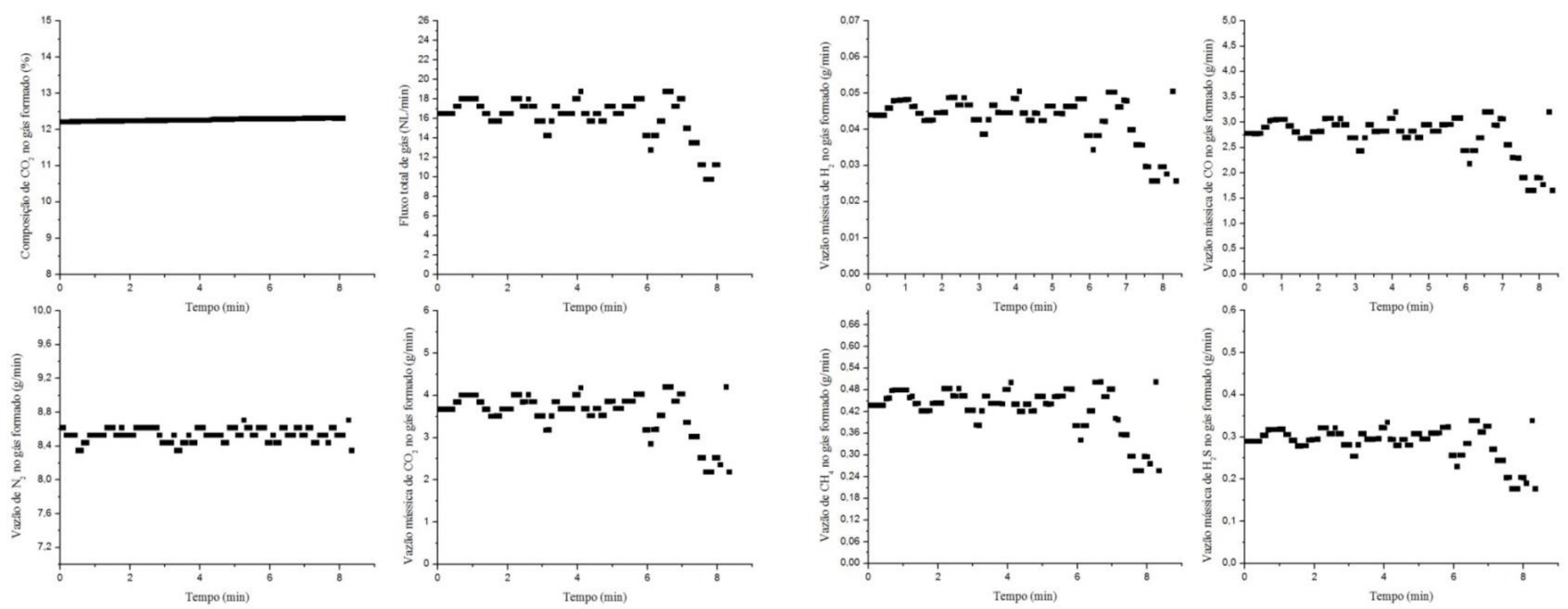

Figura 11.11 - Perfil do gás $\mathrm{CO}_{2}$ em porcentagem, fluxo total Figura 11.12 - Perfis de vazão $(\mathrm{g} / \mathrm{min})$ dos gases $\mathrm{H}_{2}, \mathrm{CO} \mathrm{CH}_{4} \mathrm{e}$ volumétrico de gás formado (NL/min), e vazão mássica de $\mathrm{N}_{2}$ e $\mathrm{CO}_{2}$ em função do tempo em gaseificação utilizando ar como agente de $\mathrm{H}_{2} \mathrm{~S}$, em função do tempo, formados em gaseificação utilizando ar como agente de fluidização para $\mathrm{RE}=0,31$.

fluidização para $\mathrm{RE}=0,31$ 

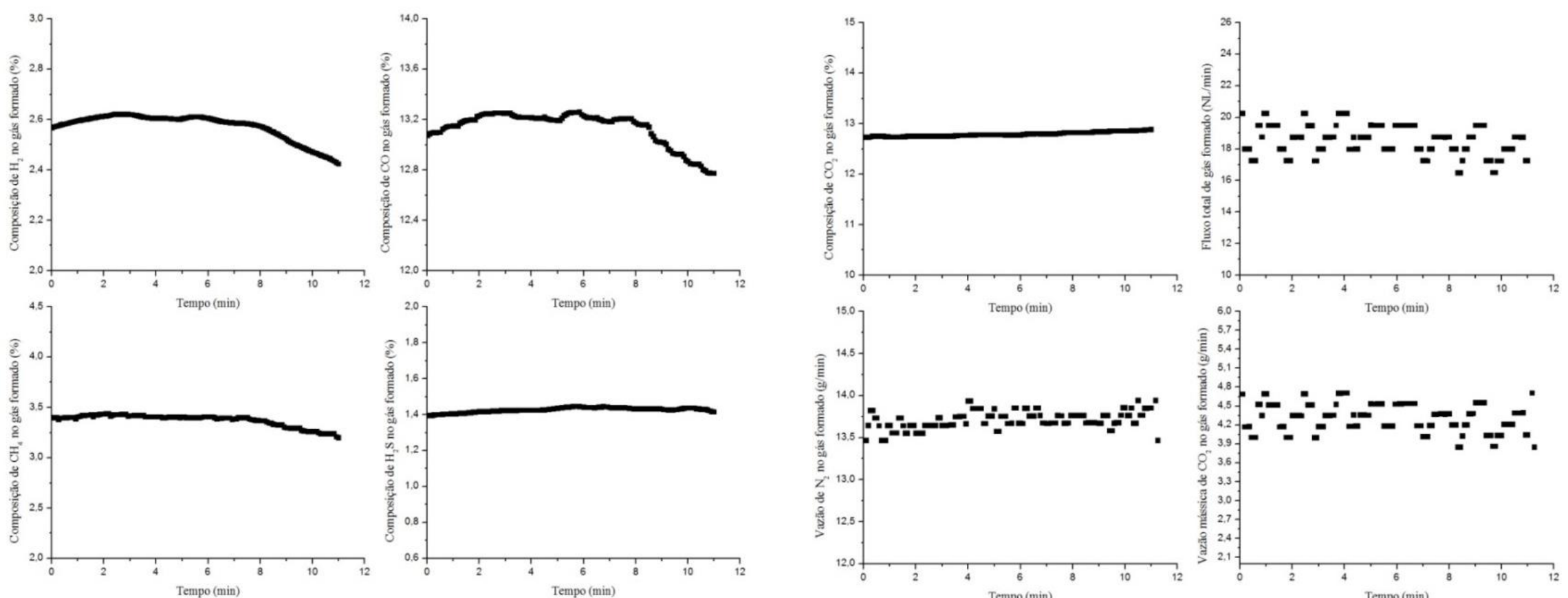

Figura 11.13 - Perfis dos gases $\mathrm{H}_{2}, \mathrm{CO}, \mathrm{CH}_{4}$ e $\mathrm{H}_{2} \mathrm{~S}$, em Figura 11.14 - Perfil do gás $\mathrm{CO}_{2}$ em porcentagem, fluxo total porcentagem, formados de gaseificação utilizando ar como agente de fluidização para $\mathrm{RE}=0,37$.

volumétrico de gás formado (NL/min), e vazão mássica de $\mathrm{N}_{2}$ e $\mathrm{CO}_{2}$ em função do tempo em gaseificação utilizando ar como agente de fluidização para $\mathrm{RE}=0,37$. 

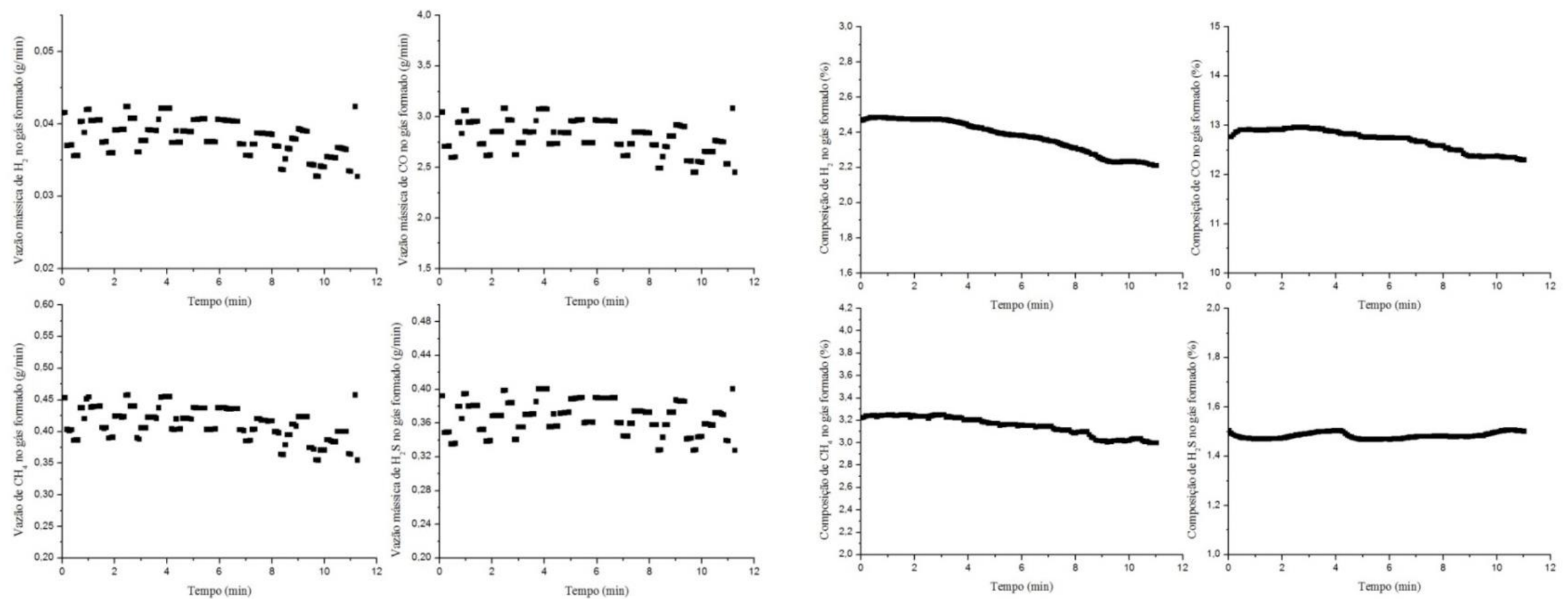

Figura 11.15 - Perfis de vazão $(\mathrm{g} / \mathrm{min})$ dos gases $\mathrm{H}_{2}, \mathrm{CO}, \mathrm{CH}_{4}$ e $\mathrm{H}_{2} \mathrm{~S}$, Figura 11.16 - Perfis dos gases $\mathrm{H}_{2}, \mathrm{CO}_{2} \mathrm{CH}_{4}$ e $\mathrm{H}_{2} \mathrm{~S}$, em em função do tempo, formados em gaseificação utilizando ar como agente de fluidização para $\mathrm{RE}=0,37$.

porcentagem, formados de gaseificação utilizando ar como agente de fluidização para $\mathrm{RE}=0,40$. 

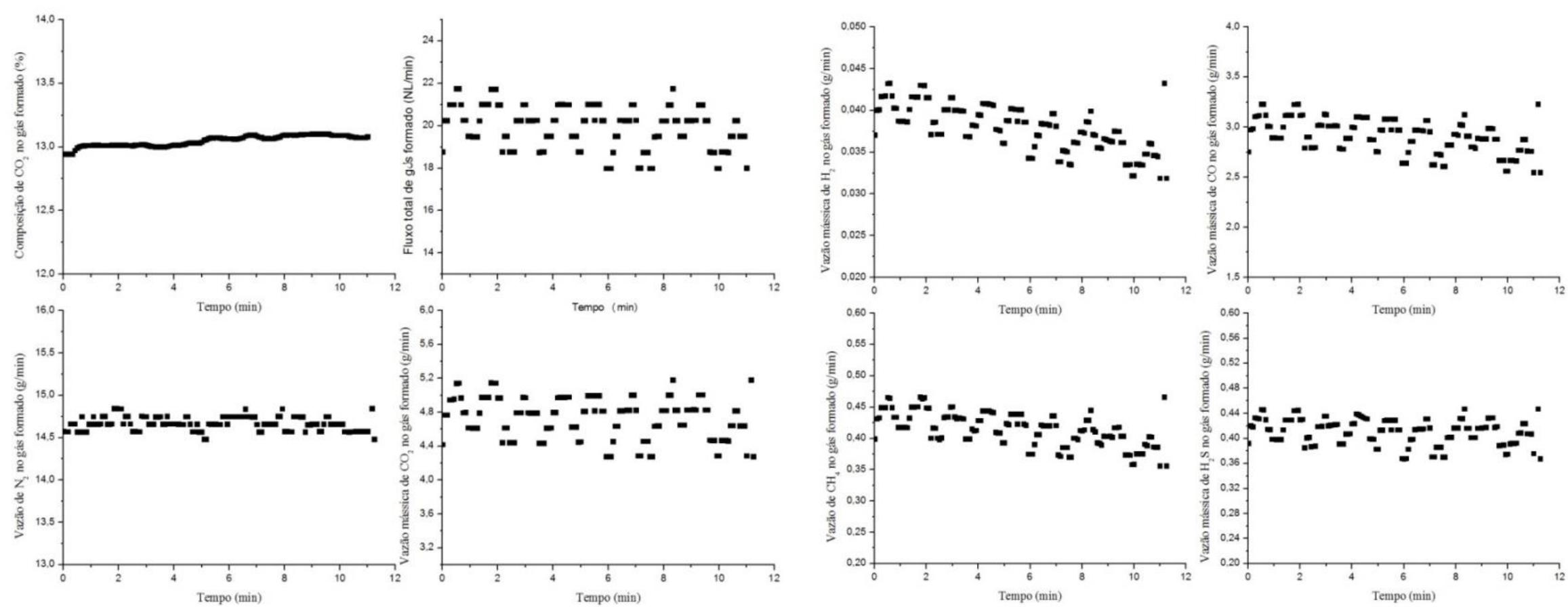

Figura 11.17 - Perfil do gás $\mathrm{CO}_{2}$ em porcentagem, fluxo total Figura 11.18 - Perfis de vazão $(\mathrm{g} / \mathrm{min})$ dos gases $\mathrm{H}_{2}, \mathrm{CO}_{2} \mathrm{CH}_{4} \mathrm{e}$ volumétrico de gás formado (NL/min), e vazão mássica de $\mathrm{N}_{2}$ e $\mathrm{CO}_{2} \quad \mathrm{H}_{2} \mathrm{~S}$, em função do tempo, formados em gaseificação utilizando ar em função dotempo em gaseificação utilizando ar como agente de como agente de fluidização para $\mathrm{RE}=0,40$.

fluidização para $\mathrm{RE}=0,40$. 


\section{APÊNDICE 2}

Serão apresentados os perfis individuais dos gases $\mathrm{H}_{2}, \mathrm{CO}, \mathrm{CH}_{4}, \mathrm{H}_{2} \mathrm{~S}$ e $\mathrm{CO}_{2}$ contendo a vazão mássica produzida de cada gás, um comparativo em porcentagem da medição realizada pelo analisador de gases (considerando a injeção de $\mathrm{N}_{2}$ ), além do fluxo total de gás obtido (NL/min) medido no medidor de fluxo da planta piloto de pirólise e gaseificação, todos em função do tempo (min), para a gaseificação com vapor. 

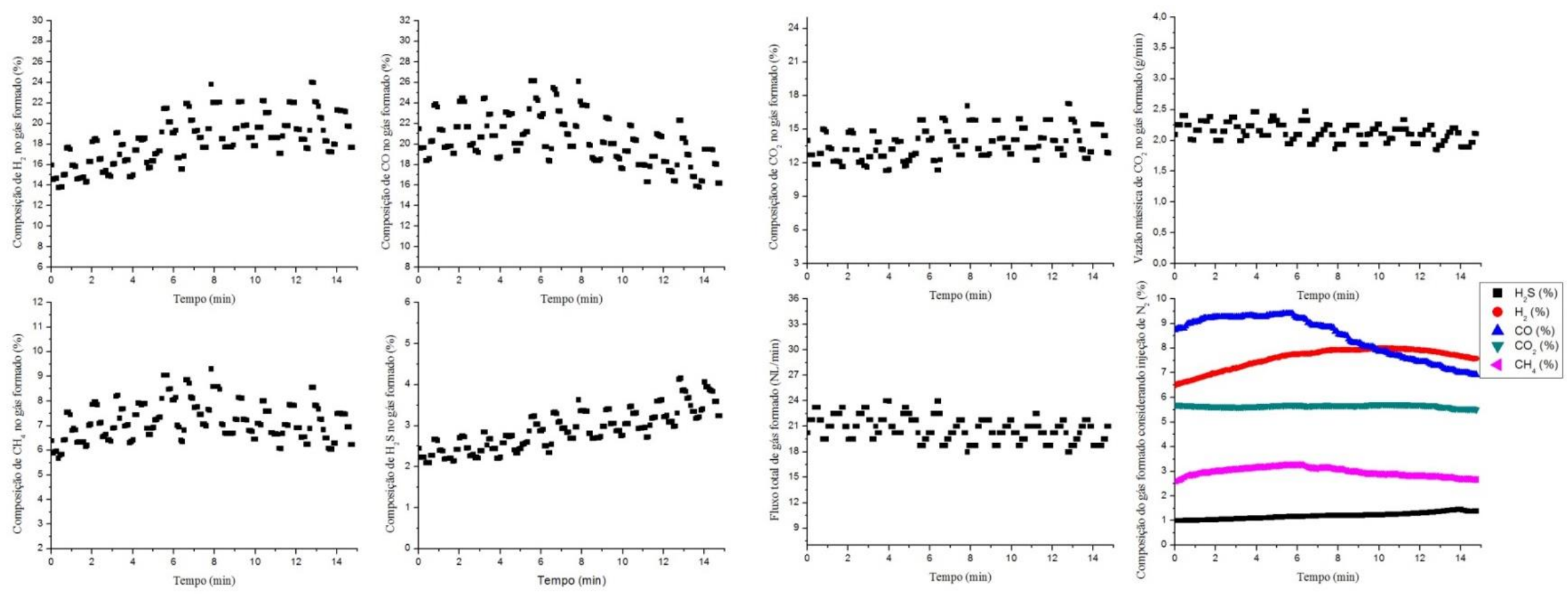

Figura 12.1 - Perfis dos gases $\mathrm{H}_{2}, \mathrm{CO}, \mathrm{CH}_{4}$ e $\mathrm{H}_{2} \mathrm{~S}$, em porcentagem, formados de gaseificação utilizando vapor como agente de fluidização para SBR =1,69.

Figura 12.2 - Perfis do gás $\mathrm{CO}_{2}$ em porcentagem e vazão mássica (g/min), fluxo total volumétrico de gás formado (NL/min), e composição do gás formado determinado no analisador de gases considerando a injeção de $\mathrm{N}_{2}(\%)$, em função do tempo, em gaseificação utilizando vapor como agente de fluidização para $\mathrm{SBR}=$ 1,69 . 

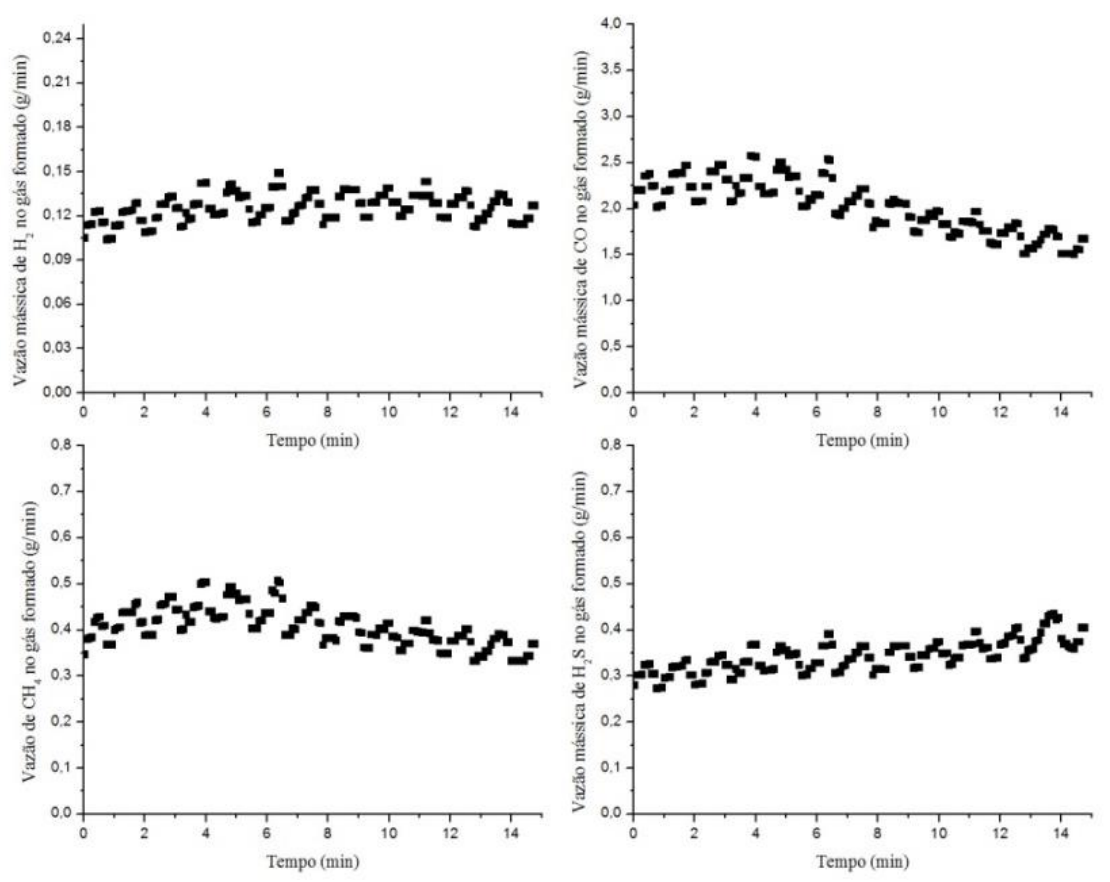

Figura 12.3 - Perfis de vazão (g/min) dos gases $\mathrm{H}_{2}, \mathrm{CO}, \mathrm{CH}_{4}$ e $\mathrm{H}_{2} \mathrm{~S}$, em função do tempo, formados em gaseificação utilizando vapor como agente de fluidização para SBR = 1,69.
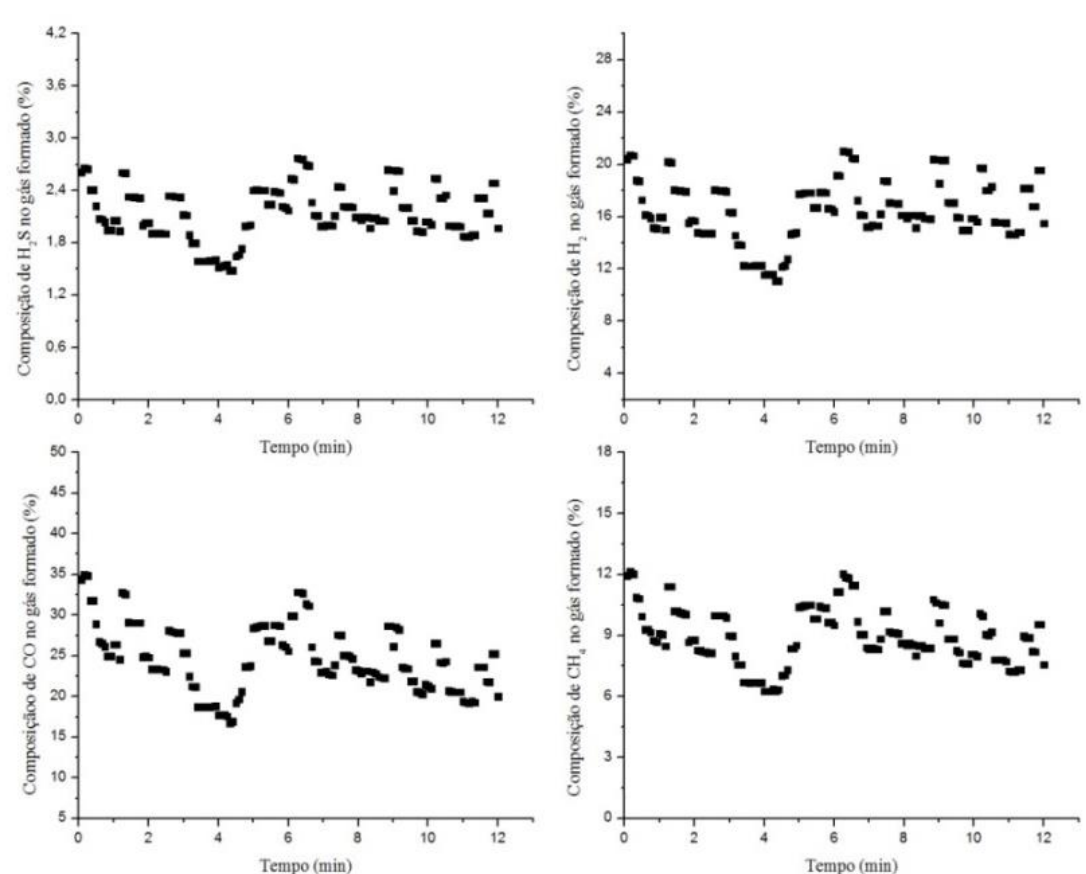

Figura 12.4 - Perfis dos gases $\mathrm{H}_{2}, \mathrm{CO}, \mathrm{CH}_{4}$ e $\mathrm{H}_{2} \mathrm{~S}$, em porcentagem, formados de gaseificação utilizando vapor como agente de fluidização para $\mathrm{SBR}=1,97$. 

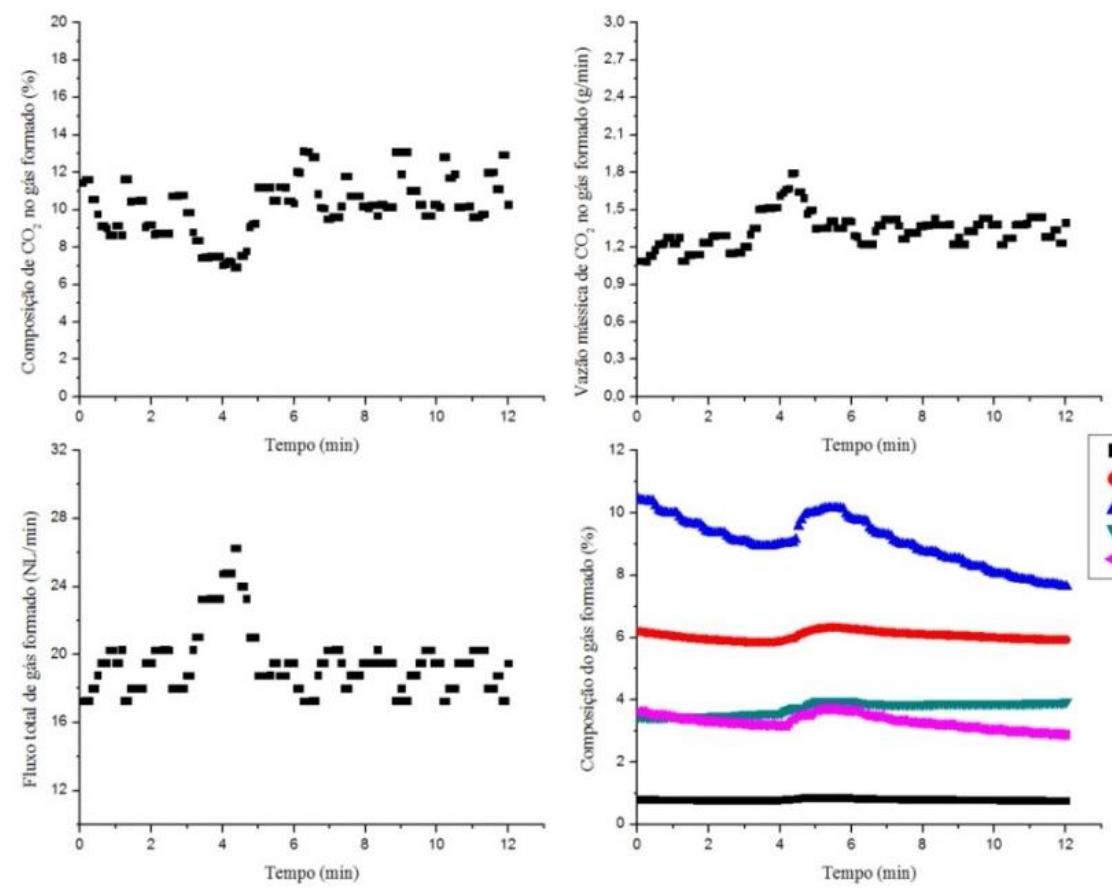

Figura 12.5 - Perfis do gás $\mathrm{CO}_{2}$ em porcentagem e vazão mássica (g/min), fluxo total volumétrico de gás formado (NL/min), e composição do gás formado determinado no analisador de gases considerando a injeção de $\mathrm{N}_{2}(\%)$, em função do tempo, em gaseificação utilizando vapor como agente de fluidização para SBR = 1,97 .
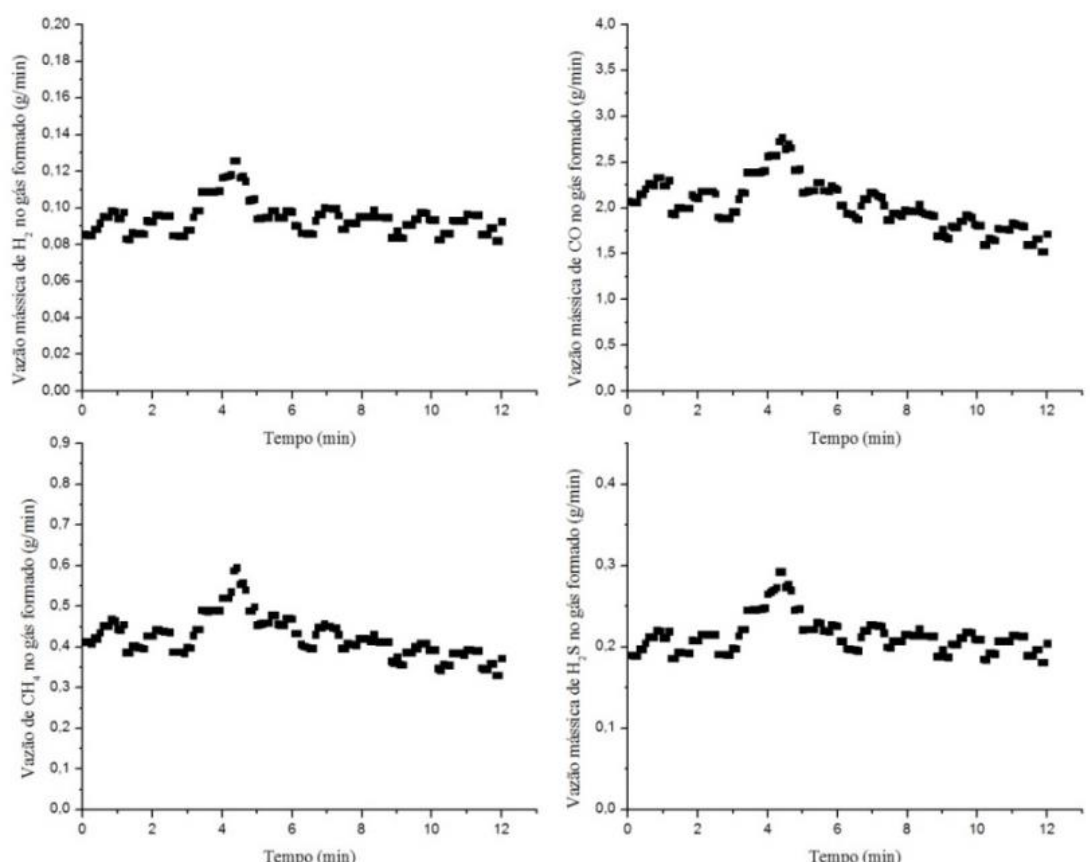

Figura 12.6 - Perfis de vazão $(\mathrm{g} / \mathrm{min})$ dos gases $\mathrm{H}_{2}, \mathrm{CO}, \mathrm{CH}_{4} \mathrm{e}$

$\mathrm{H}_{2} \mathrm{~S}$, em função do tempo, formados em gaseificação utilizando vapor como agente de fluidização para $\mathrm{SBR}=1,97$. 

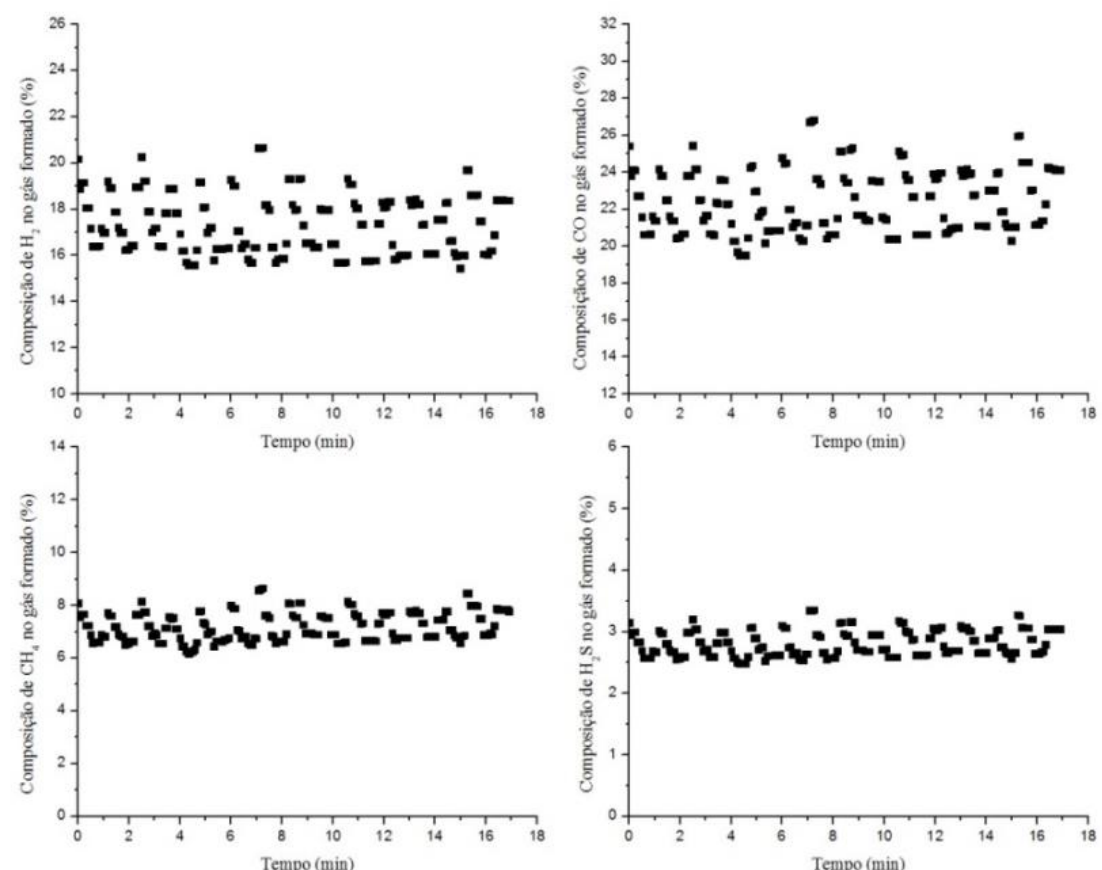

Figura 12.7 - Perfis dos gases $\mathrm{H}_{2}, \mathrm{CO}, \mathrm{CH}_{4}$ e $\mathrm{H}_{2} \mathrm{~S}$, em porcentagem, formados de gaseificação utilizando vapor como agente de fluidização para $\mathrm{SBR}=2,25$.

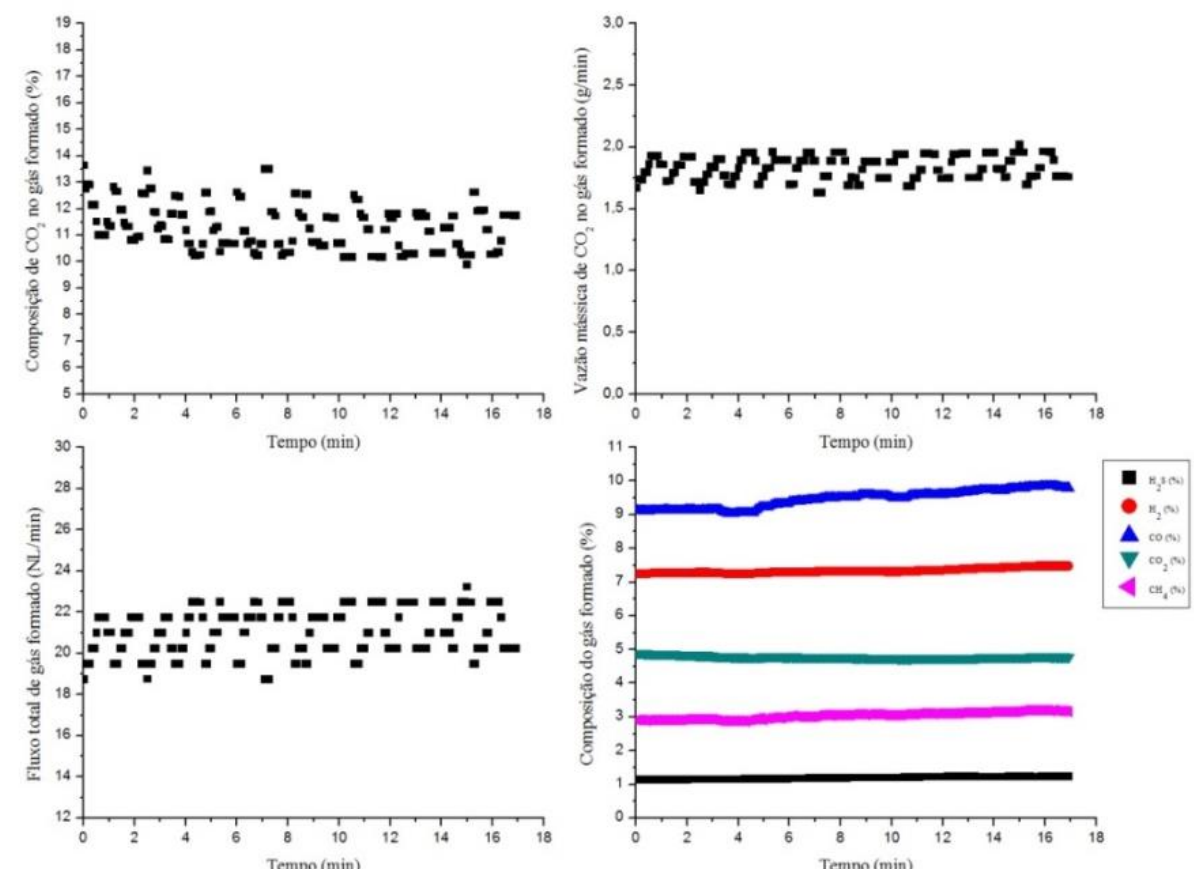

Figura 12.8 - Perfis do gás $\mathrm{CO}_{2}$ em porcentagem e vazão mássica (g/min), fluxo total volumétrico de gás formado ( $\mathrm{NL} / \mathrm{min}$ ), e composição do gás formado determinado no analisador de gases considerando a injeção de $\mathrm{N}_{2}(\%)$, em função do tempo, em gaseificação utilizando vapor como agente de fluidização para SBR = 2,25 . 

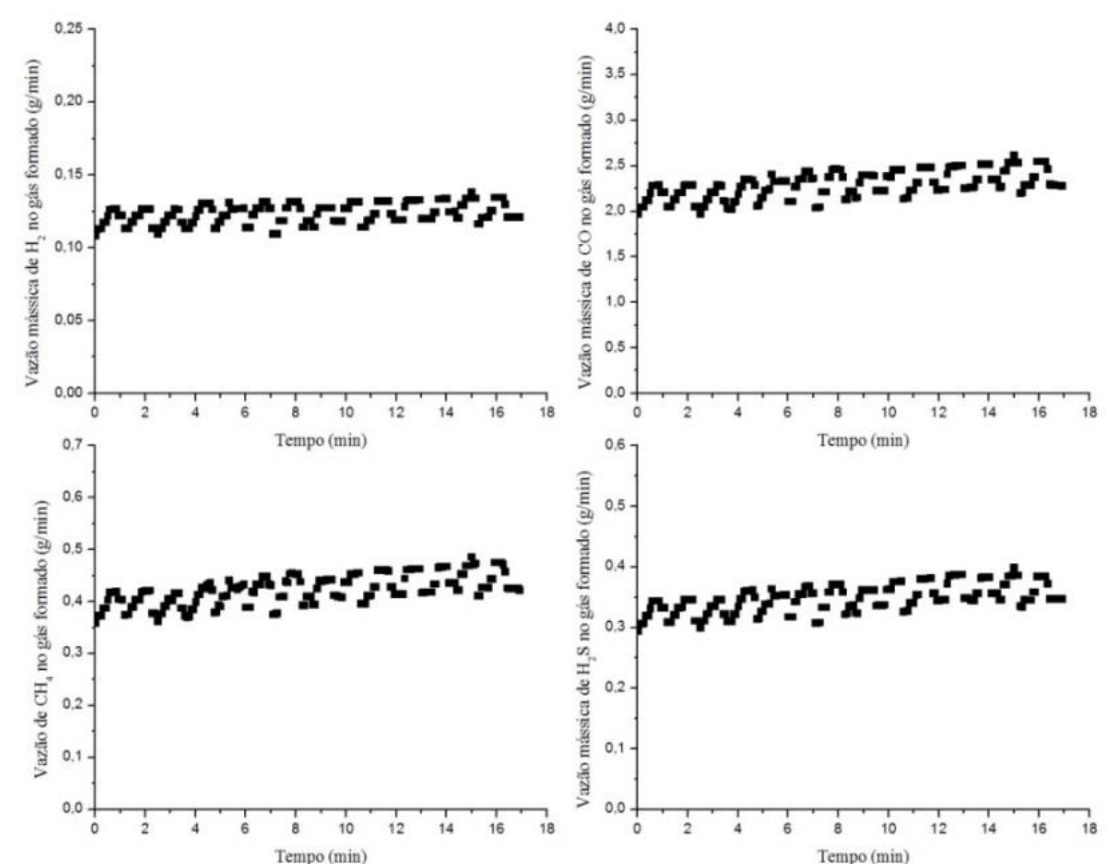

Figura 12.9 - Perfis de vazão (g/min) dos gases $\mathrm{H}_{2}, \mathrm{CO}, \mathrm{CH}_{4}$ e $\mathrm{H}_{2} \mathrm{~S}$ em função do tempo, formados em gaseificação utilizando vapor como agente de fluidização para $\mathrm{SBR}=2,25$.
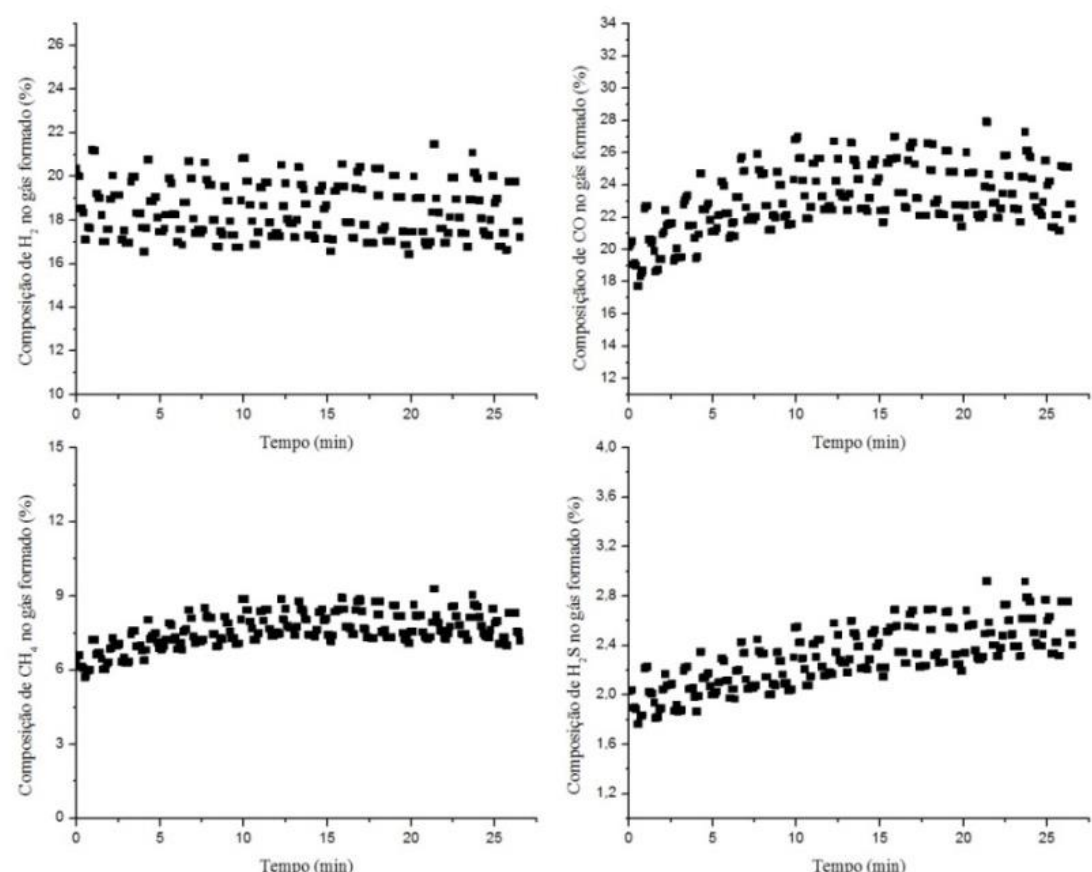

Figura 12.10 - Perfis dos gases $\mathrm{H}_{2}, \mathrm{CO}, \mathrm{CH}_{4}$ e $\mathrm{H}_{2} \mathrm{~S}$, em porcentagem, formados de gaseificação utilizando vapor como agente de fluidização para $\mathrm{SBR}=2,53$. 

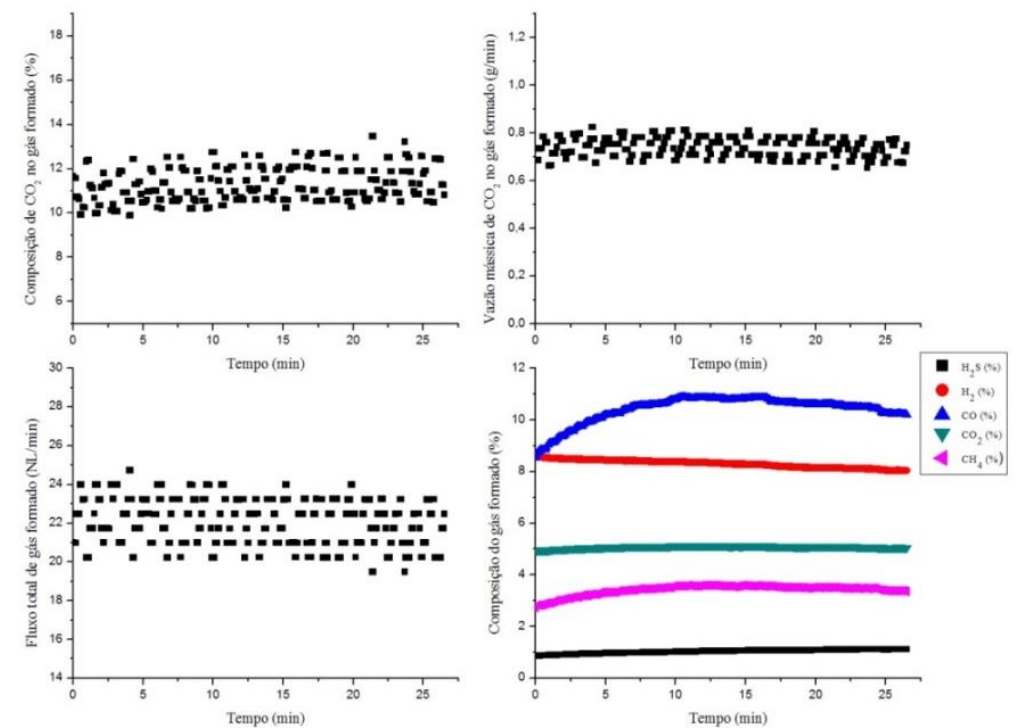

Figura 12.11 - Perfis do gás $\mathrm{CO}_{2}$ em porcentagem e vazão mássica $(\mathrm{g} / \mathrm{min})$, fluxo total volumétrico de gás formado (NL/min), e composição do gás

formado determinado no analisador de gases considerando a injeção de $\mathrm{N}_{2}$ (\%), em função do tempo, em gaseificação utilizando vapor como agente de fluidização para $\mathrm{SBR}=2,53$.
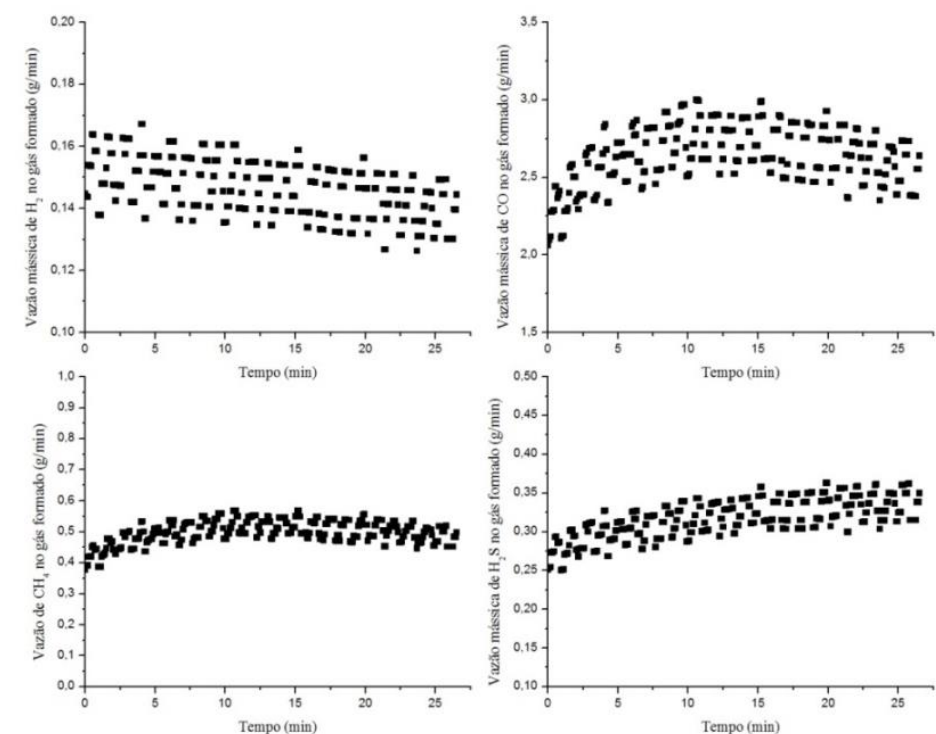

Figura 12.12 - Perfis de vazão (g/min) dos gases $\mathrm{H}_{2}, \mathrm{CO}$, $\mathrm{CH}_{4}$ e $\mathrm{H}_{2} \mathrm{~S}$, em função do tempo, formados em gaseificação utilizando vapor como agente de fluidização para SBR = 2,53 . 

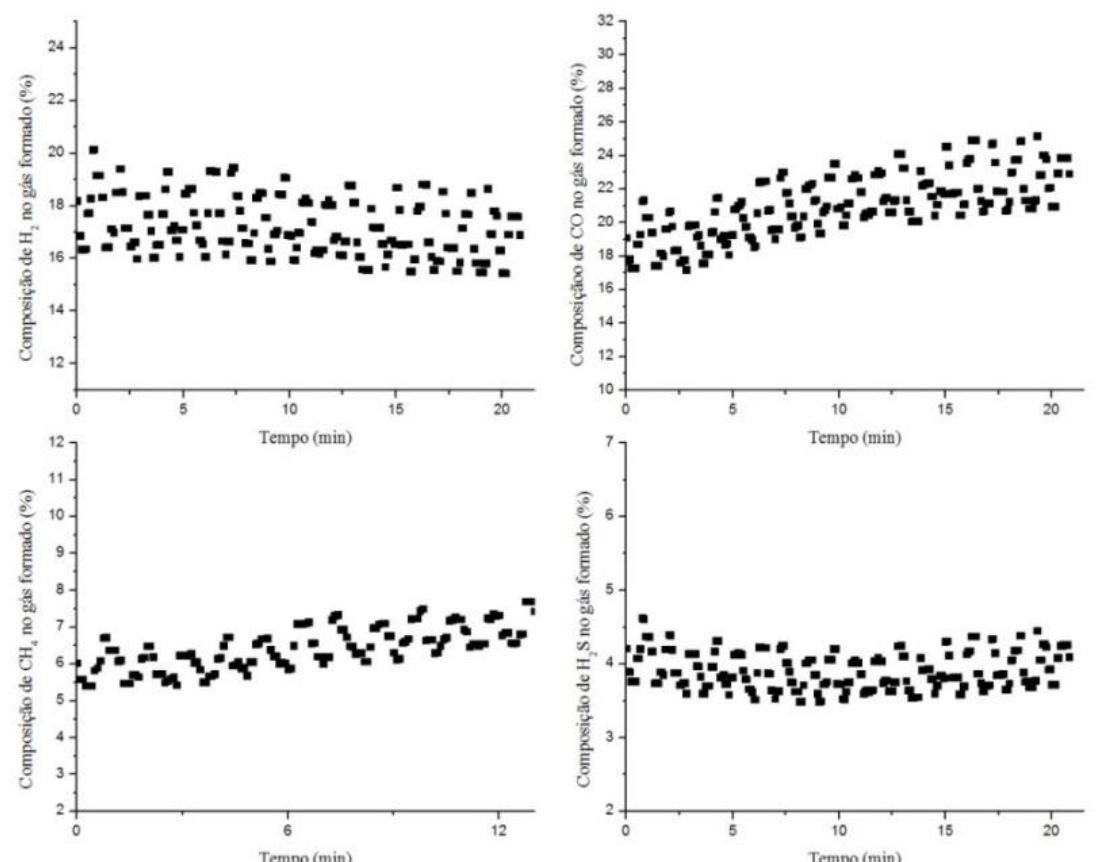

Figura 12.13 - Perfis dos gases $\mathrm{H}_{2}, \mathrm{CO}, \mathrm{CH}_{4}$ e $\mathrm{H}_{2} \mathrm{~S}$, em porcentagem, formados de gaseificação utilizando vapor como agente de fluidização para $\mathrm{SBR}=2,81$.
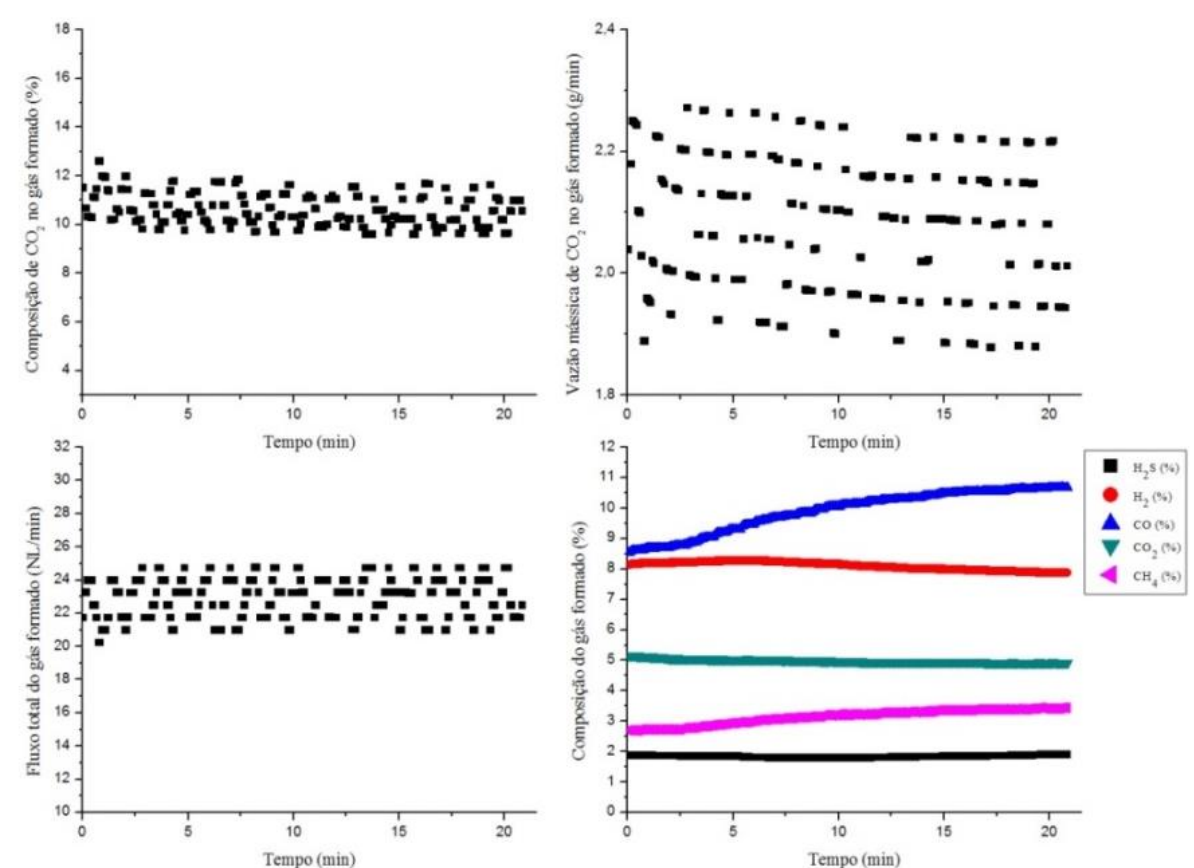

Figura 12.14 - Perfis do gás $\mathrm{CO}_{2}$ em porcentagem e vazão mássica ( $\mathrm{g} / \mathrm{min})$, fluxo total volumétrico de gás formado ( $\mathrm{NL} / \mathrm{min})$, e composição do gás formado determinado no analisador de gases considerando a injeção de $\mathrm{N}_{2}(\%)$, em função do tempo, em gaseificação utilizando vapor como agente de fluidização para SBR = 2,81 

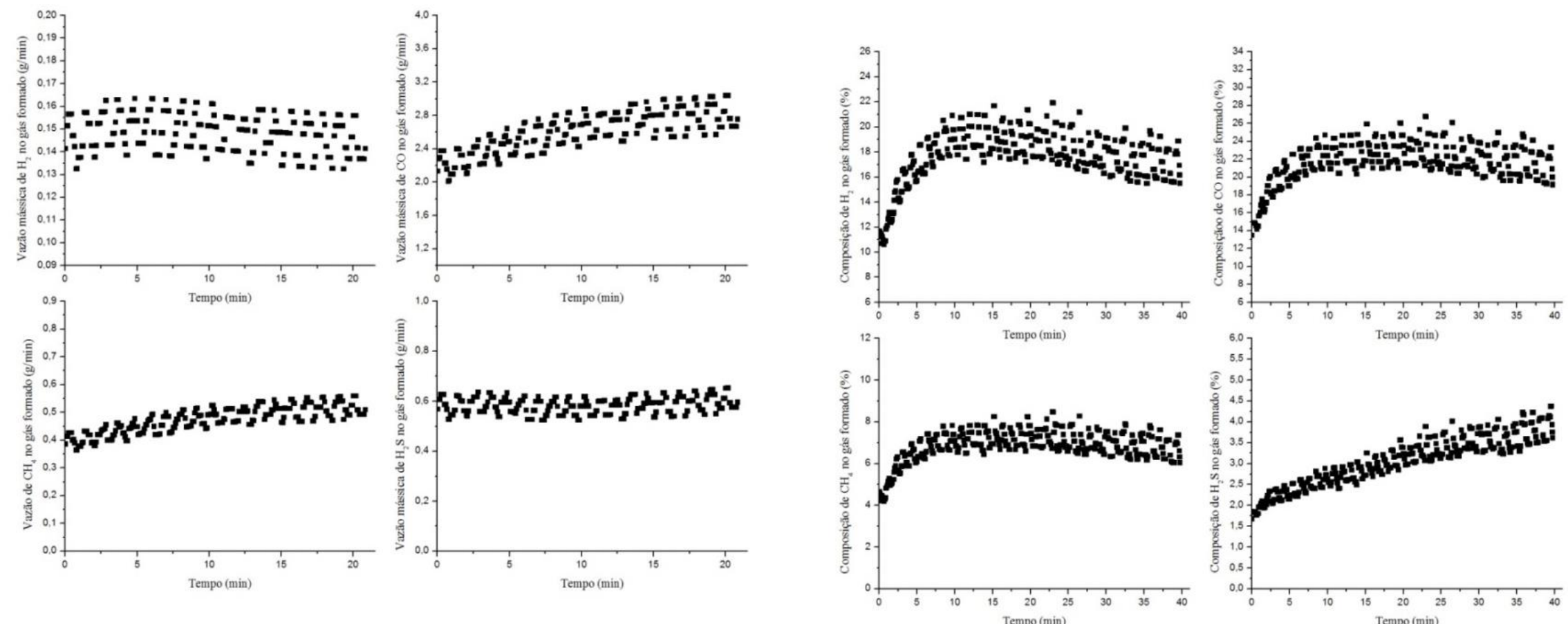

Figura 12.15 - Perfis de vazão (g/min) dos gases $\mathrm{H}_{2}, \mathrm{CO}, \mathrm{CH}_{4}$ e $\mathrm{H}_{2} \mathrm{~S}$, em função do tempo, formados em gaseificação utilizando vapor

Figura 12.16 - Perfis dos gases $\mathrm{H}_{2}, \mathrm{CO}, \mathrm{CH}_{4}$ e $\mathrm{H}_{2} \mathrm{~S}$, em porcentagem, formados de gaseificação utilizando vapor como agente de fluidização para SBR =3,10. 

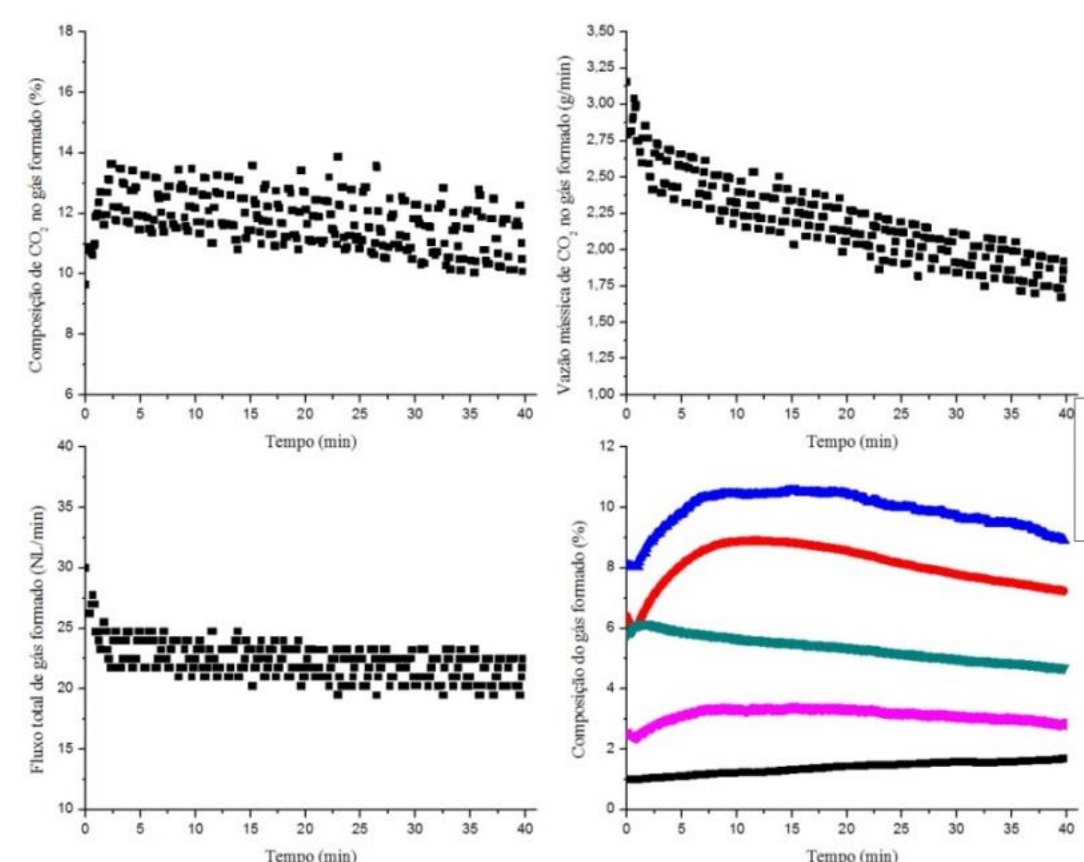

Figura 12.17 - Perfis do gás $\mathrm{CO}_{2}$ em porcentagem e vazão mássica ( $\mathrm{g} / \mathrm{min})$, fluxo total volumétrico de gás formado (NL/min), e composição do gás formado determinado no analisador de gases considerando a injeção de $\mathrm{N}_{2}(\%)$, em função do tempo, em gaseificação utilizando vapor como agente de fluidização para SBR = 3,10 .
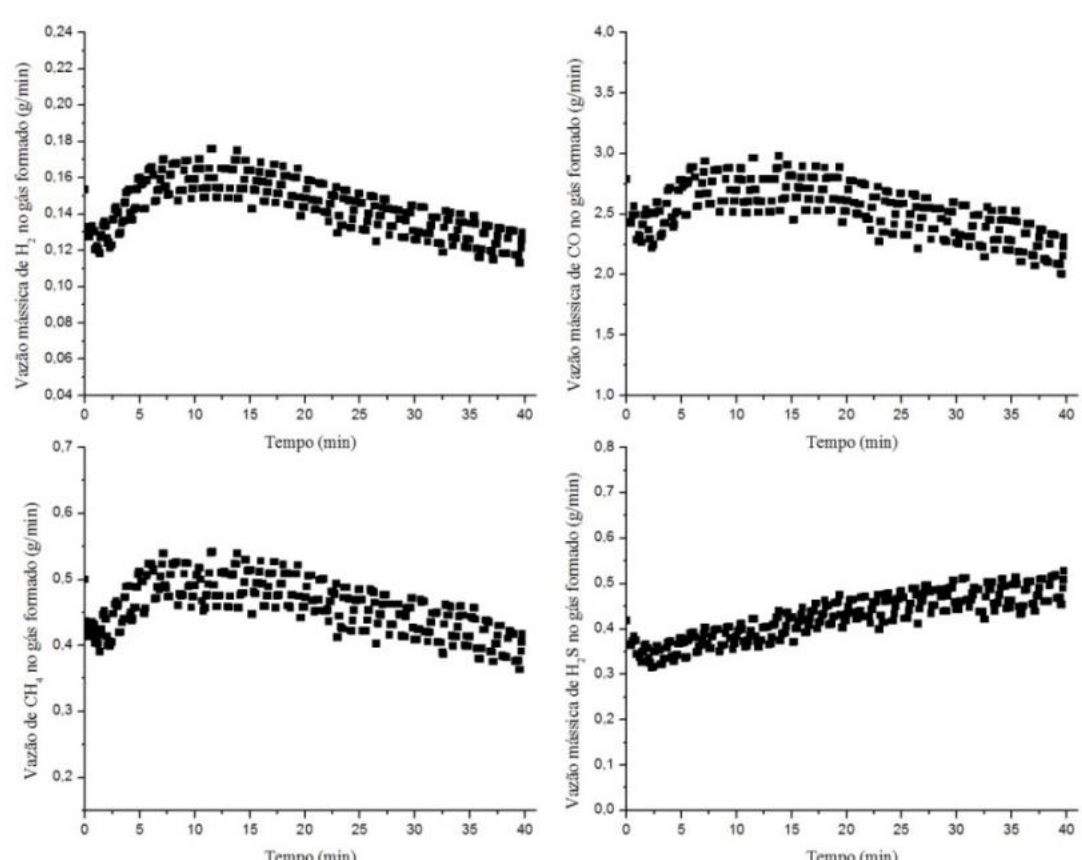

Figura 12.18 - Perfis de vazão $(\mathrm{g} / \mathrm{min})$ dos gases $\mathrm{H}_{2}, \mathrm{CO}, \mathrm{CH}_{4} \mathrm{e}$ $\mathrm{H}_{2} \mathrm{~S}$, em função do tempo, formados em gaseificação utilizando vapor como agente de fluidização para $\mathrm{SBR}=3,10$. 

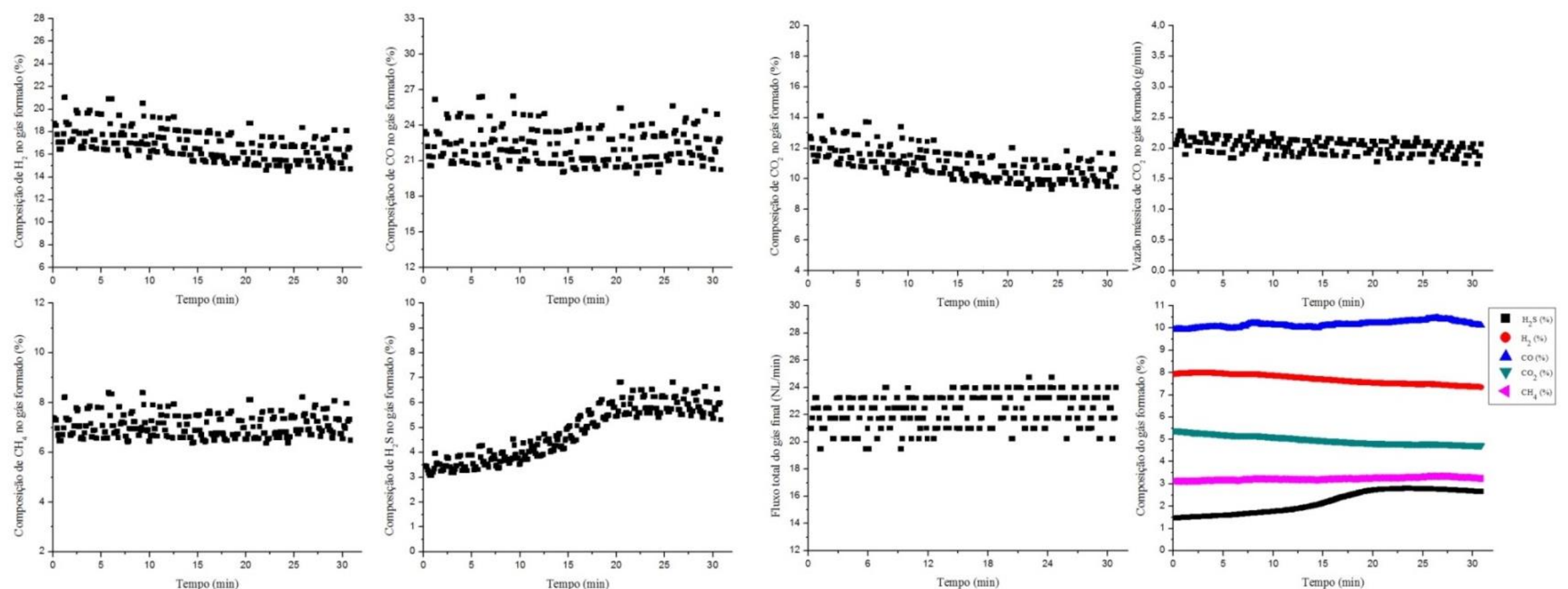

Figura 12.19 - Perfis dos gases $\mathrm{H}_{2}, \mathrm{CO}, \mathrm{CH}_{4}$ e $\mathrm{H}_{2} \mathrm{~S}$, em porcentagem, formados de gaseificação utilizando vapor como agente de fluidização para SBR = 3,38.

Figura 12.20 - Perfis do gás $\mathrm{CO}_{2}$ em porcentagem e vazão mássica (g/min), fluxo total volumétrico de gás formado (NL/min), e composição do gás formado determinado no analisador de gases considerando a injeção de $\mathrm{N}_{2}(\%)$, em função do tempo, em gaseificação utilizando vapor como agente de fluidização para $\mathrm{SBR}=$ 3,38 . 

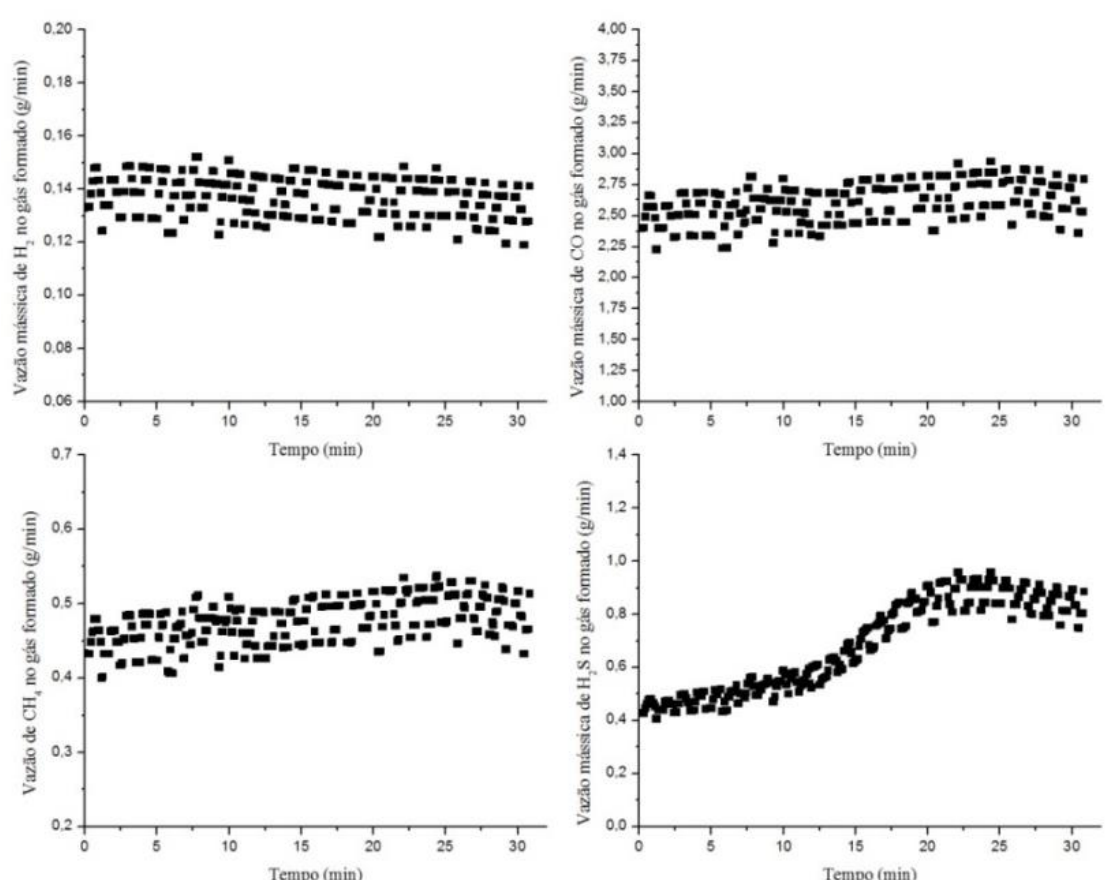

Figura 12.21 - Perfis de vazão (g/min) dos gases $\mathrm{H}_{2}, \mathrm{CO}, \mathrm{CH}_{4}$ e $\mathrm{H}_{2} \mathrm{~S}$, em

função do tempo, formados em gaseificação utilizando vapor como agente de fluidização para $\mathrm{SBR}=3,38$. 


\section{APÊNDICE 3}

Serão apresentados os perfis individuais dos gases $\mathrm{H}_{2}, \mathrm{CO}, \mathrm{CH}_{4}, \mathrm{H}_{2} \mathrm{~S}$ e $\mathrm{CO}_{2}$ contendo a vazão mássica produzida de cada gás, o fluxo total de gás obtido (NL/min) medido no medidor de fluxo da planta piloto de pirólise e gaseificação, e o fluxo do gás nitrogênio (NL/min) na entrada do sistema de reação todos em função do tempo (min) para todas as condições experimentais realizados com nitrogênio como agente de fluidização. 

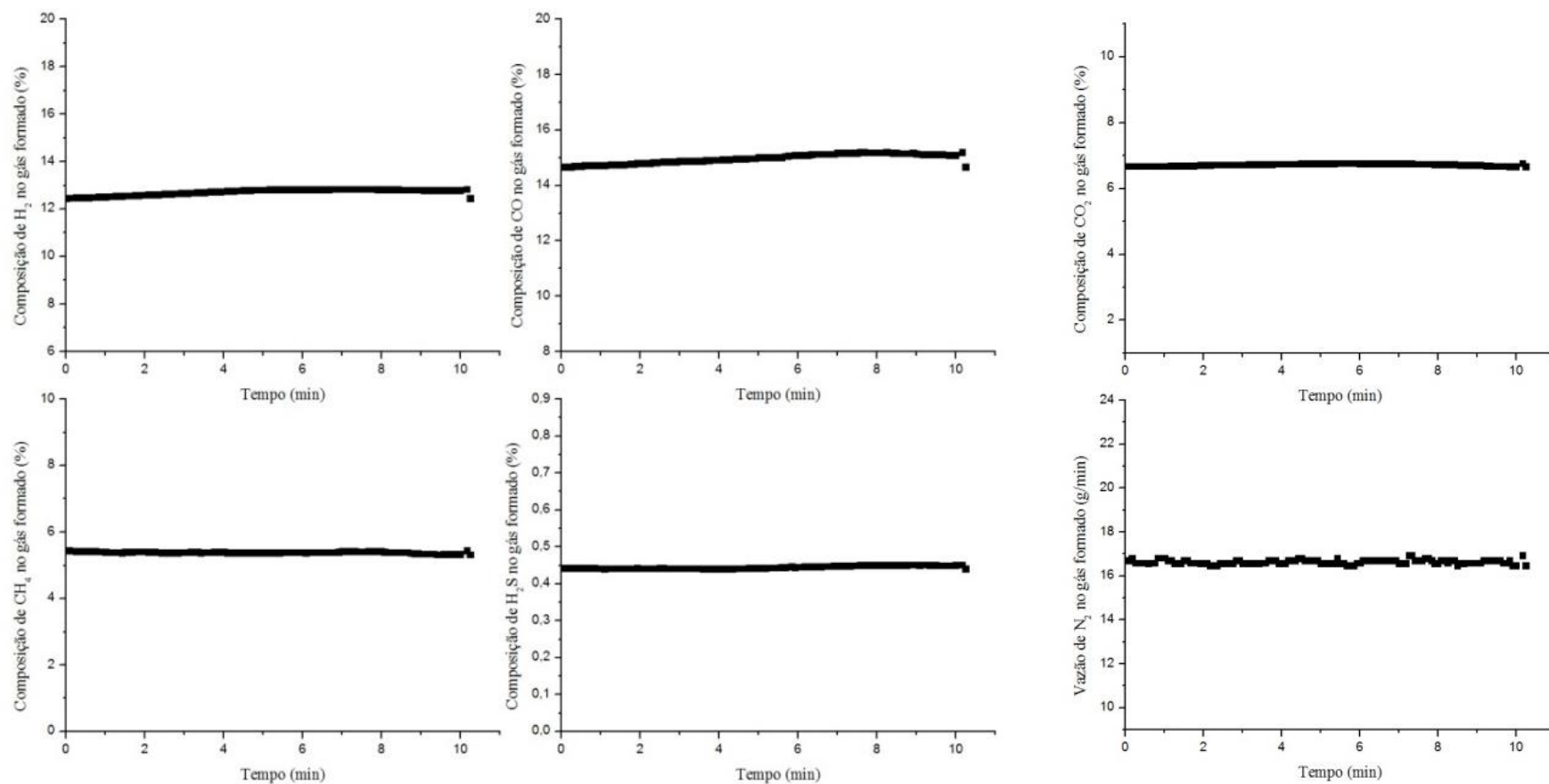

Figura 13.1 - Perfis dos gases $\mathrm{H}_{2}, \mathrm{CO}, \mathrm{CH}_{4}$ e $\mathrm{H}_{2} \mathrm{~S}$, em porcentagem, formados de pirólise utilizando $12 \mathrm{NL} / \mathrm{min}$ de nitrogênio como agente de fluidização.

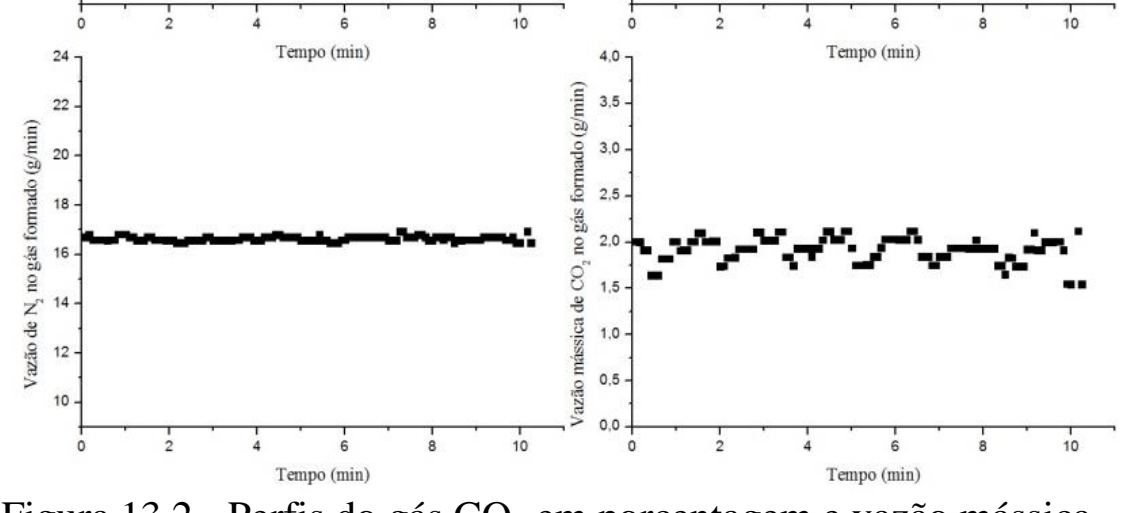

Figura 13.2 - Perfis do gás $\mathrm{CO}_{2}$ em porcentagem e vazão mássica (g/min), fluxo total volumétrico de gás formado (NL/min), e vazão volumétrica de nitrogênio de entrada ( $\mathrm{NL} / \mathrm{min})$, em pirólise utilizando $12 \mathrm{NL} / \mathrm{min}$ de nitrogênio como agente de fluidização. 

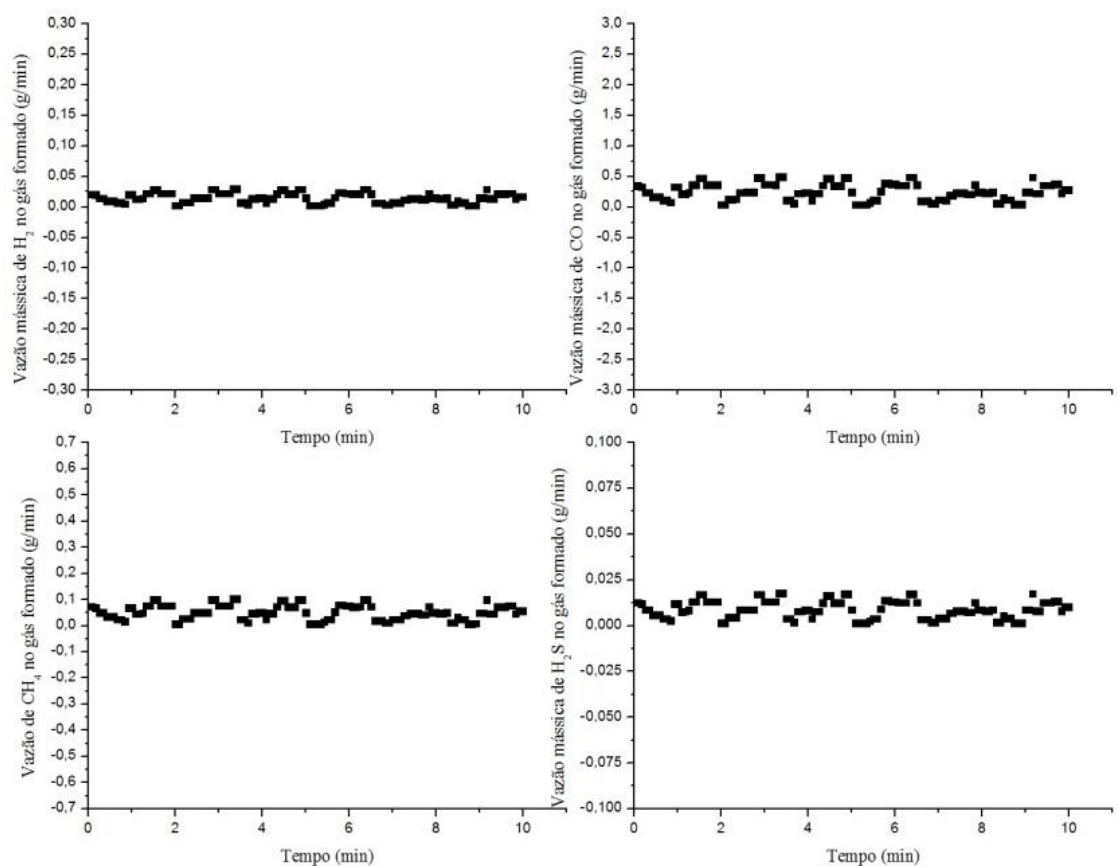

Figura 13.3 - Perfis de vazão (g/min) dos gases $\mathrm{H}_{2}, \mathrm{CO}, \mathrm{CH}_{4}$ e $\mathrm{H}_{2} \mathrm{~S}$, em função do tempo, formados em pirólise utilizando $12 \mathrm{NL} / \mathrm{min}$ de nitrogênio como agente de fluidização.
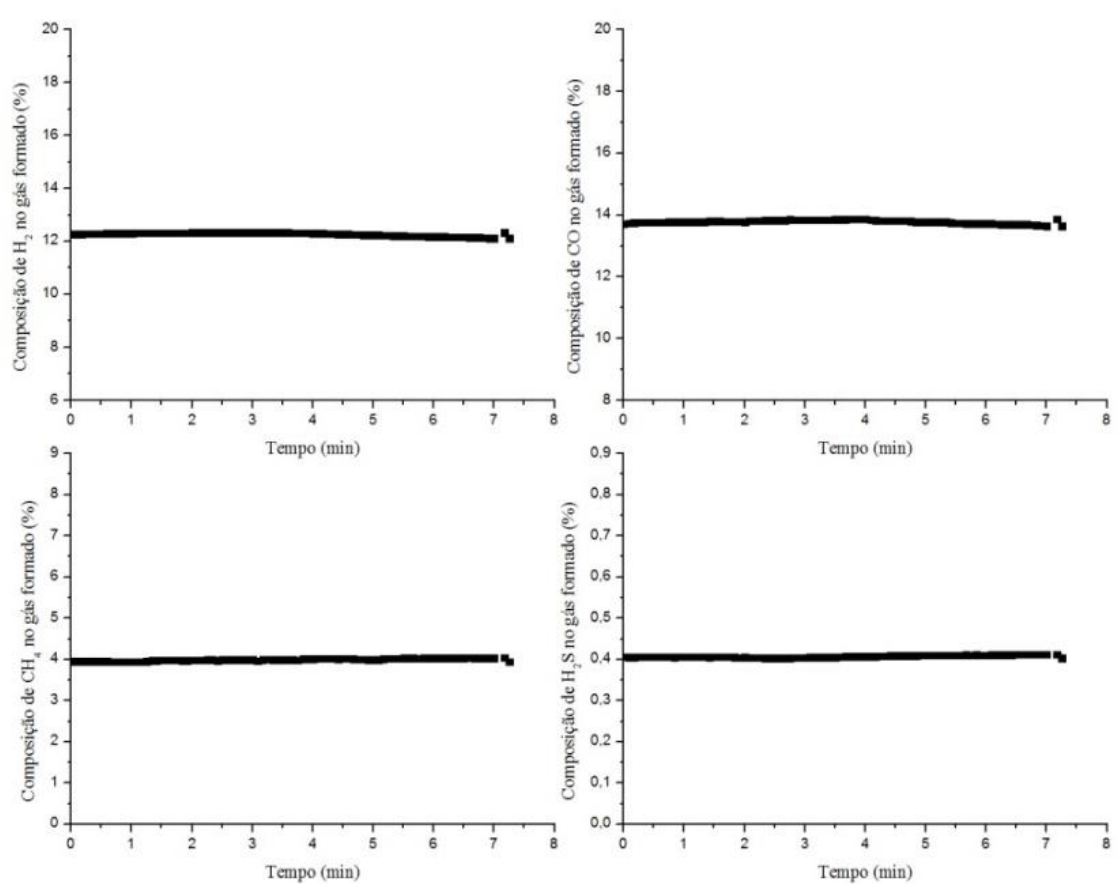

Figura 13.4 - Perfis dos gases $\mathrm{H}_{2}, \mathrm{CO}, \mathrm{CH}_{4}$ e $\mathrm{H}_{2} \mathrm{~S}$, em porcentagem, formados de pirólise utilizando $14 \mathrm{NL} / \mathrm{min}$ de nitrogênio como agente de fluidização. 

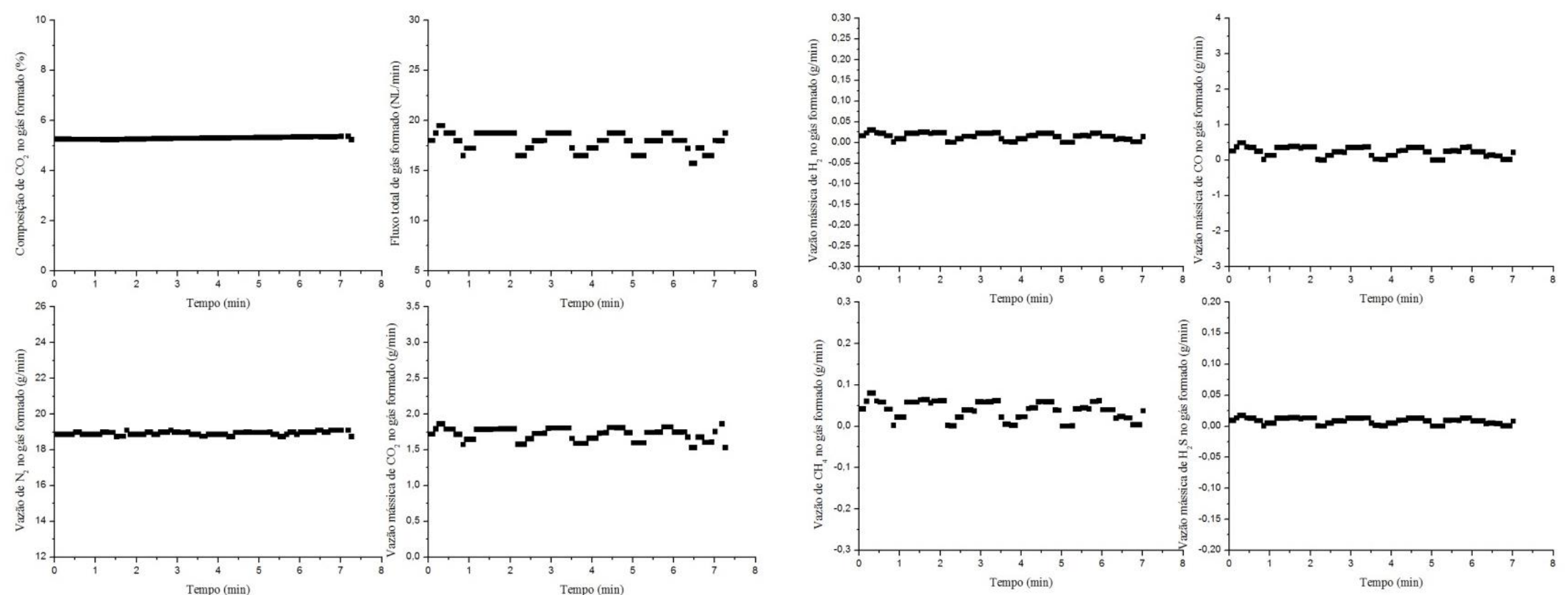

Figura 13.5 - Perfis do gás $\mathrm{CO}_{2}$ em porcentagem e vazão mássica (g/min), fluxo total volumétrico de gás formado (NL/min), e vazão volumétrica de nitrogênio de entrada $(\mathrm{NL} / \mathrm{min})$, em pirólise

Figura 13.6 - Perfis de vazão $(\mathrm{g} / \mathrm{min})$ dos gases $\mathrm{H}_{2}, \mathrm{CO}, \mathrm{CH}_{4}$ e $\mathrm{H}_{2} \mathrm{~S}$, em função do tempo, formados em pirólise utilizando $14 \mathrm{NL} / \mathrm{min}$ de nitrogênio. 

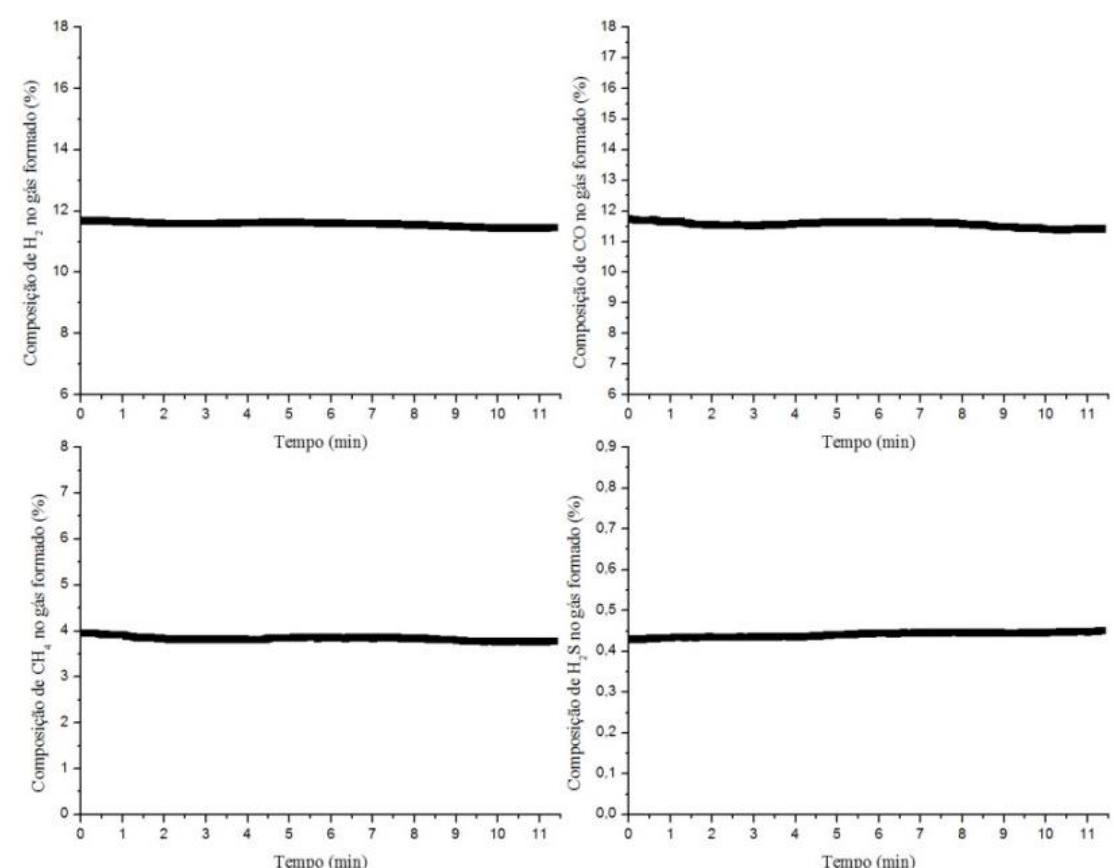

Figura 13.7 - Perfis dos gases $\mathrm{H}_{2}, \mathrm{CO}, \mathrm{CH}_{4}$ e $\mathrm{H}_{2} \mathrm{~S}$, em porcentagem, formados de pirólise utilizando $16 \mathrm{NL} / \mathrm{min}$ de nitrogênio como agente de fluidização.

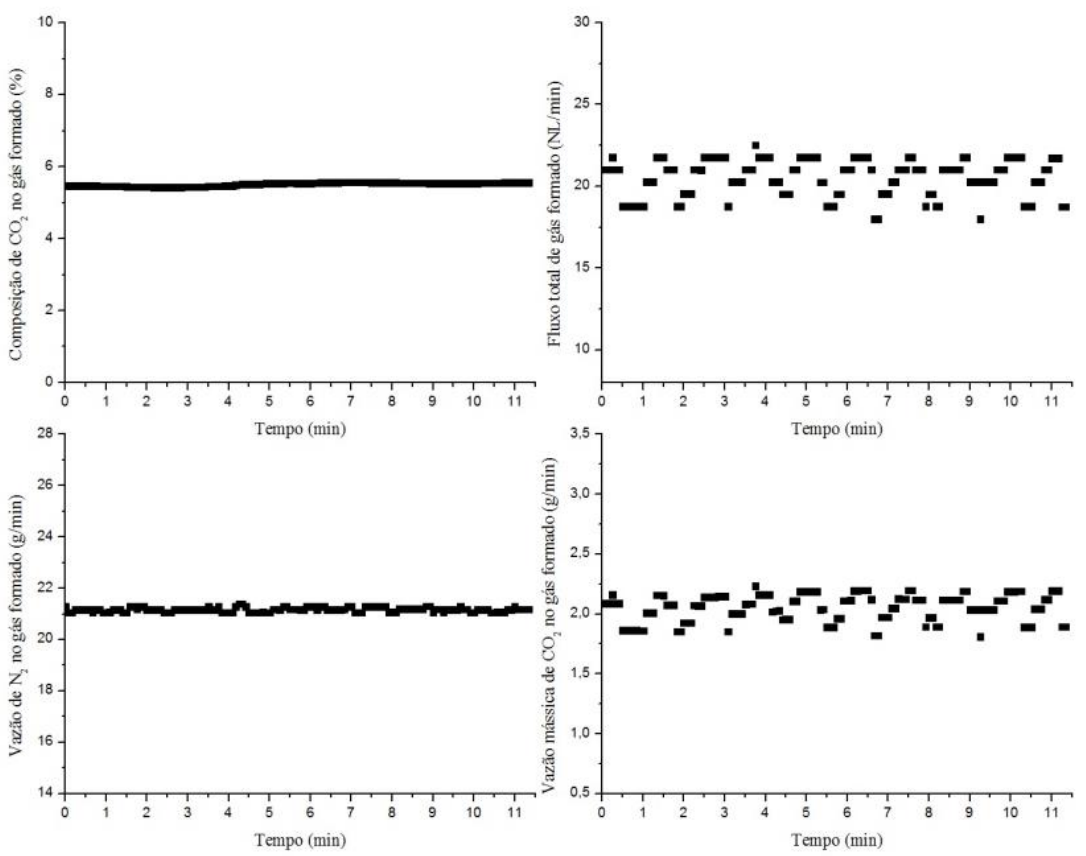

Figura 13.8 - Perfis do gás $\mathrm{CO}_{2}$ em porcentagem e vazão mássica (g/min), fluxo total volumétrico de gás formado (NL/min), e vazão volumétrica de nitrogênio de entrada (NL/min), em pirólise

utilizando $16 \mathrm{NL} / \mathrm{min}$ de nitrogênio como agente de fluidização. 

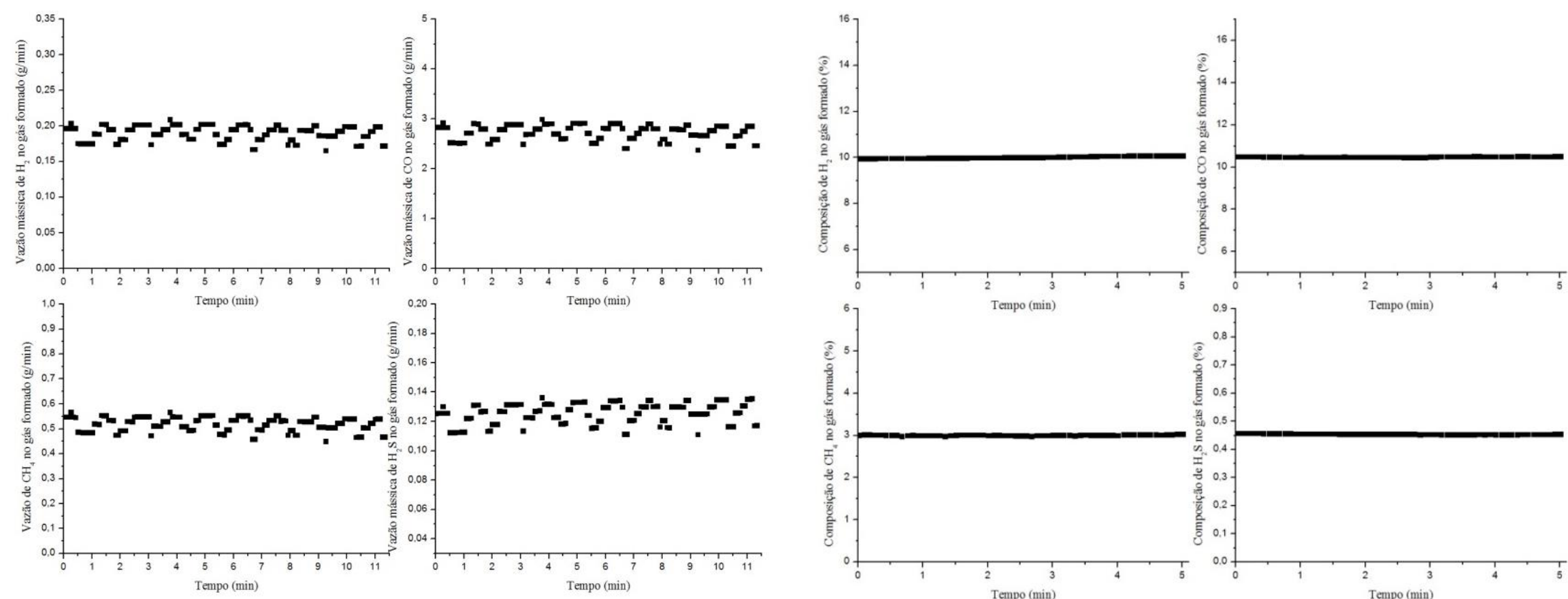

Figura 13.9 - Perfis de vazão (g/min) dos gases $\mathrm{H}_{2}, \mathrm{CO}, \mathrm{CH}_{4}$ e $\mathrm{H}_{2} \mathrm{~S}$, em função do tempo, formados em pirólise utilizando $16 \mathrm{NL} / \mathrm{min}$ de nitrogênio como agente de fluidização.

Figura 13.10 - Perfis dos gases $\mathrm{H}_{2}, \mathrm{CO}, \mathrm{CH}_{4}$ e $\mathrm{H}_{2} \mathrm{~S}$, em porcentagem, formados de pirólise utilizando $18 \mathrm{NL} / \mathrm{min}$ nitrogênio como agente de fluidização. 

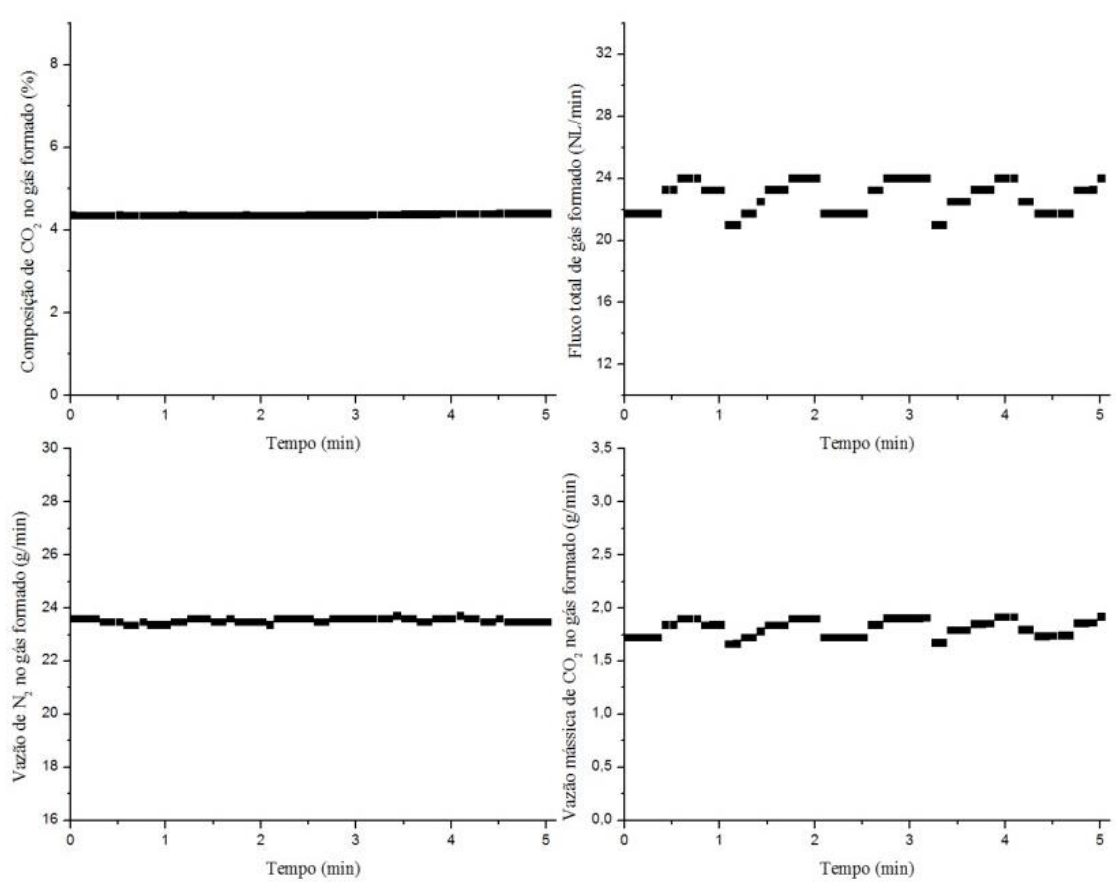

Figura 13.11 - Perfis do gás $\mathrm{CO}_{2}$ em porcentagem e vazão mássica (g/min), fluxo total volumétrico de gás formado (NL/min), e vazão volumétrica de nitrogênio de entrada $(\mathrm{NL} / \mathrm{min})$, em pirólise utilizando $18 \mathrm{NL} / \mathrm{min}$ de nitrogênio como agente de fluidização.
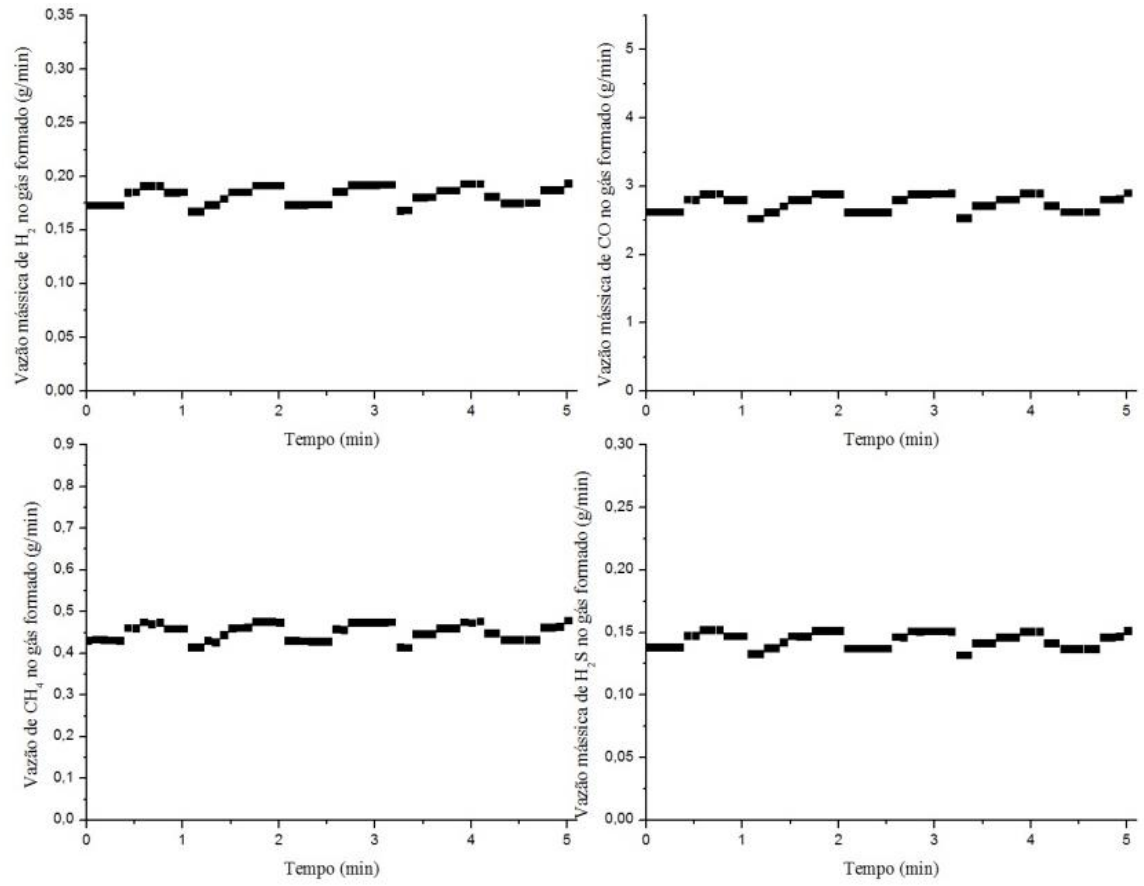

Figura 13.12 - Perfis de vazão $(\mathrm{g} / \mathrm{min})$ dos gases $\mathrm{H}_{2}, \mathrm{CO}, \mathrm{CH}_{4} \mathrm{e}$ $\mathrm{H}_{2} \mathrm{~S}$, em função do tempo, formados em gaseificação utilizando 18 $\mathrm{NL} /$ min de nitrogênio como agente de fluidização. 

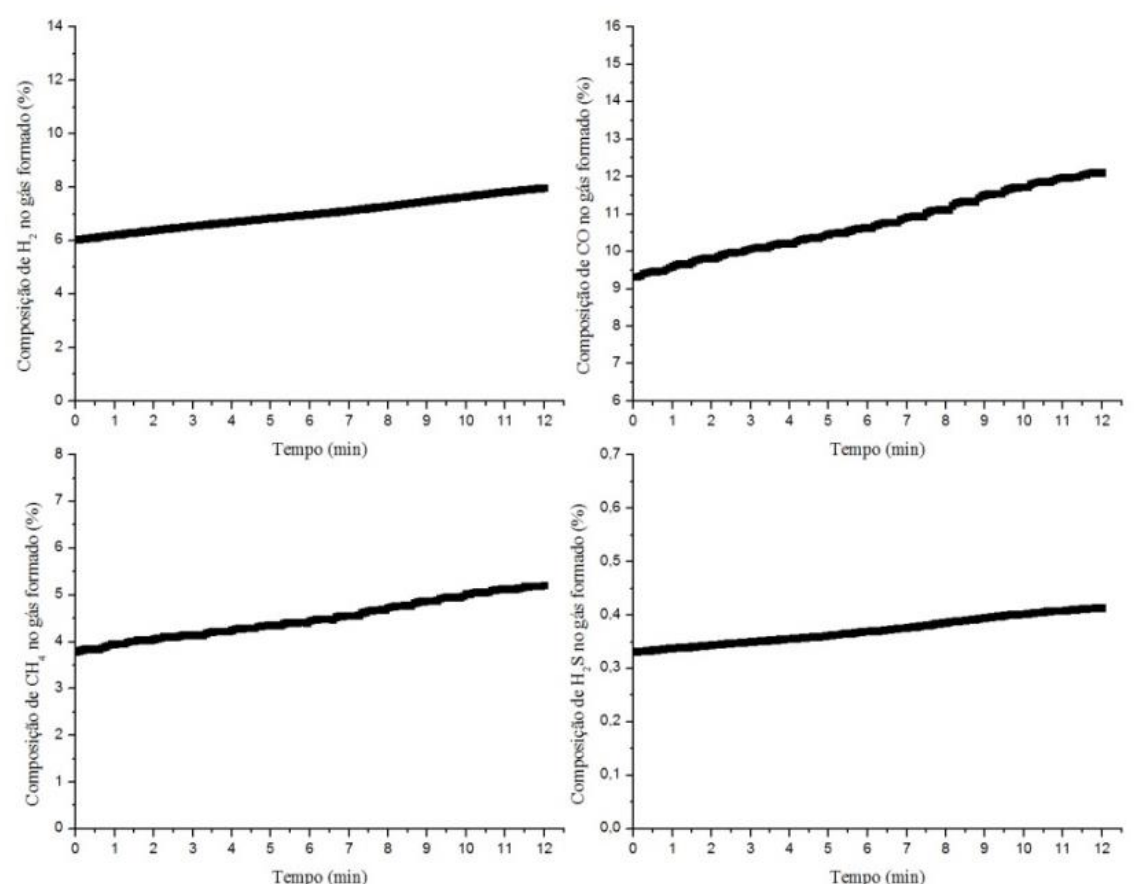

Figura 13.13 - Perfis dos gases $\mathrm{H}_{2}, \mathrm{CO}, \mathrm{CH}_{4}$ e $\mathrm{H}_{2} \mathrm{~S}$, em porcentagem, formados de pirólise utilizando $20 \mathrm{NL} / \mathrm{min}$ de nitrogênio como agente de fluidização.
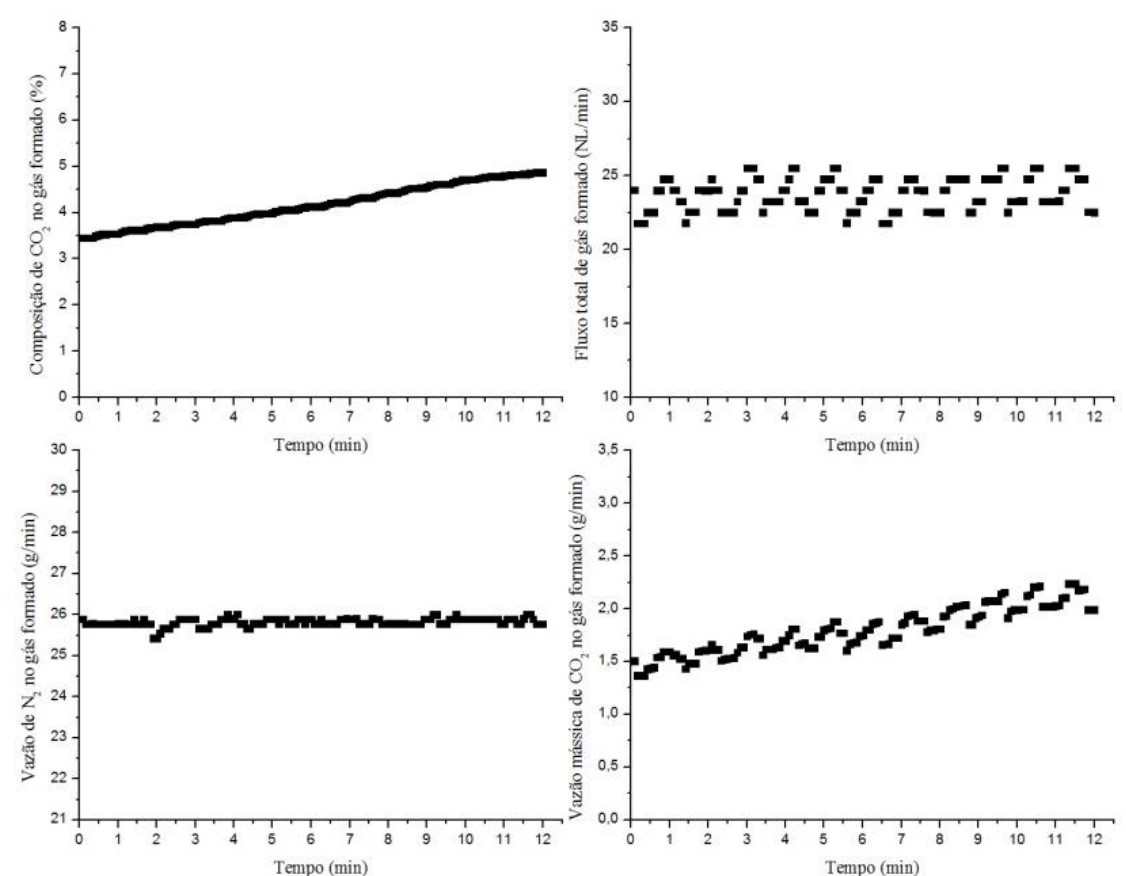

Figura 13.14 - Perfis do gás $\mathrm{CO}_{2}$ em porcentagem e vazão mássica (g/min), fluxo total volumétrico de gás formado (NL/min), e vazão volumétrica de nitrogênio de entrada (NL/min), em pirólise utilizando $20 \mathrm{NL} / \mathrm{min}$ de nitrogênio como agente de fluidização. 

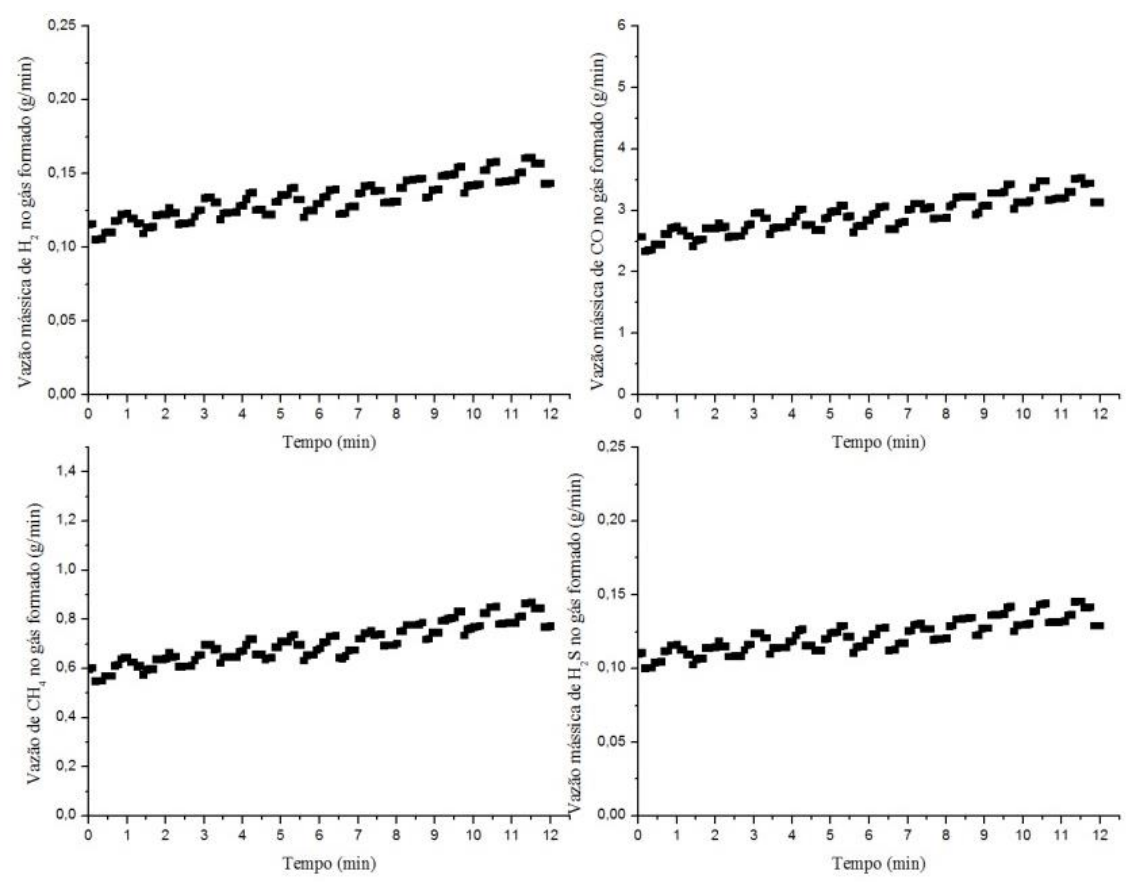

Figura 13.15 - Perfis de vazão (g/min) dos gases $\mathrm{H}_{2}, \mathrm{CO}, \mathrm{CH}_{4}$ e $\mathrm{H}_{2} \mathrm{~S}$, em função do tempo, formados em pirólise utilizando $20 \mathrm{NL} / \mathrm{min}$ de nitrogênio como agente de fluidização. 


\section{APÊNDICE 4}

Como foi relatado na seção 8.2.4.1 de apresentação dos resultados do processo com nitrgoênio, encontrou-se uma inconsistência que não foi observada nos processos com ar e vapor d'água. O fluxo de saída de gás medido no medidor de gás de fluxo total, após a lavadora de gases, foi muito baixo, sendo inferior a soma dos gases de entrada no processo. Tomando-se como exemplo a condição experimental utilizando 12 $\mathrm{NL} / \mathrm{min}$ de nitrogênio, tem-se que o fluxo médio $(\mathrm{NL} / \mathrm{min})$ de nitrogênio adicionado ao sistema de reação (soma do fluxo adicionado na alimentação de biomassa com o fluxo de nitrogênio utilizado como agente de fludização) foi de 14,45 NL/min, e que o fluxo de saída de gás total, medido no medidor de fluxo, foi em média de 15,72 NL/min. O analisador de gases mediu as concentrações percentuais de $\mathrm{H}_{2} \mathrm{~S}, \mathrm{H}_{2}, \mathrm{CO}, \mathrm{CO}_{2}$ e $\mathrm{CH}_{4}$ como sendo $0,44 \%, 12,70 \%, 14,95 \%, 6,71 \%$ e 5,37\%, respectivamente, o que dá no total um somatório de 40,18\% do gás produzido. Assim, os outros 59,82\% do gás produzido seriam de nitrogênio e outros gases não identificáveis pelo sistema de análise de gases. Logo, como foi adicionado $14,45 \mathrm{NL} / \mathrm{min}$ de $\mathrm{N}_{2}$, considerando os percentuais medidos no analisador de gases, o fluxo total de saída de gás deveria ser de 24,16 $\mathrm{NL} /$ min (considerando os 59,82\% como sendo só $\mathrm{N}_{2}$ ), e não de 15,72 NL/min.

A Figura 14.1 apresenta um fluxograma para facilitar a visualização do que foi relatado. Este fato ocorreu em todos os processos com nitrogênio como agente de fluidização. Uma primeira explicação seria a ocorrência de um vazamento antes da entrada do nitrogênio no reator, mas isso de certa forma acarretaria em não fluidização do leito e prejudicaria o processo de produção de gás combustível. Um vazamento pode ter ocorrido após o sistema de reação, comprometendo a medição de fluxo total do gás produzido. Uma outra alternativa é o erro de medição no medidor de fluxo total, e por fim o nitrogênio pode ter ficado retido na lavadora de gases, acarretando assim em uma medição alterada no medidor de fluxo total. Traçou-se os perfis de fluxo volumétrico total (NL/min) dos gases gerados (medidos no medidor de fluxo) e os perfis de nitrogênio de entrada (NL/min) em função do tempo, estes gráficos estão apresentados nas Figuras 13.2, 13.5, 13.8, 13.11 e 13.14 no Apêndice 3. 


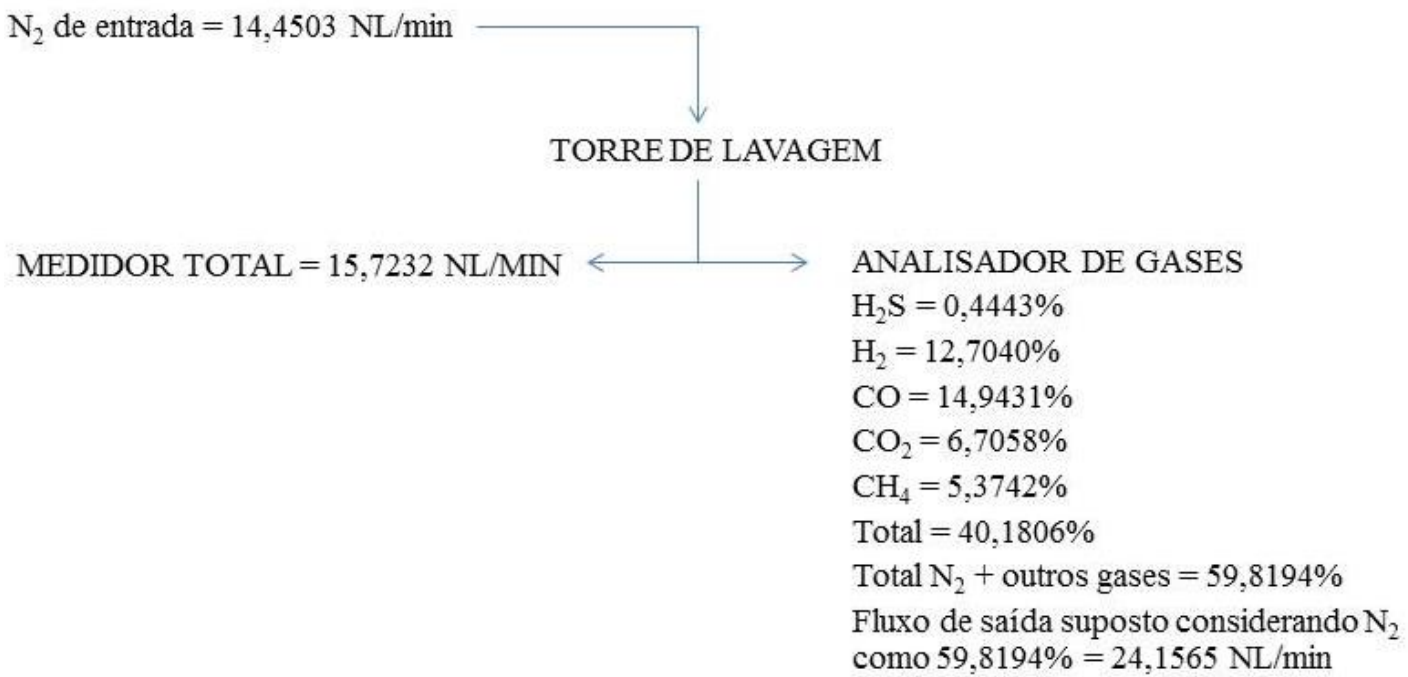

Figura 14.1 - Balanço de vazão volumétrica de entrada e saída de $\mathrm{N}_{2}$ analisando pela medição no medidor de fluxo total e suposição pelo resultado obtido do analisador de gases. 